U.S. Department of Transportation

Federal Railroad Administration

\title{
An Examination of Railroad Yard Worker Safety
}

Office of Research

and Development

Washington, DC 20590

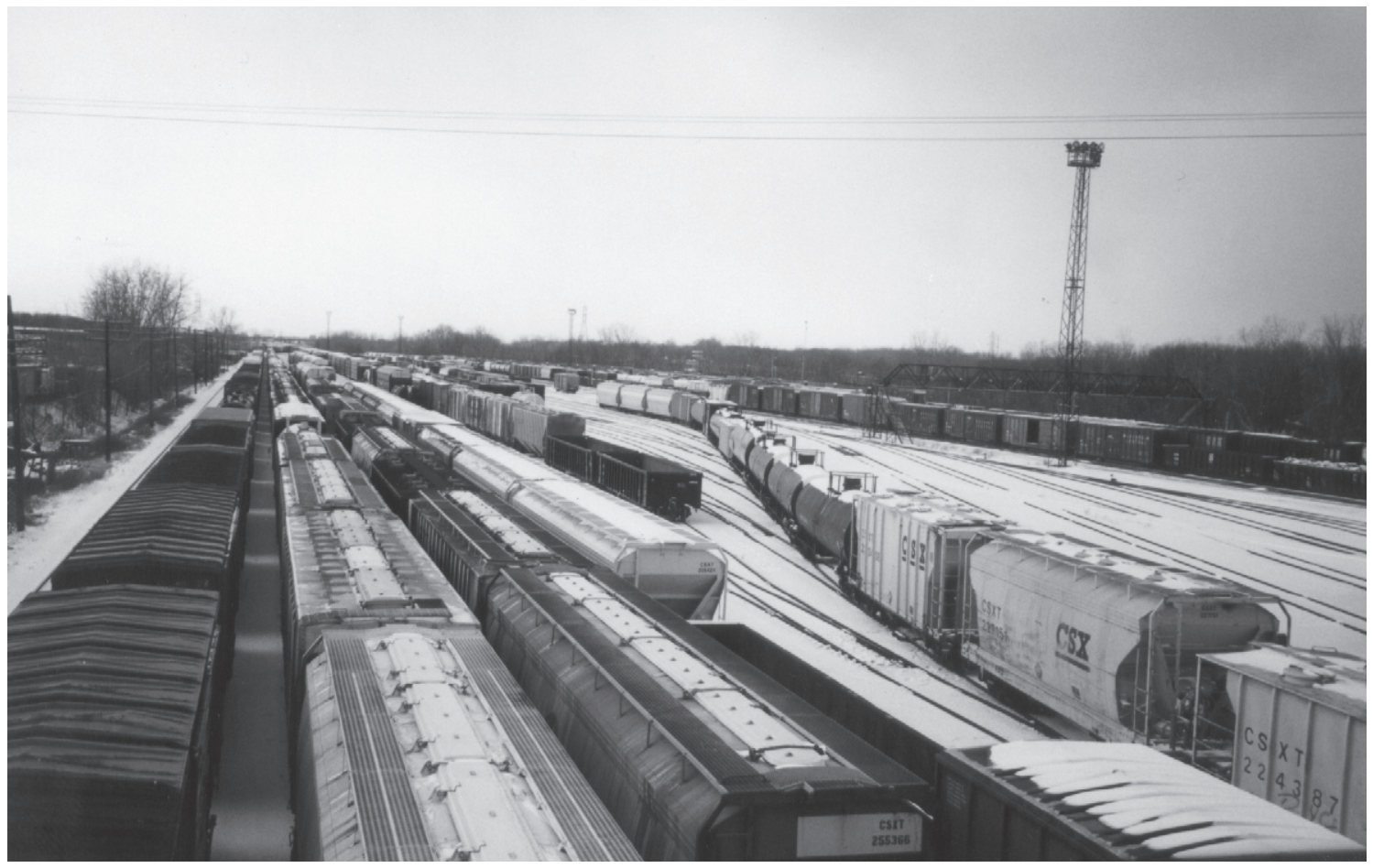




\section{NOTICE}

This document is disseminated under the sponsorship of the Department of Transportation in the interest of information exchange. The United States Government assumes no liability for its contents or use thereof.

\section{NOTICE}

The United States Government does not endorse products or manufacturers. Trade or manufacturers' names appear herein solely because they are considered essential to the objective of this report. 
Technical Report Documentation Page

\begin{tabular}{|c|c|c|c|c|}
\hline 1. Report No. & 2. Government Accessio & & 3. Recipient's C & \\
\hline $\begin{array}{l}\text { 4. Title and Subtitle } \\
\text { An Examination of Railroad Yard }\end{array}$ & ker Safety & & 5. Report Date & 2001 \\
\hline & & & 6. Performing $\mathrm{C}$ & ation Code \\
\hline $\begin{array}{l}\text { 7. Author(s) } \\
\text { Reinach, S., and Gertler, J. }\end{array}$ & & & $\begin{array}{l}\text { 8. Performing C } \\
\text { DOT/FRA/OR }\end{array}$ & ation Report No. \\
\hline 9. Performing Organization Name ar & didress & & 10. Work Unit $\mathrm{N}$ & \\
\hline Foster-Miller, Inc. & & & & \\
\hline $\begin{array}{l}350 \text { Second Avenue } \\
\text { Waltham, MA 02154-1196 }\end{array}$ & & & $\begin{array}{r}\text { 11. Contract o } \\
\text { DTF }\end{array}$ & N-C-00049 \\
\hline $\begin{array}{l}\text { 12. Sponsoring Agency Name and } A \\
\text { U.S. Department of Transportatic } \\
\text { Federal Railroad Administration } \\
\text { Office of Research and Developr } \\
1120 \text { Vermont Avenue NW }\end{array}$ & & & $\begin{array}{l}\text { 13. Type of Rep } \\
\text { Final Report } \\
\text { March, } 1998\end{array}$ & $\begin{array}{l}\text { Period Covered } \\
\text { mber, } 2000\end{array}$ \\
\hline Washington, D.C. 20590 & & & \begin{tabular}{|l|} 
14. Sponsoring \\
RDV-32 \\
\end{tabular} & Code \\
\hline 15. Supplementary Notes & & & & \\
\hline $\begin{array}{l}\text { 16. Abstract } \\
\text { This report presents the methods } \\
\text { worker safety issues in railroad ya } \\
\text { railroad yard worker safety. A br } \\
\text { labor-management relations; wor } \\
\text { railroad relations. The research } \\
\text { research methods. Existing FRA } \\
\text { and accident demographics. An } \\
\text { injuries from } 1997 \text { to } 1998 \text { found, } \\
\text { workdays compared to } 76 \text { percen } \\
\text { compared to } 20 \text { for all railroad inju } \\
\text { for in-depth analysis of factors as } \\
\text { were no statistically significant di } \\
\text { and a non-injured control group. } \\
\text { around the country provided add } \\
\text { data and analyses of railroad inju } \\
\text { of recent safety improvements, in } \\
\text { "walking" stone around switch lea } \\
\text { labor identified a number of addit } \\
\text { fostering a positive safety climate } \\
\text { FRA's accident and injury data cc } \\
\text { identified. }\end{array}$ & $\begin{array}{l}\text { dings and recommendati } \\
\text { The research program } \\
\text { range of issues were ex } \\
\text { hedules; injury reporting } \\
\text { am's technical approach } \\
\text { ry and accident data wer } \\
\text { s of human factor-attribu } \\
\text { ong other results, that } 80 \\
\text { ailroad-wide injuries. Th } \\
\text { Personal injury and wo } \\
\text { ated with worker injuries } \\
\text { nces in work schedules } \\
\text { ctured interviews with ra } \\
\text { al understanding of the s } \\
\text { ld work schedule data. } \\
\text { ling implementation of er } \\
\text { ind tow paths, that have } \\
\text { l opportunities to reduce } \\
\text { reducing the risk of wo } \\
\text { tion and reporting proces }\end{array}$ & $\begin{array}{l}\text { from a } \\
\text { used on } \\
\text { ned, inc } \\
\text { cedure } \\
\text { mbined } \\
\text { nalyzed } \\
\text { y yard a } \\
\text { rcent o } \\
\text { hedian r } \\
\text { schedul } \\
\text { lards. } \\
\text { ween in } \\
\text { ad man } \\
\text { ty issue } \\
\text { ong oth } \\
\text { tomic s } \\
\text { to a rec } \\
\text { d injurie } \\
\text { injuries } \\
\text { re discl }\end{array}$ & $\begin{array}{l}\text { ear research pr } \\
\text { factor-related } r \\
\text { safety culture; } t \\
\text { ederal Railroad } \\
\text { ative data analy } \\
\text { ide statistical in } \\
\text { s from } 1994 \text { to } \\
\text { d yard injuries r } \\
\text { of lost workday } \\
\text { rom one railroa } \\
\text { s found, among } \\
\text { ain and Engine } \\
\text { t and focus gro } \\
\text { could not be gle } \\
\text { gs, railroad offic } \\
\text { ands and incre } \\
n \text { injuries. Foct } \\
\text { ty, railroad indu } \\
\text { ntified, possibl } \\
\text { nd additional re }\end{array}$ & $\begin{array}{l}\text { that examined } \\
\text { and solutions to } \\
\text {; communications; } \\
\text { histration (FRA)- } \\
\text { h qualitative } \\
\text { into national injury } \\
\text { nd employee yard } \\
\text { d in one or more lost } \\
\text { rd injuries was } 25 \\
\text { ded an opportunity } \\
\text { results, that there } \\
\text { (T\&E) employees } \\
\text { h railroad labor } \\
\text { rom existing FRA } \\
\text { ggested a number } \\
\text { ee use of small } \\
\text { ps with railroad } \\
\text { st practices for } \\
\text { ncements to the } \\
\text { topics are }\end{array}$ \\
\hline $\begin{array}{l}\text { 17. Key Words } \\
\text { railroad yard safety, ergonomics, } \\
\text { occupational safety }\end{array}$ & and accident analysis, & $\begin{array}{l}\text { 18. Di } \\
\text { Docur } \\
\text { Natior } \\
\text { VA } 2 \text { ? }\end{array}$ & $\begin{array}{l}\text { on Statement } \\
\text { available to the } \\
\text { hnical Informati }\end{array}$ & $\begin{array}{l}\text { Ublic through the } \\
\text { ice, Springfield, }\end{array}$ \\
\hline $\begin{array}{c}\text { 19. Security Classif. (of this report) } \\
\text { Unclassified }\end{array}$ & $\begin{array}{r}\text { 20. Security Classif. (of } \\
\text { Unclassif }\end{array}$ & s page) & $\begin{array}{c}\text { 21. No. of Pages } \\
195\end{array}$ & 22. Price \\
\hline
\end{tabular}

Form DOT F 1700.7 (8-72)

Reproduction of completed page authorized 
This report presents the findings of a research study to examine worker safety in railroad yards. The work was performed under Contract DTFR53-95-C00049 with guidance from Dr. Thomas Raslear of the Office of Research and Development, Federal Railroad Administration. The authors wish to express their gratitude to Mr. Stan Ellis and Mr. Robert Finkelstein, Office of Safety, Federal Railroad Administration, for providing assistance in understanding and utilizing the Federal Railroad Administration's accident and injury databases.

Thanks are also due to the four railroads for arranging and allowing the authors to visit their facilities and meet with yard management. The information learned from these site visits was invaluable. The authors also wish to thank the participating railroad for allowing us to collect personal injury and work schedule data from their records.

The focus group research would not have been possible without the generous cooperation of numerous officers, including general and local chairmen, from the Brotherhood of Locomotive Engineers, United Transportation Union, and Brotherhood Railway Carmen Division, Transportation Communications Union. The authors wish to thank all of the focus group participants for being open and sharing their experiences, ideas, and opinions regarding yard worker safety.

The authors also wish to acknowledge and thank Mr. Tom Griego, Mr. Kurt Walecki, and Mr. Robert McCulloch from Booz, Allen \& Hamilton for their valuable contributions in the formative stages of this research. The authors also wish to thank several individuals from FosterMiller for their support in this project. Ms. Sally Pham assisted in collecting and coding the personal injury and work schedule data from the participating railroad and assisted in recruiting participants for the focus groups. Mr. Jeff Crane also participated in coding the personal injury data. Lastly, a special thanks to Ms. Susan McDonough for assisting in preparing the figures and tables for this report. 


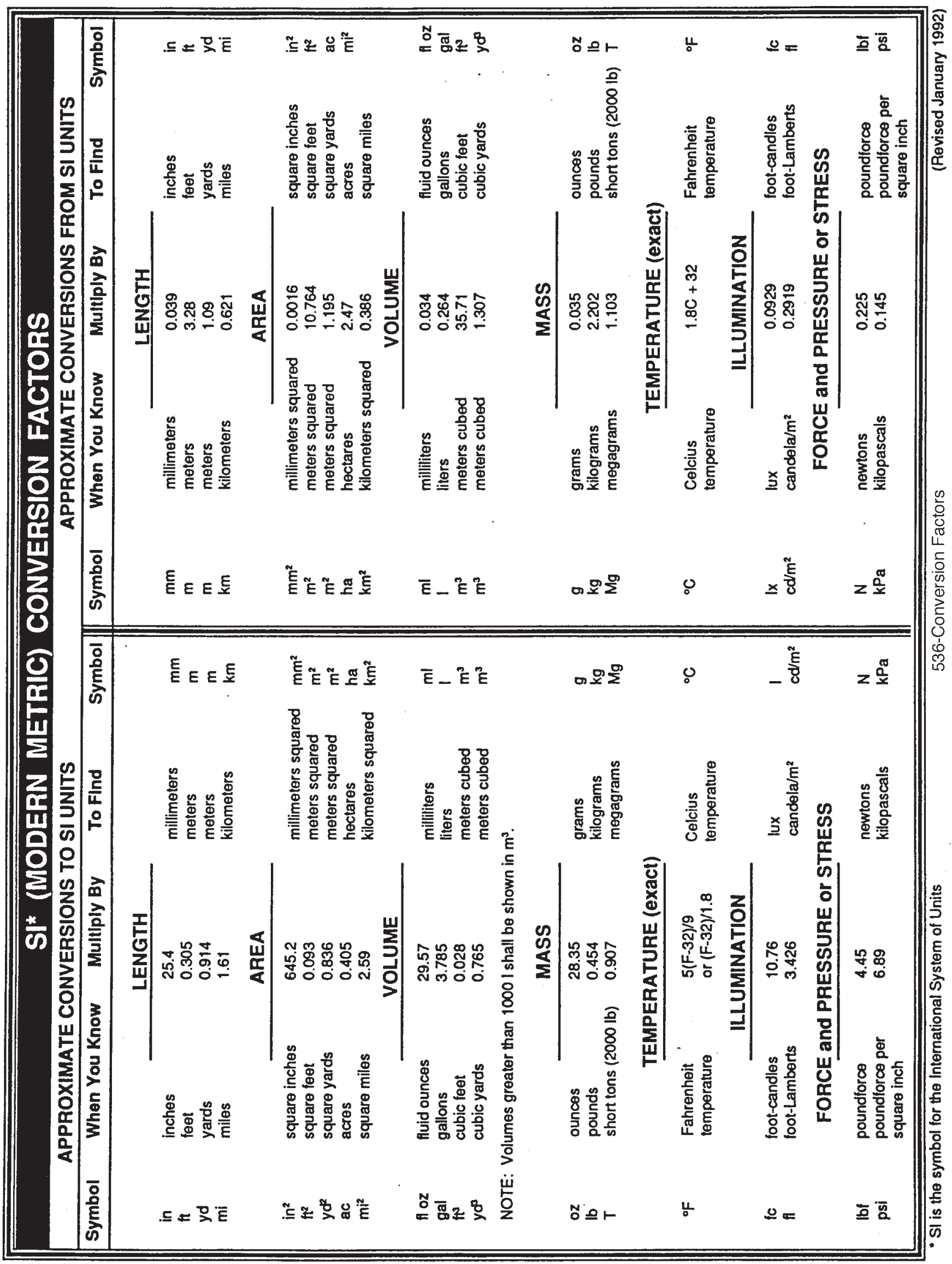


$\begin{array}{lll}\text { Section } & \text { Page }\end{array}$

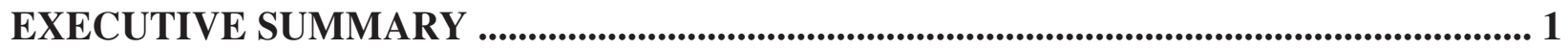

1. INTRODUCTION _............................................................................................................ 7

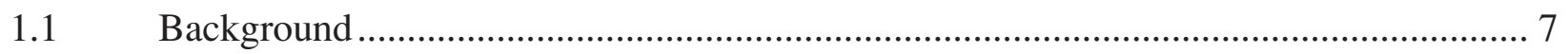

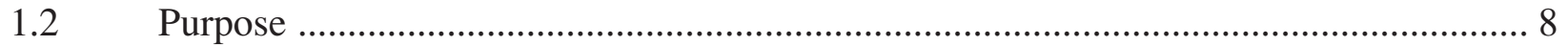

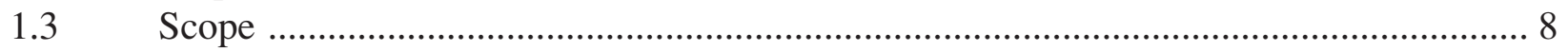

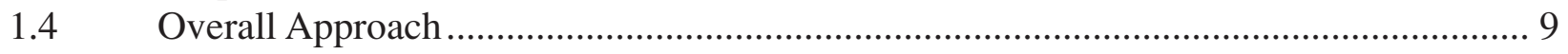

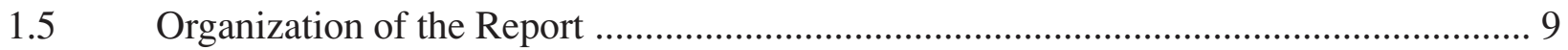

2. OVERVIEW OF RAILROAD YARD OPERATIONS ........................................ 11

2.1 Railroad Yard Functions ...................................................................................... 11

2.2 Typical Railroad Yard Layout and Operation .................................................................. 12

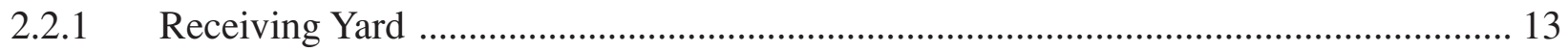

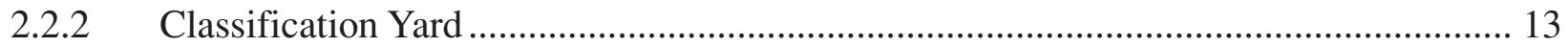

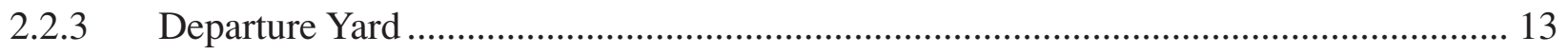

2.2.4 Other Areas within the Railroad Yard ........................................................................... 14

2.3 Railroad Departments and Their Functions ……....................................................... 14

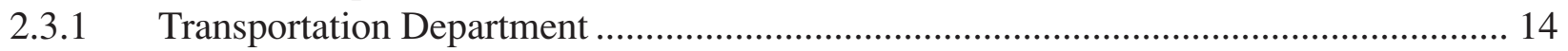

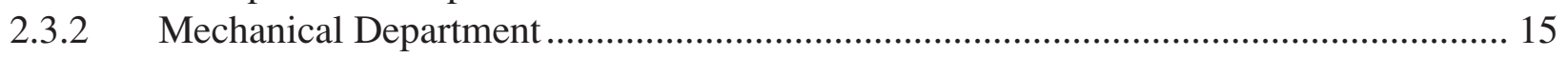

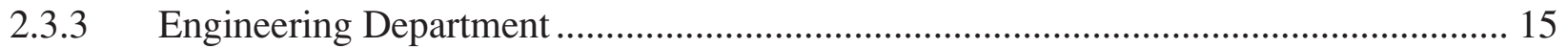

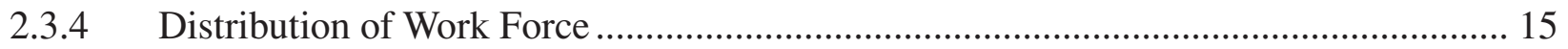

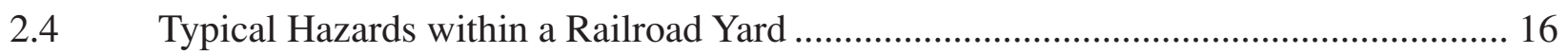

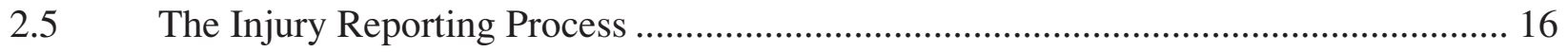

3. FEDERAL EMPLOYERS' LIABILITY ACT (FELA) ......................................... 18

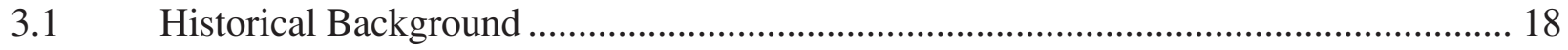

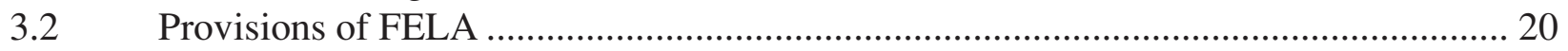

3.3 Impact of FELA on Railroad Worker Safety ………................................................... 21

4. ANALYSIS OF FRA ACCIDENT AND INJURY DATA ..................................... 22

4.1 Description of FRA Accident and Injury Databases ..................................................... 23

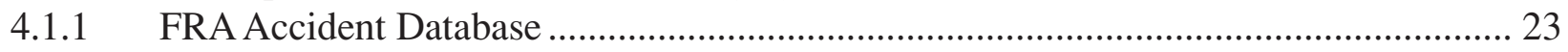




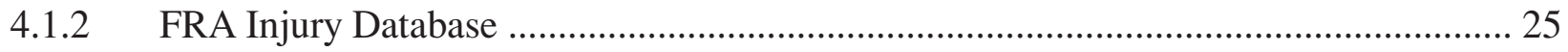

4.2 Analysis of 1994-1998 Railroad Yard Accidents ................................................... 26

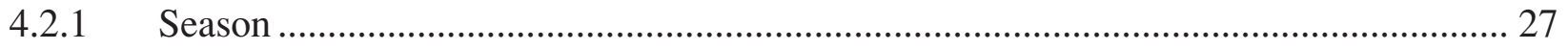

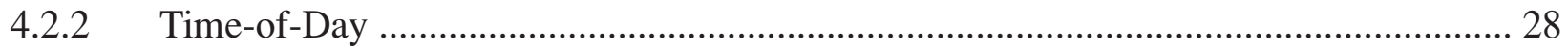

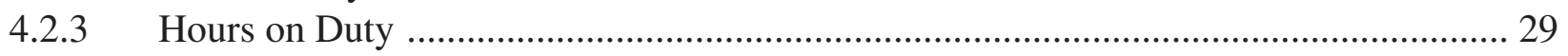

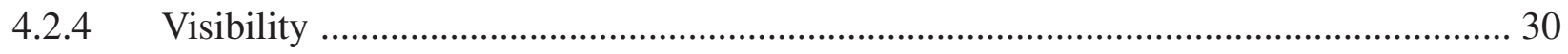

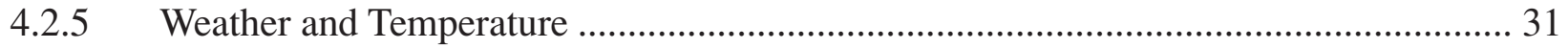

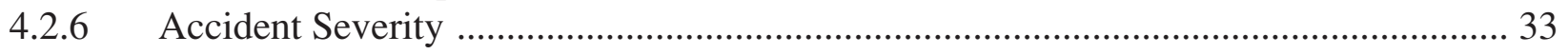

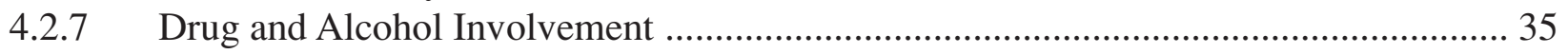

4.2.8 Hazmat Accidents ............................................................................................... 36

4.3 Analysis of 1997-1998 Railroad Yard Injuries ...................................................... 36

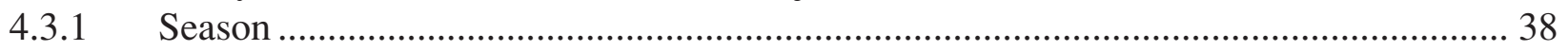

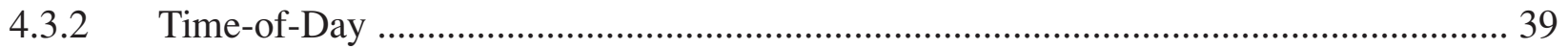

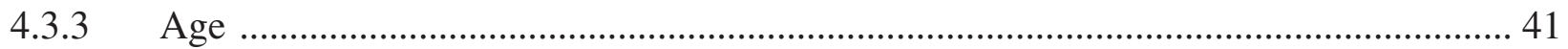

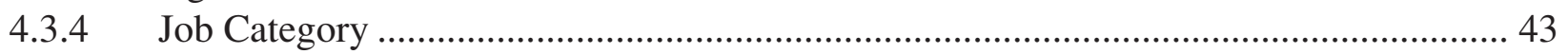

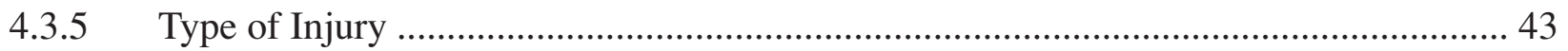

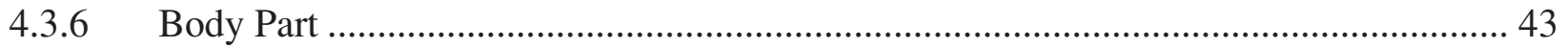

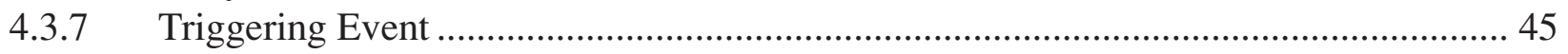

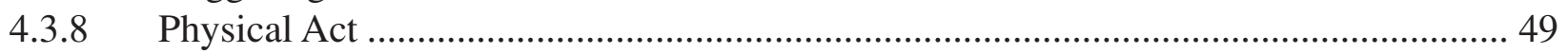

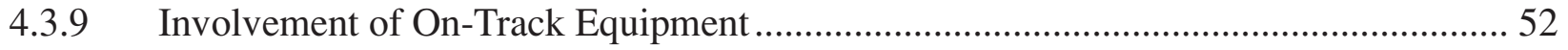

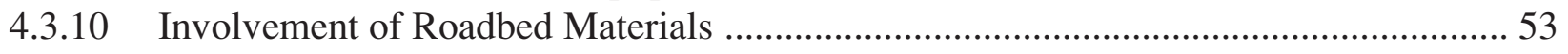

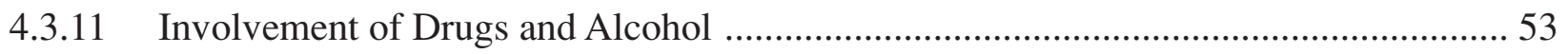

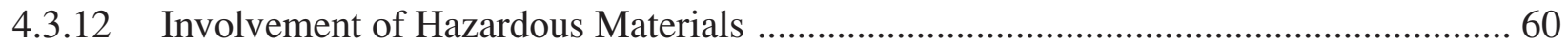

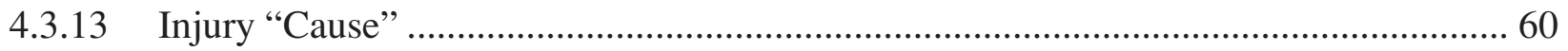

4.4 Comparison of Railroad Yard Injuries to Private Industry Injuries ........................... 60

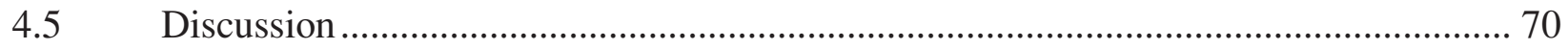

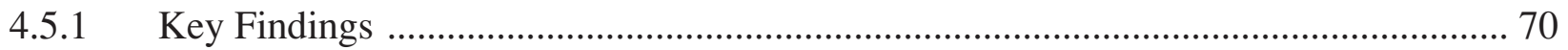

4.5.2 Limitations of the FRA Accident and Injury Data Analyses ................................... 71

5. SUPPLEMENTAL INJURY DATA COLLECTION AND ANALYSIS ............... 73

5.1 Supplemental Data Collection and Analysis Methods ............................................ 73

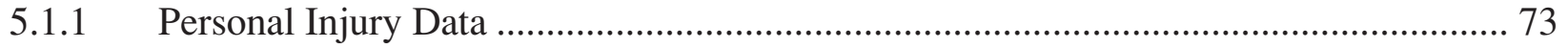

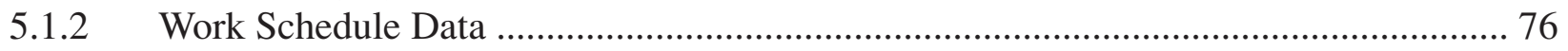

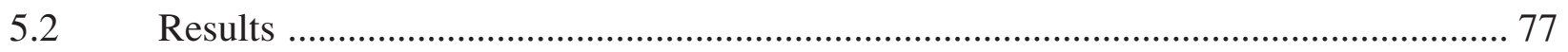

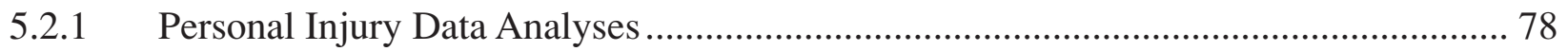

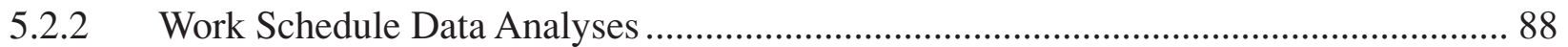

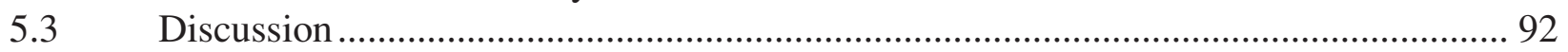

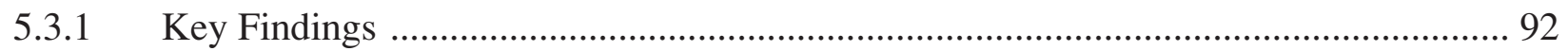

5.3.2 Limitations of the Study Methods and Data ..................................................... 95 
6. STRUCTURED INTERVIEWS WITH RAILROAD OFFICIALS 97

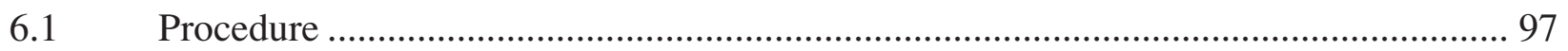

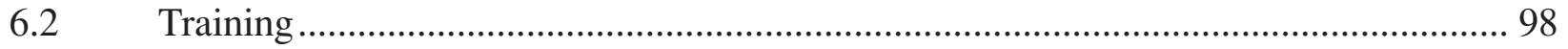

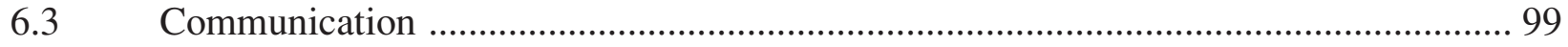

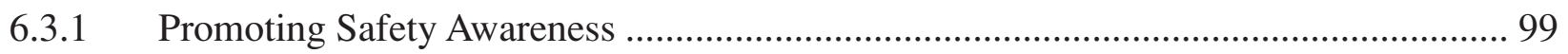

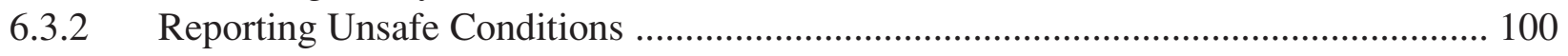

6.4 Safety Programs, Incentives and Awards ……........................................................... 102

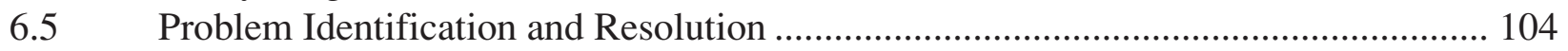

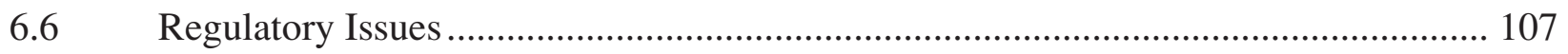

6.6.1 FRA's Role in Promoting Safety in Railroad Yards .................................................. 107

6.6.2 FELA and the Railroad Yard Work Environment ....................................................... 108

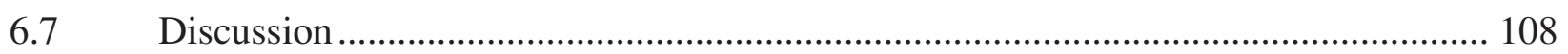

7. FOCUS GROUP INTERVIEWS WITH RAILROAD LABOR .......................... 110

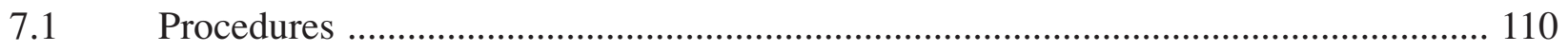

7.2 Participant Profile ..................................................................................... 111

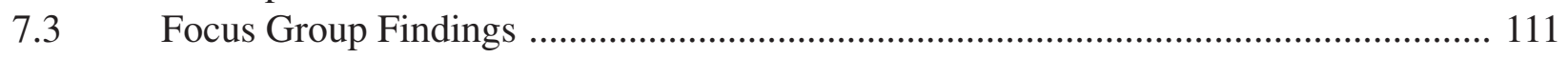

7.3.1 Factors Contributing to Yard Injuries ................................................................... 113

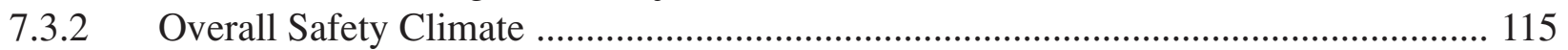

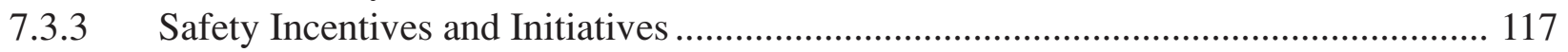

7.3.4 Injury Reporting and Follow-up Process ……..................................................... 118

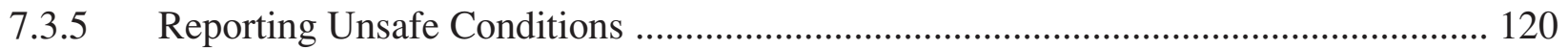

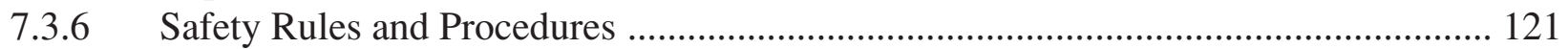

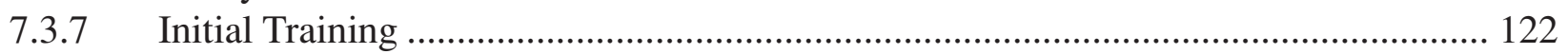

7.3.8 Training on New Rules, Procedures and Equipment ………...................................... 127

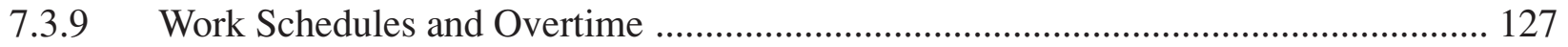

7.3.10 Supplemental Anonymous Injury Survey .................................................................... 130

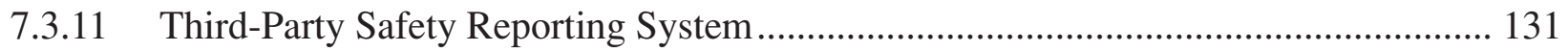

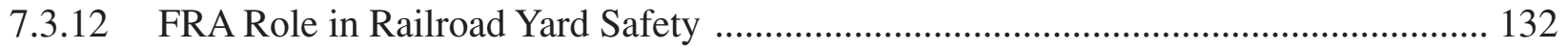

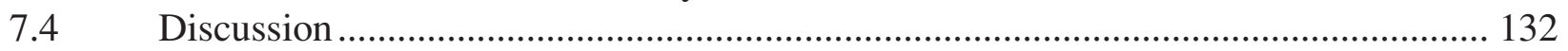

8. CONCLUSIONS AND RECOMMENDATIONS _.............................................. 135

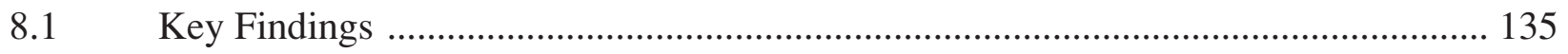

8.2 Best Practices for Fostering a Positive Safety Climate and Reducing Injuries ........... 137

8.3 Recommendations for Improved Analysis of Worker Safety ......................................... 139

8.3.1 Improved Data Collection and Reporting Procedures ................................................. 139

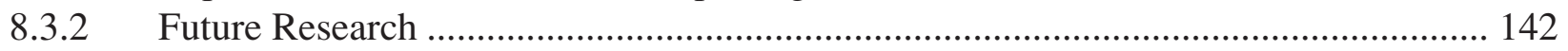

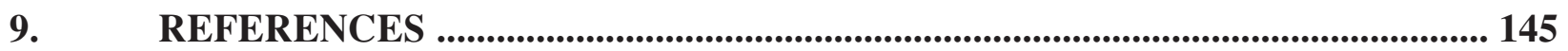


APPENDIX A - FRA AND OSHA JURISDICTION OVER RAILROAD EMPLOYEE OCCUPATIONAL SAFETY AND HEALTH

APPENDIX B - FRA AND MSHA ACCIDENT/INJURY REPORT FORMS 151

APPENDIX C - DATA COLLECTION FORMS .......................................................... 161

APPENDIX D - STRUCTURED INTERVIEW QUESTIONS ........................................... 165

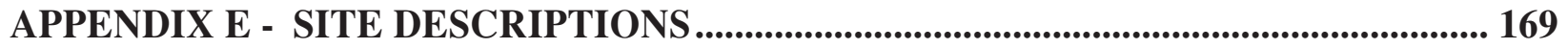

APPENDIX F - FOCUS GROUP QUESTIONS ............................................................... 176 


\section{ILLUSTRATIONS}

Figure

Page

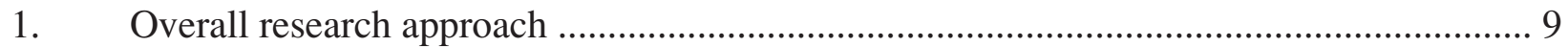

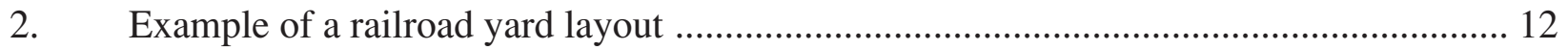

3. Example of debris on the ground of a railroad yard ....................................................... 16

4. Human factor-attributed train accidents in yards per million train switching miles

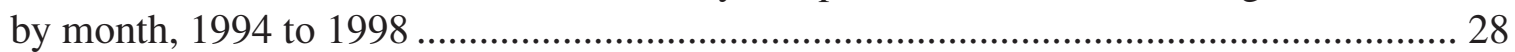

5. Human factor-attributed train accidents in railroad yards by time-of-day, 1994 to 1998

6. Human factor-attributed train accidents in railroad yards by hours on duty, 1994 to 1998 30

7. Human factor-attributed train accidents in railroad yards by temperature, 1994 to 1998 32

8. Human factor-attributed train accidents in railroad yards as a function of ambient temperature, 1994 to 1998

9. LWD yard injuries per million switching miles by month, 1997 to 1998 ......................... 39

10. LWD yard injuries by time-of-day, 1997 to 1998 ........................................................... 40

11. LWD yard injuries by age, 1997 to 1998 ........................................................................ 41

12. Weighted frequency of LWD injuries relative to age distribution ...................................... 43

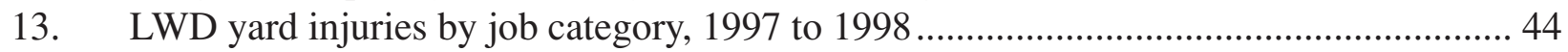

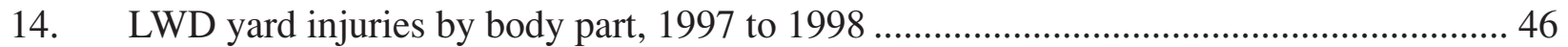

15. LWD yard injuries by physical act, 1997 to 1998 ........................................................... 58

16. LWD yard injuries by involvement of on-track equipment, 1997 to 1998 ........................ 59

17. Participating railroad yard injuries by type, 1996 to 1998 ………………….................. 79

18. Participating railroad yard injuries by body part, 1996 to 1998 ....................................... 80

19. Participating railroad yard injuries by physical act, 1996 to 1998 ................................... 81

20. Participating railroad yard injuries by triggering event, 1996 to 1998 .............................. 82

21. Participating railroad yard injuries by injury severity, 1996 to 1998 .............................. 83

22. Participating railroad yard injuries by age, 1996 to 1998 ................................................. 84

23. Participating railroad yard injuries per 1,000,000 cars switched per month,

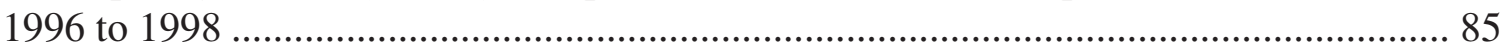

24. Participating railroad yard injuries per 100 employees per month, 1996 to 1998 ............. 86

25. Participating railroad yard injuries by time-of-day, 1996 to 1998 ………....................... 87

26. Participating railroad yard injuries by hours on duty, 1996 to 1998 ................................ 88

27. Participating railroad yard injuries by railroad experience, 1996 to 1998 ........................ 89

28. Interaction between participating railroad yard injury severity and age, 1996 to $1998 \ldots 90$

29. Interaction between participating railroad yard injury severity and time-of-day, 1996 to 1998 
30. Interaction between participating railroad yard injury severity and hours on duty, 1996 to 1998

31. Interaction between participating railroad yard injury severity and experience, ] 1996 to 1998

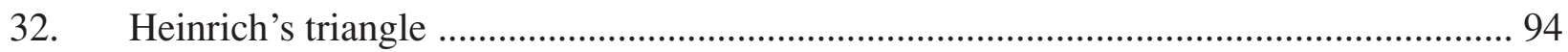

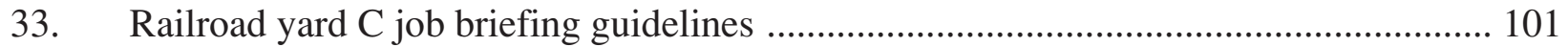

34. Example of an ergonomic switch stand .............................................................. 106

36. Focus group participant experience in present craft ............................................. 112

35. Distribution of focus group participants by craft ................................................... 112

37. Example of close clearance between railroad tracks in a railroad yard ....................... 114

B-1. Form FRA F 6180.55 railroad injury and illness summary ..................................... 152

B-2. Form FRA F 6180.55a railroad injury and illness summary (continuation sheet) ......... 153

B-3. Form FRA F 6180.98 railroad employee injury and/or illness record ......................... 154

B-4. Form FRA F 6180.54 rail equipment accident/incident report .................................. 156

B-5. Form FRA F 6180.78 notice to railroad employee involved in rail equipment accident/incident attributed to employee human factor ............................................. 157

B-6. Form FRA F 6180.81 employee human factor attachment ........................................ 158

B-7. MSHA Form 7000-1 mine accident, injury and illness report ................................. 160

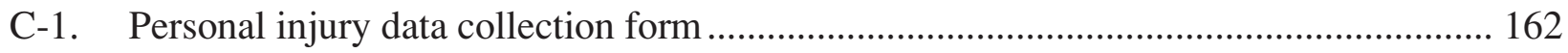

C-2. Work schedule data collection form ................................................................. 164 


\section{TABLES}

Table

Page

1. Human factor-attributed train accidents in railroad yards, 1994 to 1998 ....................... 27

2. Human factor-attributed train accidents in railroad yards, 1994 to 1998 ..................... 27

3. Human factor-attributed train accidents in railroad yards by visibility, 1994 to 1998 ..... 31

4. Human factor-attributed train accidents in railroad yards by weather condition, 1994 to 1998

5. Human factor-attributed train accidents in railroad yards by temperature, 1994 to 1998 32

6. Train accident severity by track type, 1994 to 1998 ................................................ 34

7. Railroad yard train accident severity by cause, 1994 to 1998 ..................................... 34

8. Railroad yard injuries resulting from human factor-attributed train accidents, 1994 to 1998 35

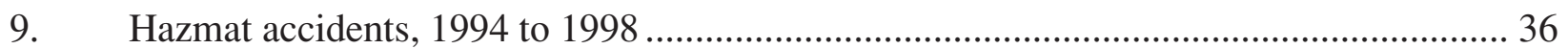

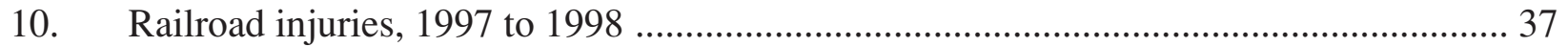

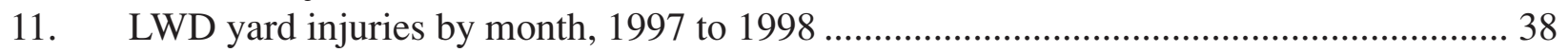

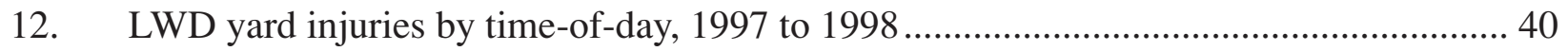

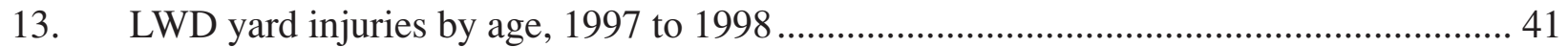

14. Weighted frequency of LWD yard injuries by age, 1997 to 1998 ............................... 42

15. LWD yard injuries by job category, 1997 to 1998 ..................................................... 44

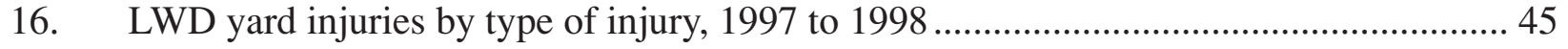

17. LWD yard injuries by body part, 1997 to 1998 ....................................................... 46

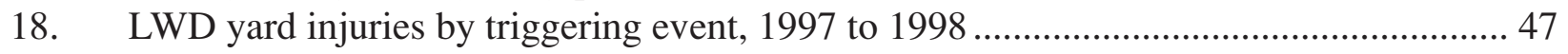

19. LWD yard injuries by triggering event and sorted by the number of injuries,

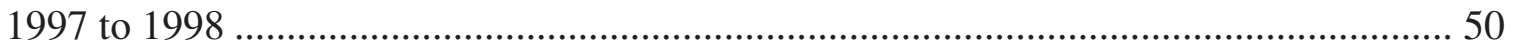

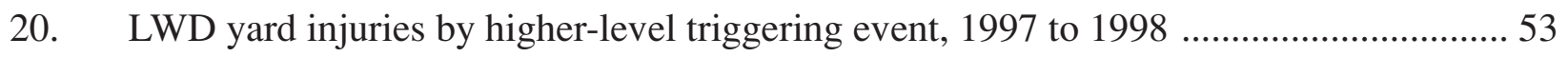

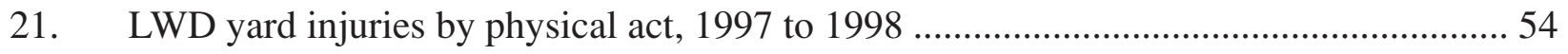

22. LWD yard injuries by physical act and sorted by the number of injuries,

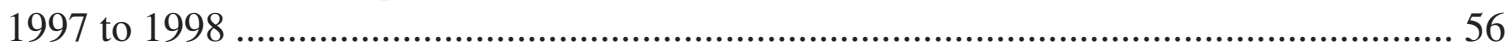

23. LWD yard injuries by higher-level physical act, 1997 to 1998 .................................... 58

24. LWD yard injuries by involvement of on-track equipment, 1997 to 1998 ..................... 59

25. LWD yard injuries by involvement of roadbed materials, 1997 to 1998 ...................... 60

26. Comparison of 1997 nonfatal occupational injuries and illnesses for selected

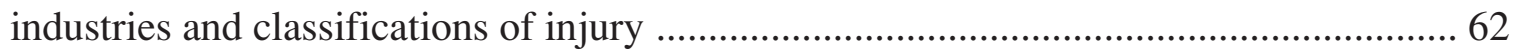

27. Percent distributions for 1997 nonfatal occupational days-away-from-work injuries and illnesses for selected industries and age groups....

28. Percent distributions for 1997 nonfatal occupational days-away-from-work injuries and illnesses for selected industries and injury types.... 
29. Percent distributions for 1997 nonfatal occupational days-away-from-work injuries and illnesses for selected industries and body parts affected

30. Percent distributions for 1997 nonfatal occupational days-away-from-work injuries and illnesses for selected industries and triggering events

31. Percent distributions for 1997 nonfatal occupational days-away-from-work injuries and illnesses for selected categories of DAFW and age groups

32. Percent distributions for 1997 nonfatal occupational days-away-from-work injuries and illnesses for selected categories of DAFW and industries

33. Participating railroad distribution of injuries by location, 1996 to 1998 ....................... 78

34. Variables that lacked sufficient data to report ....................................................... 78

35. Participating railroad yard injuries involving track and train equipment, 1996 to 1998

36. Age distribution weighted frequencies for participating railroad yard injuries, 1996 to 1998

37. Railroad experience-weighted frequencies for participating railroad yard injuries, 1996 to 1998 89

38. Total and expected number of shifts worked ......................................................... 93

39. Total and expected number of shift start times between 8 p.m. and 4 a.m.................. 93

40. Total and expected number of shifts greater than $8 \mathrm{hr}$............................................. 94

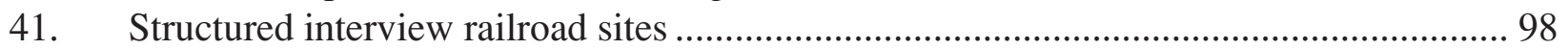

42. Factors contributing to injuries in railroad yards .................................................. 104

43. Factors that might help reduce railroad yard injuries ............................................. 105

44. Focus group location, worker experience and topics discussed ................................ 111

45. Suggestions to improve initial training ............................................................. 125 


\section{ABBREVIATIONS}

BLE Brotherhood of Locomotive Engineers

BLS Bureau of Labor Statistics

CBT Computer-Based Training

DAFW Days Away From Work

DOT Department of Transportation

FELA Federal Employers' Liability Act

FRA Federal Railroad Administration

GAO General Accounting Office

HOS Hours of Service

ICC Interstate Commerce Commission

LWD Lost Workday

MOE Maintenance of Equipment

MOW Maintenance of Way

MSHA Mine Safety and Health Administration

MSM Million Yard Switching Miles

OJT On-the-Job Training

OSHA Occupational Safety and Health Administration

PPE Personal Protective Equipment

RIP Track Repair, Inspect and Paint Track

RNT Random Number Table

RRB Railroad Retirement Board

RSI Repetitive Stress Injury

SME Subject Matter Expert

SOFA Switching Operations Fatality Analysis

T\&E Train and Engine (Crew)

TCU Transportation Communications Union (Brotherhood Railway Carmen Division)

UTU United Transportation Union 


\section{EXECUTIVE SUMMARY}

Safety in the railroad industry has improved markedly over the last two decades. Both accidents and injures have declined substantially. In 1990, almost 21,000 railroad employees were injured while on duty and an additional 40 were killed. By 1998 the number of injuries declined to 8,398 , less than half of the 1990 level, and fatalities totaled 27 . The injury rate for railroad employees has fallen from a high of 12.1 casualties per 200,000 employee-hours in 1979 to 3.27 in 1998. While this rate is relatively low in comparison to other modes of transportation, several job categories within the railroad industry experience injury rates and severities far in excess of the industry average. Many of these jobs are located in railroad yards. In fact, almost half of all train accidents (48 percent) and almost a third of all railroad employee injuries (31 percent) occurred in railroad yards in 1998. Understanding the circumstances and characteristics of these accidents and injuries is a necessary prerequisite to reducing workplace hazards and dangerous work practices in railroad yards.

To assist the railroad industry in its efforts to improve safety in the workplace, the Federal Railroad Administration (FRA) initiated this research to examine worker safety issues in yards. The research program focused on human factor-related hazards and solutions. The specific objectives of this program were to:

1. Identify injury and accident trends using the FRA accident/injury database.

2. Examine the effect of work schedule on yard injuries.

3. Solicit and evaluate railroad labor and management opinions and experiences regarding safety strategies.

4. Explore methods for collecting additional injury causal factor data.

The research was limited to train accidents and employee injuries that occur in railroad yards in the United States. Analyses of train accidents were limited to human factor-attributed yard accidents, since the overall program effort centered on human factor-related hazards and solutions. Train accident data from 1994 to 1998 were analyzed. Analyses of personal injuries focused on those injuries that were sustained in a yard, by employees-on-duty, and that resulted in one or more lost workdays (LWD). A LWD injury is one that results in at least one day away from work (i.e., absent) and/or one day of restricted, or "light" duty. This subset represents the most serious injuries and those with potentially the largest economic impact to both the railroad and the worker. Injury data from 1997 to 1998 were analyzed. 
This study examined a broad range of issues that affect yard worker safety, including:

- Safety culture.

- Training.

- Communications.

- Labor-management relations.

- Work schedules.

- Injury reporting procedures.

- FRA-railroad relations.

The technical approach of this research program combined quantitative data analyses with qualitative research methods. Existing FRA injury and accident data were analyzed to provide statistical insights into national injury and accident demographics, while personal injury and work schedule data from a participating railroad provided an opportunity for in-depth analysis of factors associated with worker injuries in yards. Structured interviews with railroad management and focus groups with railroad labor provided a further understanding of the safety issues that could not be gleaned from existing FRA data and analyses of railroad injury and work schedule data.

The FRA's Office of Safety maintains databases with reports of all U.S. railroad accidents and all railroad-related injuries and occupational illnesses that meet the FRA's reporting criteria. These databases contain information on a variety of factors that describe the circumstances and events associated with train accidents and personal injuries.

Analyses of the FRA accident and injury data revealed the following:

- Eighty percent of railroad yard injuries resulted in one or more LWDs compared to 77 percent of railroad-wide injuries and 47 percent of private industry injuries. Of all private industries, mining was the most similar to the yard and railroad environments.

- Sprains and strains accounted for more than half of the LWD injuries in railroad yards; the trunk/torso was the most affected body part; slips, trips and falls were the most common triggering event; and the acts of walking, running, or stepping over were the leading physical acts associated with LWD yard injuries.

- The rate of human factor-attributed yard train accidents and LWD yard injuries per million switching miles were among the highest in July.

- Human factor-attributed train accidents in railroad yards appear to be a function of ambient temperature. Specifically, more train accidents occur during colder and hotter temperatures than during the milder temperatures.

- The hours between 10 a.m. to 12 p.m. are associated with the greatest number of LWD yard injuries and a relatively large number of human factor-attributed train accidents. The hours 
between 2 a.m. and 4 a.m. are also associated with a large number of human factor-attributed train accidents, but relatively few LWD yard injuries.

- Employees younger than 35 appear to suffer a greater percentage of LWD yard injuries than their proportion within the workforce.

There were several limitations to the FRA accident and injury data and the analytical methods of the study. These limitations centered on the types of data and reporting definitions. Of particular note was that there were minimal exposure measures available for the accident and injury data.

Three years (1996 to 1998) of employee injury data were also collected from a participating railroad. These data included FRA reportable injuries as well as non-reportable injuries. Information was collected on the circumstances of the injury, personal factors (e.g., age, railroad experience), and environmental factors (e.g., location of the injury, weather).

Analysis of work schedule data centered on Train and Engine (T\&E) employees injured in the yard, since work schedule data was only available for these crafts. Thirty days of work schedule data prior to the injury were collected for each injured employee. Similar data were also collected for a craft, experience, and age-matched sample of non-injured T\&E employees to allow a statistical comparison to be performed between the two groups.

Key findings from the data analyses of the participating railroad include:

- The greatest number of injuries occurred during the injured employees' 4th through 6th hour on duty.

- Although the most injuries in any 2 hour time period occurred between 10 a.m. and 12 p.m., the second-most injuries occurred between 8 p.m. and 10 p.m.

- May, July and August were associated with the highest injury rates.

- The most affected body parts were the arms and hands; sprains and strains were the most frequent type of injury; the physical acts of walking, running or stepping over were associated with the most number of injuries; and being struck by or against an object was the most common triggering event.

- There were no statistically significant differences between the injured T\&E employees and the non-injured T\&E employees with respect to the work schedule variables analyzed. A lack of statistically significant differences does not necessarily mean that operator fatigue is not an issue in yard operations, however.

Structured interviews were conducted at four different railroad yards across the country. Interviews were conducted with railroad officials responsible for the development, implementation, and/or oversight of safety programs at their respective railroad yards. The 
interviews focused on issues that were specific to railroad yards, such as contributors to injuries in yards; however, many of these issues are not limited to railroad yards.

The structured interviews identified a number of strategies that foster worker safety in yards. These strategies centered around training, communications, equipment and facilities, and employee performance. Some examples include:

- The most effective on-the-job training (OJT) mentors are those who are selected because of their desire to train others and their skill in teaching others.

- Railroads offer a variety of ways for employees to report unsafe conditions; the more options, the more likely unsafe conditions will be reported.

- Ergonomic and push button switch stands, use of radio communication in place of hand signals, use of "walking" stone on switch leads, and a clean work environment can all help to reduce injuries in railroad yards. Many of these, in fact, have already been implemented at the railroads that were visited.

- Employees must feel ownership of safety in the yard and must take responsibility for safe work practices. Improved training, emphasis on behavioral observation, and daily job briefings are methods used by the four sites to help keep employees focused on safe work practices.

Focus group interviews with railroad yard workers provided a forum to gather information about worker experiences in the yard environment and to solicit ideas, from the worker's perspective, as to how safety can be improved in railroad yards. These structured group meetings also provided a forum to obtain feedback on two concepts for future data collection-a supplemental anonymous injury survey and a third-party anonymous safety reporting system.

St. Louis, Houston, and Chicago were selected as focus group interview sites due to the large number of railroad yard workers available in each location. Participants were recruited from the three general crafts that make up the majority of yard workers: trainmen (switchmen and conductors/foremen), engineers, and carmen. A total of 11 focus groups were conducted, and a total of 11 topics were addressed. The information from the focus group interviews provided a rich source of information about yard worker safety from the worker's perspective. Some of the findings include:

- Participants felt that employees in some yards experience harassment and intimidation. According to participants, harassment and intimidation result in: 1) less effective training; 2) underreporting of injuries and unsafe conditions; 3) under-maintained equipment and facilities; 4) fatigued employees; and 5) unsafe work practices (e.g., pressure to rush to get a job done). According to participants, this animosity hinders sharing information and working collaboratively with management to solve problems. 
- Participants felt that incentive programs with material rewards have little or nothing to do with worker motivation to work safely.

- Participants were of the opinion that initial training for novice trainmen did not adequately prepare them to do the job. Experienced workers expressed a concern that new trainmen with whom they work were not adequately trained.

- Several aspects of current T\&E crew management practices were a source of dissatisfaction to participants. These included difficulty in taking a personal or sick day, schedule uncertainty for the extra board, and pressure to work overtime.

The negative organizational climate that appears to exist in the yard environment likely will limit the effectiveness of new data collection initiatives that focus on obtaining supplemental information on injuries. Specifically, based on focus group participants' concerns about retribution from the railroads, a supplemental anonymous injury survey is not recommended as a means to collect additional data regarding the circumstances of an injury. Further, the success of a third-party anonymous safety reporting system will depend on the cooperation and involvement of the railroad industry and labor organizations.

Based on discussions with railroad officials during the site visits and focus group interviews with representatives of yard crafts, a set of best practices for fostering a positive safety climate and reducing the risk of worker injuries was identified. Best practices are organized around major themes. Some best practices that were identified include:

- Remove trash, debris, and other slip and trip hazards from the yard on a regular and frequent basis.

- $\quad$ Select OJT mentors who are interested in training new hires and are effective trainers. Compensate mentors appropriately.

- Offer several methods for reporting an unsafe condition. Some individuals will take the time to fill out a written report, some prefer to have their union representative do the reporting for them while others may find a telephone message suitable.

- Spend money on capital safety improvements rather than on material incentives.

- Create a more supportive work environment.

The findings and experiences from this study also suggest several ways in which the FRA can improve the analysis of worker safety. These are organized into 1) enhancements to the FRA's accident and injury data collection and reporting process, and 2) additional research.

Recommendations to enhance the FRA's accident and injury data collection and reporting process include the following: 
- Develop better exposure measures.

- Develop better or more complete instructions, definitions and guidelines to assist railroad personnel in completing FRA accident and injury forms.

- Collect additional injury-related data.

- Report data on injury severity.

- Encourage and facilitate industry adoption of computer-based data collection and reporting.

- Continue to work collaboratively with railroad management and labor.

Areas for future research on issues related to worker safety in yards that are identified and discussed in the report include:

- Examine the relationship of work schedules to yard injuries.

- Examine the impact of the Federal Employers' Liability Act (FELA) on injury reporting and data collection.

- Examine the feasibility of developing a third-party anonymous safety reporting system.

- Conduct a root cause and error analysis of railroad yard injuries.

- Conduct an information exchange workshop to gain knowledge about injury reporting methods and procedures used in other modes of transportation and in other industries.

- Explore the feasibility and effectiveness of behavior-based safety programs in the railroad environment. 


\section{INTRODUCTION}

\subsection{Background}

Safety in the railroad industry has improved markedly over the last two decades. Both accidents and injures have declined substantially. In 1990, almost 21,000 railroad employees were injured while on duty and an additional 40 were killed. By 1998 the number of injuries declined to 8,398 , less than half of the 1990 level, and fatalities totaled 27 . The injury rate for railroad employees has fallen from a high of 12.1 casualties per 200,000 employee-hours in 1979 to 3.27 in 1998 (FRA, 1995; FRA, 1999). While this rate is relatively low in comparison to other modes of transportation, several job categories within the railroad industry experience injury rates and severities far in excess of the industry average. Many of these jobs are located in railroad yards. In fact, almost half of all train accidents (48 percent) and almost a third of all railroad employee injuries (31 percent) occurred in railroad yards in 1998. Understanding the circumstances and characteristics of these accidents and injuries is a prerequisite to reducing workplace hazards and dangerous work practices in railroad yards.

An issue that has received particular attention in recent years is human operator fatigue and its contribution to injuries and accidents. Transportation system safety is compromised by fatigue due to innate circadian factors, as well as overwork. The railroad industry operates around the clock, and this continuous type of activity requires worker flexibility in terms of shift start times, on-call work arrangements, and extended work hours. The circadian desynchronization resulting from interference with natural biological rhythms has a significant potential to negatively impact railroad personnel. Although the majority of the work-rest research in the railroad industry has concentrated on locomotive engineers, yard employees may also suffer the effects of working nights and rotating shifts, leading to fatigue and an increased likelihood of injury. Industry representatives report that, in some yards, up to 30 percent of the work force may change shifts at least once per week.

Job-related injuries cost American railroads over $\$ 1$ billion annually (TRB, 1994). American railroads do not operate under workers' compensation statutes, as do most other industries in the United States. Instead, railroads operate under FELA which, despite its name, applies only to railroads. Unlike workers' compensation statutes, FELA, does not automatically hold the railroads liable for on-the-job injuries. When a railroad employee is injured, depending on the circumstances, he or she may submit a claim to the railroad, which in turn chooses either to pay or to litigate the case. Though only a small number of claims are resolved in court, the litigation costs to the railroads are high, and settlements to injured employees are often delayed due to the legal process. Continued improvements in railroad worker safety, therefore, will not only reduce the number and severity of worker injuries, but also will result in significant savings for railroads. 
To assist the railroad industry in its efforts to improve safety in the workplace, the FRA initiated an evaluation of worker safety issues in yards, where a large number of employee injuries occur. The evaluation effort involved analyses of FRA-maintained railroad injury and accident data, data collection and analysis of site-specific injury and work schedule data from a participating railroad, and the collection of qualitative data in the form of structured interviews with railroad management and focus groups with railroad labor. The research program focused on human factor-related hazards and solutions. This report describes the methods and results of this entire research program.

\subsection{Purpose}

The purpose of this research was to understand the mechanisms underlying injuries and accidents that occur in railroad yards throughout the United States. The specific objectives of this program were to:

- Identify injury and accident trends using the FRA accident/injury database.

- Examine the effect of work schedule on yard injuries.

- Solicit and evaluate railroad labor and management opinions and experiences regarding safety strategies.

- Explore methods for collecting additional injury causal factor data.

\subsection{Scope}

The scope of the research was limited to train accidents and employee injuries that occur in railroad yards in the United States. Analyses of train accidents were limited to human factorattributed yard accidents, since the overall program effort centered on human factor-related hazards and solutions. Train accident data from 1994 to 1998 were analyzed. Analyses of personal injuries focused on those injuries that were sustained in a yard, by employees-on-duty, and that resulted in one or more LWD. A LWD injury is one that results in at least one day away from work (i.e., absent) and/or one day of restricted, or "light" duty. This subset represents the most serious injuries and those with potentially the largest economic impact to both the railroad and the worker. Injury data from 1997 to 1998 were analyzed. 1997 was the first year in which the specific location (on the railroad property) where the injury occurred was reported to the FRA, thus analyses of yard-specific injuries could only be conducted starting in 1997.

This study examined a broad range of data and issues which are likely to affect yard worker safety, including:

- Injury reporting procedures.

- Work schedules.

- Training.

- Safety culture. 
- Communications.

- Labor-management relations.

- FRA-railroad relations.

\subsection{Overall Approach}

The overall technical approach combined quantitative data analyses with qualitative research methods. (See Figure 1.) Quantitative data analyses of existing FRA injury and accident databases provided valuable statistical insights into national injury and accident demographics, while analysis of personal injury and work schedule data from a participating railroad provided an opportunity for in-depth analysis of factors associated with worker injuries in yards. Qualitative methods, specifically structured interviews with railroad management and focus groups with railroad labor, provided a further understanding of the safety issues that could not be gleaned from existing FRA databases and analyses of personal injury and work schedule data from the participating railroad. The anonymity of all of the employees and railroads that participated in this research was maintained due to the sensitive legal issues that are associated with injuries and accidents that occur in the workplace.

\subsection{Organization of the Report}

This report is divided into several major sections. Section 2 presents an overview of railroad yard operations. Section 3 discusses FELA and its relevance to railroad yard safety. Section 4

Quantitative Data

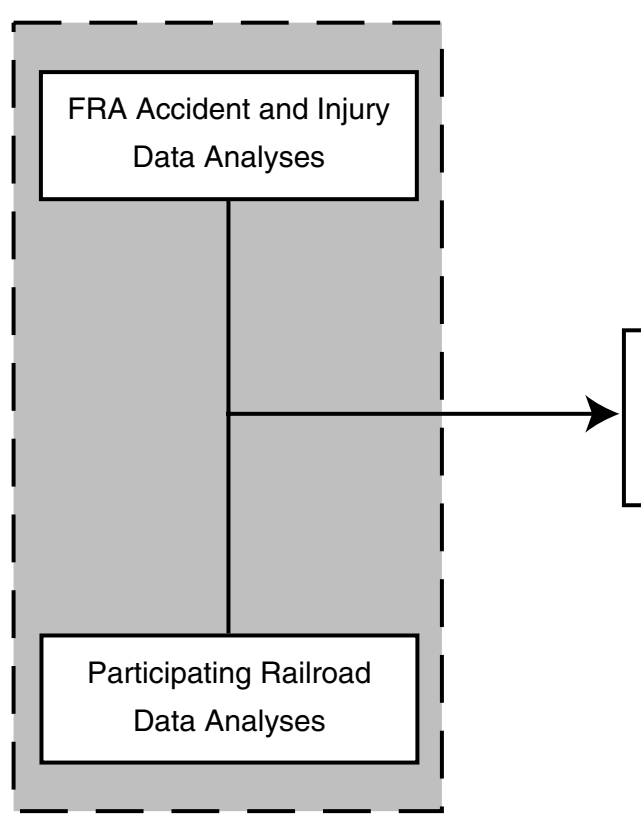

Qualitative Data

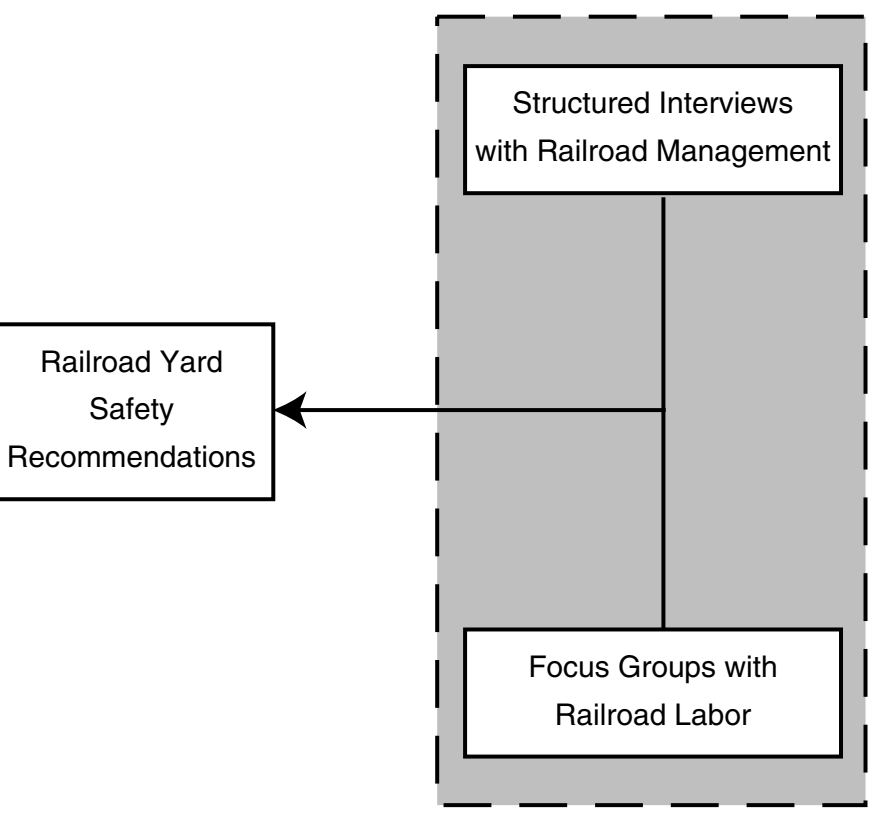

Figure 1. Overall research approach 
presents the analyses of the FRA accident and injury data, while Section 5 presents the methods and results of analyses of injury and work schedule data from a participating railroad. Section 6 presents the methods and findings from the structured interviews with management, and Section 7 presents the methods and findings from the focus groups with labor. Section 8 presents key findings from the research, suggestions regarding best practices for fostering a positive safety climate and reducing injuries, and recommendations for improvements in the injury data collection process and future research. Section 9 includes the references used in conducting this research.

A set of Appendices are included at the end of the report. Each appendix either provides supplemental information that is germane to the research or contains supporting materials. Appendix A discusses the FRA and Occupational Safety and Health Administration (OSHA) jurisdictions over railroad employee occupational safety and health. Appendix B provides copies of several relevant FRA accident and injury report forms. Appendix $\mathrm{C}$ contains copies of the data collection forms used to collect personal injury and work schedule data from the participating railroad. Appendix D contains the structured interview questions used with railroad management. Appendix E contains descriptions of the sites that were visited as part of the project. Lastly, Appendix F contains the focus group questions used with railroad labor. 


\section{OVERVIEW OF RAILROAD YARD OPERATIONS}

Railroad yards are not analogous to any other transportation or industrial facility. Railroad yards can be very large, may be dark at night, contain stones and possibly debris on the ground, and include large, sometimes silent, moving equipment. An understanding of the activities that are performed in railroad yards is a prerequisite to analyzing the train accidents and personal injuries that occur in this environment. This section presents a brief overview of a typical railroad yard layout and describes the functions that are carried out in each area of the yard. The specific railroad crafts or job categories that work in the yard are also identified along with their functions. Lastly, typical job hazards associated with a yard are discussed.

\subsection{Railroad Yard Functions}

A railroad yard is a system of railroad tracks with defined limits that is used for classifying strings of cars into "blocks" going to common destinations, assembling blocks of cars into trains, and storing cars for later use. Trains arrive and are inspected, disassembled, and reassembled. Newly assembled trains are then inspected before departing for another destination. Many yards also have facilities to inspect and service locomotives and some yards have facilities to conduct major car repairs. Yards come in all sizes and shapes; no two yards are identical, since each is generally built to fit a particular geographical area or a particular logistical need. Many yards have areas for transferring intermodal freight to and from the rail system. Some yards handle primarily through freight while others service local industries.

Historically, railroad yards were built close to traffic origins and destinations so that they could better serve major traffic sources, and receive and build trains for main line movement. As the country grew, operating divisions were formed and smaller yards were frequently built between divisions in order to switch trains for further movement and to change locomotives and crews. These "divisional yards" were typically 100 to 125 miles apart. This was the distance that an average crew (four to six employees) could achieve in a 16 hour workday, and the distance steam locomotives could travel before needing to be serviced. At one time, the number of divisional yards was in the thousands.

Although the functions of railroad yards remain the same today as they were 100 years ago, the number of present day yards has been greatly reduced to reflect the operational changes that have occurred in the railroad industry. As diesel locomotives replaced steam locomotives, it was no longer necessary to service locomotives every 100 to 125 miles. Railroad traffic patterns changed as well. Large volume shippers replaced numerous small customers and consequently railroads removed many branch lines and local delivery tracks. Much of the short haul portion of the business went to trucks, and the railroads developed the intermodal market. As a result of 
these changes, many of the smaller yards have disappeared, and the remaining yards have fewer employees. Locomotives and trains can now go hundreds of miles between servicing. Crew agreements have also changed. Today there are fewer employees on each crew; two to three instead of four to six employees previously assigned to each freight train. Many crews run on more than one crew district of 100 plus miles and work on longer inter-divisional runs of 200 to $300 \mathrm{mi}$.

Although the remaining classification yards may look different than they did 100 years ago, they still perform the same basic functions: receive trains, classify the cars according to destination, and assemble new trains in preparation for travel to their next destination.

\subsection{Typical Railroad Yard Layout and Operation}

Most railroad yards operate around the clock, year-round. The volume of traffic may vary by time of day, day of the week, or season. Depending upon the industries served by the yard, traffic will increase on certain days of the week and decrease on other days. Further, certain times of the year may experience an increase in traffic volume. Track work in the yard tends to occur on those days with the lightest traffic.

In order to receive trains, classify cars, and assemble trains for forwarding, a railroad yard must have areas where trains or cars can leave the main tracks for inspection, maintenance, sorting, aggregation and segregation; where locomotives can be fueled and serviced; and where crews can change. Figure 2 shows an example of a layout for a yard, which includes a receiving yard, a classification yard, and a departure yard.

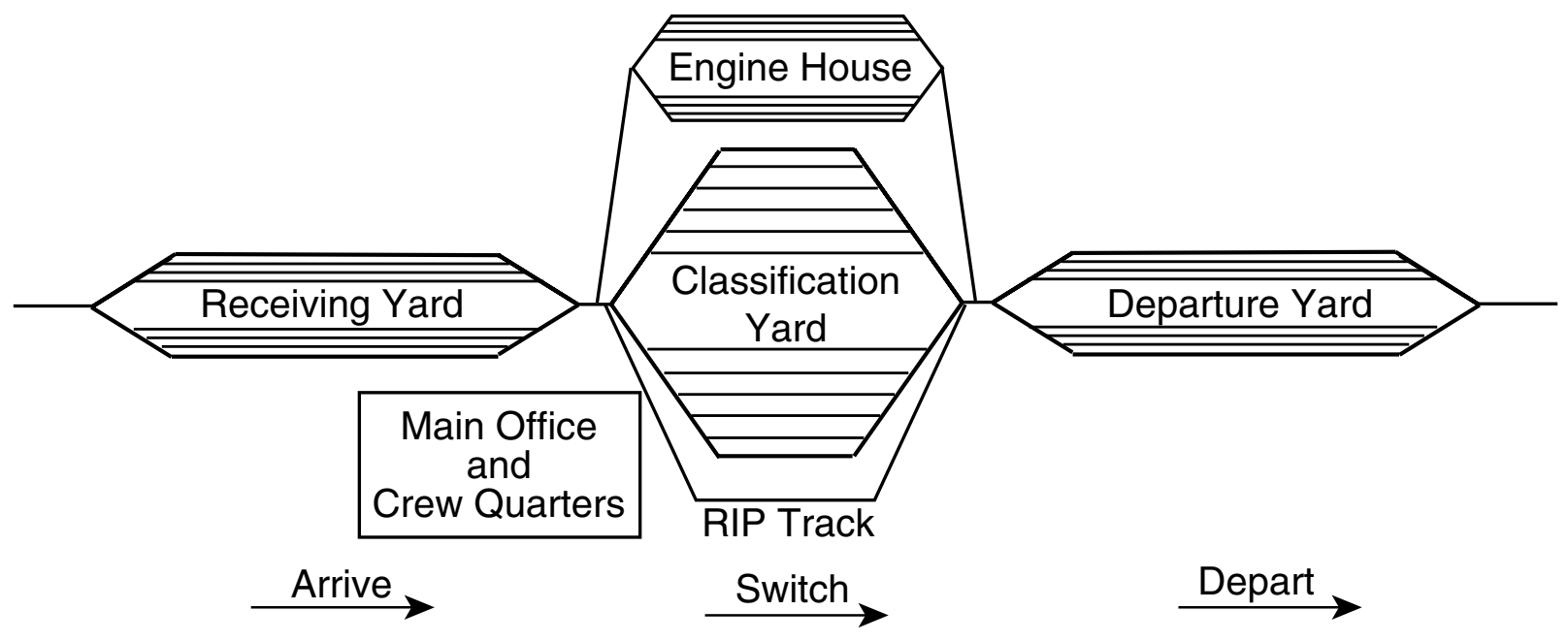

Figure 2. Example of a railroad yard layout 


\subsubsection{Receiving Yard}

Trains enter the yard through the receiving yard. This is the area where railroad personnel thoroughly inspect the physical condition of the incoming cars, and if necessary, crawl under cars to inspect running gear and brakes. This area must be isolated and secured to prevent equipment movement during these inspections. When trains are received and are being inspected, locomotives are uncoupled and sent to a locomotive servicing area, where they are inspected and fueled.

Employees who usually work in the receiving yard include road crews (two to three people per crew); inspection crews (two to five people per crew); and yard crews (two to three people per crew). Some yards may employ switch tenders who assign trains to the proper tracks.

To prepare for the next step in the process (classification), the inspection crew (carmen) bleedsoff the brakes and identifies cars that need further repair. Cars in need of repair are moved to a car repair location such as a Repair, Inspect and Paint (RIP) track. Meanwhile, clerical employees prepare and forward a switch list to the yardmaster. The yardmaster is usually located in an area where activities at key locations in the yard can be observed, such as between the receiving and classification yards, and/or between the classification and departure yards. Larger yards may employ more than one yardmaster. The yardmaster uses the switch list to determine how to best utilize the classification yard. This may require modifications to the switch list, such as classifications requiring more than one track, or cars in need of repairs.

\subsubsection{Classification Yard}

There are many tracks of different lengths in classification yards, but they are typically shorter in length than either receiving or departure yard tracks. In the classification yard, the switch list is used to identify cars going to the same destination. These cars are then placed together on the same track. Cars are "humped" or "kicked" into the classification yard. Humping is a method of classifying cars whereby cars to be classified are pushed up a hill (or hump). At the top of the hill, cars are uncoupled, usually in sets of one, two, or three, and roll down the other side of the hill and into a designated classification track using their own momentum and automatic car retarders. Kicking is another method of classifying cars whereby uncoupled cars are pushed by locomotive with sufficient speed to allow free forward movement into the selected classification track. Employees in the classification yard typically include a yard engineer, a conductor (called a foreman in a yard), and a switchman.

\subsubsection{Departure Yard}

The departure yard resembles a receiving yard. Each track is typically one train length long and track centers are ideally wide enough to accommodate mechanized car inspection vehicles. Yard engines are used to couple and pull the cars in the proper order from the classification tracks to the departure tracks. Once a train is assembled (or "built"), with cars in proper blocks, the car department inspection crews are notified and car inspection begins. During the inspection, the air hose at one end of the car is coupled to the air hose of the adjacent car. Running gear and 
loads are also inspected. When these inspections have been completed, the brakes are then charged and tested. When the brake tests are completed, the locomotives are attached and final brake tests are performed. After final brake tests the train is dispatched from the departure yard.

In the departure yard, typically yard crews, car inspection personnel, and road crews operate to prepare the newly assembled trains for departure.

\subsubsection{Other Areas within the Railroad Yard}

Within the railroad yard there may be other areas, such as a locomotive servicing area, car repair shops, RIP tracks, industrial yard, cleaning tracks, intermodal facilities, office areas, crew reporting areas, bunk house and track maintenance facilities. The type of facilities at each yard depends on the yard's function within the railroad network, its location, and its size, among other factors.

\subsection{Railroad Departments and Their Functions}

To perform the basic functions of receiving trains, classifying the cars, and assembling trains for forwarding, yards primarily require the services of three different railroad departments: the transportation department, the mechanical department, and the engineering department. These three departments are described briefly in the following sections.

\subsubsection{Transportation Department}

Transportation department personnel are responsible for operating the trains. They come from the ranks of trainmen (mostly conductors) and engineers. Often, a conductor who works primarily in the yard is called a foreman. The current minimum crew size for a train crew is two-a conductor and a locomotive engineer. Such a two-person crew typically operates trains that run from one terminal to another, often called "through" trains. Trains that service local industries, often called "local" trains, frequently have a third person, a switchman, on the crew to assist with the additional switching and picking up and setting out of cars. Yard and local freight crews often also contain three-person crews because of the large amount of switching that they do in the yard. The job of these employees requires being on and around moving railroad equipment. Locomotive engineers are responsible for the operation of the train and never leave the cab of the locomotive while it is in operation, unless the engineer is remotely controlling the locomotive, in which case he or she may be on the ground operating the locomotive. The conductor, or foreman, is responsible for operating the switches and coupling/uncoupling cars, and is often aided by a switchman on the ground. In the yard, a hostler, instead of a locomotive engineer, occasionally will be responsible for the limited movement of the train, typically from a track to the engine house for inspection, refueling or repairs.

The clerical personnel in the transportation department generally work in an office environment, where they serve as the interface between the communications systems and the ground personnel. Their primary responsibility is the preparation of switch lists to guide the classification of trains according to each car's destination. They prepare instructions for the 
crews and check and update computer databases. They ensure that the crews are aware of each car's destination and any particular instructions that are needed such as the presence of excessive car dimensions or hazardous cargo in their trains.

\subsubsection{Mechanical Department}

There are two different groups of mechanical personnel; those involved with locomotive servicing and maintenance, and those involved with car maintenance. Both are considered "maintenance of equipment," or MOE, jobs. The locomotive personnel generally perform their work in an indoor engine house. The car department personnel normally work in three areas of a large yard: the receiving yard where they inspect and bleed the cars in preparation for classification, the departure yard area where they prepare the cars for movement on the mainline; and the repair yard and/or shop area.

\subsubsection{Engineering Department}

Also referred to as the Maintenance of Way (MOW) department, the engineering department is responsible for inspecting, repairing, and maintaining the roadbed and track structures; all switches and retarders; all buildings; and all communication and signaling devices.

\subsubsection{Distribution of Work Force}

A typical railroad yard has the following work forces, all of whom are directly or indirectly involved with the movement of trains inside a yard:

- $\quad$ Trainmaster - The individual responsible for all crews working in the yard.

- Yardmaster - The individual in charge of all movements within yard limits.

- Yard Crews - Yard conductors, yard foremen, switchmen, yard engineers, yard brakemen, and car retarder operators.

- Road Crews - Locomotive engineers, firemen, conductors and brakemen.

- Car Mechanical Work force - Foremen, car inspectors and repairmen.

- Locomotive Mechanical Work force - Foremen, laborers, hostlers and electricians.

- Maintenance of Way Work Forces - Track and gang foremen, supervisors, laborers, inspectors, and communication and signal maintainers.

- Clerical Work Force - Arrival clerks, classification clerks, bill rack personnel, equipment dispatchers and chief clerk. 


\subsection{Typical Hazards within a Railroad Yard}

There are numerous hazards associated with railroad yards due to the high traffic volume, the physical layout of the yard, and the labor-intensive nature of switching cars. These job hazards include a high volume of large, heavy, moving equipment; uneven surfaces; manual switches; equipment and debris on the ground (see Figure 3); noise and visual distractions; inclement weather; and greasy and slippery work areas and surfaces (e.g., a switching step or vertical handhole of a locomotive). These and other hazards will be discussed later in the report.

\subsection{The Injury Reporting Process}

In general, all railroads have a similar procedure for reporting personal injuries, though there is some variation across railroads, and even across yards within a railroad. Although every railroad provides the same information to the FRA via monthly injury and illness summaries (Form FRA F 6180.55a), each railroad has its own specific forms, investigation procedures and resolution procedures that are used in collecting information about a personal injury.

Typically, the injured employee or another crew member notifies the yardmaster, who in turn notifies the trainmaster. The injured employee receives appropriate first aid or medical treatment, as necessary. The trainmaster, director of safety, and possibly a claim agent then investigate the injury. In many railroads a formal hearing is held after the investigation, at which time discipline may be imposed on the employee. The injured employee may appeal the decision through a contractually established mediation process, though this depends on the railroad and

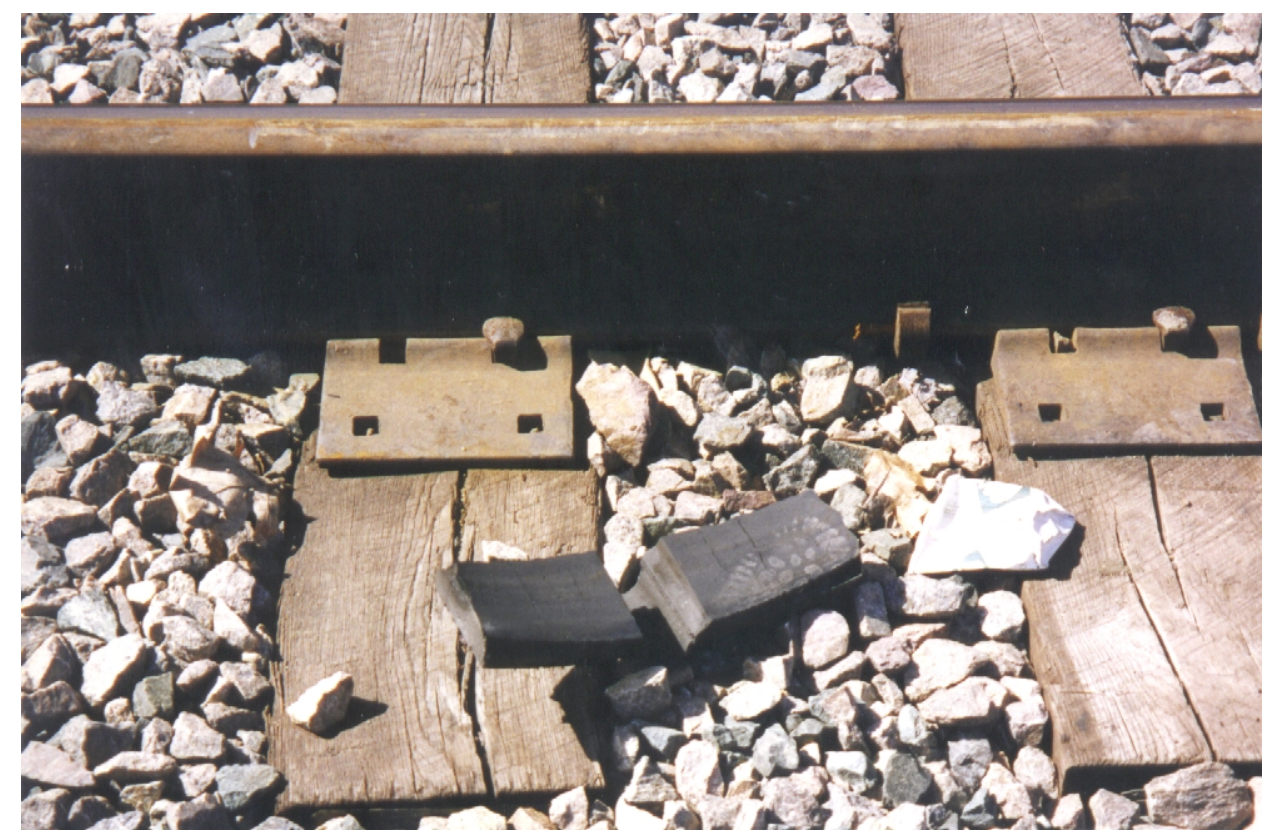

Figure 3. Example of debris on the ground of a railroad yard 
the contract that was negotiated between the injured employee's representative union and the railroad. The injured employee may also make a legal claim against the railroad to obtain monetary compensation for additional medical expenses and other costs. The railroad may then choose to settle the claim or litigate. Section 3 further discusses the background and context in which railroads and employees settle or litigate injury-related claims in the U.S. 


\section{FEDERAL EMPLOYERS' LIABILITY ACT (FELA)}

Provisions of FELA govern employee injury settlements in the railroad industry. The provisions of this law and its effect on both workers and railroad management are an important element of the overall safety environment in the railroad industry. Section 3 discusses FELA's historical background, provisions, and impact on railroad worker safety.

\subsection{Historical Background}

Many procedures and requirements governing the employment and compensation of railroad workers date to the late 19th century when railroads were the premier U.S. industry employing the largest work force in the nation and facing little competition from other transportation modes. Railroad work at the turn of the century was extremely dangerous. One out of eight workers was injured on the job and one in every 125 was killed every year. Compare this with one in 31 workers injured in 1998 and 27 deaths out of 257,000 railroad workers. At that time the average life expectancy of switchmen after starting work was seven years.

Lacking any systematic procedure for recovering for injuries, railroad workers could seek to recover damages through the court system. However, the concept of guaranteeing compensation to injured employees, which had already been adopted in Europe, had not yet gained acceptance in the U.S. If the injured worker were to attempt a legal remedy, the burden of proof was on the employee to prove that the employer was negligent in providing a safe work place.

Injured workers found it difficult to recover for their injuries under this system because railroads could offer one of three defenses. "Through the use of the principle of contributory negligence, employers were able to avoid liability if they could demonstrate that any negligence lay with the employee. Under the fellow-servant doctrine, the injured employee could not establish employer negligence solely based on the negligence of a fellow employee. Employers could also use a defense based on the assumption-of-risk doctrine, which held that the employee in continuing to work after knowing of a particular danger assumed the risks of injury or death entailed by that particular danger" (TRB, 1994, p. 16).

Around the turn of the century states began considering and adopting limited no-fault approaches to compensating injured workers. Because of the difficulty experienced by injured workers in recovering through the courts, a number of states passed employer liability laws which sought to limit or eliminate the defenses to liability that allowed employers to avoid being found negligent. Between 1855 and 1911, 25 states passed some form of employment liability law which limited the defense which employers could offer. By 1921 all but six states had instituted some form of workers' compensation coverage. 
Amidst a period of reform of labor liability law, Congress enacted FELA in 1908. FELA kept the fault-based system that already existed but the process for recovering damages became substantially easier because FELA eliminated or restricted the defenses that a railroad employer could use to avoid responsibility for injuries. More specifically, FELA eliminated the fellowservant defense and restricted the assumption-of-risk doctrine. The act also eliminated the contributory negligence defense and replaced it with the concept of comparative negligence. Comparative negligence allows the employee to recover proportionate damages when part of the responsibility for the injury is due to the employee's own negligence.

Within two years of the passage of FELA, Congress appointed a commission to study the feasibility of abandoning FELA and replacing it with a no-fault system of the type being adopted by many states for workers' compensation in all other industries. The commission recommended that FELA be repealed and replaced by a no-fault system. Bills to rescind FELA passed both the House and Senate but minor differences could not be reconciled in conference and the bills expired before being passed into law. Subsequent efforts to repeal FELA were opposed by the railroad unions. Through the 1930s Congress made incremental changes to FELA rather than replacing it. The last changes, in 1939, eliminated the assumption-of-risk defense and added provisions to prevent interference with any person attempting to provide information on a FELA claim (Schwartz and Mahshigian, 1986). Today the railroad industry's injury compensation system remains the fault-based one created by FELA. However, many aspects of it have become more like the no-fault system that applies to most of the U.S. work force.

Recognizing that FELA has been a long-time source of controversy in the railroad industry, the House Appropriations Committee in 1991 requested that the Transportation Research Board (TRB) undertake a comprehensive analysis of FELA. TRB's report, issued in 1994, presents a description of the provisions and costs of FELA along with a thorough comparison of FELA with workers' compensation systems. The objective of the TRB study was to analyze the FELA system and compare it with other approaches to compensating injured workers; Congress did not ask TRB to recommend specific changes in federal policy. However, the TRB study team did suggest that "... it would be wise if all changes to FELA were developed through negotiation" (TRB, 1994, p. 167).

The TRB study estimated that the level of benefits under FELA is two to four times higher than under workers' compensation for comparable injuries but benefits can be delayed by a significant period if litigation is involved. The AAR reports that in 1991 Class I railroads spent \$911 million in FELA damage claims and another \$288 million for administrative costs and legal fees. In cases where the employee had legal representation, the lawyer's fee claimed 25 to 30 percent of the settlement (TRB, 1994, p. 14).

In 1995 the Subcommittee on Railroads, House Committee on Transportation and Infrastructure, asked the U.S. General Accounting Office (GAO) to examine the implications for railroad costs and railroad workers of 1) replacing FELA with a no-fault compensation system or 2) modifying FELA. At the same time the GAO was also asked to assess the affect of FELA on railroads with annual revenues of less than $\$ 250$ million. Since the TRB study compared FELA with state workers' compensation systems, the GAO considered two types of no-fault compensation 
systems: one covering civilian federal workers and one covering maritime workers (GAO, 1996).

The GAO concluded that replacing FELA with a no-fault compensation system could reduce railroad costs if less than two-thirds of the workers receiving settlements were permanently and totally disabled. Railroad's compensation costs would be less under a no-fault system for workers able to return to work because a no-fault system does not provide compensation for noneconomic losses. The GAO also found that placing limits on awards for non-economic damages might reduce injury compensation costs, depending on the proportion of FELA awards representing non-economic damages. Similarly, the effect of a limit on attorneys' fees would depend upon how the fees relate to settlement amounts. The FELA experiences of small railroads differed somewhat from their larger counterparts. Using 1994 data from a survey of 560 small railroads, The GAO found that FELA costs per employee-hour worked were less than those of larger railroads ( $\$ 0.96$ versus $\$ 2.26$ per employee-hour worked). This is due to the fact that the small railroads had, on average, fewer lost workdays per injury and lower average wages. The GAO also found that nearly all of the respondents to its survey are covered by insurance for FELA claims.

The debate over FELA continues. For at least the near term, the FELA system will be the means for compensating railroad workers for workplace injuries.

\subsection{Provisions of FELA}

The process for compensating injured railroad workers is based on both the FELA statute and provisions of collective bargaining agreements between railroad labor and management. Since passage of FELA in 1908 the injury compensation process employed by the railroads has evolved from one that is totally fault-based to one that now incorporates many features of the no-fault workers' compensation system that covers workers in most other industries. Some procedures, designed to streamline and expedite the compensation process, have been instituted by the railroads unilaterally.

Railroad health insurance plans provide coverage for medical expenses. An employee need not take action under FELA to recover medical bills. However, unlike workers' compensation plans, payment for pain and suffering or loss of future earning potential is not guaranteed to a railroad employee.

The right to sue guaranteed by FELA does not mean that an employee must resort to litigation to receive compensation for his/her work-related injury. After being injured, the worker is required to file an accident and injury report that describes the circumstances of the accident and the nature of the injury. In most cases this report initiates the claim process.

For most claims, the employee and the railroad's representative negotiate directly and reach a settlement on the employee's compensation. Approximately 70 percent of claims are settled in this manner. Another 10 percent are settled after the employee retains legal counsel but before a 
suit is filed and the remaining 20 percent are litigated. Of the 20 percent of claims that are litigated each year, only 5 percent (1 percent of all claims) reach the point of a jury verdict.

For minor injuries and little lost work time, FELA functions administratively in much the same way as a workers' compensation system. However, compensation to the employee tends to be higher under FELA. For more serious claims, negotiation may fail, especially if the railroad believes that the employee should bear a substantial portion of the negligence burden.

\subsection{Impact of FELA on Railroad Worker Safety}

Proponents and opponents of FELA have different views regarding the impact of the law on worker safety. Railroad labor contends that FELA is an incentive to railroad management to hold railroads accountable for the safety of their operations. The cost of potential FELA awards, they claim, is an incentive to eliminate unsafe conditions.

Railroad management, on the other hand, points out that railroad work is not any more dangerous than work in comparable industries and that railroad workers no longer need special provisions to compensate them for injuries. Management also points out that the cost of damaged equipment and freight shipments is a strong inducement to avoid accidents.

Most railroads have safety and accident prevention committees made up of employee and management representatives. These committees are responsible for monitoring compliance with safety rules and regulations and investigating accidents. However, the economic motivations created by FELA may limit the effectiveness of these committees in promoting a safe workplace.

"Because the employee's right to be compensated for injuries is conditioned on showing the railroad was at fault, and because conversely, the railroad can eliminate or reduce its liability by showing that the employee's negligence contributed to the injury, both parties have an economic incentive to place the blame for accidents on the other. This provides motivation to obscure the true causes of workplace accidents, and thus hinder their objective investigation. As a result, effective modifications of workplace procedures and equipment may be delayed or prevented" (Saphire, 1991, p. 411).

The fault-based nature of FELA has the potential to foster an adversarial relationship between railroad management and labor and may inhibit working cooperatively to correct unsafe working conditions. Full and complete investigation of an accident or injury might not occur because the incentives for both the employee and railroad management are to avoid revealing any facts or circumstances that would indicate their responsibility for the accident or injury. This system discourages a cooperative working relationship between labor and management and may hinder efforts to improve safety in the workplace. 


\section{ANALYSIS OF FRA ACCIDENT AND INJURY DATA}

Unlike most industries in the U.S. that report injuries to OSHA, the railroad industry reports accidents and injuries to the FRA. Dating back to the late nineteenth century, the Interstate Commerce Commission (ICC) had long standing statutory authority regarding railroad safety. Upon FRA's establishment in 1967, the ICC's safety regulatory responsibilities were transferred to the FRA. These responsibilities pre-date the creation of OSHA in 1970. The FRA, therefore, continues to be responsible for collecting injury and accident data from U.S. railroads.

Since OSHA's creation in 1970, the FRA and OSHA have worked together to define the areas where the FRA has jurisdiction over occupational safety, and where OSHA has jurisdiction. The FRA chose to oversee five specific areas: 1) track, roadbed, and associated devices and structures; 2) equipment; 3) operating practices; 4) signalling and train control; and 5) hazardous materials transportation by rail. With respect to railroad yard worker safety, OSHA's regulations, then, apply to such issues as noise exposure in shops, personal protective equipment (PPE), hand and power tools and surfaces in repair facilities (except for equipment inspection pits). Appendix A contains additional background on the FRA and OSHA jurisdictions, and discusses the specific areas within the railroad industry over which the FRA and OSHA have jurisdiction over railroad employee safety and health.

The FRA's Office of Safety maintains databases with reports of all railroad accidents and all railroad-related injuries and occupational illnesses that meet the FRA's reporting criteria. Railroad accidents and injuries were analyzed to gain insight into the nature and causes of employee injuries and accidents that occurred in yards. The results from the analyses are presented and discussed below. The injury analyses also include a comparison of injuries with other modes of transportation as well as other industries to provide an indication of the relative frequency and severity of the injuries occurring in railroad yards.

Since the FRA train accident and injury databases contain a large number of cases, the power of any statistical tests that are performed on the data will be great. In other words, a very large sample size increases the chances of finding a small, albeit non-meaningful, statistically significant difference among values. Essentially, the larger the sample size (n) the easier it is to find a statistically significant difference (or effect), although the difference may be minimal. To combat this problem, the significance value of the statistical tests, alpha $(\alpha)$, was reduced from the standard criterion of 0.05 to 0.01 . Lowering $\alpha$ reduces the probability of identifying a significant difference when one does not exist (Type I error). Thus, a lower $\alpha$ results in a more stringent test, and serves to balance the problem that is caused by such a large sample size. In addition to setting $\alpha$ to 0.01 , results will be discussed so that the reader has enough information to decide whether the difference is meaningful for his/her own purposes. 


\subsection{Description of FRA Accident and Injury Databases}

The following two subsections describe the accident and injury databases that the FRA maintains, and on which the accident and injury analyses are based. The reporting procedures that railroads must follow when reporting train accidents or injuries are also discussed.

\subsubsection{FRA Accident Database}

All railroads under the jurisdiction of the FRA are required to report to the FRA any train accident or incident (e.g., collisions, derailments) involving on-track equipment and/or that occurred on railroad property and that resulted in property damage to on-track equipment, track, roadbed or signal system that exceeds a monetary threshold determined by the FRA. The amount was $\$ 6300$ for accidents occurring between 1994 and 1996; $\$ 6500$ in 1997; and $\$ 6600$ in 1998.

Each railroad whose on-track equipment or property was involved in the accident (including the owner of the track on which the accident occurred, even if there was no damage to the track) must complete form FRA F 6180.54 and submit it to the FRA. Information that is reported to the FRA includes the location of the accident, date of the accident, time of day the accident occurred, weather and visibility conditions, temperature, the number of consists involved, property damage, involvement of hazardous materials, and the primary and contributing causes of the train accident. For a complete listing of the information that is reported, see the FRA Guide for Preparing Accident/Incident Reports (FRA, 1997). Copies of relevant accident and injury forms that railroads are required to complete are provided in Appendix B.

Typically each railroad has a reporting officer who is responsible for completing and submitting accident reports (as well as many other mandated FRA forms) to the FRA. One of the more challenging aspects of reporting train accidents is to identify the primary and contributing (if any) cause(s) of the train accident. Reporting officers are given minimal information and training on how to identify the most likely cause(s) of a given train accident. Rather, they are principally guided by accident cause codes provided by the FRA in the FRA Guide for Preparing Accident/Incident Reports. The accident cause codes are divided into five broad categories:

1. Mechanical/electrical.

2. Train operation - human factor.

3. Signal and communication.

4. Track, roadbed and structure.

5. Miscellaneous.

Although some causes might be apparent, such as broken rail, others are not, particularly causes related to the employee human factor. The Code of Federal Regulations (49 CFR 225.5) defines an employee human factor simply as, "....any of the accident causes signified by the train accident cause codes listed under 'Train Operation - Human Factors' in the current 'FRA Guide for Preparing Accident/Incident Reports' except for those train accident cause codes pertaining to 
non-railroad workers" (49 CFR 225.5, p. 228). These "Train Operation - Human Factors" codes are divided into the following 10 broad categories:

1. Use of brakes.

2. Employee physical condition.

3. Flagging, fixed, hand, and radio signals.

4. General switching rules.

5. Main track authority.

6. Train handling/train make-up.

7. Speed.

8. Use of switches.

9. Cab signals.

10. Miscellaneous.

If an employee's physical condition, act, or omission is identified as having caused or contributed to the train accident (i.e., any of the above 10 categories of employee human factor cause), the railroad is also required to formally notify the employee(s) and explain what specific action(s) the railroad has identified as having caused or contributed to the train accident and whether or not the railroad is going to investigate the employee. The employee is also given an opportunity to explain their perspective and submit it to the FRA; however, they are not required to do so. If the employee chooses to complete an employee statement (Form FRA F6180.78), the employee must also submit a copy of the statement to the railroad. The information that the employee provides cannot be used against him or her by the railroad in any "...suit or action for damages growing out of any matter mentioned in said report...” (U.S. Code 20903. See 49 CFR 225.7). However, the law does not protect the employee from being fired by the railroad if the employee has violated any of the railroad's operating rules.

Since the scope of this report is limited to the human factor-related causes of railroad yard accidents and injuries, only those accidents that resulted in a primary human-factor cause code were analyzed $^{1}$. Due to the inherent complications and difficulties of inferring the true cause of an accident or injury, especially human factor causes, those accidents in which the primary cause code was human factor-related according to FRA's cause codes will be referred to as human factor-attributed train accidents. The use of human factor-attributed train accidents rather than human factor-caused accidents is preferable because it better describes the situation since the true causes are not always clear, while it is accurate to say that the accident was attributed to a human factor cause. The following analyses, therefore, focused on human factor-attributed train accidents in railroad yards from 1994 to 1998.

The FRA collects a variety of different information pertaining to the circumstances around a train accident. Data that are collected include, but are not limited to, the time of the accident; month, day, and year of the accident; the location on the railroad where the accident occurred; the railroads involved; the type of accident (e.g., derailment, head on collision, etc.); consist

\footnotetext{
${ }^{1}$ Form FRA F 6180.54 allows railroads to report up to two "causes" for each train accident, a primary cause and a contributing or secondary cause.
} 
information (e.g., involvement of hazardous material cars); train operational information (e.g., direction of travel, speed); the number of injuries and fatalities involved; the cause(s) of the train accident; damage associated with the accident; and information on the train crews (e.g., total time on duty at time of the accident; number of positive alcohol and drug tests). Appendix B contains copies of the accident report forms that the FRA requires railroads to submit when a train accident has occurred on railroad property or involves railroad property.

The FRA Guide for Preparing Accident/Incident Reports (FRA, 1997) is published by the FRA and is made available to railroads to assist them in completing accident reports, as well as other mandatory reports. This Guide provides instructions for completing all FRA accident/incident and injury forms, and provides definitions and reporting criteria. The FRA Office of Safety collects, collates and maintains the train accident data and makes it publicly available by posting the data to its website, www.fra.dot.gov, and by publishing annual reports of statistical data and tables.

\subsubsection{FRA Injury Database}

Each month, railroads must submit a Form FRA F6180.55 to the FRA. This form contains a summary of the reportable injuries and illnesses that occurred on the railroad's property, as well as railroad operational data (e.g., yard switching miles operated). Railroads are required to submit this form regardless of whether any injuries or illnesses occurred during the month. For each reportable injury or illness, the railroad must also submit a Form FRA F6180.55a (see Appendix B for a copy of this form). An injury is "reportable" if "Any event connected with the operation of a railroad ...results in one or more of the following consequences...:

1. Death of a person within 365 calendar days of the accident/incident;

2. Injury to a person, other than a railroad employee, that requires medical treatment;

3. Injury to a railroad employee that requires medical treatment or results in restrictions of work for one or more work days, the loss of one ore more work days, termination of employment (as interpreted by FRA), transfer to another job, or loss of consciousness; or

4. Any occupational illness of a railroad employee" (FRA Guide for Preparing Accident) Incident Reports, 1997, Ch. 6, p. 1).

Medical treatment is considered treatment beyond first aid (see the FRA Guide for Preparing Accident/Incident Reports for more specific reporting criteria).

Form FRA F 6180.55a contains the following information about each reported injury or illness:

1. Name of reporting railroad.

2. Alphabetic code.

3. Report month.

4. Report year. 
5. Accident/injury number.

6. Day.

7. Time of day.

8. County.

9. State.

10. Type person/job code.

11. Age.

12. Drug/alcohol test.

13. Injury/illness code.

14. Physical act.

15. Location.

16. Event.

17. Result.

18. Cause.

19. Number of days away from work.

20. Number of days restricted.

21. Exposure to hazmat.

22. Termination or permanent transfer.

23. Narrative.

The FRA Guide for Preparing Accident/Incident Reports also provides instructions for completing the relevant injury forms, and provides definitions and criteria for reportable injuries and illnesses. Similar to the accident/incident data, the FRA Office of Safety collects, collates and maintains this data and makes it publicly available by posting the data to its website, www.fra.dot.gov, and by publishing annual reports of statistical data and tables.

\subsection{Analysis of 1994-1998 Railroad Yard Accidents}

Railroad yard accident data were downloaded from the FRA's website and analyzed ${ }^{2}$. According to the data maintained by the FRA, a total of 13,169 train accidents were reported to the FRA between 1994 and 1998. Almost half of these train accidents (6400, or 49 percent of all train accidents) occurred in railroad yards. And of the 6400 train accidents that occurred in railroad yards over the last five years, 47 percent (3026 train accidents) were attributed to human factors causes. Thus, human factor-attributed train accidents in railroad yards accounted for almost a quarter (23 percent) of all train accidents occurring between 1994 and 1998.

Table 1 provides train accident figures for the last five years. After several years of decreasing figures, the number and rate (per million yard switching miles, or MSM) of human factorattributed train accidents in yards increased in 1997 and 1998, while the number of yard switching miles has steadily decreased over the last five years.

In the last five years 60 percent of all human factor-attributed yard accidents have been associated with problems with switches and switching. These accidents include cars shoved out and left out of the clear, cars left foul, failure to couple, improperly applied portable derail,

\footnotetext{
${ }^{2}$ Analyses were conducted using SPSS v8.0 and Microsoft Excel.
} 
Table 1. Human factor-attributed train accidents in railroad yards, 1994 to 1998

\begin{tabular}{lccccr}
\hline & $\begin{array}{c}\text { Human Factor- } \\
\text { Attributed Train } \\
\text { Accidents }\end{array}$ & $\begin{array}{c}\text { \% Change } \\
\text { from Previous } \\
\text { Year }\end{array}$ & $\begin{array}{c}\text { Yard Switching } \\
\text { Miles } \\
(\text { MSM) }\end{array}$ & $\begin{array}{c}\text { Accidents } \\
\text { per } \\
\text { MSM }\end{array}$ & $\begin{array}{c}\text { \% Change } \\
\text { from Previous } \\
\text { Year }\end{array}$ \\
\hline 1994 & 653 & N/A & $89,776,044$ & 7.27 & N/A \\
1995 & 629 & -4 & $89,891,866$ & 7.00 & -4 \\
1996 & 513 & -18 & $87,823,254$ & 5.84 & -17 \\
1997 & 581 & 13 & $84,873,799$ & 6.85 & 17 \\
1998 & 650 & 12 & $83,692,064$ & 7.77 & 15 \\
${ }^{1}$ Source: & Www.fra.dot.gov. & & & \\
${ }^{2}$ Source: & FRA Accident/Incident Bulletin (1994-96) and Safety Statistics (1997-98). \\
\end{tabular}

improperly lined switch, and spring switch not cleared before reversing. Specific cause codes can be found in the FRA Guide for Preparing Accident/Incident Reports. The second largest proportion of human factor-attributed yard accidents over the last five years (14 percent) was due to brake-related problems. Table 2 shows the number and percentage of yard accidents attributable to each general category of human factors cause over the last five years.

\subsubsection{Season}

To determine if there were seasonal (i.e., monthly) differences, the rate of human factorattributed train accidents per million switching miles was analyzed. The FRA collects monthly data on the number of yard switching train-miles from each railroad under its jurisdiction. A railroad may report the specific number of yard train-miles operated, or they may use a convention provided to them by the FRA, as specified in the FRA Guide for Completing Accident/Incident Reports (Ch. 2, p. 11): "[A yard switching train-mile] May be computed at the rate of $6 \mathrm{mph}$ for the time actually engaged in yard switching service (or any other method that will yield a more accurate count) if actual mileage is not known." A chi-square test conducted on the accident rate did not show a significant monthly difference over the last five years $\left(\chi^{2}=\right.$ $0.19 \mathrm{df}=11, \mathrm{p}=1.0000)($ see Figure 4).

Table 2. Human factor-attributed train accidents in railroad yards, 1994 to 1998

\begin{tabular}{lcc}
\hline \multicolumn{1}{c}{ Human Factor-Attributed Cause } & $\begin{array}{c}\text { Human Factor-Attributed } \\
\text { Train Accidents }\end{array}$ & $\begin{array}{c}\% \text { of Total Train } \\
\text { Accidents }\end{array}$ \\
\hline Switching & 1,810 & 59.8 \\
Use of Brakes & 434 & 14.3 \\
Train Handling/Make-Up & 386 & 12.8 \\
Speed & 173 & 5.7 \\
Flag, Fixed, Hand and Radio Signals & 84 & 2.8 \\
Other & 82 & 2.7 \\
Main Track Authority & 53 & 1.8 \\
Employee Physical Condition & 4 & 0.1 \\
Cab Signals & 0 & 0.0 \\
\hline
\end{tabular}




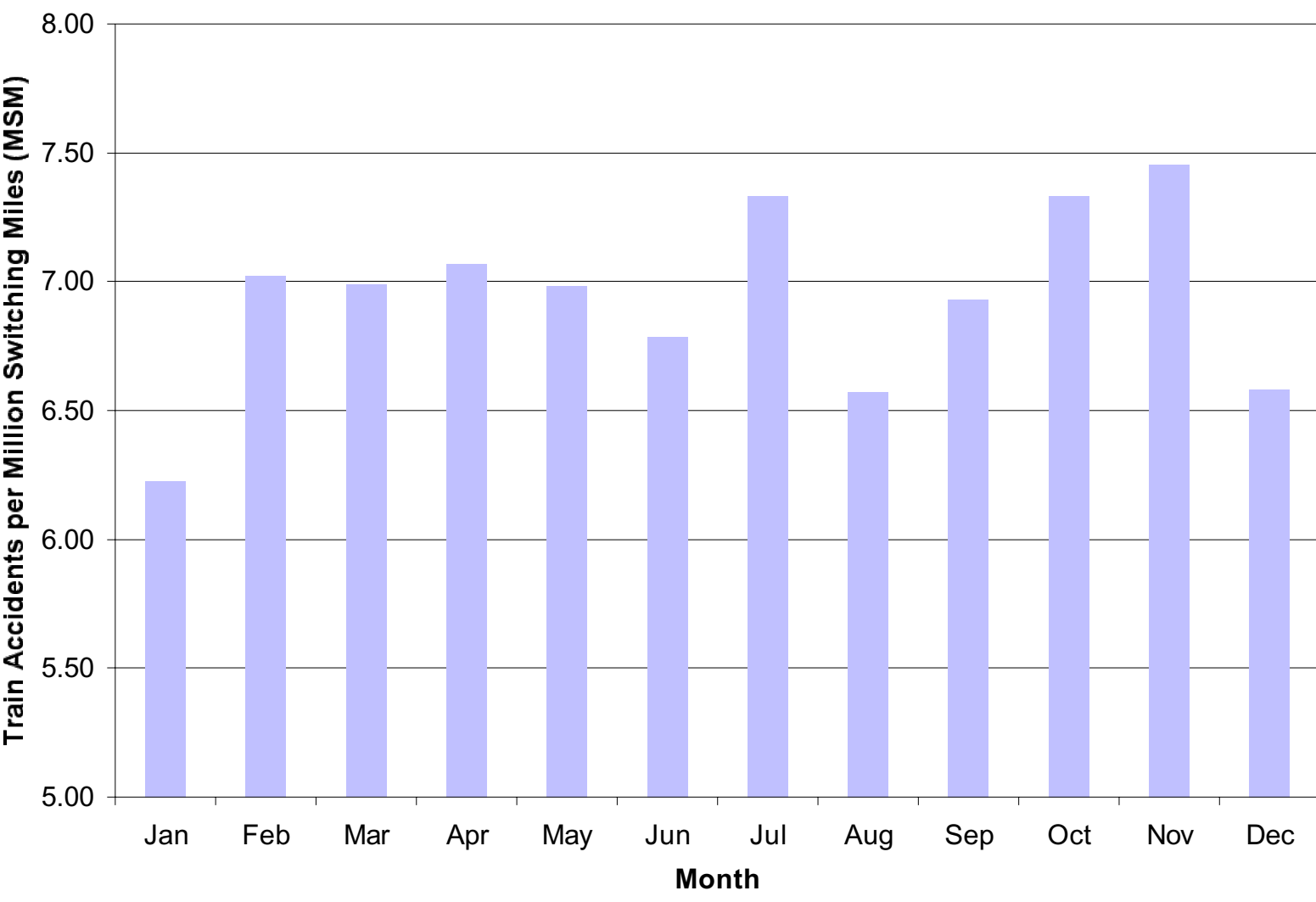

Figure 4. Human factor-attributed train accidents in yards per million train switching miles by month, 1994 to 1998

\subsubsection{Time-of-Day}

Next, time-of-day was examined to determine if it had an effect on the number of human factorattributed train accidents in railroad yards over the last five years. Analysis of the data showed two peaks in accidents (See Figure 5). A slight, but possible, circadian effect may explain these two peaks: one in the early morning hours (2 to 4 a.m.) and one in late afternoon (4 to 6 p.m.). These peaks correspond with the natural troughs in human circadian rhythms.

While it is possible that these results may be a function of a circadian pattern, it is also possible that the differences in time-of-day are a function of the amount of traffic volume or number of personnel on duty. For example, the increase in train accidents between 4 and 6 p.m. could be due to the overlap of first and second shift assignments. It is also possible that trains are scheduled to depart yards around this time, resulting in an increase in train movements. Exposure data could clarify the role of traffic volume or personnel volume in the number of accidents per two hour time period; however, no exposure data were available.

A chi-square test comparing the number of accidents every two hours indicated that there is also a significant difference among two hour time periods $\left(\chi^{2}=80.969, \mathrm{df}=11, \mathrm{p}<0.001\right)$. However, a chi-square test does not indicate where the significant difference lies. Visual inspection of the 


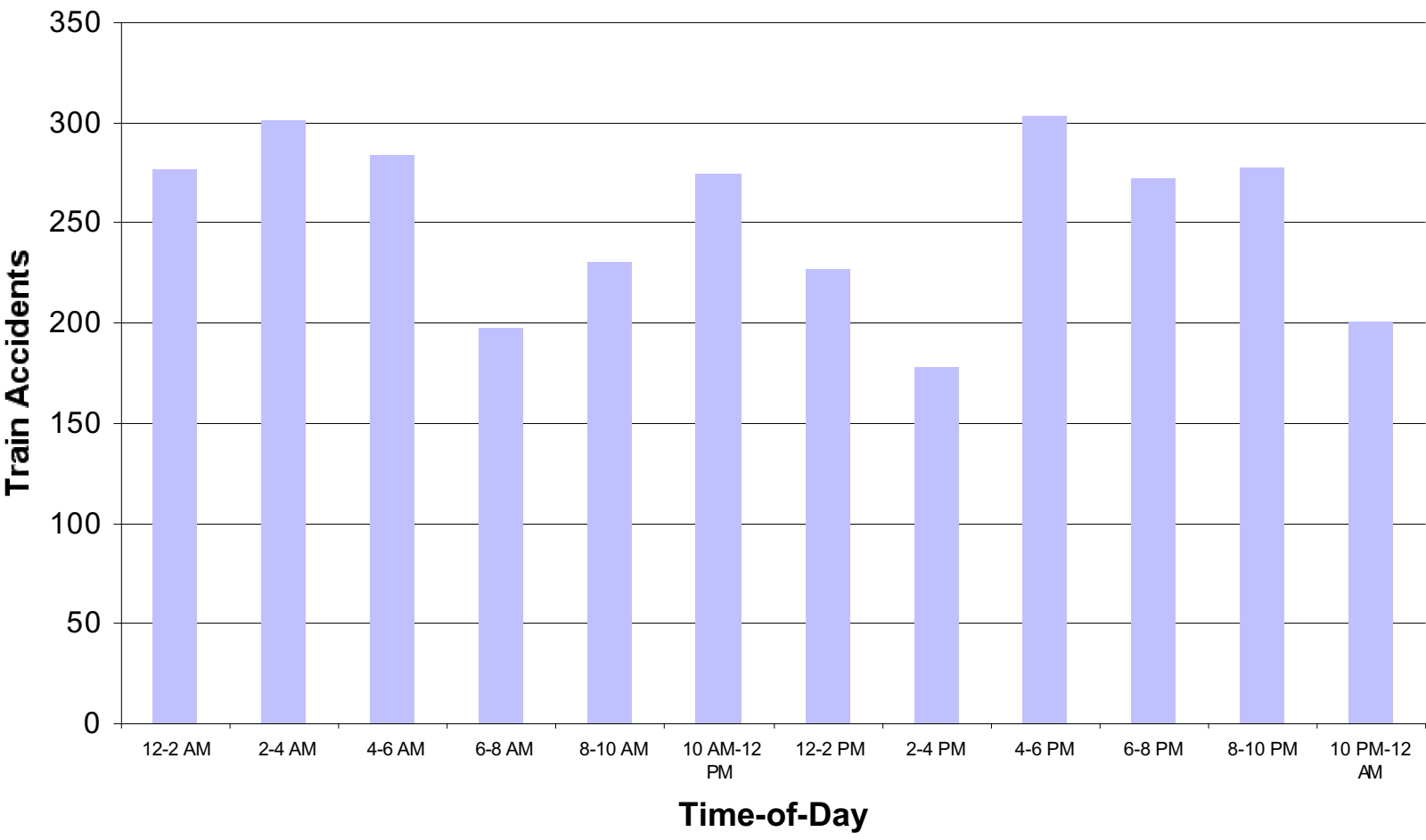

Figure 5. Human factor-attributed train accidents in railroad yards by time-of-day, 1994 to 1998

data reveals that the greatest difference in the number of train accidents between any two two-hour time periods occurs between consecutive time periods: 2 to 4 p.m. (178 train accidents) and 4 to 6 p.m. (304 train accidents).

\subsubsection{Hours on Duty}

Analyses were next conducted to determine if there were differences in the number of human factor-attributed train accidents in railroad yards based on the amount of time that a crew had been on duty at the time of the train accident. Since crew members usually begin and end the shift at the same time ${ }^{3}$, it was necessary to only look at the hours on duty for one of the crew members. The engineer's time on duty was used since there were more cases in which the engineer's time on duty was reported. Two cases where the engineer's hours on duty exceeded 24 hours were eliminated from the analysis since these figures were more likely the result of coding error than a reflection of true time on duty.

A chi-square test indicated that there was a significant difference in the number of human factorattributed train accidents occurring in railroad yards based on the number of hours on duty

\footnotetext{
${ }^{3}$ A Pearson product-moment correlation analysis between engineer's hours on duty and conductor's yielded a significant correlation of $0.91, \underline{\mathrm{p}}<0.01$.
} 
$\left(\chi^{2}=751.1, \mathrm{df}=11, \mathrm{p}<0.001\right)$. The second through fifth hours on duty are associated with the greatest number of accidents (per hour), while the sixth through eighth hour on duty are associated with the next most accidents (per hour). Then there is a substantial drop in the number of accidents after the eighth hour (see Figure 6). However, the reduction in the number of train accidents after the eighth hour may be a function of exposure. That is, there may be fewer crews that work longer than 8 hours per shift.

\subsubsection{Visibility}

Most human factor-attributed train accidents occurring in railroad yards occurred either during daylight or darkness - almost 45 percent of the accidents occurred during the "day," while almost 48 percent occurred during "dark." Together, "day" and "dark" combine to account for 92 percent of all human factor-attributed train accidents occurring in railroad yards between 1994 to 1998 . Table 3 presents visibility data at the time of the accidents. Dawn and dusk each account for about 4 percent of the train accidents. If it is assumed that dawn and dusk each last one hour per day, the percentage of accidents occurring in one hour is expected to be 4 percent. The proportion of accidents in each of the four visibility categories, then, appears to represent the

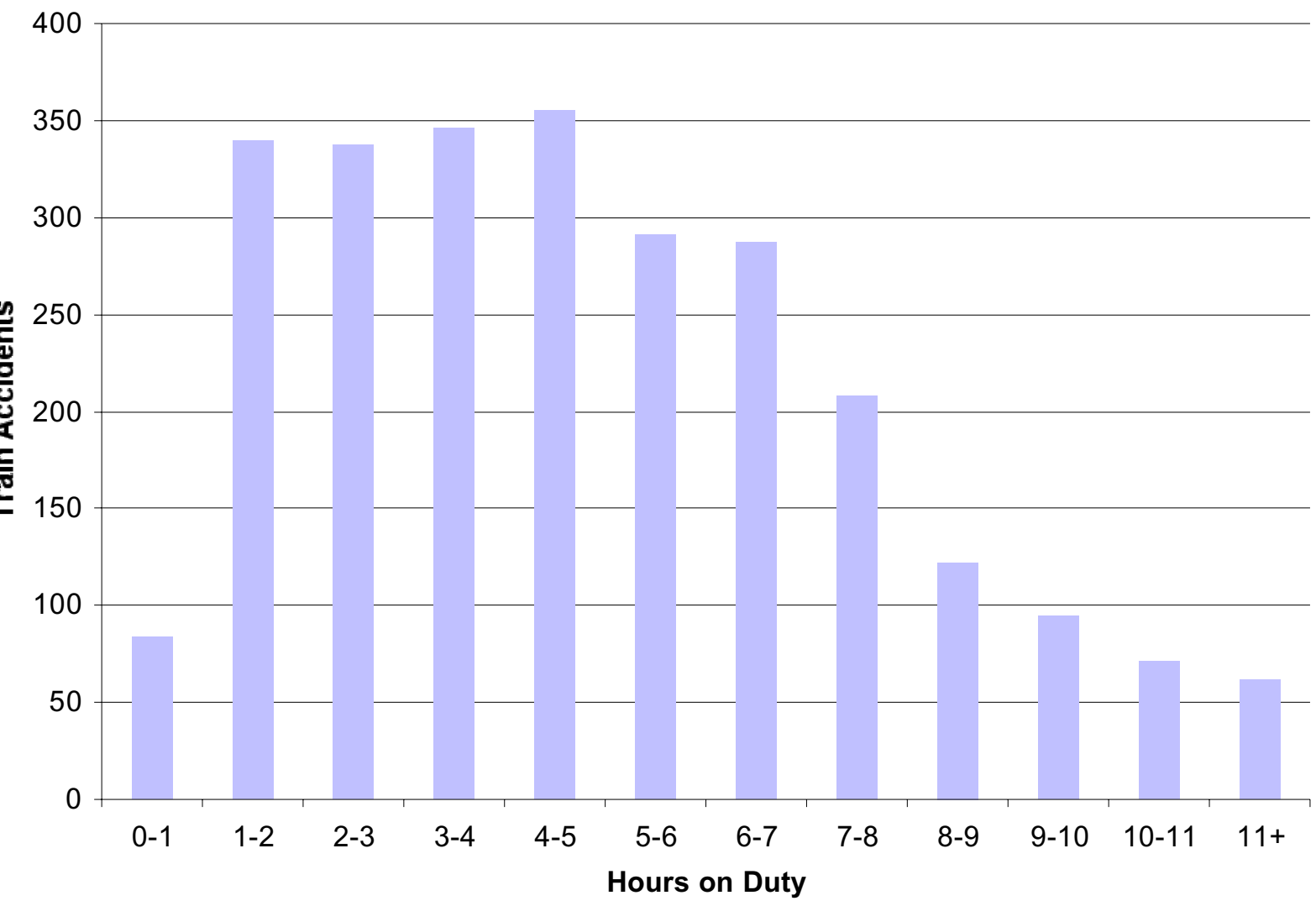

Figure 6. Human factor-attributed train accidents in railroad yards by hours on duty, 1994 to 1998 
proportion of time in each of the four visibility categories and thus visibility does not appear to be related to the likelihood of an accident.

\subsubsection{Weather and Temperature}

Weather-related data for the train accidents are shown in Table 4. It does not appear that inclement weather conditions play a major factor in human factor-attributed train accidents in railroad yards. Sixty-five percent of the train accidents were reported to have occurred during clear conditions. The high percentage of train accidents occurring during clear days may be similar to the actual proportion of clear days over the five year period for which data are analyzed.

Analysis of temperature data for human factor-attributed train accidents in railroad yards indicates that accidents are relatively normally distributed across temperature. Table 5 and Figure 7 present temperature-related data. The normal distribution seen in the number of train accidents may simply correspond to the number of days within each temperature range; that is, the number of accidents may simply be a function of the number of days at a given temperature range. To adjust for exposure to specific temperatures, and to better determine whether temperature may have an effect on the number of human factor-attributed train accidents occurring in railroad yards, the national mean ambient daily temperature (and standard deviation), excluding Hawaii and U.S. territories, was calculated from historical National Weather Service data from 1961 to 1990 (http://nndc.noaa.gov/?http://ols.nndc.noaa.gov:7777/ plolstore/plsq1/olstore.prodspecific?prodnum +C00095-PUB-A0001). Once the mean and standard deviation were known, and assuming that temperature is normally distributed, it was possible to calculate the expected number of days at a given mean ambient temperature. The number of accidents per day within various temperature ranges was then computed.

First, a normal cumulative distribution of temperatures was calculated based on Z-scores, given that the mean daily temperature across the continental United States between 1961 to 1990 was $53^{\circ} \mathrm{F}$ and the standard deviation was 10.9. The number of expected days per year at each mean daily temperature (one degree Fahrenheit increments) was then computed, and then values were combined into 10 degree temperature brackets. Since so few days were expected when the temperature was less than $10^{\circ} \mathrm{F}$, this bracket was combined with the next warmer temperature range to become 'less than $20^{\circ} \mathrm{F}$ '. This served as the lower bound for the temperature range. The upper bound
Table 4. Human factor-attributed train accidents in railroad yards by weather condition, 1994 to 1998

\begin{tabular}{lrc}
\hline \multicolumn{1}{c}{ Weather } & & \\
Condition & Accidents & \% of Total \\
\hline Clear & 1,967 & 65 \\
Cloudy & 734 & 24 \\
Rain & 226 & 7 \\
Fog & 39 & 1 \\
Sleet & 7 & 0 \\
Snow & 53 & 2 \\
Total & 3,026 & 100 \\
\hline
\end{tabular}


for the temperature range was set at ${ }^{\prime} 90^{\circ} \mathrm{F}$ or greater' since so few days were expected when the mean daily temperature was greater than $100^{\circ} \mathrm{F}$. The number of accidents that took place within each temperature bracket was then divided by the expected number of days within the temperature bracket (multiplied by five since five years of accident data were used).

The result, shown in, Figure 8 indicates that human factor-attributed train accidents in railroad yards are a function of ambient temperature. Specifically, more train accidents occurred during the extremes - colder and hotter temperatures - than during the milder temperatures. However, since other variables
Table 5. Human factor-attributed train accidents in railroad yards by temperature, 1994 to 1998

\begin{tabular}{lrc}
\hline $\begin{array}{c}\text { Temperature } \\
\left({ }^{\circ} \mathrm{F}\right)\end{array}$ & Accidents & \% of Total \\
\hline$<10$ & 49 & 2 \\
10 to 19 & 67 & 2 \\
20 to 29 & 145 & 5 \\
30 to 39 & 344 & 11 \\
40 to 49 & 430 & 14 \\
50 to 59 & 470 & 16 \\
60 to 69 & 519 & 17 \\
70 to 79 & 509 & 17 \\
80 to 89 & 343 & 11 \\
90 to 99 & 137 & 5 \\
$100+$ & 13 & 0 \\
Total & 3,026 & 100 \\
\hline
\end{tabular}

600

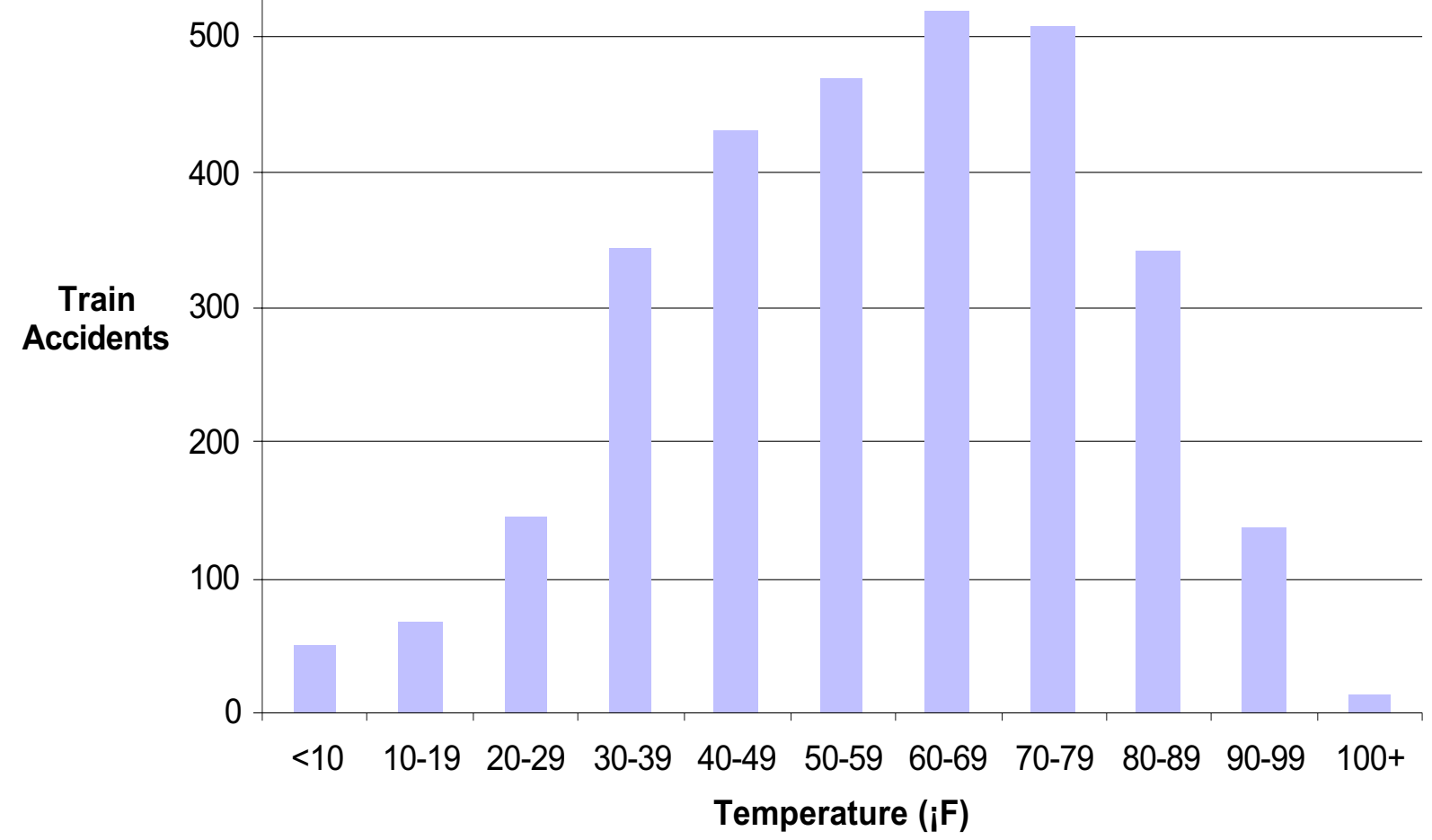

Figure 7. Human factor-attributed train accidents in railroad yards by temperature, 1994 to 1998 


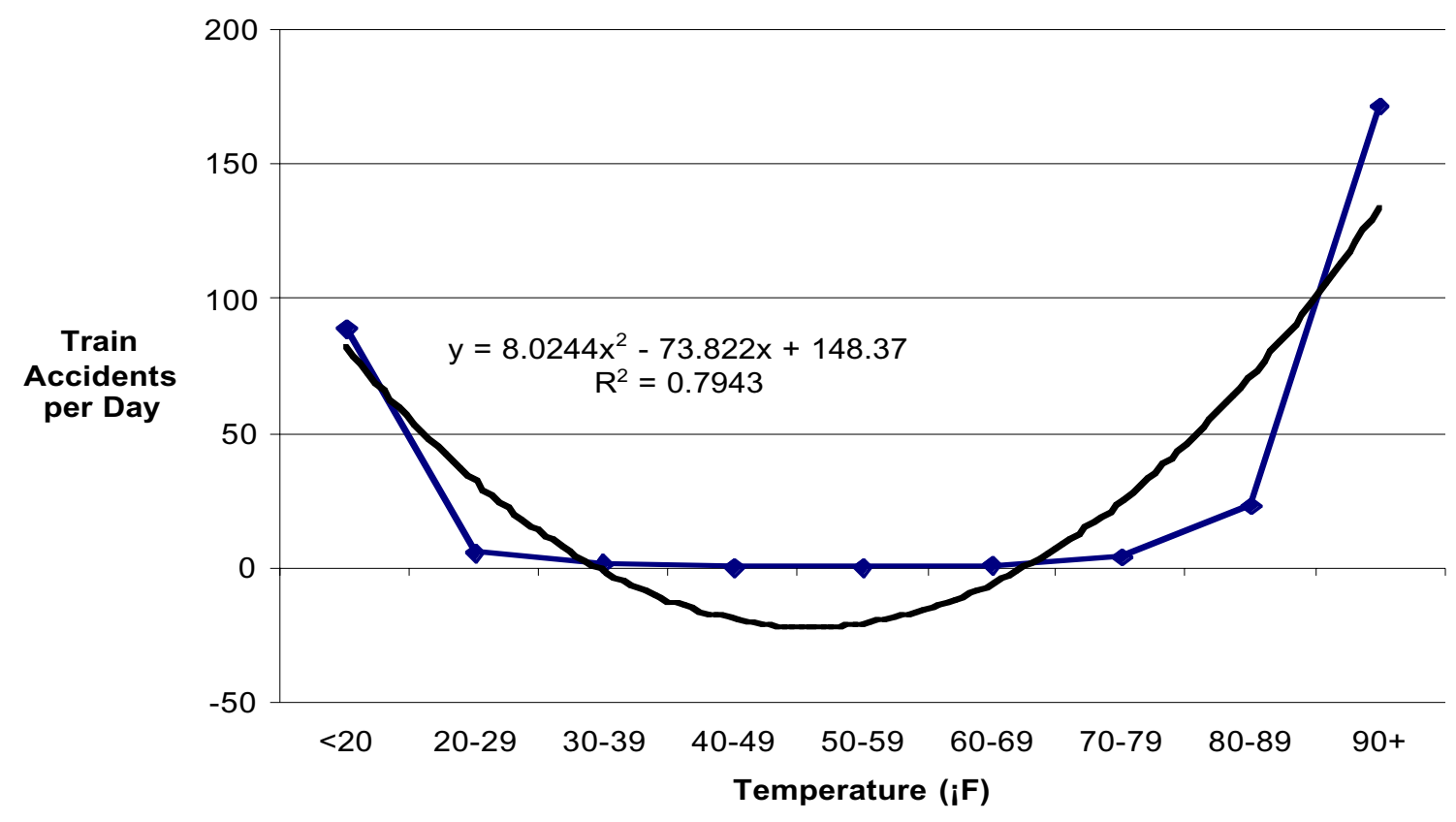

Figure 8. Human factor-attributed train accidents in railroad yards as a function of ambient temperature, 1994 to 1998

are closely related to temperature, such as time-of-day, weather, and visibility, it is difficult to say just how much of an effect temperature has on these train accidents. However, the quadratic equation, $y=8.0244 \mathrm{x}^{2}-73.822 \mathrm{x}+148.37$, where $\mathrm{x}$ represents temperature and $\mathrm{y}$ represents the number of train accidents, may serve as an adequate predictor of train accidents in the absence of other information. This equation accounts for almost 80 percent of the variance in the train accidents.

\subsubsection{Accident Severity}

There are several ways in which to measure the severity of a train accident. One way is to measure the total amount of property damage associated with the accident. A second method is to count the casualties (i.e., those injured and killed) that resulted from the train accident.

Analyses of train accident data for 1994 to 1998 revealed that although train accidents occurring in railroad yards make up almost half of all train accidents (49 percent), they result in only onethird of the total property damage $(\$ 185,784,372$ out of a total of $\$ 559,474,693$ between 1994 and 1998), and only three percent of those killed and nine percent of those injured as a result of train accidents (see Table 6). Mainline train accidents, in comparison, made up 40 percent of the total number of train accidents between 1994 and 1998; however, they accounted for 56 percent of all costs associated with the train accidents, 96 percent of those killed and 88 percent of those injured as a result of train accidents during the five year period. The higher costs associated with mainline train accidents are probably due to the higher speeds associated with mainline travel. Train speeds in railroad yards are typically less than $20 \mathrm{mph}$ and often less than $10 \mathrm{mph}$, while 
Table 6. Train accident severity by track type, 1994 to 1998

\begin{tabular}{|c|c|c|c|c|c|c|c|c|}
\hline $\begin{array}{l}\text { Track } \\
\text { Type }\end{array}$ & Accidents & $\begin{array}{c}\% \text { of } \\
\text { Accidents }\end{array}$ & $\begin{array}{l}\text { Costs } \\
(\$)\end{array}$ & $\begin{array}{l}\% \text { of } \\
\text { Costs }\end{array}$ & Fatalities & $\begin{array}{c}\% \text { of } \\
\text { Fatalities }\end{array}$ & Injuries & $\begin{array}{c}\% \text { of } \\
\text { Injuries }\end{array}$ \\
\hline Mainline & 5,261 & 40.3 & $310,922,300$ & 55.6 & 233 & 95.5 & 1,665 & 87.5 \\
\hline Yard & 6,400 & 49.1 & $185,784,372$ & 33.2 & 7 & 2.9 & 175 & 9.2 \\
\hline Siding & 488 & 3.7 & $31,915.80$ & 5.7 & 2 & 0.8 & 29 & 1.5 \\
\hline Industry & 907 & 6.9 & $30,852.21$ & 5.5 & 2 & 0.8 & 34 & 1.8 \\
\hline
\end{tabular}

freight train speeds along mainlines can reach $60 \mathrm{mph}$ or faster (passenger trains can reach even greater speeds).

Human factor-attributed train accidents that occurred in railroad yards from 1994 to 1998 resulted in almost half of all yard accidents (47 percent) and costs (47 percent), and two-thirds (69 percent) of all yard accident injuries (see Table 7). These human-factor attributed yard accidents produced 120 injuries and one fatality. Of the 88 train accidents that produced the 120 injuries, a majority resulted in only one injury. In fact, only four of these 88 accidents resulted in three or more injuries each (see Table 8).

To examine whether visibility, weather, temperature, time-of-day, hours on duty, month, or human factor-attributed cause ${ }^{4}$ affected the costs associated with the human factor-attributed train accidents in railroad yards, separate nonparametric Kruskal-Wallis tests were conducted for each variable of interest. Due to the large sample size, a significance value of 0.01 was selected to counter the possibility of committing a Type I error.

Two significant differences were found among these variables in terms of differential costs associated with the train accidents. First, there was a significant difference among visibility

Table 7. Railroad yard train accident severity by cause, 1994 to 1998

\begin{tabular}{lcccccccr}
\hline \multicolumn{1}{c}{ Cause } & Accidents & $\begin{array}{c}\text { \% of } \\
\text { Accidents }\end{array}$ & $\begin{array}{c}\text { Costs } \\
(\$)\end{array}$ & $\begin{array}{c}\text { \% of } \\
\text { Costs }\end{array}$ & Fatalities & $\begin{array}{c}\text { \% of } \\
\text { Fatalities }\end{array}$ & $\begin{array}{c}\text { \% of } \\
\text { Injuries }\end{array}$ & $\begin{array}{c}\text { of } \\
\text { Injuries }\end{array}$ \\
\hline $\begin{array}{l}\text { Mechanical/ } \\
\text { Electrical }\end{array}$ & 355 & 5.5 & $9,180,138$ & 4.9 & 0 & 0.0 & 5 & 2.9 \\
$\begin{array}{l}\text { Human } \\
\text { Factor }\end{array}$ & 3,026 & 47.3 & $88,121,822$ & 47.4 & 1 & 14.3 & 120 & 68.6 \\
$\begin{array}{l}\text { Miscellaneous } \\
\text { Signal and }\end{array}$ & 765 & 12.0 & $25,403,383$ & 13.7 & 5 & 71.4 & 22 & 12.6 \\
$\begin{array}{l}\text { Comm. } \\
\text { Track, }\end{array}$ & 172 & 2.7 & $3,423,026$ & 1.8 & 1 & 14.3 & 2 & 1.1 \\
$\begin{array}{l}\text { Roadbed and } \\
\text { Structures }\end{array}$ & 2,082 & 32.5 & $59,656,003$ & 32.1 & 0 & 0.0 & 26 & 14.9 \\
\hline
\end{tabular}

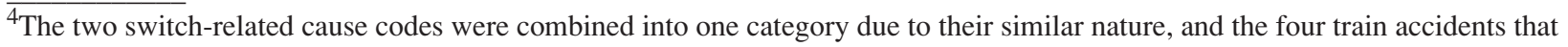
were attributable to the employee's physical condition were removed prior to the analysis due to such a small N.
} 
Table 8. Railroad yard injuries resulting from human factor-attributed train accidents, 1994 to 1998

\begin{tabular}{crc}
\hline No. of Injuries per Accident & No. of Accidents & No. of Injuries \\
\hline 0 & 2,938 & 0 \\
1 & 64 & 64 \\
2 & 20 & 40 \\
3 & 1 & 3 \\
4 & 2 & 8 \\
5 & 1 & 5 \\
Total & 3,026 & 120 \\
\hline
\end{tabular}

conditions, $\left(\chi^{2}=20.0, \mathrm{df}=3, \mathrm{p}<0.001\right)$. A visual inspection of the data indicates that the likely difference is between dawn (the least costly accidents) and darkness (the most costly accidents). The second significant difference was among the different human factor-attributed cause categories $\left(\chi^{2}=25.2, \mathrm{df}=6, \underline{\mathrm{p}}<0.001\right)$. Visual inspection of the data suggests that accidents due to "main track authority" were the most costly, even though there were only 54 of this type of accident between 1994 and 1998 in railroad yards, while those accidents classified simply as "miscellaneous" were the least costly.

\subsubsection{Drug and Alcohol Involvement}

The FRA requires railroads to conduct post-accident toxicological testing under certain situations. These situations generally include the following:

1. A train accident where there was a) a fatality; b) a public evacuation or a reportable injury due to the release of hazardous material; or c) $\$ 1,000,000$ or more in railroad property damage.

2. An impact accident (see 49 CFR 219.5; e.g., head on collision, side collision) that resulted in a reportable injury or $\$ 150,000$ or more in property damage.

3. A train incident that resulted in an on-duty railroad employee fatality.

4. A passenger train accident involving a reportable injury to any person.

See 49 CFR 219.201 for the specific toxicological reporting requirements and exceptions.

Very few human factor-attributed train accidents occurring in railroad yards were associated with positive drug or alcohol tests. Approximately one-third of the reported train accidents ( $\mathrm{n}=960)$ contained data on alcohol and drug tests (the remaining two-thirds contained no information on

\footnotetext{
$\overline{5}$ The "Main track authority" category is a misnomer since data that are reported here are for yard accidents. However, the specific codes that make up "main track authority" include "failure to stop train in (the) clear" and "movement of engine without authority," both of which can and do occur in railroad yards.
} 
drug or alcohol tests). Of those cases in which data were reported, there was only one human factor-attributed train accident that was associated with a positive alcohol test and 17 train accidents that were associated with positive drug tests. Thus, altogether, positive drug or alcohol tests made up less than 2 percent of all human factor-attributed train accidents occurring in railroad yards between 1994 and 1998.

\subsubsection{Hazmat Accidents}

Less than one-fifth (544, or 18 percent) of the human factor-attributed train accidents occurring in railroad yards between 1994 and 1998 involved cars that contained hazardous materials (see Table 9). Furthermore, only 10 percent of all train accidents involved damage to the cars containing the hazardous materials. Yet, only 16 accidents involved the release of hazardous materials ( 0.5 percent of all human factor-attributed train accidents occurring in railroad yards between 1994 and 1998). Fourteen of the 16 train accidents involved the release of hazardous material from one car only, while the other two train accidents each involved two cars that released hazmat. No injuries or fatalities resulted from these 16 train accidents.

\subsection{Analysis of 1997-1998 Railroad Yard Injuries}

1997 was the first year that railroads were required to report to the FRA the railroad location (e.g., yard) where the injury occurred. Injury analyses are therefore based on 1997 and 1998 FRA injury data since 1998 was the most recent year for which complete injury data were available at the time of the analyses. Injury data were downloaded from the FRA's website and

analyzed. ${ }^{6}$ The following selection criteria were used to select the data to be analyzed:

- The injury occurred in a railroad yard or on repair track ${ }^{7}$.

- The injury occurred to an employee-on-duty.

Table 9. Hazmat accidents, 1994 to 1998

\begin{tabular}{|c|c|c|c|c|c|c|c|}
\hline & $\begin{array}{c}\text { Total } \\
\text { Accidents }\end{array}$ & $\begin{array}{c}\text { Accidents } \\
\text { Involving } \\
\text { Consists } \\
\text { Carrying } \\
\text { Hazmat } \\
\end{array}$ & $\begin{array}{c}\text { Cars } \\
\text { Containing } \\
\text { Hazmat } \\
\end{array}$ & $\begin{array}{c}\text { Accidents } \\
\text { Involving } \\
\text { Damaged } \\
\text { or Derailed } \\
\text { Hazmat } \\
\text { Cars } \\
\end{array}$ & $\begin{array}{c}\text { Damaged } \\
\text { or } \\
\text { Derailed } \\
\text { Hazmat } \\
\text { Cars }\end{array}$ & $\begin{array}{c}\text { Accidents } \\
\text { Involving } \\
\text { Release } \\
\text { of } \\
\text { Hazmat } \\
\end{array}$ & $\begin{array}{c}\text { Cars } \\
\text { Releasing } \\
\text { Hazmat } \\
\end{array}$ \\
\hline All Accidents & 13,169 & 2494 & 20,946 & 1296 & 3,477 & 162 & 256 \\
\hline Yard Accidents & 6,400 & 1123 & 7,687 & 649 & 1,363 & 43 & 52 \\
\hline $\begin{array}{l}\text { Human Factor- } \\
\text { Attributed Yard } \\
\text { Accidents }\end{array}$ & 3,026 & 544 & 3,110 & 316 & 586 & 16 & 18 \\
\hline
\end{tabular}

${ }^{6}$ Analyses wre conducted using SPSS v8.0 and Microsoft Excel.

${ }^{7}$ Repair tracks share many of the same characteristics as yard tracks, including large, slow-moving equipment and inclement weather. Although repair tracks have a different function than other parts of the yard, those who work along the repair tracks must move in and out of, as well as in between and on top of, equipment, similar to yard crews switching cars. 
- The injury was nonfatal.

- The injury resulted in one or more lost workdays. A lost workday can result from either a day absent or a day of restricted (a.k.a. "light") duty. Lost workdays were used in the selection criteria because lost workday injuries are the most severe and have the greatest economic impact to both the injured employee and the railroad.

- The injury did not occur as a result of a grade-crossing collision.

Filters were used on the FRA injury data to select those injuries that fit the selection criteria. Both the frequency of injuries and the severity of the injuries were examined. Severity was measured in two ways: the median number of lost workdays and the total number of lost workdays that resulted from the injuries. Although the FRA collects data on the number of days absent and days of restricted duty, it does not report this information in its annual Railroad Safety Statistics report.

Tables and figures containing mostly descriptive information are used to present the results of the data analyses. Chi-square tests were used to analyze frequency counts for some of the variables, while the Kruskal-Wallis nonparametric test was used to analyze the lost workday data for other variables. In addition, proportions of injuries (i.e., percentages) were examined within some categories (e.g., age), since these proportions are not sensitive to differences in frequency counts between categories. Proportions enable pseudo-normalized comparisons to be made in the absence of exposure data. Separately, since some of the injury cases are missing certain data (e.g., no 'event' code was provided), data in some of the tables presented in this section will not add up to 100 percent of the total number of injury cases.

Table 10 presents overall statistics to provide a frame of reference with respect to yard injuries. Specifically, there were 5722 nonfatal employee-on-duty yard injuries between 1997 to 1998 , about 35 percent of all railroad injuries. Of the 5722 yard injuries, 80 percent $(n=4575)$ resulted in one or more lost workdays (LWDs). This proportion is slightly higher than the proportion of LWD injuries in the railroad industry as a whole (76 percent). The median number of lost workdays from yard injuries is 25,25 percent greater than the industry-wide median number of lost workdays (20). Further, the total number of lost workdays that resulted from yard injuries $(n=276,282)$ accounted for over 41 percent of all lost workdays in the railroad industry for 1997 to $1998(668,984)$.

Table 10. Railroad injuries, 1997 to 1998

\begin{tabular}{lccccc}
\hline \multicolumn{1}{c}{$\begin{array}{c}\text { Railroad } \\
\text { Location }\end{array}$} & $\begin{array}{c}\text { Total Railroad } \\
\text { Injuries }\end{array}$ & $\begin{array}{c}\text { Lost Workday } \\
\text { Injuries }\end{array}$ & $\begin{array}{c}\text { \% of Total } \\
\text { Injuries }\end{array}$ & $\begin{array}{c}\text { Median Lost } \\
\text { Workdays }\end{array}$ & $\begin{array}{c}\text { Total No. of } \\
\text { LWDs }\end{array}$ \\
\hline All & 16,457 & 12,564 & 76 & 20 & 668,984 \\
$\begin{array}{l}\text { Mainline/ } \\
\text { Branch }\end{array}$ & 4,743 & 3,621 & 76 & 19 & 191,960 \\
Yard & 5,722 & 4,575 & 80 & 25 & 276,282 \\
\hline
\end{tabular}




\subsubsection{Season}

Table 11 presents monthly injury data for 1997 and 1998. The first column contains the month. The second column contains data on the number of injuries per month. The third column contains data on the percentage of injuries for the particular month relative to the total number of injuries. For example, in January, there were 423 injuries that occurred between 1997 and 1998, resulting in 9.2 percent of all injuries for these two years. The fourth column contains data on the injury rate, and is based on the number of yard switching miles reported to the FRA by railroads each month. The fifth column contains data on the median number of lost workdays, the sixth column contains data on the total number of lost workdays, and the seventh column contains data on the percentage of total lost workdays for each month. The format of Table 11 is similar to other tables in this section, except for the column that contains the injury rate. This is unique to the monthly data, since exposure data is available for monthly comparisons, and is not available for most other variables of interest.

A chi-square determined that there was not a significant difference among months with respect to the injury rate $^{8}\left(\chi^{2}=1.9, \mathrm{df}=11, \mathrm{p}=0.99\right)$.

As can be seen in Figure 9, there are minimal differences among months with respect to the injury rate (range: 23.1-29.6). However, there do appear to be greater differences in terms of the median number of lost workdays each month. In fact, a Kruskal-Wallis test indicated a significant difference exists $\left(\mathrm{H}_{\mathrm{calc}}=28.4, \mathrm{df}=11, \mathrm{p}=0.003\right)$. Visual examination of the data suggests that, at a minimum, December (median of 20 LWDs) and February (median of 31 LWDs) are likely significantly different from each other.

Table 11. LWD yard injuries by month, 1997 to 1998

\begin{tabular}{lcccccc}
\hline \multicolumn{1}{c}{ Month } & $\begin{array}{c}\text { No. of } \\
\text { Injuries }\end{array}$ & $\begin{array}{c}\text { \% of } \\
\text { Injuries }\end{array}$ & $\begin{array}{c}\text { Injury / } \\
\text { MSM }\end{array}$ & $\begin{array}{c}\text { Median } \\
\text { LWDs }\end{array}$ & $\begin{array}{c}\text { Total } \\
\text { LWDs }\end{array}$ & $\begin{array}{c}\text { \% of Total } \\
\text { LWDs }\end{array}$ \\
\hline Jan & 423 & 9.2 & 29.1 & 22.0 & 24,831 & 9.0 \\
Feb & 316 & 6.9 & 23.1 & 31.0 & 23,098 & 8.4 \\
Mar & 423 & 9.2 & 28.6 & 28.0 & 30,788 & 11.1 \\
Apr & 336 & 7.3 & 23.1 & 24.0 & 25,718 & 9.3 \\
May & 365 & 8.0 & 26.5 & 25.0 & 23,095 & 8.4 \\
Jun & 392 & 8.6 & 28.3 & 23.0 & 23,956 & 8.7 \\
Jul & 400 & 8.7 & 29.2 & 24.0 & 24,222 & 8.8 \\
Aug & 380 & 8.3 & 27.1 & 21.5 & 21,197 & 7.7 \\
Sep & 385 & 8.4 & 27.7 & 30.0 & 22,775 & 8.2 \\
Oct & 438 & 9.6 & 29.6 & 29.5 & 25,164 & 9.1 \\
Nov & 352 & 7.7 & 26.2 & 24.0 & 16,170 & 5.9 \\
Dec & 365 & 8.0 & 27.0 & 20.0 & 15,268 & 5.5 \\
Total & 4,575 & 100 & 27.1 & 25.0 & 276,282 & 100 \\
& & & & & & \\
\hline
\end{tabular}

\footnotetext{
${ }^{8}$ The injury rate was used in the analysis since it has been "normalized" to account for differences in exposure across months. This was preferable to using the raw number of injury cases.
} 


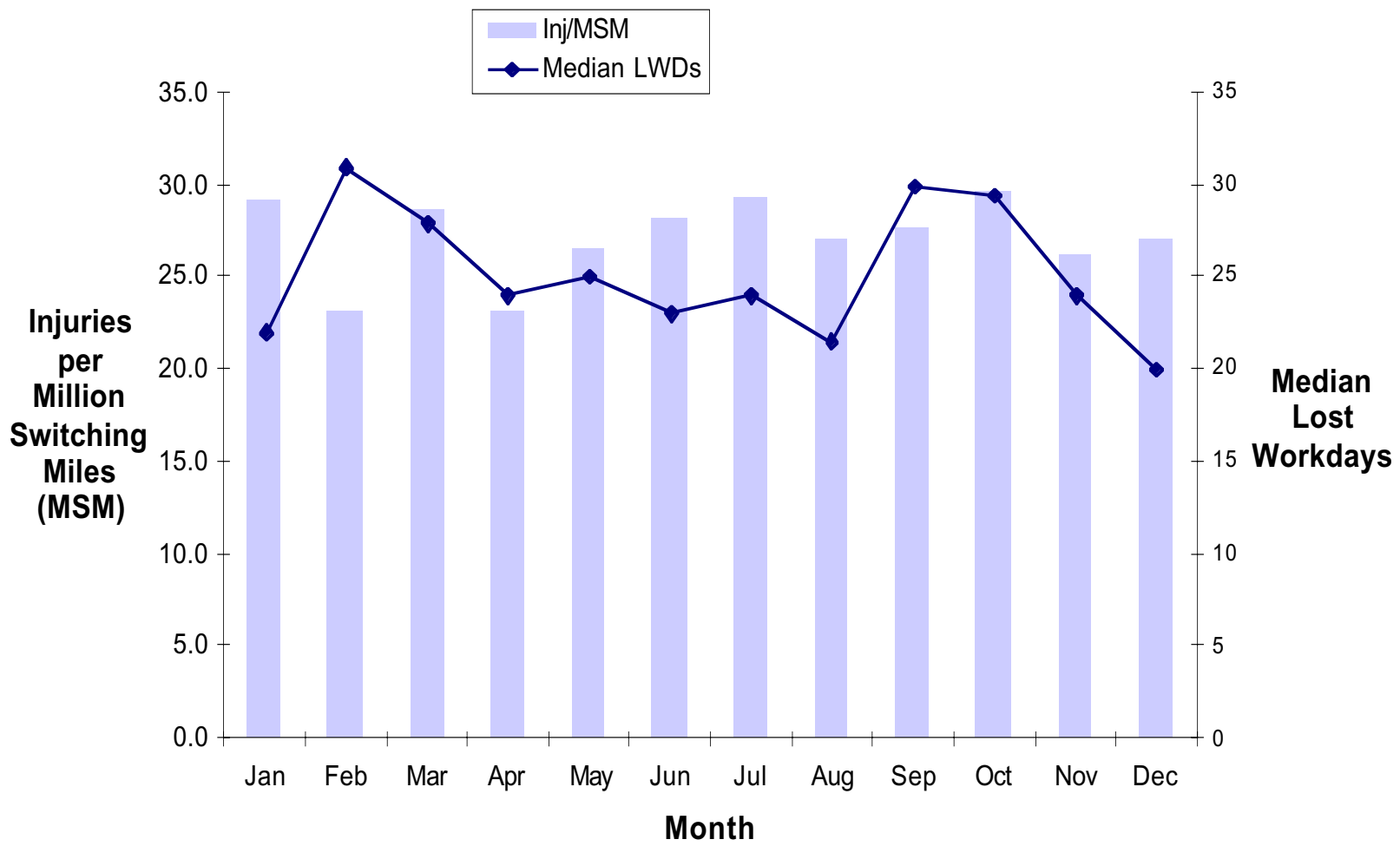

Figure 9. LWD yard injuries per million switching miles by month, 1997 to 1998

\subsubsection{Time-of-Day}

Analysis of the data in 2 hour periods is presented in Table 12 and illustrated in Figure 10. Over a quarter of the injuries occur between 8 a.m. and 12 p.m. A chi-square test yielded a significant difference among 2 hour time periods $\left(\chi^{2}=536.8, \mathrm{df}=11, \underline{\mathrm{p}}<0.001\right)$. However, exposure data were not available, and without this data, it is very difficult to conclude that the differences are strictly due to the time-of-day. In particular, it is possible that there are more crews working between 8 a.m. and 12 p.m., accounting for the increase in injuries at this time. Interestingly, the 2 a.m. to 4 a.m. time period, associated with a natural trough in humans' circadian rhythms, is associated with a relatively low number of injuries. However, it is also possible that there are fewer crews working in railroad yards at this time of the day, accounting for the relatively low number.

A significant difference was also found with respect to the median number of lost workdays across 2 hour time periods $\left(\mathrm{H}_{\mathrm{calc}}=29.3, \mathrm{df}=11, \mathrm{p}=0.002\right)$. Whereas the time between 8 a.m. and 12 p.m. experiences the most number of injuries, these injuries are the least severe. In fact, the "daylight" hours of 6 a.m. to 6 p.m. experience the least severe injuries while the 6 p.m. to 6 a.m. time period experiences the most severe injuries. 
Table 12. LWD yard injuries by time-of-day, 1997 to 1998

\begin{tabular}{lrrrrr}
\hline \multicolumn{1}{c}{ Time } & Injuries & $\begin{array}{c}\text { \% of } \\
\text { Injuries }\end{array}$ & $\begin{array}{c}\text { Median } \\
\text { LWDs }\end{array}$ & $\begin{array}{c}\text { Total } \\
\text { LWDs }\end{array}$ & $\begin{array}{r}\text { \% of Total } \\
\text { LWDs }\end{array}$ \\
\hline 12 to 2 a.m. & 351 & 7.7 & 30.0 & 23,099 & 8.4 \\
2 to 4 a.m. & 315 & 6.9 & 25.0 & 18,894 & 6.8 \\
4 to 6 a.m. & 249 & 5.4 & 28.0 & 16,175 & 5.9 \\
6 to 8 a.m. & 245 & 5.4 & 21.0 & 13,872 & 5.0 \\
8 to 10 a.m. & 566 & 12.4 & 21.0 & 28,608 & 10.4 \\
10 a.m. to 12 p.m. & 707 & 15.5 & 21.0 & 40,304 & 14.6 \\
12 to 2 p.m. & 427 & 9.3 & 21.0 & 22,373 & 8.1 \\
2 to 4 p.m. & 425 & 9.3 & 25.0 & 24,266 & 8.8 \\
4 to 6 p.m. & 378 & 8.3 & 23.5 & 24,026 & 8.7 \\
6 to 8 p.m. & 309 & 6.8 & 31.0 & 20,610 & 7.5 \\
8 to 10 p.m. & 325 & 7.1 & 30.0 & 22,294 & 8.1 \\
10 p.m. to 12 a.m. & 278 & 6.1 & 36.0 & 21,761 & 7.9 \\
Total & 4,575 & 100 & 25.0 & 276,282 & 100 \\
\end{tabular}

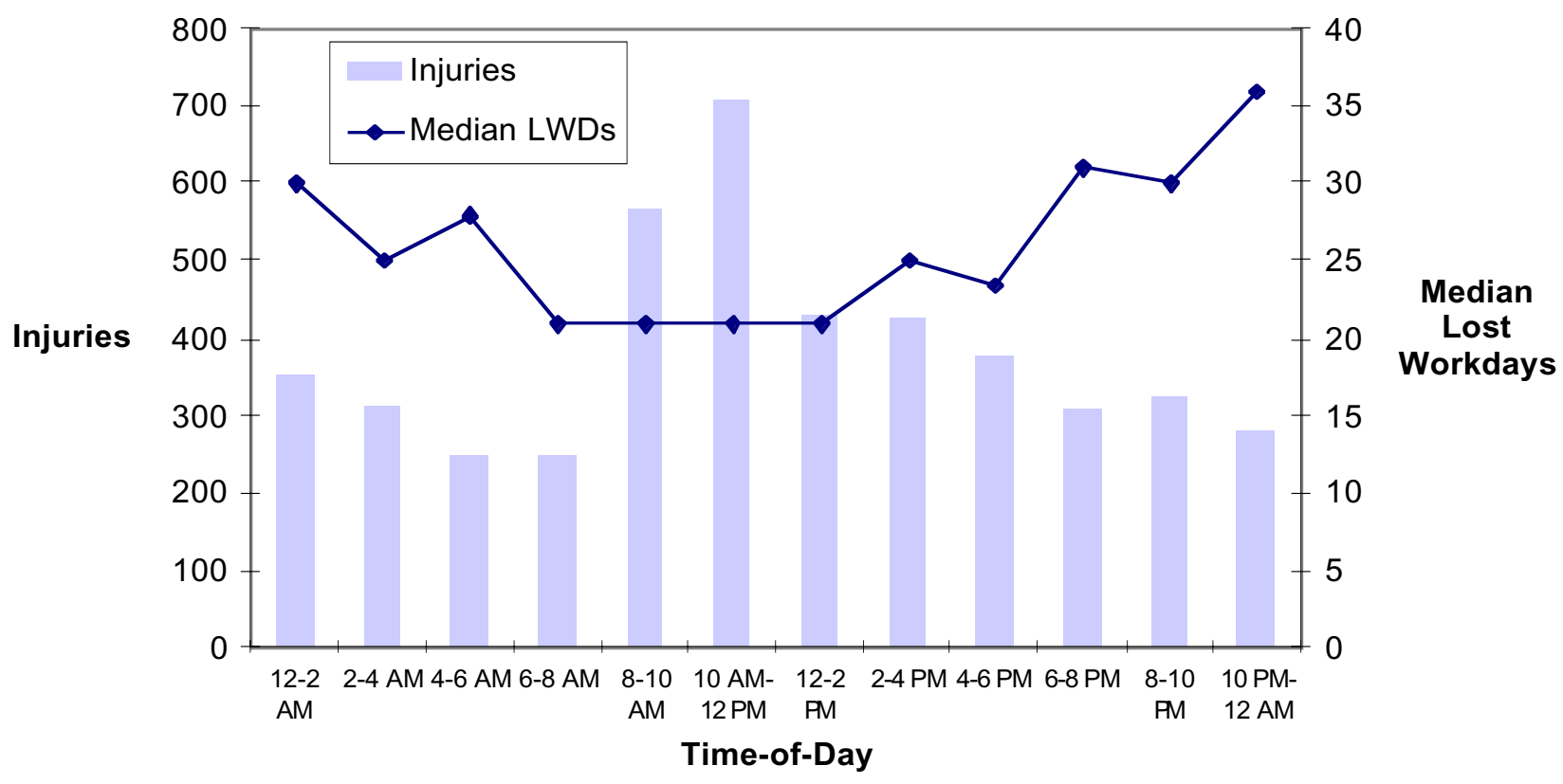

Figure 10. LWD yard injuries by time-of-day, 1997 to 1998 


\subsubsection{Age}

Table 13 and Figure 11 present injury data by age for 1997 to 1998 . A positive linear relationship appears to exist for the number of injuries per age category. To assist in understanding the possible relationship of age to injuries, it was desirable to control for age exposure; that is, the number of injuries in an age category may be a function of the number of railroad yard employees in that age category rather than a function of age, per se. The only agerelated data that were available were the age distribution across the entire railroad industry, as reported by the Railroad Retirement Board (RRB). The RRB publishes various annual statistics on railroad demographics, including the distribution of ages. These data were used as a

Table 13. LWD yard injuries by age, 1997 to 1998

\begin{tabular}{lcccrr}
\hline $\begin{array}{c}\text { Age } \\
\text { Bracket }\end{array}$ & Injuries & $\begin{array}{c}\text { \% of } \\
\text { Injuries }\end{array}$ & $\begin{array}{c}\text { Median } \\
\text { LWDs }\end{array}$ & $\begin{array}{r}\text { Total } \\
\text { LWDs }\end{array}$ & $\begin{array}{r}\% \text { of Total } \\
\text { LWDs }\end{array}$ \\
\hline$<25$ & 220 & 4.8 & 10 & 6,599 & 2.4 \\
25 to 34 & 789 & 17.3 & 18 & 37,226 & 13.5 \\
35 to 44 & 1,292 & 28.3 & 24 & 77,145 & 27.9 \\
45 to 54 & 1,651 & 36.1 & 29 & 108,104 & 39.1 \\
$55+$ & 621 & 13.6 & 33 & 47,173 & 17.1 \\
Total & 4,573 & 100 & 25 & 276,247 & 100 \\
\hline
\end{tabular}

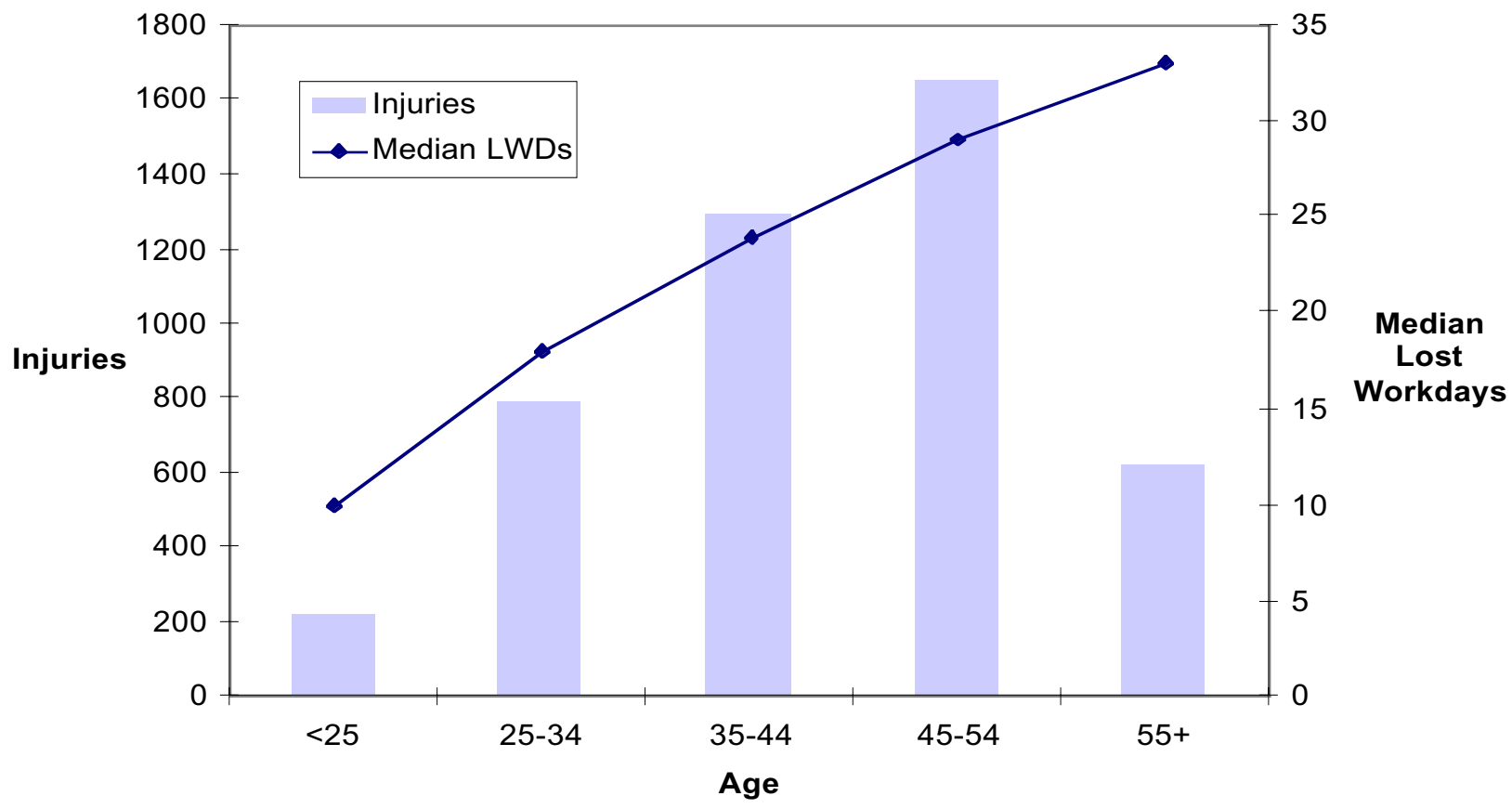

Figure 11. LWD yard injuries by age, 1997 to 1998 
surrogate exposure measure for age, since these data were not available for railroad yards, specifically. The use of surrogate measures, or proxies, of exposure may be used when specific exposure measures are not available (BTS, 1998, p. 88).

An assumption was made that the age distribution of the yard workforce is the same as the age distribution of the railroad industry as a whole. Based on this assumption, the RRB age data were used to calculate the relative proportions (i.e., percentages) for each age category, and are presented in Table 14, along with the injury data. A weighted frequency was then computed for each age bracket. A weighted frequency is simply the proportion of injuries for a particular age bracket divided by the proportion of employees (in the industry as a whole) in the same age bracket. For example, the weighted frequency for the 25 to 34 age category $=1.3$, or 17.3/13.4. A weighted frequency greater than one for a given age group indicates an overrepresentation of injuries relative to their proportion of the workforce. As shown in Figure 12, where the dotted line indicates an equal proportion of LWD injuries relative to the percentage of individuals in an age group, weighted frequencies provide a different picture of the age data. Specifically, it is the younger employees who suffer more injuries relative to their proportion in the workforce. Of course, the assumption that the railroad industry-wide age distribution data is comparable to that of the yard workforce must be satisfied for this data to be valid.

A Kruskal-Wallis test was then performed to determine if there were differences in age with respect to injury severity. In fact, a significant difference was found $\left(\mathrm{H}_{\mathrm{calc}}=104.1, \mathrm{df}=4\right.$, $\mathrm{p}<0.001)$. Based on Figure 11, it appears that the older the injured employee is, the greater the severity of the injury. There are several possible explanations for these data. It is possible that it takes longer for an older employee to recover from an injury than a younger employee. Age certainly affects the ability to heal, slowing down the process as age increases. It may also be possible that older employees censor their own reporting so that they report only the more severe injuries, while younger employees may report most of their injuries, regardless of the severity. This would explain the higher number of injuries and lower severity of the injuries sustained by younger employees as compared to the older employees.

Table 14. Weighted frequency of LWD yard injuries by age, 1997 to 1998

\begin{tabular}{lcccc}
\hline $\begin{array}{c}\text { Age } \\
\text { Bracket }\end{array}$ & Injuries & $\begin{array}{c}\text { \% of Total } \\
\text { Injuries }\end{array}$ & $\begin{array}{c}\text { Age Distribution } \\
(\%)^{*}\end{array}$ & $\begin{array}{c}\text { Weighted } \\
\text { Frequency }\end{array}$ \\
\hline$<25$ & 220 & 4.8 & 3.5 & 1.4 \\
25 to 34 & 789 & 17.3 & 13.4 & 1.3 \\
35 to 44 & 1,292 & 28.3 & 27.6 & 1.0 \\
45 to 54 & 1,651 & 36.1 & 38.7 & 0.9 \\
$55+$ & 621 & 13.6 & 16.9 & 0.8 \\
Total & 4,573 & & &
\end{tabular}

*Source: Railroad Retirement Board Statistical Table D-10, 1997 to 1998. 


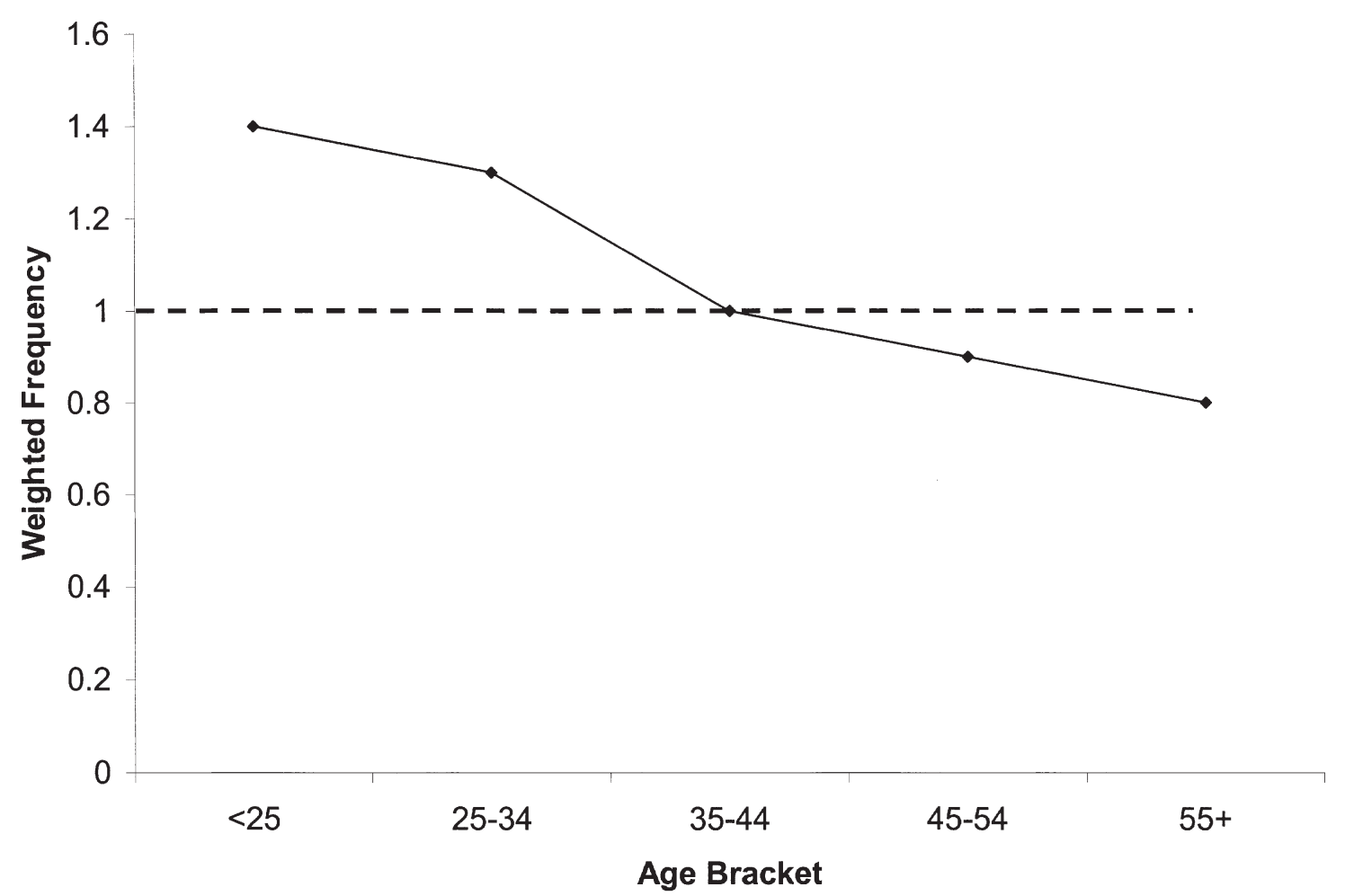

Figure 12. Weighted frequency of $L W D$ injuries relative to age distribution

\subsubsection{Job Category}

Train and Engine (T\&E) crews suffered the majority of the yard injuries (61 percent), while MOE and MOW suffered smaller percentages of the injuries (22 percent and 14 percent, respectively) (see Table 15 and Figure 13). This is most likely due to the fact that the majority of the yard workforce is made up of T\&E crews. T\&E crews also suffer the most severe injuries (median of 30 lost workdays, and 69 percent of all lost workdays due to yard injuries).

\subsubsection{Type of Injury}

Table 16 presents the data for the type of injury that occurred. Sprains and strains made up the largest category of injuries, accounting for 58 percent of all yard LWD injuries. These injuries also resulted in 63 percent of all lost workdays (a measure of severity). Thus, although not the most severe injury type, the moderate severity combined with the high incidence makes sprains and strains a serious issue among railroad yard LWD injuries.

\subsubsection{Body Part}

Results of the analyses of the affected body part are presented in Table 17 and Figure 14. The torso was the most affected body part, accounting for 42 percent of the injuries and 47 percent of the total number of LWDs. The lower extremities were the next most affected body part, accounting for 29 percent of injuries and 30 percent of the lost workdays, while the upper 
Table 15. LWD yard injuries by job category, 1997 to 1998

\begin{tabular}{lcccrc}
\hline \multicolumn{1}{c}{ Job Category } & Injuries & $\begin{array}{c}\text { \% of Total } \\
\text { Injuries }\end{array}$ & $\begin{array}{c}\text { Median } \\
\text { LWDs }\end{array}$ & $\begin{array}{c}\text { Total } \\
\text { LWDs }\end{array}$ & $\begin{array}{c}\text { \% of Total } \\
\text { LWDs }\end{array}$ \\
\hline Transportation, T\&E & & & & & \\
MOE & 2,795 & 61.1 & 30.0 & 190,934 & 69.1 \\
MOW & 1,009 & 22.1 & 20.0 & 48,147 & 17.4 \\
P\&A & 622 & 13.6 & 19.0 & 28,828 & 10.4 \\
Transportation, Non T\&E & 72 & 1.6 & 30.5 & 5,880 & 2.1 \\
Executive & 68 & 1.5 & 10.0 & 2,263 & 0.8 \\
Total & 9 & 0.2 & 14.0 & 230 & 0.1 \\
& 4,575 & 100 & 25.0 & 276,282 & 100 \\
\hline
\end{tabular}

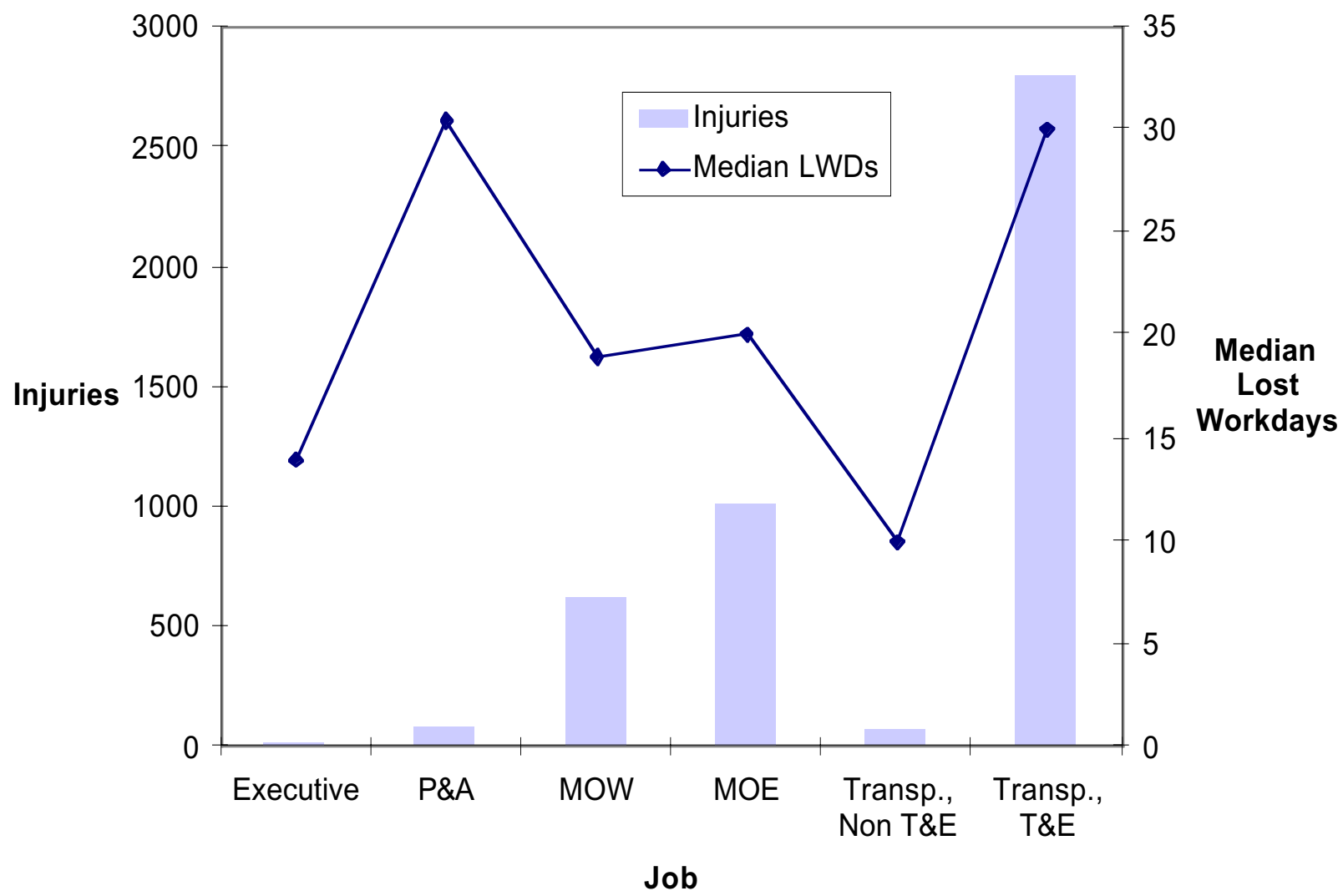

Figure 13. LWD yard injuries by job category, 1997 to 1998 
Table 16. LWD yard injuries by type of injury, 1997 to 1998

\begin{tabular}{lrrrrr}
\hline \multicolumn{1}{c}{ Type of Injury } & Injuries & $\begin{array}{c}\text { \% of Total } \\
\text { Injuries }\end{array}$ & $\begin{array}{r}\text { Median } \\
\text { LWDs }\end{array}$ & $\begin{array}{r}\text { Total } \\
\text { LWDs }\end{array}$ & $\begin{array}{r}\text { \% of Total } \\
\text { LWDs }\end{array}$ \\
\hline Sprain or Strain & 2,643 & 58.3 & 27 & 173,355 & 63.0 \\
Bruise or Contusion & 655 & 14.4 & 15 & 29,533 & 10.7 \\
Fracture & 396 & 8.7 & 41 & 26,477 & 9.6 \\
Cut/Laceration or Abrasion & 296 & 6.5 & 10 & 11,170 & 4.1 \\
All other Injuries & 158 & 3.5 & 28 & 11,166 & 4.1 \\
Dislocation & 60 & 1.3 & 85 & 6,336 & 2.3 \\
Foreign Object in Eye & 59 & 1.3 & 2 & 165 & 0.1 \\
Hernia & 56 & 1.2 & 46.5 & 3,635 & 1.3 \\
Amputation & 46 & 1.0 & 91 & 6,450 & 2.3 \\
Puncture Wound & 35 & 0.8 & 9 & 989 & 0.4 \\
Other burns & 28 & 0.6 & 10.5 & 455 & 0.2 \\
Occupational Illness & 25 & 0.6 & 20 & 1,900 & 0.7 \\
Concussion & 22 & 0.5 & 27 & 1,472 & 0.5 \\
Electrical Shock or Burn & 19 & 0.4 & 9 & 621 & 0.2 \\
Reaction from One-Time External & 19 & 0.4 & 7 & 271 & 0.1 \\
Exposure to Chemicals & & & & & \\
Internal Injury & 7 & 0.2 & 91 & 905 & 0.3 \\
One-Time Exposure to Loud & 7 & 0.2 & 27 & 267 & 0.1 \\
Noise & & & & & \\
Dental Related & 2 & 0.0 & 24 & 48 & 0.0 \\
Nervous Shock (Injury Related) & 1 & 0.0 & N/A & 167 & 0.1 \\
Total & 4,534 & 100 & 25 & 275,382 & 100 \\
\hline
\end{tabular}

extremities — the arm and hand — were the third-most affected body part, accounting for 17 percent of injuries and 13 percent of lost workdays. The head and face region was the fourthmost affected body part, accounting for 10 percent of the injuries and 9 percent of the lost workdays.

\subsubsection{Triggering Event}

Table 18 presents data alphabetically on the triggering events that caused the railroad yard injuries. The FRA provides railroads with over 65 codes from which to choose and categorize the triggering event. Consequently, no single event category is associated with a significant number of injuries. Table 19 presents the same data sorted by the number of injuries. As can be seen, the event associated with the greatest number of injuries is overexertion, accounting for 16 percent of all yard LWD injuries in 1997 to 1998. 
Table 17. LWD yard injuries by body part, 1997 to 1998

\begin{tabular}{lrccrc}
\hline \multicolumn{1}{c}{ Body Part } & Injuries & $\begin{array}{c}\text { \% of Total } \\
\text { Injuries }\end{array}$ & $\begin{array}{c}\text { Median } \\
\text { LWDs }\end{array}$ & $\begin{array}{c}\text { Total } \\
\text { LWDs }\end{array}$ & $\begin{array}{c}\text { \% of Total } \\
\text { LWDs }\end{array}$ \\
\hline Torso & & & & & \\
Leg/Foot & 1,889 & 41.8 & 30 & 128,930 & 46.9 \\
Arm/Hand & 1,318 & 29.2 & 29 & 82,381 & 30.0 \\
Head/Face & 787 & 17.4 & 20 & 34,488 & 12.6 \\
Multiple Body Parts & 454 & 10.1 & 13 & 24,125 & 8.8 \\
Other Body Parts & 34 & 0.8 & 35 & 2,906 & 1.1 \\
Occ. Illness & 28 & 0.6 & 18 & 1,919 & 0.7 \\
Total & 7 & 0.2 & 4 & 29 & 0.0 \\
& 4,517 & 100 & 25 & 274,778 & 100 \\
\hline
\end{tabular}

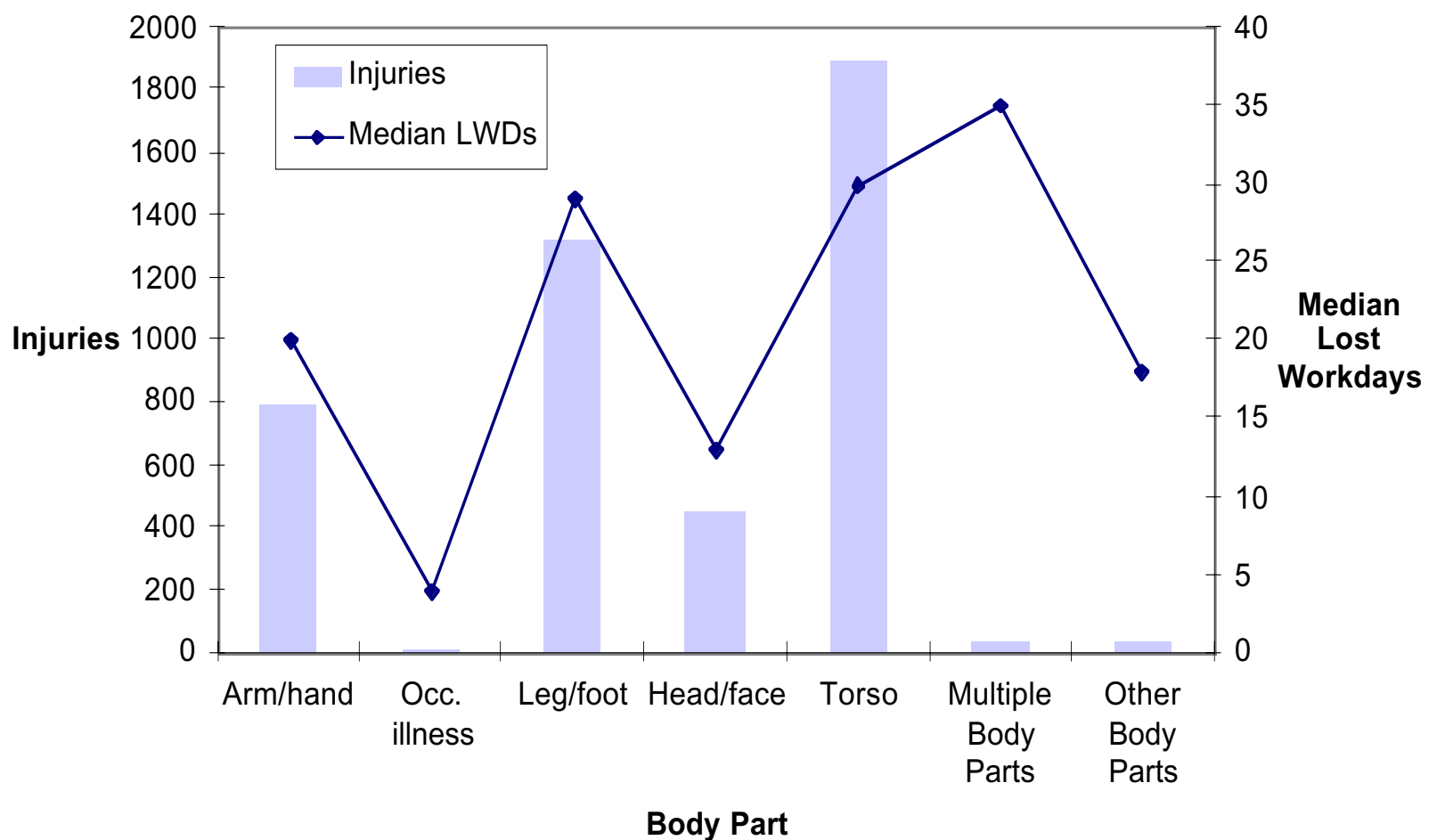

Figure 14. LWD yard injuries by body part, 1997 to 1998 
Table 18. LWD yard injuries by triggering event, 1997 to 1998

\begin{tabular}{|c|c|c|c|c|c|}
\hline Triggering Event & Injuries & $\begin{array}{c}\% \text { of } \\
\text { Total } \\
\text { Injuries }\end{array}$ & $\begin{array}{l}\text { Median } \\
\text { LWDs }\end{array}$ & $\begin{array}{c}\text { Total } \\
\text { LWDs }\end{array}$ & $\begin{array}{l}\% \text { of } \\
\text { Total } \\
\text { LWDs }\end{array}$ \\
\hline Aggravated Pre-Existing Condition & 60 & 1.3 & 25.0 & 4,248 & 1.5 \\
\hline Apprehending/Removing From Property & 2 & 0.0 & 63.5 & 127 & 0.0 \\
\hline Assaulted by Coworker & 4 & 0.1 & 11.5 & 113 & 0.0 \\
\hline Assaulted by Other & 10 & 0.2 & 14.0 & 357 & 0.1 \\
\hline Bitten by Animal & 1 & 0.0 & N/A & 25 & 0.0 \\
\hline $\begin{array}{l}\text { Bitten/stung by Bee, Spider, Other } \\
\text { Insect }\end{array}$ & 12 & 0.3 & 1.5 & 75 & 0.0 \\
\hline $\begin{array}{l}\text { Bodily Function/Sudden Movement, } \\
\text { e.g., Sneezing }\end{array}$ & 178 & 3.9 & 26.0 & 11,984 & 4.3 \\
\hline $\begin{array}{l}\text { Caught in or Compressed by Hand } \\
\text { Tools }\end{array}$ & 23 & 0.5 & 20.0 & 496 & 0.2 \\
\hline $\begin{array}{l}\text { Caught in or Compressed by Other } \\
\text { Machinery }\end{array}$ & 40 & 0.9 & 23.5 & 2,125 & 0.8 \\
\hline $\begin{array}{l}\text { Caught in or Compressed by Powered } \\
\text { hand Tools }\end{array}$ & 6 & 0.1 & 26.0 & 211 & 0.1 \\
\hline Caught in or Crushed by Materials & 65 & 1.4 & 18.0 & 2,252 & 0.8 \\
\hline $\begin{array}{l}\text { Caught in or Crushed in Excavation, } \\
\text { Land Slide, Cave-In, etc. }\end{array}$ & 1 & 0.0 & N/A & 86 & 0.0 \\
\hline Caught in, Compressed, Pinched, Other & 37 & 0.8 & 15.0 & 1263 & 0.5 \\
\hline $\begin{array}{l}\text { Climatic Condition, Exposure to } \\
\text { Environmental Cold }\end{array}$ & 5 & 0.1 & 69.0 & 420 & 0.2 \\
\hline $\begin{array}{l}\text { Climatic Condition, Exposure to } \\
\text { Environmental Heat }\end{array}$ & 9 & 0.2 & 3.0 & 42 & 0.0 \\
\hline $\begin{array}{l}\text { Climatic Conditions, Other (e.g., High } \\
\text { Winds) }\end{array}$ & 20 & 0.4 & 4.5 & 416 & 0.2 \\
\hline $\begin{array}{l}\text { Collision - Between on Track } \\
\text { Equipment }\end{array}$ & 88 & 1.9 & 57.5 & 7,705 & 2.8 \\
\hline $\begin{array}{l}\text { Collision/Impact - Auto, Truck, Bus, } \\
\text { Van, etc. }\end{array}$ & 28 & 0.6 & 52.5 & 3,383 & 1.2 \\
\hline Defective/Malfunctioning Equipment & 120 & 2.6 & 28.0 & 8,717 & 3.2 \\
\hline Derailment & 27 & 0.6 & 41.0 & 2,234 & 0.8 \\
\hline $\begin{array}{l}\text { Electrical Shock Due to Contact with 3rd } \\
\text { Rail, Catenary, Pantograph }\end{array}$ & 8 & 0.2 & 10.0 & 128 & 0.0 \\
\hline Electrical Shock from Hand Tool & 5 & 0.1 & 9.0 & 128 & 0.0 \\
\hline $\begin{array}{l}\text { Electrical Shock while Operating } \\
\text { Welding Equipment }\end{array}$ & 1 & 0.0 & N/A & 113 & 0.0 \\
\hline $\begin{array}{l}\text { Electrical Shock, Other (Explain in } \\
\text { Narrative) }\end{array}$ & 6 & 0.1 & 7.5 & 296 & 0.1 \\
\hline Exposure to Chemicals - External & 20 & 0.4 & 4.0 & 282 & 0.1 \\
\hline
\end{tabular}


Table 18. LWD yard injuries by triggering event, 1997 to 1998 (continued)

\begin{tabular}{|c|c|c|c|c|c|}
\hline Triggering Event & Injuries & $\begin{array}{c}\% \text { of } \\
\text { Total } \\
\text { Injuries }\end{array}$ & $\begin{array}{l}\text { Median } \\
\text { LWDs }\end{array}$ & $\begin{array}{l}\text { Total } \\
\text { LWDs }\end{array}$ & $\begin{array}{l}\% \text { of } \\
\text { Total } \\
\text { LWDs }\end{array}$ \\
\hline Exposure to Fumes - Inhalation & 49 & 1.1 & 8.0 & 1,038 & 0.4 \\
\hline Exposure to Noise - Single Incident & 10 & 0.2 & 22.5 & 528 & 0.2 \\
\hline Exposure to Noise Over Time & 1 & 0.0 & $\mathrm{~N} / \mathrm{A}$ & 28 & 0.0 \\
\hline Exposure to Poisonous Plants & 1 & 0.0 & $\mathrm{~N} / \mathrm{A}$ & 4 & 0.0 \\
\hline Exposure to Welding Light & 4 & 0.1 & 1.0 & 5 & 0.0 \\
\hline Horseplay, Practical Joke, etc. & 2 & 0.0 & 5.0 & 10 & 0.0 \\
\hline Lost Balance & 274 & 6.0 & 30.0 & 18,351 & 6.6 \\
\hline Missed Handhold, Grabiron, Step, etc. & 92 & 2.0 & 26.5 & 5,744 & 2.1 \\
\hline Needle Puncture/Prick/Stick & 4 & 0.1 & 4.5 & 25 & 0.0 \\
\hline On-Track Equipment, Other Incident & 8 & 0.2 & 69.0 & 630 & 0.2 \\
\hline Other Impacts - on Track Equipment & 35 & 0.8 & 45.0 & 2,826 & 1.0 \\
\hline Overexertion & 726 & 15.9 & 30.0 & 49,089 & 17.8 \\
\hline Pushed/Shoved from & 16 & 0.3 & 35.5 & 911 & 0.3 \\
\hline Pushed/Shoved Into/Against & 39 & 0.9 & 29.0 & 2,445 & 0.9 \\
\hline Pushed/Shoved Onto & 8 & 0.2 & 48.5 & 617 & 0.2 \\
\hline Ran into Object/Equipment & 20 & 0.4 & 42.0 & 1,310 & 0.5 \\
\hline Ran into On-Track Equipment & 12 & 0.3 & 30.0 & 432 & 0.2 \\
\hline Repetitive Motion - Other & 8 & 0.2 & 31.5 & 298 & 0.1 \\
\hline Repetitive Motion - Tools & 23 & 0.5 & 14.0 & 1,546 & 0.6 \\
\hline $\begin{array}{l}\text { Repetitive Motion - Typing, Keyboard, } \\
\text { etc. }\end{array}$ & 3 & 0.1 & 6.0 & 14 & 0.0 \\
\hline Repetitive Motion - Work Processes & 91 & 2.0 & 24.0 & 4,750 & 1.7 \\
\hline Rubbed, Abraded, etc. & 18 & 0.4 & 9.0 & 414 & 0.1 \\
\hline Shot & 1 & 0.0 & N/A & 8 & 0.0 \\
\hline $\begin{array}{l}\text { Slack Action, Draft, Compressive } \\
\text { Buff/Coupling }\end{array}$ & 64 & 1.4 & 38.0 & 4,251 & 1.5 \\
\hline Slip, Fall, Stumble, Other & 48 & 1.0 & 33.0 & 3,230 & 1.2 \\
\hline $\begin{array}{l}\text { Slipped, Fell, Stumbled, etc. Due to } \\
\text { Climatic Condition (Rain, Snow, Ice, } \\
\text { etc.) }\end{array}$ & 224 & 4.9 & 27.0 & 12,716 & 4.6 \\
\hline $\begin{array}{l}\text { Slipped, Fell, Stumbled, etc. Due to } \\
\text { Irregular Surface, e.g., Depression, } \\
\text { Slope, etc. }\end{array}$ & 297 & 6.5 & 28.0 & 17,606 & 6.4 \\
\hline $\begin{array}{l}\text { Slipped, Fell, Stumbled, etc. Due to } \\
\text { Object, e.g., Ballast, Spike, Material, } \\
\text { etc. }\end{array}$ & 449 & 9.8 & 35.0 & 31,849 & 11.5 \\
\hline $\begin{array}{l}\text { Slipped, Fell, Stumbled, etc. on Oil, } \\
\text { Grease, Other Slippery Substance }\end{array}$ & 108 & 2.4 & 27.5 & 9,346 & 3.4 \\
\hline Stabbing, Knifing, etc. & 3 & 0.1 & 9.0 & 25 & 0.0 \\
\hline
\end{tabular}


Table 18. LWD yard injuries by triggering event, 1997 to 1998 (continued)

\begin{tabular}{lrrrrr}
\hline \multicolumn{1}{c}{ Triggering Event } & \multicolumn{2}{c}{$\begin{array}{c}\text { \% of } \\
\text { Total } \\
\text { Injuries }\end{array}$} & $\begin{array}{c}\text { Median } \\
\text { LWDs }\end{array}$ & $\begin{array}{c}\text { Total } \\
\text { LWDs }\end{array}$ & $\begin{array}{r}\text { \% of } \\
\text { LWDs }\end{array}$ \\
\hline Stepped on Object & 116 & 2.5 & 17.0 & 5,645 & 2.0 \\
Struck Against Object & 158 & 3.5 & 18.0 & 6,914 & 2.5 \\
Struck by Falling Object & 73 & 1.6 & 14.0 & 3,199 & 1.2 \\
Struck by Object & 176 & 3.8 & 17.5 & 7,174 & 2.6 \\
Struck by On-Track Equipment & 80 & 1.7 & 42.5 & 7,872 & 2.8 \\
Struck by Thrown or Propelled Object & 57 & 1.2 & 6.0 & 1,809 & 0.7 \\
Sudden Release of Air & 12 & 0.3 & 15.0 & 657 & 0.2 \\
Sudden/Unexpected Movement of & 68 & 1.5 & 26.0 & 3,809 & 1.4 \\
Material & & & & & \\
Sudden/Unexpected Movement of On- & 103 & 2.3 & 73.0 & 9,908 & 3.6 \\
Track Equipment & & & & & \\
Sudden/Unexpected Movement of & 25 & 0.5 & 27.0 & 1,630 & 0.6 \\
Vehicle & & & & & \\
Sudden/Unexpected Movement, Other & 21 & 0.5 & 17.0 & 625 & 0.2 \\
Sustained Viewing & 1 & 0.0 & N/A & 2 & 0.0 \\
Thrill Seeking & 1 & 0.0 & N/A & 1 & 0.0 \\
Other (Describe in Narrative) & 270 & 5.9 & 13.0 & 9,765 & 3.5 \\
Total & 4,575 & 100 & 25.0 & 276,282 & 100 \\
\hline
\end{tabular}

To obtain a better understanding of the triggering events, a set of higher-level triggering events that were specifically relevant to yard work were created. Each higher-level category was comprised of several related triggering event codes. These data are presented in Table 20. As can be seen, slips, trips and falls account for the largest number of injuries (42 percent) as well as the largest proportion of lost workdays (44 percent). The most severe types of triggering event, as measured by the median number of LWDs, though, are collisions and impacts with equipment and sudden or unexpected movement of equipment (medians of 45 and 40 lost workdays, respectively).

\subsubsection{Physical Act}

The physical act engaged in at the time of the injury was examined next. Similar to the event codes, there are over 70 physical act codes from which to choose and categorize an injury. Table 21 presents the injury data alphabetically for each of the physical act codes provided by the FRA, while Table 22 presents the data sorted by the number of injuries in each category.

To obtain a better understanding of the physical acts, a set of higher-level acts that were relevant to yard work was created. Each higher-level physical act was comprised of several related FRA physical act codes. These data are presented in Table 23 as well as in Figure 15. As can be seen, 
Table 19. LWD yard injuries by triggering event and sorted by the number of injuries, 1997 to 1998

\begin{tabular}{|c|c|c|c|c|c|}
\hline Triggering Event & Injuries & $\begin{array}{c}\% \text { of } \\
\text { Total } \\
\text { Injuries }\end{array}$ & $\begin{array}{l}\text { Median } \\
\text { LWDs }\end{array}$ & $\begin{array}{l}\text { Total } \\
\text { LWDs }\end{array}$ & $\begin{array}{l}\% \text { of } \\
\text { Total } \\
\text { LWDs }\end{array}$ \\
\hline Overexertion & 726 & 15.9 & 30.0 & 49,089 & 17.8 \\
\hline $\begin{array}{l}\text { Slipped, Fell, Stumbled, etc. Due to } \\
\text { Object, e.g., Ballast, Spike, Material, } \\
\text { etc. }\end{array}$ & 449 & 9.8 & 35.0 & 31,849 & 11.5 \\
\hline $\begin{array}{l}\text { Slipped, Fell, Stumbled, etc. due to } \\
\text { Irregular Surface, e.g., Depression, } \\
\text { Slope, etc. }\end{array}$ & 297 & 6.5 & 28.0 & 17,606 & 6.4 \\
\hline Lost Balance & 274 & 6.0 & 30.0 & 18,351 & 6.6 \\
\hline Other (Describe in Narrative) & 270 & 5.9 & 13.0 & 9,765 & 3.5 \\
\hline $\begin{array}{l}\text { Slipped, Fell, Stumbled, etc. due to } \\
\text { Climatic Condition (Rain, Snow, Ice, } \\
\text { etc.) }\end{array}$ & 224 & 4.9 & 27.0 & 12,716 & 4.6 \\
\hline $\begin{array}{l}\text { Bodily Function/Sudden Movement, } \\
\text { e.g., Sneezing }\end{array}$ & 178 & 3.9 & 26.0 & 11,984 & 4.3 \\
\hline Struck by Object & 176 & 3.8 & 17.5 & 7,174 & 2.6 \\
\hline Struck against Object & 158 & 3.5 & 18.0 & 6,914 & 2.5 \\
\hline Defective/Malfunctioning Equipment & 120 & 2.6 & 28.0 & 8,717 & 3.2 \\
\hline Stepped on Object & 116 & 2.5 & 17.0 & 5,645 & 2.0 \\
\hline $\begin{array}{l}\text { Slipped, Fell, Stumbled, etc. on Oil, } \\
\text { Grease, Other Slippery Substance }\end{array}$ & 108 & 2.4 & 27.5 & 9,346 & 3.4 \\
\hline $\begin{array}{l}\text { Sudden/Unexpected Movement of On- } \\
\text { Track Equipment }\end{array}$ & 103 & 2.3 & 73.0 & 9,908 & 3.6 \\
\hline Missed Handhold, Grabiron, Step, etc. & 92 & 2.0 & 26.5 & 5,744 & 2.1 \\
\hline Repetitive Motion - Work Processes & 91 & 2.0 & 24.0 & 4,750 & 1.7 \\
\hline $\begin{array}{l}\text { Collision - Between On Track } \\
\text { Equipment }\end{array}$ & 88 & 1.9 & 57.5 & 7,705 & 2.8 \\
\hline Struck by On-Track Equipment & 80 & 1.7 & 42.5 & 7,872 & 2.8 \\
\hline Struck by Falling Object & 73 & 1.6 & 14.0 & 3,199 & 1.2 \\
\hline $\begin{array}{l}\text { Sudden/Unexpected Movement of } \\
\text { Material }\end{array}$ & 68 & 1.5 & 26.0 & 3,809 & 1.4 \\
\hline Caught in or Crushed by Materials & 65 & 1.4 & 18.0 & 2,252 & 0.8 \\
\hline $\begin{array}{l}\text { Slack Action, Draft, Compressive } \\
\text { Buff/Coupling }\end{array}$ & 64 & 1.4 & 38.0 & 4,251 & 1.5 \\
\hline Aggravated Pre-Existing Condition & 60 & 1.3 & 25.0 & 4,248 & 1.5 \\
\hline Struck by Thrown or Propelled Object & 57 & 1.2 & 6.0 & 1,809 & 0.7 \\
\hline Exposure to Fumes - Inhalation & 49 & 1.1 & 8.0 & 1,038 & 0.4 \\
\hline Slip, Fall, Stumble, Other & 48 & 1.0 & 33.0 & 3,230 & 1.2 \\
\hline
\end{tabular}


Table 19. LWD yard injuries by triggering event and sorted by the number of injuries, 1997 to 1998 (continued)

\begin{tabular}{|c|c|c|c|c|c|}
\hline Triggering Event & Injuries & $\begin{array}{c}\% \text { of } \\
\text { Total } \\
\text { Injuries }\end{array}$ & $\begin{array}{l}\text { Median } \\
\text { LWDs }\end{array}$ & $\begin{array}{l}\text { Total } \\
\text { LWDs }\end{array}$ & $\begin{array}{l}\% \text { of } \\
\text { Total } \\
\text { LWDs }\end{array}$ \\
\hline $\begin{array}{l}\text { Caught in or Compressed by Other } \\
\text { Machinery }\end{array}$ & 40 & 0.9 & 23.5 & 2,125 & 0.8 \\
\hline Pushed/Shoved Into/Against & 39 & 0.9 & 29.0 & 2,445 & 0.9 \\
\hline Caught in, Compressed, Pinched, Other & 37 & 0.8 & 15.0 & 1,263 & 0.5 \\
\hline Other impacts - On Track Equipment & 35 & 0.8 & 45.0 & 2,826 & 1.0 \\
\hline $\begin{array}{l}\text { Collision/Impact - Auto, Truck, Bus, } \\
\text { Van, etc. }\end{array}$ & 28 & 0.6 & 52.5 & 3,383 & 1.2 \\
\hline Derailment & 27 & 0.6 & 41.0 & 2,234 & 0.8 \\
\hline $\begin{array}{l}\text { Sudden/Unexpected Movement of } \\
\text { Vehicle }\end{array}$ & 25 & 0.5 & 27.0 & 1,630 & 0.6 \\
\hline $\begin{array}{l}\text { Caught in or Compressed by Hand } \\
\text { Tools }\end{array}$ & 23 & 0.5 & 20.0 & 496 & 0.2 \\
\hline Repetitive Motion - Tools & 23 & 0.5 & 14.0 & 1,546 & 0.6 \\
\hline Sudden/Unexpected Movement, Other & 21 & 0.5 & 17.0 & 625 & 0.2 \\
\hline $\begin{array}{l}\text { Climatic Conditions, Other (e.g., High } \\
\text { Winds) }\end{array}$ & 20 & 0.4 & 4.5 & 416 & 0.2 \\
\hline Exposure to Chemicals - External & 20 & 0.4 & 4.0 & 282 & 0.1 \\
\hline Ran into Object/Equipment & 20 & 0.4 & 42.0 & 1,310 & 0.5 \\
\hline Rubbed, Abraded, etc. & 18 & 0.4 & 9.0 & 414 & 0.1 \\
\hline Pushed/Shoved From & 16 & 0.3 & 35.5 & 911 & 0.3 \\
\hline $\begin{array}{l}\text { Bitten/stung by Bee, Spider, Other } \\
\text { Insect }\end{array}$ & 12 & 0.3 & 1.5 & 75 & 0.0 \\
\hline Ran into On-Track Equipment & 12 & 0.3 & 30.0 & 432 & 0.2 \\
\hline Sudden Release of Air & 12 & 0.3 & 15.0 & 657 & 0.2 \\
\hline Assaulted by Other & 10 & 0.2 & 14.0 & 357 & 0.1 \\
\hline Exposure to Noise - Single Incident & 10 & 0.2 & 22.5 & 528 & 0.2 \\
\hline $\begin{array}{l}\text { Climatic Condition, Exposure to } \\
\text { Environmental Heat }\end{array}$ & 9 & 0.2 & 3.0 & 42 & 0.0 \\
\hline $\begin{array}{l}\text { Electrical Shock Due to Contact with 3rd } \\
\text { Rail, Catenary, Pantograph }\end{array}$ & 8 & 0.2 & 10.0 & 128 & 0.0 \\
\hline Pushed/Shoved Onto & 8 & 0.2 & 48.5 & 617 & 0.2 \\
\hline Repetitive Motion - Other & 8 & 0.2 & 31.5 & 298 & 0.1 \\
\hline On-Track Equipment, Other Incident & 8 & 0.2 & 69.0 & 630 & 0.2 \\
\hline $\begin{array}{l}\text { Caught in or Compressed by Powered } \\
\text { Hand Tools }\end{array}$ & 6 & 0.1 & 26.0 & 211 & 0.1 \\
\hline $\begin{array}{l}\text { Electrical Shock, Other (Explain in } \\
\text { Narrative) }\end{array}$ & 6 & 0.1 & 7.5 & 296 & 0.1 \\
\hline
\end{tabular}


Table 19. LWD yard injuries by triggering event and sorted by the number of injuries, 1997 to 1998 (continued)

\begin{tabular}{lcccrr}
\hline \multicolumn{1}{c}{ Triggering Event } & \% of & $\begin{array}{c}\text { \%otal } \\
\text { Injuries }\end{array}$ & $\begin{array}{c}\text { Median } \\
\text { LWDs }\end{array}$ & $\begin{array}{c}\text { Total } \\
\text { LWDs }\end{array}$ & $\begin{array}{r}\text { Total } \\
\text { LWDs }\end{array}$ \\
\hline Climatic Condition, Exposure to & 5 & 0.1 & 69.0 & 420 & 0.2 \\
Environmental Cold & & & & & \\
Electrical Shock from Hand Tool & 5 & 0.1 & 9.0 & 128 & 0.0 \\
Assaulted by Coworker & 4 & 0.1 & 11.5 & 113 & 0.0 \\
Exposure to Welding Light & 4 & 0.1 & 1.0 & 5 & 0.0 \\
Needle Puncture/Prick/Stick & 4 & 0.1 & 4.5 & 25 & 0.0 \\
Repetitive Motion - Typing, Keyboard, & 3 & 0.1 & 6.0 & 14 & 0.0 \\
etc. & & & & & \\
Stabbing, Knifing, etc. & 3 & 0.1 & 9.0 & 25 & 0.0 \\
Apprehending/Removing from Property & 2 & 0.0 & 63.5 & 127 & 0.0 \\
Horseplay, Practical Joke, etc. & 2 & 0.0 & 5.0 & 10 & 0.0 \\
Bitten by Animal & 1 & 0.0 & N/A & 25 & 0.0 \\
Caught in or Crushed In Excavation, & 1 & 0.0 & N/A & 86 & 0.0 \\
Land Slide, Cave-In, etc. & & & & & \\
Electrical Shock While Operating & 1 & 0.0 & N/A & 113 & 0.0 \\
Welding Equipment & & & & & \\
Exposure to Poisonous Plants & 1 & 0.0 & N/A & 4 & 0.0 \\
Exposure to Noise Over Time & 1 & 0.0 & N/A & 28 & 0.0 \\
Shot & 1 & 0.0 & N/A & 8 & 0.0 \\
Sustained Viewing & 1 & 0.0 & N/A & 2 & 0.0 \\
Thrill Seeking & 1 & 0.0 & N/A & 1 & 0.0 \\
Total & 4,575 & 100 & 25.0 & 276,282 & 100 \\
\hline
\end{tabular}

the act of walking, running, or stepping over accounted for the largest number of injuries (25 percent) and the greatest number of total lost workdays. The second largest number of injuries occurred while getting on, off, up or down (22 percent). Lining switches accounted for 11 percent of the injuries, while sitting or riding accounted for another 10 percent. The most severe types of physical acts as measured by the median number of LWDs were sitting or riding, and coupling and uncoupling (each had a median of 36 lost workdays).

\subsubsection{Involvement of On-Track Equipment}

The involvement of on-track equipment was then examined, in particular, the involvement of moving versus standing on-track equipment. Data are presented in Table 24 and Figure 16. Interestingly, half of all 1997 and 1998 yard LWD injuries (50 percent) involved standing ontrack equipment, while less than one-fifth of the injuries (18 percent) involved moving on-track equipment. Although injuries that involved moving on-track equipment were the most severe as 
Table 20. LWD yard injuries by higher-level triggering event, 1997 to 1998

\begin{tabular}{lcrrrr}
\hline \multicolumn{1}{c}{ Triggering Event } & \multicolumn{2}{c}{$\begin{array}{c}\text { \% of } \\
\text { Total } \\
\text { Injuries }\end{array}$} & $\begin{array}{c}\text { Median } \\
\text { Injuries }\end{array}$ & $\begin{array}{c}\text { TWDs } \\
\text { Total } \\
\text { LWDs }\end{array}$ & $\begin{array}{c}\text { \%otal } \\
\text { LWDs }\end{array}$ \\
\hline Slips, Trips, Falls and Lost Balance & 1,516 & 41.6 & 30.0 & 98,743 & 44.1 \\
Overexertion & 726 & 19.9 & 30.0 & 49,089 & 21.9 \\
Struck by or Against Object & 562 & 15.4 & 18.0 & 27,382 & 12.2 \\
Sudden/Unexpected Movement of & 217 & 6.0 & 40.0 & 15,972 & 7.1 \\
Equipment & & & & & \\
Collision/Impact (Includes Derailment) & 186 & 5.1 & 45.0 & 16,778 & 7.5 \\
Caught in/Compressed/Crushed & 172 & 4.7 & 19.5 & 6,433 & 2.9 \\
RSI & 125 & 3.4 & 22.0 & 6,608 & 3.0 \\
Exp. to Harmful Substances & 69 & 1.9 & 7.0 & 1,320 & 0.6 \\
(Fumes/Chemical) & & & & & \\
Climate/Natural Environment & 48 & 1.3 & 4.0 & 982 & 0.4 \\
Security Issues & 20 & 0.5 & 9.5 & 630 & 0.3 \\
Horseplay/Thrillseeking/Sustained & 3 & 0.1 & 4.0 & 11 & 0.0 \\
Viewing & & & & & \\
Total & 3,644 & 100 & 25.0 & 223,948 & 100 \\
\hline
\end{tabular}

indicated by the median number of lost workdays, injuries involving standing equipment resulted in over half (52 percent) of all lost workdays.

\subsubsection{Involvement of Roadbed Materials}

Roadbed materials such as ballast, ties, and switches can play a role in yard injuries, and thus were examined. Data are presented in Table 25. Switches were involved in 354 injuries, or 7.7 percent of the injuries, while ballast was involved in 304 injuries, or 6.6 percent. Ties were involved in 98 injuries, or 2.1 percent of the injuries. With respect to the severity of the injuries, ballast-related injuries resulted in the most severe injuries (median of 30 lost workdays). The total percentage of lost workdays due to roadbed materials, less than 18 percent, is not significant, however. Thus, it appears that roadbed materials were not heavily involved in yard injuries. Interestingly, there was no "rail" circumstance code from which to select.

\subsubsection{Involvement of Drugs and Alcohol}

Drugs and alcohol played a very minor part in railroad yard injuries in 1997 and 1998. No injuries were associated with positive alcohol tests while eight injuries ( 0.2 percent) were associated with positive drug use (median of 15.5 lost workdays and a total of 246 lost workdays). 
Table 21. LWD yard injuries by physical act, 1997 to 1998

\begin{tabular}{|c|c|c|c|c|c|}
\hline Physical Act & Injuries & $\begin{array}{c}\% \text { of } \\
\text { Total } \\
\text { Injuries }\end{array}$ & $\begin{array}{l}\text { Median } \\
\text { LWDs }\end{array}$ & $\begin{array}{l}\text { Total } \\
\text { LWDs }\end{array}$ & $\begin{array}{c}\% \text { of } \\
\text { Total } \\
\text { LWDs }\end{array}$ \\
\hline Adjusting Coupler & 52 & 1.1 & 21.0 & 2,660 & 1.0 \\
\hline Adjusting Drawbar & 41 & 0.9 & 60.0 & 3,701 & 1.3 \\
\hline Adjusting, Other & 74 & 1.6 & 25.0 & 5,607 & 2.0 \\
\hline Applying Rail Anchor/Fastener & 9 & 0.2 & 8.0 & 344 & 0.1 \\
\hline Bending, Stooping & 69 & 1.5 & 13.0 & 3,681 & 1.3 \\
\hline Carrying & 38 & 0.8 & 19.5 & 1,717 & 0.6 \\
\hline Chaining, Cabling Car or Locomotive & 4 & 0.1 & 17.5 & 68 & 0.0 \\
\hline Cleaning & 51 & 1.1 & 18.0 & 1,963 & 0.7 \\
\hline Climbing Over/On & 99 & 2.2 & 21.0 & 5,061 & 1.8 \\
\hline Closing & 61 & 1.3 & 20.0 & 3,331 & 1.2 \\
\hline Coupling Air Hose & 68 & 1.5 & 32.5 & 5,121 & 1.9 \\
\hline Coupling Electric Cables & 6 & 0.1 & 12.0 & 255 & 0.1 \\
\hline Coupling Steam Hose & 1 & 0.0 & $\mathrm{~N} / \mathrm{A}$ & 4 & 0.0 \\
\hline Crossing Between & 6 & 0.1 & 41.0 & 709 & 0.3 \\
\hline Crossing or Crawling Under & 2 & 0.0 & 14.0 & 28 & 0.0 \\
\hline Crossing Over & 25 & 0.5 & 9.0 & 1,781 & 0.6 \\
\hline Cutting Rail & 11 & 0.2 & 11.0 & 206 & 0.1 \\
\hline Cutting Vegetation & 2 & 0.0 & 3.0 & 6 & 0.0 \\
\hline Cutting, Other & 9 & 0.2 & 9.0 & 279 & 0.1 \\
\hline Derail, Applying & 5 & 0.1 & 22.0 & 340 & 0.1 \\
\hline Derail, Removing & 4 & 0.1 & 19.5 & 156 & 0.1 \\
\hline Digging, Excavating & 9 & 0.2 & 42.0 & 802 & 0.3 \\
\hline Driving (Motor Vehicle, Forklift, etc.) & 33 & 0.7 & 21.0 & 2,304 & 0.8 \\
\hline Flagging & 5 & 0.1 & 8.0 & 165 & 0.1 \\
\hline Fueling & 8 & 0.2 & 22.0 & 352 & 0.1 \\
\hline Getting Off & 283 & 6.2 & 28.0 & 17,413 & 6.3 \\
\hline Getting On & 111 & 2.4 & 28.0 & 6,887 & 2.5 \\
\hline Grinding & 12 & 0.3 & 2.0 & 306 & 0.1 \\
\hline Handbrake, Applying & 37 & 0.8 & 48.0 & 3,454 & 1.3 \\
\hline Handbrake, Other & 4 & 0.1 & 21.0 & 163 & 0.1 \\
\hline Handbrake, Releasing & 25 & 0.5 & 86.0 & 3,230 & 1.2 \\
\hline Handling Baggage & 4 & 0.1 & 12.5 & 70 & 0.0 \\
\hline Handling Car Parts & 25 & 0.5 & 30.0 & 1,907 & 0.7 \\
\hline Handling Locomotive Parts & 17 & 0.4 & 17.0 & 393 & 0.1 \\
\hline Handling Material, General & 31 & 0.7 & 9.0 & 910 & 0.3 \\
\hline Handling Other Track Material/Supplies & 21 & 0.5 & 18.0 & 791 & 0.3 \\
\hline Handling Rail & 19 & 0.4 & 19.0 & 632 & 0.2 \\
\hline Handling Tie Plates & 6 & 0.1 & 19.5 & 217 & 0.1 \\
\hline Handling Ties & 20 & 0.4 & 15.5 & 933 & 0.3 \\
\hline Handling Wheels/Trucks & 6 & 0.1 & 61.0 & 440 & 0.2 \\
\hline
\end{tabular}


Table 21. LWD yard injuries by physical act, 1997 to 1998 (continued)

\begin{tabular}{|c|c|c|c|c|c|}
\hline Physical Act & Injuries & $\begin{array}{c}\% \text { of } \\
\text { Total } \\
\text { Injuries }\end{array}$ & $\begin{array}{l}\text { Median } \\
\text { LWDs }\end{array}$ & $\begin{array}{l}\text { Total } \\
\text { LWDs }\end{array}$ & $\begin{array}{c}\% \text { of } \\
\text { Total } \\
\text { LWDs } \\
\end{array}$ \\
\hline Handling, Other & 49 & 1.1 & 22.0 & 3,138 & 1.1 \\
\hline Inspecting & 60 & 1.3 & 23.0 & 2,789 & 1.0 \\
\hline Installing & 50 & 1.1 & 20.5 & 2,767 & 1.0 \\
\hline Jumping From & 35 & 0.8 & 53.0 & 2,899 & 1.0 \\
\hline Jumping Onto & 5 & 0.1 & 6.0 & 106 & 0.0 \\
\hline Laying & 3 & 0.1 & 55.0 & 152 & 0.1 \\
\hline Lifting Equipment (Tools, Parts, etc.) & 78 & 1.7 & 19.5 & 4,663 & 1.7 \\
\hline Lifting Other Material & 84 & 1.8 & 17.5 & 3,445 & 1.2 \\
\hline Lining Switches & 334 & 7.3 & 29.0 & 23,801 & 8.6 \\
\hline Lining, Other & 23 & 0.5 & 19.0 & 1,433 & 0.5 \\
\hline Loading/Unloading & 57 & 1.2 & 18.0 & 2,444 & 0.9 \\
\hline Maintaining & 31 & 0.7 & 26.0 & 1,773 & 0.6 \\
\hline Opening & 64 & 1.4 & 20.5 & 3,183 & 1.2 \\
\hline Opening/Closing Angle Cock & 24 & 0.5 & 16.0 & 750 & 0.3 \\
\hline Operating & 135 & 3.0 & 30.0 & 8,987 & 3.3 \\
\hline Pulling Pin & 164 & 3.6 & 24.0 & 8,676 & 3.1 \\
\hline $\begin{array}{l}\text { Pulling Pin Lifter/Operating Uncoupling } \\
\text { Lever }\end{array}$ & 101 & 2.2 & 43.0 & 7,294 & 2.6 \\
\hline Pushing & 43 & 0.9 & 33.0 & 2,660 & 1.0 \\
\hline Reaching & 46 & 1.0 & 17.0 & 1,830 & 0.7 \\
\hline Removing Rail Anchors/Fasteners & 9 & 0.2 & 11.0 & 148 & 0.1 \\
\hline Repairing & 56 & 1.2 & 20.0 & 2,973 & 1.1 \\
\hline Riding & 239 & 5.2 & 33.0 & 16,699 & 6.0 \\
\hline Running & 14 & 0.3 & 46.5 & 1,529 & 0.6 \\
\hline Sitting & 103 & 2.3 & 41.0 & 7,505 & 2.7 \\
\hline Spiking (Installation/Removal & 42 & 0.9 & 28.5 & 2,788 & 1.0 \\
\hline Standing & 109 & 2.4 & 34.0 & 7,946 & 2.9 \\
\hline Stepping Down & 233 & 5.1 & 22.0 & 12,158 & 4.4 \\
\hline Stepping Over & 40 & 0.9 & 24.5 & 2,517 & 0.9 \\
\hline Stepping Up & 64 & 1.4 & 28.0 & 4,378 & 1.6 \\
\hline Uncoupling Air Hose & 17 & 0.4 & 63.0 & 1,687 & 0.6 \\
\hline Uncoupling Electric Cables & 5 & 0.1 & 11.0 & 180 & 0.1 \\
\hline Using Hand Tool & 72 & 1.6 & 18.0 & 2,780 & 1.0 \\
\hline Using, Other & 20 & 0.4 & 30.5 & 1,039 & 0.4 \\
\hline Walking & 762 & 16.7 & 27.5 & 47,994 & 17.4 \\
\hline Welding (Includes Field Welding) & 14 & 0.3 & 8.5 & 339 & 0.1 \\
\hline $98 *$ & 1 & 0.0 & N/A & 267 & 0.1 \\
\hline Other (Narrative Must be Provided) & 76 & 1.7 & 8.5 & 2,178 & 0.8 \\
\hline Total & 4,575 & 100 & 25.0 & 276,282 & 100 \\
\hline
\end{tabular}


Table 22. LWD yard injuries by physical act and sorted by the number of injuries, 1997 to 1998

\begin{tabular}{|c|c|c|c|c|c|}
\hline Physical Act & Injuries & $\begin{array}{c}\% \text { of } \\
\text { Total } \\
\text { Injuries }\end{array}$ & $\begin{array}{l}\text { Median } \\
\text { LWDs }\end{array}$ & $\begin{array}{c}\text { Total } \\
\text { LWDs }\end{array}$ & $\begin{array}{l}\% \text { of } \\
\text { Total } \\
\text { LWDs }\end{array}$ \\
\hline Walking & 762 & 16.7 & 27.5 & 47,994 & 17.4 \\
\hline Lining Switches & 334 & 7.3 & 29.0 & 23,801 & 8.6 \\
\hline Getting Off & 283 & 6.2 & 28.0 & 17,413 & 6.3 \\
\hline Riding & 239 & 5.2 & 33.0 & 16,699 & 6.0 \\
\hline Stepping Down & 233 & 5.1 & 22.0 & 12,158 & 4.4 \\
\hline Pulling Pin & 164 & 3.6 & 24.0 & 8,676 & 3.1 \\
\hline Operating & 135 & 3.0 & 30.0 & 8,987 & 3.3 \\
\hline Getting On & 111 & 2.4 & 28.0 & 6,887 & 2.5 \\
\hline Standing & 109 & 2.4 & 34.0 & 7,946 & 2.9 \\
\hline Sitting & 103 & 2.3 & 41.0 & 7,505 & 2.7 \\
\hline $\begin{array}{l}\text { Pulling Pin Lifter/Operating Uncoupling } \\
\text { Lever }\end{array}$ & 101 & 2.2 & 43.0 & 7,294 & 2.6 \\
\hline Climbing Over/On & 99 & 2.2 & 21.0 & 5,061 & 1.8 \\
\hline Lifting Other Material & 84 & 1.8 & 17.5 & 3,445 & 1.2 \\
\hline Lifting Equipment (Tools, Parts, etc.) & 78 & 1.7 & 19.5 & 4,663 & 1.7 \\
\hline Other (Narrative Must be Provided) & 76 & 1.7 & 8.5 & 2,178 & 0.8 \\
\hline Adjusting, Other & 74 & 1.6 & 25.0 & 5,607 & 2.0 \\
\hline Using Hand Tool & 72 & 1.6 & 18.0 & 2,780 & 1.0 \\
\hline Bending, Stooping & 69 & 1.5 & 13.0 & 3,681 & 1.3 \\
\hline Coupling Air Hose & 68 & 1.5 & 32.5 & 5,121 & 1.9 \\
\hline Opening & 64 & 1.4 & 20.5 & 3,183 & 1.2 \\
\hline Stepping Up & 64 & 1.4 & 28.0 & 4,378 & 1.6 \\
\hline Closing & 61 & 1.3 & 20.0 & 3,331 & 1.2 \\
\hline Inspecting & 60 & 1.3 & 23.0 & 2,789 & 1.0 \\
\hline Loading/Unloading & 57 & 1.2 & 18.0 & 2,444 & 0.9 \\
\hline Repairing & 56 & 1.2 & 20.0 & 2,973 & 1.1 \\
\hline Adjusting Coupler & 52 & 1.1 & 21.0 & 2,660 & 1.0 \\
\hline Cleaning & 51 & 1.1 & 18.0 & 1,963 & 0.7 \\
\hline Installing & 50 & 1.1 & 20.5 & 2,767 & 1.0 \\
\hline Handling, Other & 49 & 1.1 & 22.0 & 3,138 & 1.1 \\
\hline Reaching & 46 & 1.0 & 17.0 & 1,830 & 0.7 \\
\hline Pushing & 43 & 0.9 & 33.0 & 2,660 & 1.0 \\
\hline Spiking (Installation/Removal & 42 & 0.9 & 28.5 & 2,788 & 1.0 \\
\hline Adjusting Drawbar & 41 & 0.9 & 60.0 & 3,701 & 1.3 \\
\hline Stepping Over & 40 & 0.9 & 24.5 & 2,517 & 0.9 \\
\hline Carrying & 38 & 0.8 & 19.5 & 1,717 & 0.6 \\
\hline Handbrake, Applying & 37 & 0.8 & 48.0 & 3,454 & 1.3 \\
\hline Jumping From & 35 & 0.8 & 53.0 & 2,899 & 1.0 \\
\hline Driving (Motor Vehicle, Forklift, etc.) & 33 & 0.7 & 21.0 & 2,304 & 0.8 \\
\hline Handling Material, General & 31 & 0.7 & 9.0 & 910 & 0.3 \\
\hline Maintaining & 31 & 0.7 & 26.0 & 1,773 & 0.6 \\
\hline
\end{tabular}


Table 22. LWD yard injuries by physical act and sorted by the number of injuries, 1997 to 1998 (continued)

\begin{tabular}{|c|c|c|c|c|c|}
\hline Physical Act & Injuries & $\begin{array}{c}\text { \% of } \\
\text { Total } \\
\text { Injuries }\end{array}$ & $\begin{array}{l}\text { Median } \\
\text { LWDs }\end{array}$ & $\begin{array}{c}\text { Total } \\
\text { LWDs }\end{array}$ & $\begin{array}{l}\text { \% of } \\
\text { Total } \\
\text { LWDs }\end{array}$ \\
\hline Crossing Over & 25 & 0.5 & 9.0 & 1,781 & 0.6 \\
\hline Handling Car Parts & 25 & 0.5 & 30.0 & 1,907 & 0.7 \\
\hline Handbrake, Releasing & 25 & 0.5 & 86.0 & 3,230 & 1.2 \\
\hline Opening/Closing Angle Cock & 24 & 0.5 & 16.0 & 750 & 0.3 \\
\hline Lining, Other & 23 & 0.5 & 19.0 & 1,433 & 0.5 \\
\hline Handling Other Track Material/Supplies & 21 & 0.5 & 18.0 & 791 & 0.3 \\
\hline Handling Ties & 20 & 0.4 & 15.5 & 933 & 0.3 \\
\hline Using, Other & 20 & 0.4 & 30.5 & 1,039 & 0.4 \\
\hline Handling Rail & 19 & 0.4 & 19.0 & 632 & 0.2 \\
\hline Handling Locomotive Parts & 17 & 0.4 & 17.0 & 393 & 0.1 \\
\hline Uncoupling Air Hose & 17 & 0.4 & 63.0 & 1,687 & 0.6 \\
\hline Running & 14 & 0.3 & 46.5 & 1,529 & 0.6 \\
\hline Welding (Includes Field Welding) & 14 & 0.3 & 8.5 & 339 & 0.1 \\
\hline Grinding & 12 & 0.3 & 2.0 & 306 & 0.1 \\
\hline Cutting Rail & 11 & 0.2 & 11.0 & 206 & 0.1 \\
\hline Applying Rail Anchor/Fastener & 9 & 0.2 & 8.0 & 344 & 0.1 \\
\hline Cutting, Other & 9 & 0.2 & 9.0 & 279 & 0.1 \\
\hline Digging, Excavating & 9 & 0.2 & 42.0 & 802 & 0.3 \\
\hline Removing Rail Anchors/Fasteners & 9 & 0.2 & 11.0 & 148 & 0.1 \\
\hline Fueling & 8 & 0.2 & 22.0 & 352 & 0.1 \\
\hline Coupling Electric Cables & 6 & 0.1 & 12.0 & 255 & 0.1 \\
\hline Crossing Between & 6 & 0.1 & 41.0 & 709 & 0.3 \\
\hline Handling Wheels/Trucks & 6 & 0.1 & 61.0 & 440 & 0.2 \\
\hline Handling Tie Plates & 6 & 0.1 & 19.5 & 217 & 0.1 \\
\hline Flagging & 5 & 0.1 & 8.0 & 165 & 0.1 \\
\hline Jumping Onto & 5 & 0.1 & 6.0 & 106 & 0.0 \\
\hline Uncoupling Electric Cables & 5 & 0.1 & 11.0 & 180 & 0.1 \\
\hline Derail, Applying & 5 & 0.1 & 22.0 & 340 & 0.1 \\
\hline Chaining, Cabling Car or Locomotive & 4 & 0.1 & 17.5 & 68 & 0.0 \\
\hline Handling Baggage & 4 & 0.1 & 12.5 & 70 & 0.0 \\
\hline Handbrake, Other & 4 & 0.1 & 21.0 & 163 & 0.1 \\
\hline Derail, Removing & 4 & 0.1 & 19.5 & 156 & 0.1 \\
\hline Laying & 3 & 0.1 & 55.0 & 152 & 0.1 \\
\hline Crossing or Crawling Under & 2 & 0.0 & 14.0 & 28 & 0.0 \\
\hline Cutting Vegetation & 2 & 0.0 & 3.0 & 6 & 0.0 \\
\hline Coupling Steam Hose & 1 & 0.0 & N/A & 4 & 0.0 \\
\hline $98 *$ & 1 & 0.0 & N/A & 267 & 0.1 \\
\hline Total & 4,575 & 100 & 25.0 & 276,282 & 100 \\
\hline
\end{tabular}


Table 23. LWD yard injuries by higher-level physical act, 1997 to 1998

\begin{tabular}{|c|c|c|c|c|c|}
\hline Physical Act & Injuries & $\begin{array}{c}\% \text { of } \\
\text { Total } \\
\text { Injuries }\end{array}$ & $\begin{array}{l}\text { Median } \\
\text { LWDs }\end{array}$ & $\begin{array}{c}\text { Total } \\
\text { LWDs }\end{array}$ & $\begin{array}{l}\% \text { of } \\
\text { Total } \\
\text { LWDs }\end{array}$ \\
\hline Walking/Running/Stepping Over & 816 & 25.0 & 28.0 & 52,040 & 25.3 \\
\hline On/Off/Up/Down & 731 & 22.4 & 26.0 & 43,841 & 21.3 \\
\hline Lining Switches/Other & 357 & 10.9 & 29.0 & 25,234 & 12.3 \\
\hline Sitting/Riding & 342 & 10.5 & 36.0 & 24,204 & 11.8 \\
\hline Pull/Push & 308 & 9.4 & 29.5 & 18,630 & 9.1 \\
\hline Lift/Load & 219 & 6.7 & 18.0 & 10,552 & 5.1 \\
\hline Handling (Materials) & 198 & 6.1 & 19.0 & 9,431 & 4.6 \\
\hline Coupling/Uncoupling & 190 & 5.8 & 36.0 & 13,608 & 6.6 \\
\hline Standing & 109 & 3.3 & 34.0 & 7,946 & 3.9 \\
\hline Total & 3,270 & 100 & 27.0 & 205,486 & 100 \\
\hline
\end{tabular}

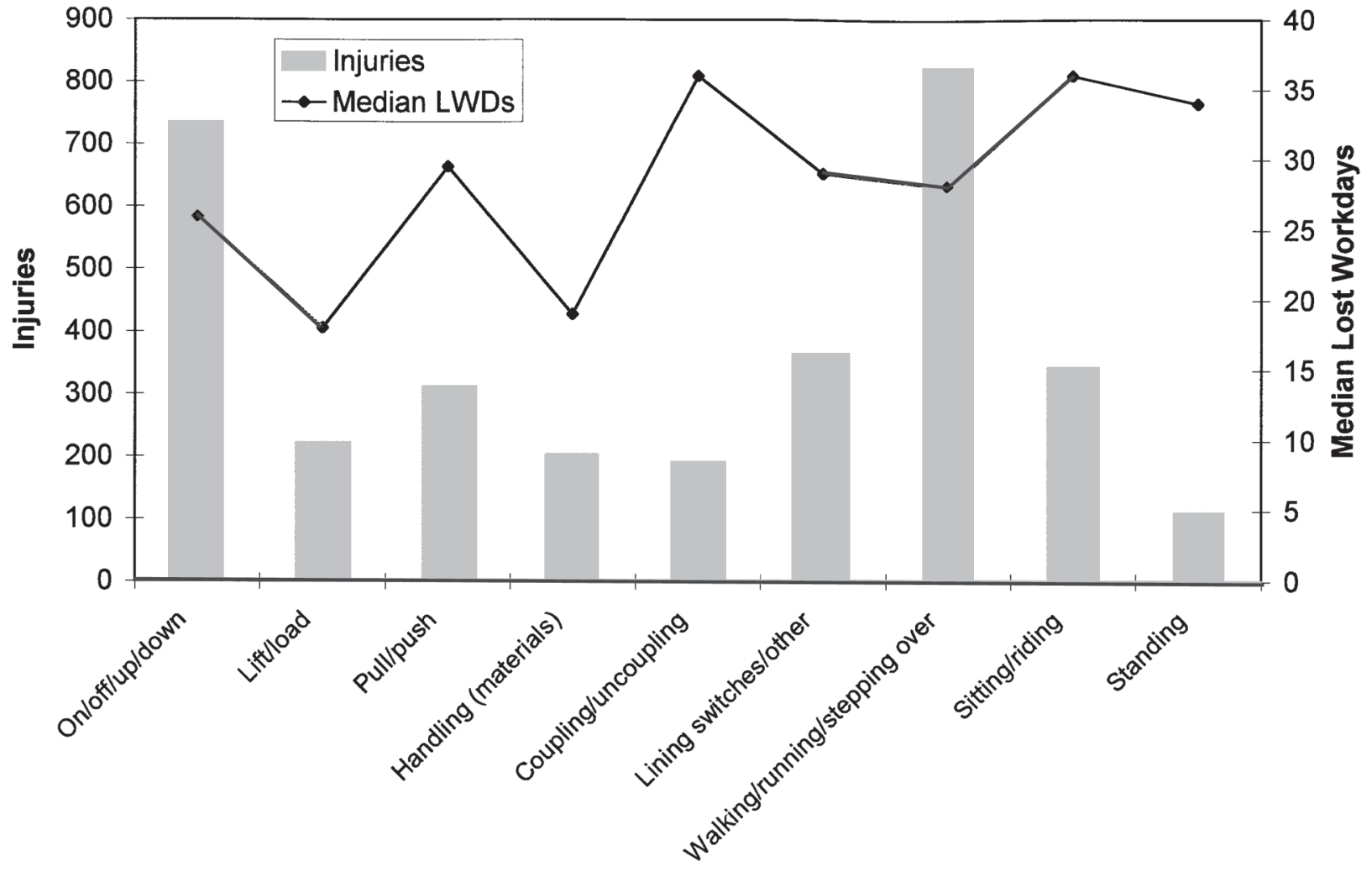

Physical Act

Figure 15. LWD yard injuries by physical act, 1997 to 1998 
Table 24. LWD yard injuries by involvement of on-track equipment, 1997 to 1998

\begin{tabular}{lccccc}
\hline $\begin{array}{c}\text { On-Track } \\
\text { Equipment }\end{array}$ & Injuries & $\begin{array}{c}\text { \% of Total } \\
\text { Injuries }\end{array}$ & $\begin{array}{c}\text { Median } \\
\text { LWDs }\end{array}$ & $\begin{array}{c}\text { Total } \\
\text { LWDs }\end{array}$ & $\begin{array}{c}\text { \% of Total } \\
\text { LWDs }\end{array}$ \\
\hline \multirow{3}{*}{ Standing } & 2,297 & 50.2 & 26 & 145,068 & 52.5 \\
None & 1,170 & 25.6 & 20 & 57,564 & 20.8 \\
Moving & 823 & 18.0 & 30 & 57,690 & 20.9 \\
Other & 285 & 6.2 & 24 & 15,960 & 5.8 \\
Total & 4,575 & 100 & 25 & 276,282 & 100 \\
& & & & & \\
\hline
\end{tabular}

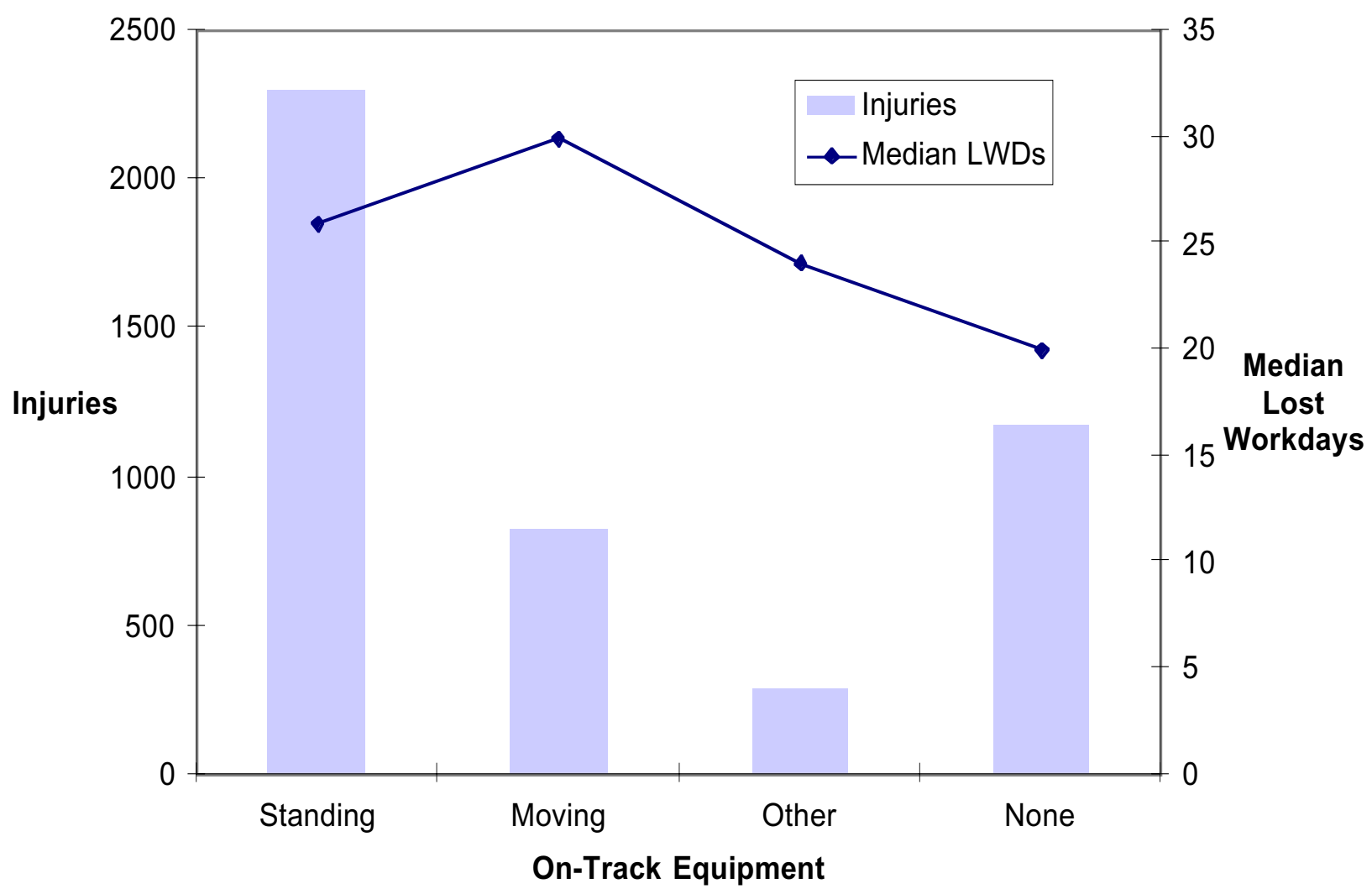

Figure 16. LWD yard injuries by involvement of on-track equipment, 1997 to 1998 
Table 25. LWD yard injuries by involvement of roadbed materials, 1997 to 1998

\begin{tabular}{lccccc}
\hline \multicolumn{1}{c}{ Material } & Injuries & $\begin{array}{c}\text { \% of Total } \\
\text { Injuries }\end{array}$ & $\begin{array}{c}\text { Median } \\
\text { LWDs }\end{array}$ & $\begin{array}{c}\text { Total } \\
\text { LWDs }\end{array}$ & $\begin{array}{c}\text { \% of Total } \\
\text { LWDs }\end{array}$ \\
\hline Switches & 354 & 7.7 & 25.0 & 24,305 & 8.8 \\
Ballast & 304 & 6.6 & 30.0 & 19,583 & 7.1 \\
Ties & 98 & 2.1 & 14.5 & 4,743 & 1.7 \\
& & & & & \\
\hline
\end{tabular}

\subsubsection{Involvement of Hazardous Materials}

Thirteen injuries ( 0.3 percent) involved hazmat exposure, resulting in a total of 278 lost workdays (a median of four lost workdays). Thus, hazmat exposure also played a minimal role in yard lost workday injuries.

\subsubsection{Injury "Cause"}

The FRA provides railroads with an opportunity to provide the probable reason for each injury or illness (i.e., attribute causality). According to the data, almost one-third of all yard lost workday injuries is attributable to a "human factor" ( $n=1467$ injuries, or 32 percent). These injuries resulted in a median of 30 lost workdays and a total of 99,614 lost workdays (36 percent of all lost workdays). Several of the other "cause" codes may also be considered "human factor" such as "safety equipment not worn or in place," "procedures for operating/using equipment not followed," "impairment, substance abuse," and "impairment, physical condition, e.g., fatigue." In fact, "human factor" is a broad category, and the FRA does not provide railroads with a clear definition, nor examples, of what is a "human factor" cause or injury.

\subsection{Comparison of Railroad Yard Injuries to Private Industry Injuries}

To gain an appreciation of the relative frequency and severity of the injuries occurring in railroad yards, data on the number, type, and severity of railroad-wide injuries and yard-specific injuries were compared to injury data from private industries based on data from the Department of Labor's Bureau of Labor Statistics (BLS). Since 1997 was the most recent year that these statistics were available from the BLS at the time of the analyses, only 1997 railroad injury data were used in the comparative analyses. The focus of this comparison is on private industry and railroad yard injuries that result in one or more days away from work (DAFW). A DAFW injury results when the injured employee misses at least one day of work, regardless of the length of restricted duty. The number of DAFW includes both days absent and days of restricted duty, however. The BLS collects data on a variety of injury characteristics on private industry DAFW injuries, including the type of injury, affected body part, triggering event, age, and median number of DAFW. DAFW injuries are essentially a large subset of LWD injuries, since a LWD injury occurs if it results in at least one day of absence or one day of restricted duty. Results from the comparisons between the railroad yard DAFW injuries and private industry DAFW injuries are discussed below. 
Table 26 presents a comparison of 1997 occupational injuries and illnesses for selected industries, including the railroad industry and railroad yard environment. Injuries occurring in the railroad industry, including railroad yards, are more severe than those occurring in private industry as a whole, as measured by the percentage of total injuries that resulted in one or more days away from work (i.e., days absent), or DAFW. Sixty-five percent (65 percent) of railroad injuries, and 68 percent of railroad yard injuries, resulted in one or more DAFW, compared to 30 percent for private industry overall. The mining industry appears closest to the railroad yard environment, with roughly 50 percent of injuries resulting in at least one DAFW. One explanation for the discrepancy between the railroad industry and other industries is that it is possible that railroad employees are underreporting the less severe injuries, thus inflating the proportion of total injuries that resulted in one or more DAFW.

Table 27 presents the percent distributions of nonfatal occupational injuries for selected industries and age groups for days-away-from-work injuries. In private industry, the greatest percentage of DAFW injuries occurred in the 25 to 34 year old category (the 35 to 44 year old category had a similar percentage, 28.2 percent), while for the railroad industry, and yard environment in particular, the greatest percentage of DAFW injuries occurred in the 45 to 54 year old category. The discrepancy between the railroad industry and other industries may be due to the difference in proportions of employees in each age group. Unfortunately, data are not available to discern the percentages or proportions of employees in each age group for most industries. ${ }^{9}$ However, these data are collected by the Railroad Retirement Board (RRB) and thus are available for the railroad industry. Based on RRB data for 1997, the largest percentage of railroad employees fell into the 45 to 54 year old age category (38.4 percent) and the largest percentage of DAFW yard injuries also fell into the 45 to 54 year old age category (37.7 percent). Though data is not available specifically for the ages of those working in and around railroad yards, it is assumed that the proportions of employees in each age bracket are similar to those industry-wide. Without knowing the age distributions of employees for other industries, it is difficult to compare the effects of age on DAFW injuries in the railroad industry with injuries suffered by employees in other industries.

Table 28 presents the percent distributions of nonfatal occupational injuries for selected industries and types of injury for DAFW injuries. The railroad industry, and the yard environment specifically, compare similarly to private industry as a whole. The greatest percentage of DAFW injuries in private industry as a whole, and the railroad industry, including yard injuries, resulted in sprains and strains: 55 percent for the railroad industry, 59 percent for the yard environment specifically, and 44 percent for private industry as a whole. In general, the railroad industry and yard environment result in greater percentages of sprains and strains, fractures, cuts and lacerations, and bruises and contusions, than private industry as a whole, though the differences are small. In all, these four types of injuries made up 86 to 88 percent of railroad DAFW injuries compared to only 66 percent of DAFW injuries in private industry as a whole.

\footnotetext{
${ }^{9}$ Neither the BLS nor MSHA, the Mining Safety and Health Administration, routinely collect age-specific data on active employees for any industries.
} 


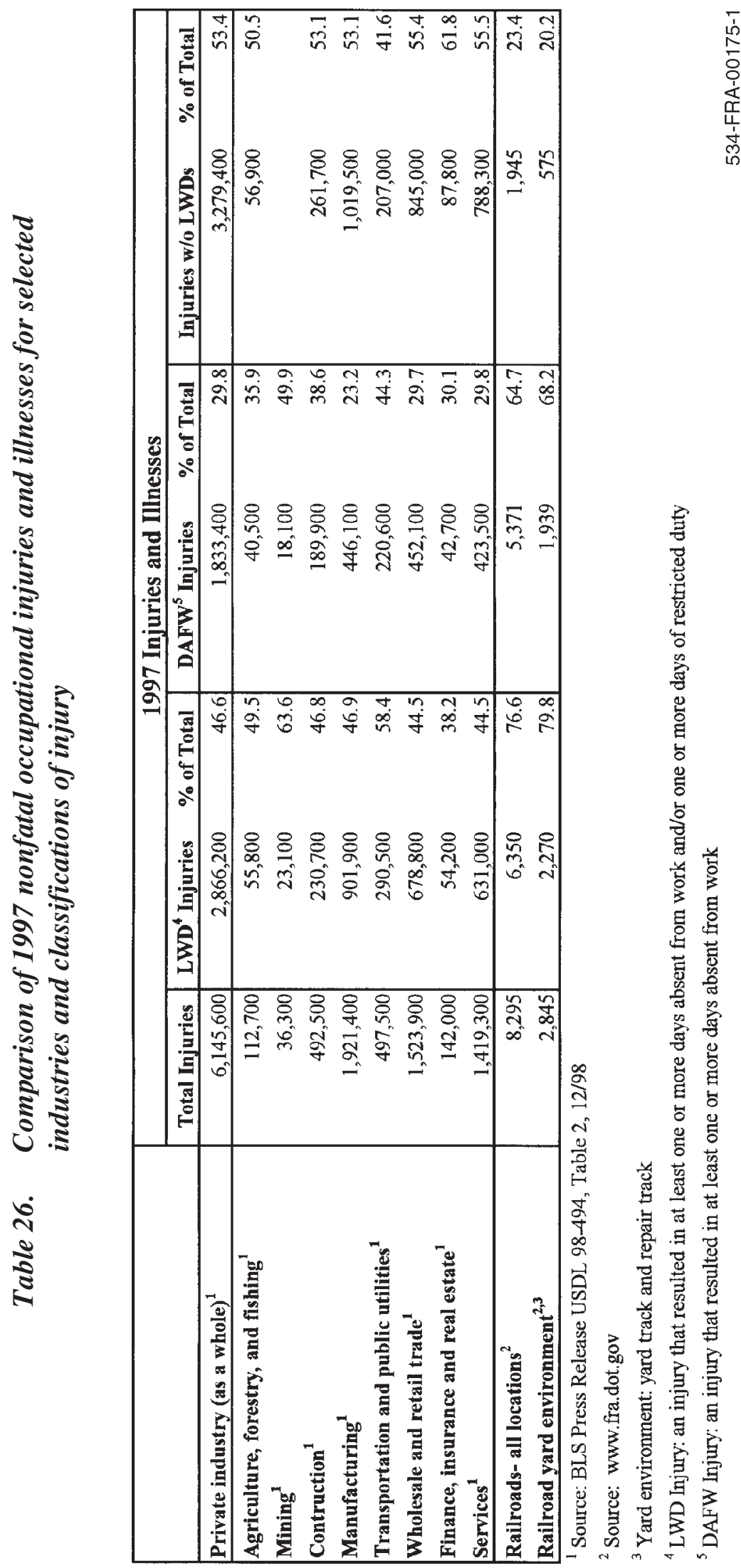




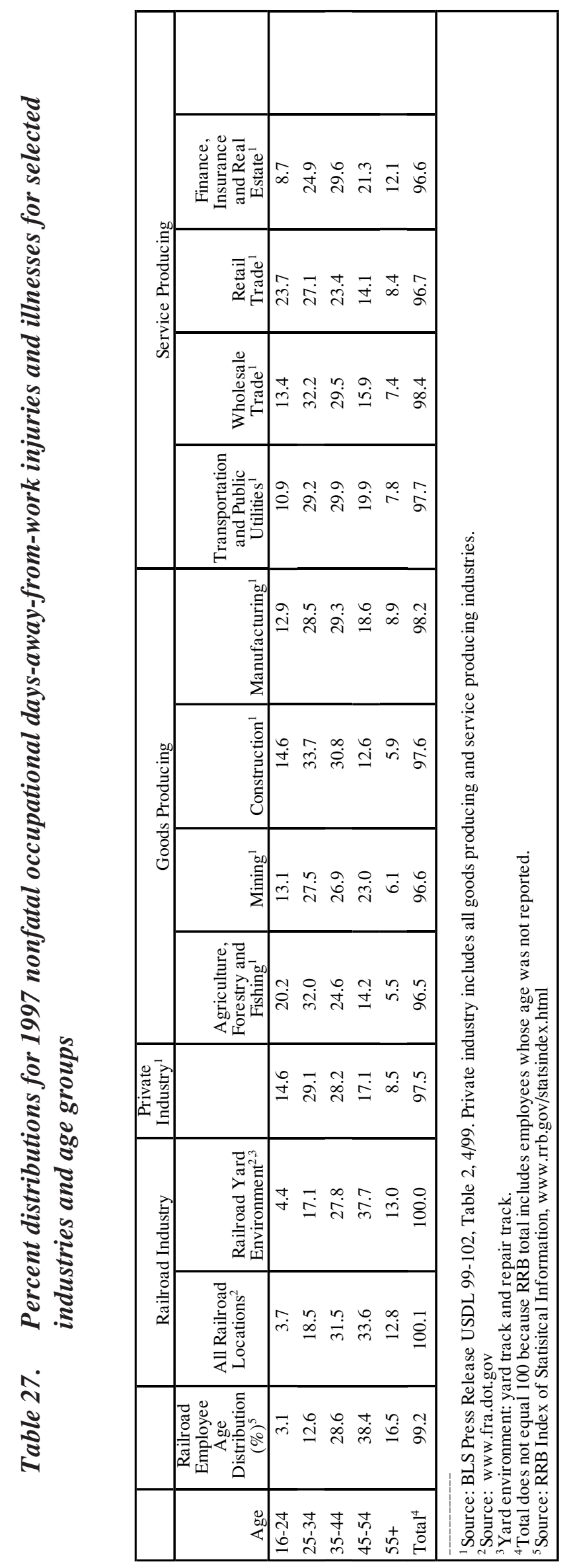




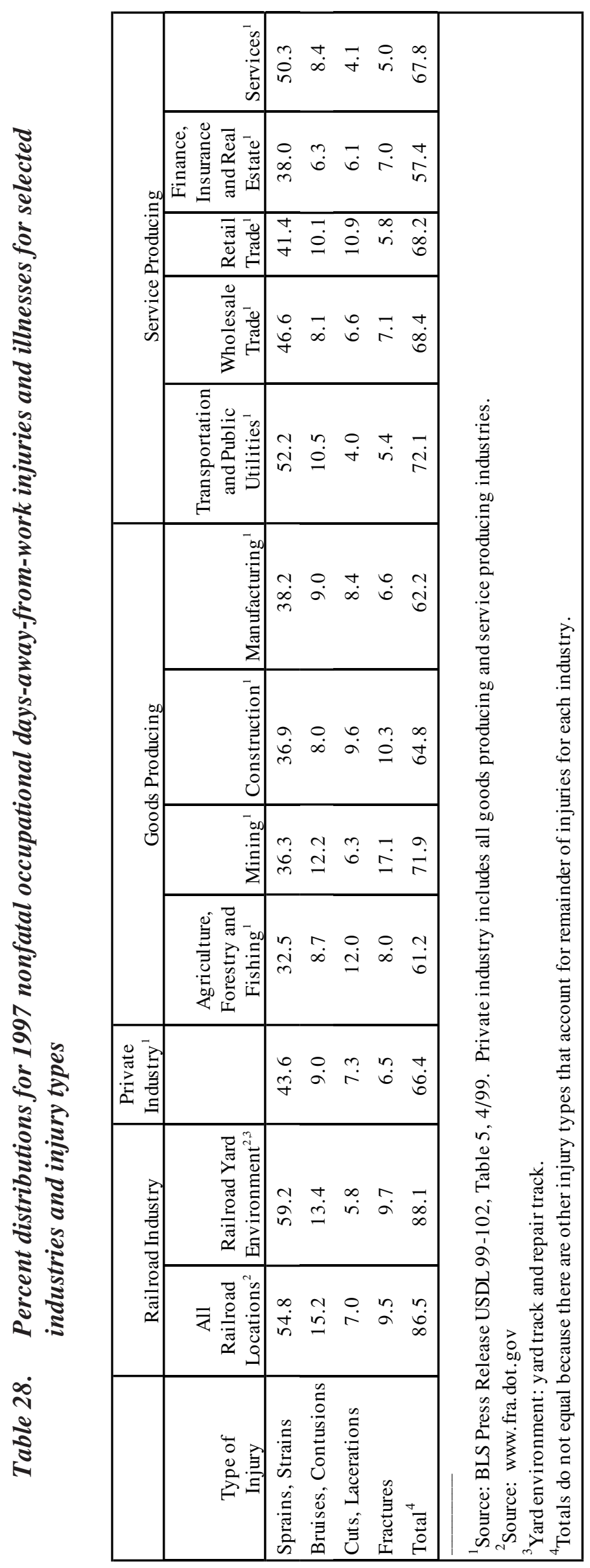


Table 29 presents the percent distributions of nonfatal DAFW occupational injuries for selected industries and body parts affected. The trunk (or torso) is the most frequently affected body part in all industries. Interestingly, in private industry, there are equal proportions of upper and lower extremity injuries, while in the railroad industry and yard environment specifically, there are twice as many lower extremity injuries than upper extremity injuries. This difference may be due to the fact that railroad employees, particularly the T\&E crews, do a lot of walking in and around yards and tracks, where there are many lower extremity hazards.

Table 30 presents the percent distributions of nonfatal DAFW occupational injuries for selected industries and events that resulted in the injury. Slips, trips and falls accounted for the single greatest percentage of DAFW injuries in the railroad industry as a whole (29 percent) and in the yard (34 percent), while overexertion and being crushed by or struck by equipment or objects accounted for the two greatest percentages of DAFW injuries in private industry as a whole (28 percent and 27 percent respectively). In fact, there were fewer percentages of DAFW injuries resulting from overexertion, being crushed by or struck by equipment or objects, repetitive stress injuries (RSIs) and exposure to harmful substances, in the railroad industry and yard environment, than in private industry as a whole.

Table 31 presents the percent distributions of nonfatal DAFW occupational injuries for selected categories of DAFW and age groups. The DAFW categories (e.g., 1,2,3 to 5,6 to 10, etc.) match those that are used by the BLS. A majority of private industry DAFW injuries resulted in 10 or fewer days away from work, regardless of the age group, while a majority of railroad industry and yard specific injuries resulted in 31 or more days away from work. However, the proportion of injuries resulting in 31 or more days away from work increases with age for both the railroad industry (including the yard environment) and private industry as a whole.

Table 32 presents the percent distributions of nonfatal DAFW occupational injuries for selected categories of DAFW and industries. The railroad industry, and yard environment specifically, are associated with twice the percentage of injuries resulting in 31 or more days away from work as compared to private industry as a whole. However, the mining industry mirrors very closely the railroad industry and yard environment with respect to the percentage of injuries in each DAFW category. For example, 34 percent of mining injuries in 1997 resulted in 31 or more days away from work, compared to 38 percent and 43 percent of railroad industry and yard environment injuries, respectively (this compared to only 18 percent of private industry injuries).

The median number of days away from work for private industry was five, while for the railroad industry it was 18 (and injuries in the yard resulted in a median of 22 days away from work). Of the specific industries reported by the BLS, again mining most closely matches the railroad industry, with mining injuries resulting in a median of 18 days away from work.

Thus, overall, the types and severities of injuries sustained in the railroad industry overall and the railroad yard environment specifically appear to be different than those injuries sustained in private industry as a whole. The specific industry that most closely matches the type and severity of injuries occurring in the railroad industry and railroad yard environments is the 


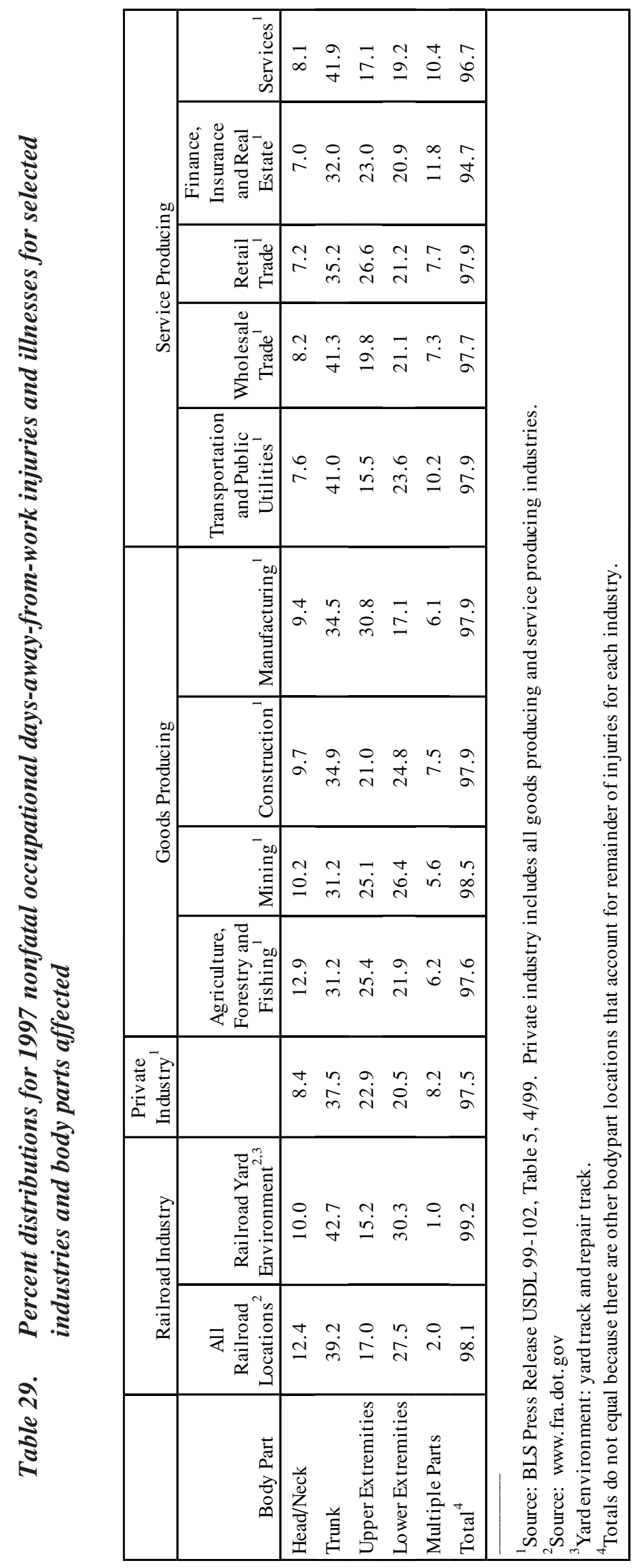




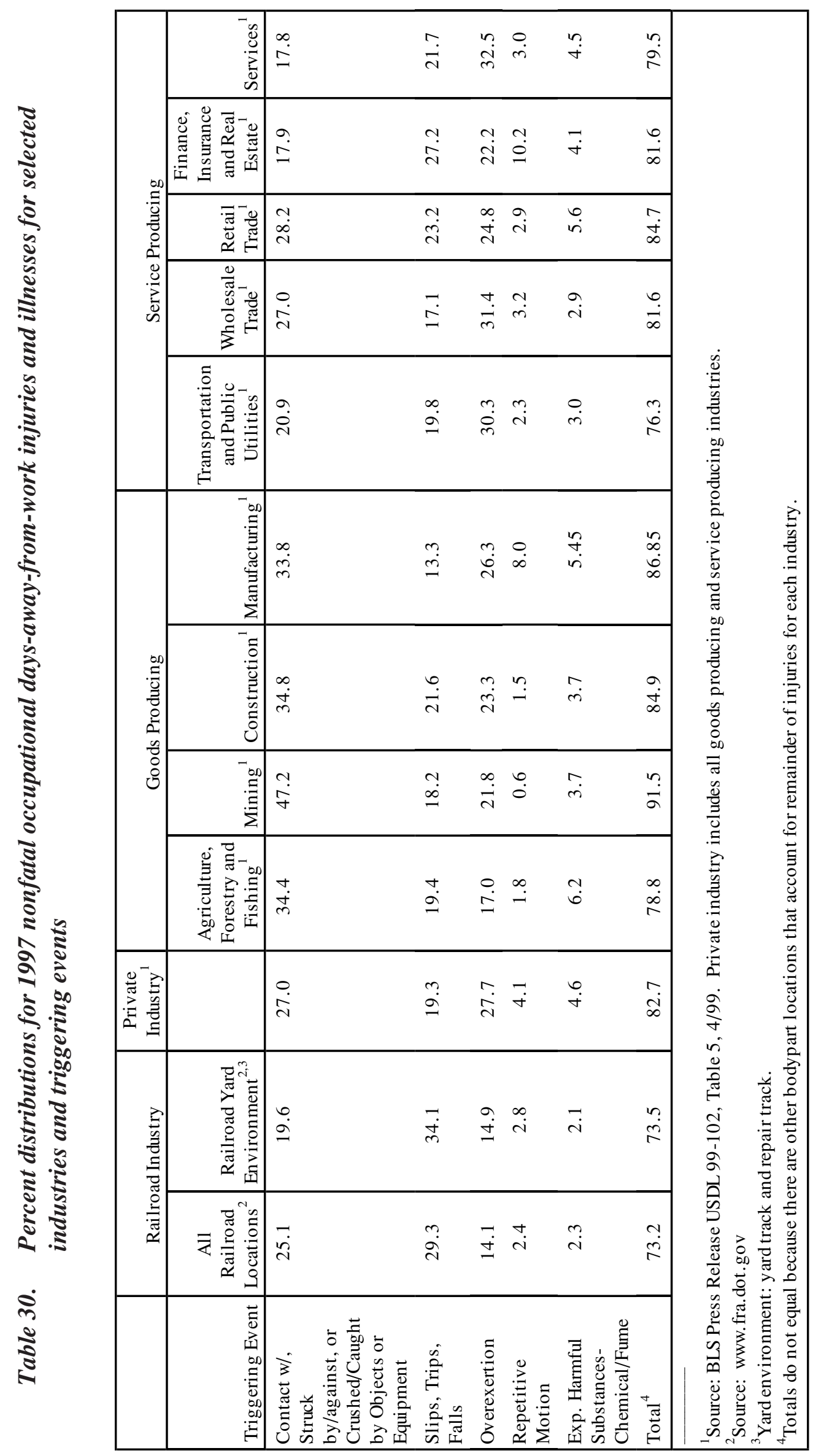



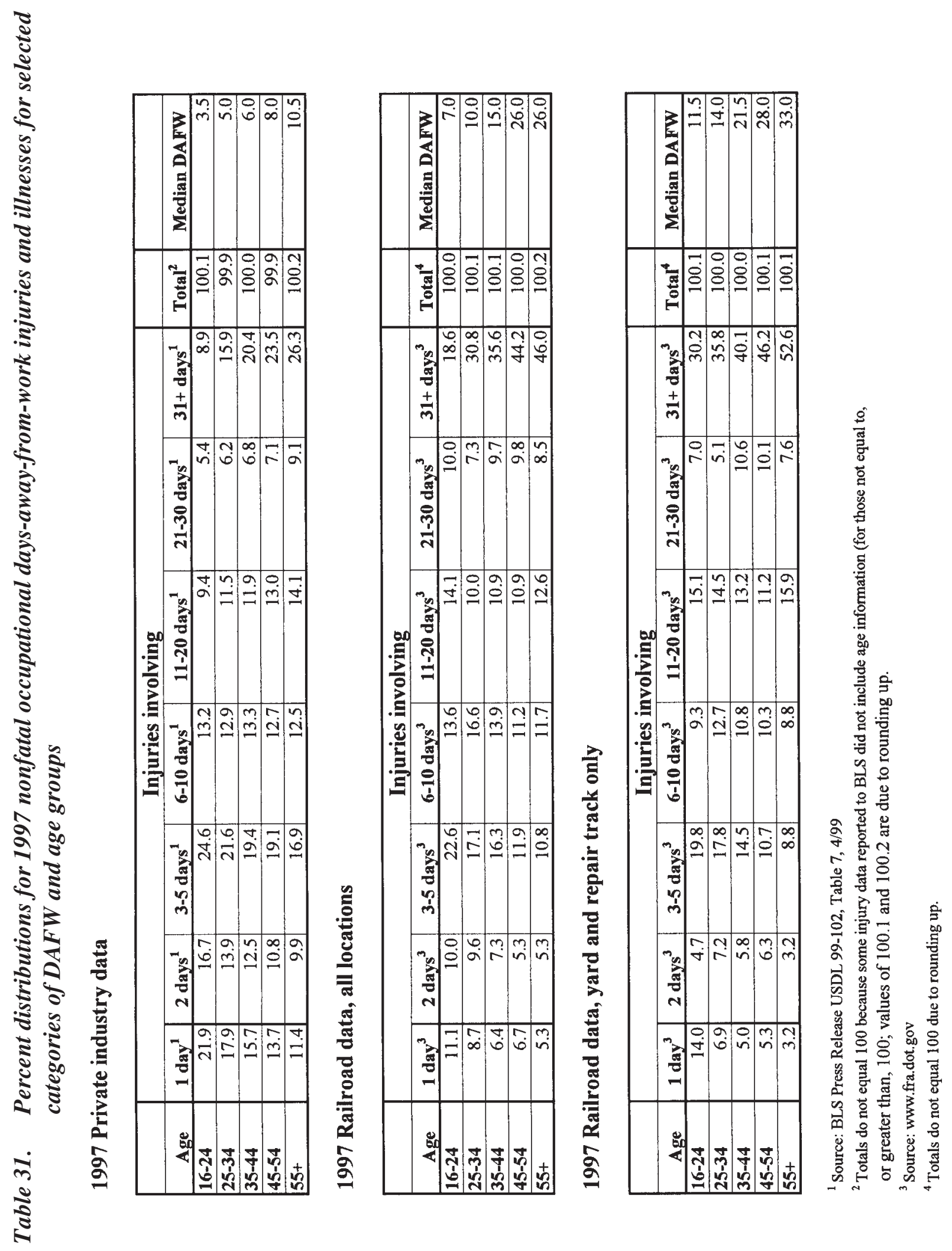


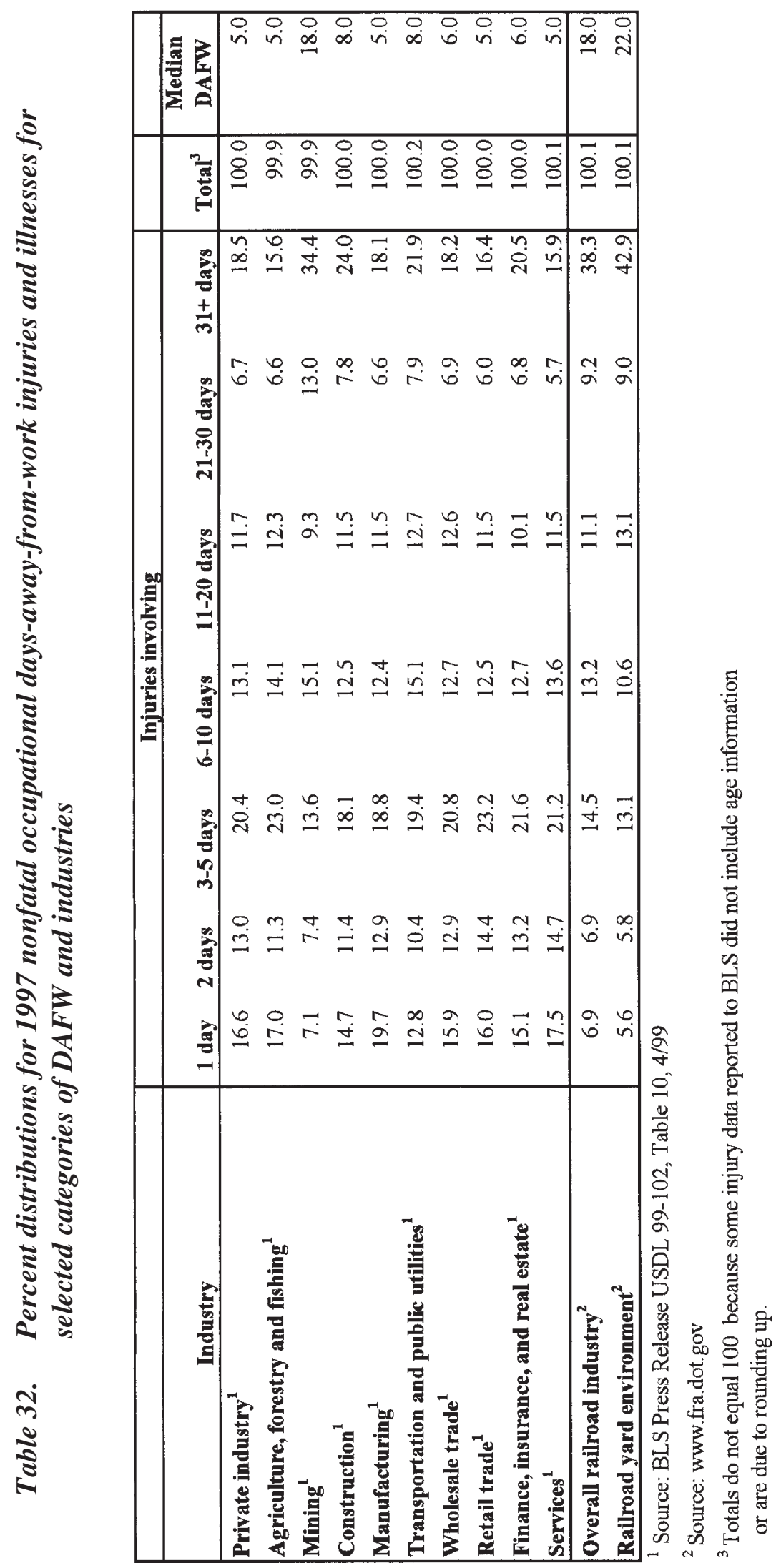


mining industry. Both mining and railroading involve substantial manual labor and both involve working around heavy equipment.

\subsection{Discussion}

Subsection 4.5 presents some of the key findings from the analyses of the FRA accident and injury data and discusses some of the limitations of both the accident and injury data and the analytical methods that were used.

\subsubsection{Key Findings}

There are several key findings based on the analyses of the human factor-attributed yard train accidents and yard LWD injuries. They are discussed below.

\section{Comparison of Yard Injuries To Railroad and Other Industries}

The railroad yard environment appears to pose more risk of a serious injury than either the railroad industry as a whole or private industry. Specifically, 80 percent of railroad yard injuries resulted in at least one or more LWDs, compared to 77 percent of railroad-wide injuries and 47 percent of private industry injuries. When examining DAFW injuries (the standard BLS metric used to measure injury severity in private industry), 68 percent of railroad yard injuries resulted in at least one or more DAFW compared to 65 percent railroad-wide and only 30 percent of private industry injuries. Private industry injuries in 1997 resulted in a median of five DAFW compared to $22 \mathrm{DAFW}$ for yard injuries and 18 for injuries railroad-wide. Of all private industries, the most similar to the yard and railroad environment is mining. Sixty-four percent of mining injuries resulted in one or more LWDs, 50 percent of mining injuries resulted in one or more DAFW, and the median number of DAFW in the mining industry in 1997 was 18.

\section{Characteristics of Yard Injuries}

Sprains and strains accounted for more than half (58 percent) of the LWD yard injuries; the trunk/torso was the most affected body part (42 percent of LWD yard injuries); slips, trips and falls were the most common triggering event (42 percent of LWD yard injuries); and the acts of walking, running, or stepping over were the leading physical acts associated with LWD yard injuries (25 percent of LWD yard injuries).

\section{Monthly Differences}

The month of July was associated with a high number of both human factor-attributed yard train accidents per million switching miles and LWD yard injuries per million switching miles. The heat associated with the month of July may play a factor in the accident and injury rate, however, the fact that June and August were associated with substantially fewer accidents and injuries argues against this explanation. 


\section{Diurnal Differences}

The hours of 10 a.m. to 12 p.m. were associated with the greatest number of LWD yard injuries and a relatively large number of human factor-attributed train accidents. This may be a function of exposure (e.g., traffic volume, increased crews working). Interestingly, the hours between 2 a.m. and 4 a.m. are associated with a large number of human factor-attributed train accidents but relatively few LWD yard injuries. One would expect to find an increase during this time in both human factor-attributed train accidents and LWD yard injuries due to circadian factors. However, this is not the case. Exposure data would help to interpret both the accident and injury results.

\section{Age Differences}

Employees younger than 35 suffer a disproportionate percentage of the LWD yard injuries relative to their proportion within the workforce. This assumes that the age distribution of the yard workforce is the same as the age distribution industry-wide.

\section{Temperature and Human Factor-Attributed Train Accidents}

Human factor-attributed train accidents in railroad yards appear to be, at least in part, a function of ambient temperature. Specifically, it was found that more train accidents occurred during colder and hotter temperatures than during the milder temperatures. The quadratic equation, $y=8.0244 x^{2}-73.822 x+148.37$, where $x$ represents temperature and y represents the number of train accidents, may serve as an adequate predictor of human factor-attributed train accidents in yards.

\subsubsection{Limitations of the FRA Accident and Injury Data Analyses}

There are several limitations to the FRA accident and injury databases and the analytical methods that were used. These limitations are organized around three main themes: Data, definitions, and comparisons to other industries. Each is discussed below.

- Limitations to the Current FRA Accident and Injury Data

- Missing variables of interest. There are several injury and accident-related variables that are missing from the accident and injury databases, but that may be important to understanding the accident and injury process. These variables include, but are not limited to, the amount of railroad experience of the injured employee, the number of hours the employee was on duty (time-on-task) at the time of the injury (this data is collected for accidents but not injuries), and pre-injury or pre-accident work schedule data for the injured employee and any crew members who are associated with a human factor-attributed train accident.

- Minimal exposure data. The only exposure data that were available were the number of switching miles per month. A surrogate age exposure measure, RRB industry-wide age 
distribution data, was used as an exposure measure for railroad yard injuries, but the adequacy of this exposure measure depends on how well the industry-wide age distribution matches the age distribution of railroad yard work forces. No other exposure measures, or surrogate exposure measures, were available.

- Shortcomings of FRA Accident and Injury Variable Definitions

- Definition of "days absent." The number of days absent that are reported to the FRA depends on the regularity or irregularity of the injured employee's work schedule, not strictly the amount of time the injury incapacitates the injured person. Specifically, according to the FRA Guide for Preparing Accident/Incident Reports, "For an employee on an irregular assignment, all days away from work or days of restriction are to be counted from the time the employee marked off until the time he or she marked up" (FRA, 1997, Ch. 6, p. 14). This differs from an individual who is scheduled to work five out of every seven days. For example, assume an injury causes two individuals to be incapacitated for 14 consecutive days each. If one of the employees worked a regular schedule with two days off per week, the number of days absent for this employee would be 10. If the second employee worked an irregular schedule, then the number of days absent that would be reported would be 14 . Thus, the number of reported days absent is a function of both the true severity of the injury and the injured employee's work schedule.

- No "rail" circumstance code. When reporting information on FRA Form F 6180.55a about what materials were associated with an injury (see field 5m, "Result"), there is no option for a railroad officer to include the involvement of rail. Other roadbed-related codes are available to describe the circumstances or involvement of other materials in the injury, including "tie," "switch," and "ballast."

- No clear definition of a "human factor" injury cause. As part of the injury reporting process, railroad officers responsible for completing this information on Form FRA $F$ 6180.55a (field 5n, "Cause") must determine and report the probable cause of the injury. The term "human factor" has many different definitions, associations and connotations, and often depends on who is using the term as to how it gets used. Whereas it is clear if an injury is caused by an "environmental" factor, it is not always clear when an injury is due to a "human factor."

- Limitations to the Current Study's Comparison of Yard Injuries to Other Industries

- Differences in the injury severity metric used. The FRA injury analyses focused on LWD injuries while the comparison to the BLS data was limited to DAFW injuries (a subset of LWD injuries). The primary reason for using LWD injuries is that injuries that result in restricted duty most likely do not permit the employee to work his or her regular yard job, and therefore impact both the railroad and the individual in a similar fashion as a day absent. However, when describing injury characteristics, the BLS reports DAFW cases. The use of a different severity metric limits the degree to which "apple-to-apple" comparisons can be made between the railroad yard LWD injuries and the BLS DAFW injuries for private industry. 


\section{SUPPLEMENTAL INJURY DATA COLLECTION AND ANALYSIS}

To provide additional information about contributors to personal injuries in railroad yards, injury and work schedule data were collected from one participating railroad's yard operation and analyzed. Section 5 discusses the methods used to select the personal injury records and collect the data from the participating railroad, and presents the results of two sets of analyses: one on factors surrounding personal injuries that occurred in the yard (e.g., nature of the injury, the physical act that led to the injury, etc.), and a second on the potential influence of work schedules on yard injuries.

Data were collected from a participating railroad for two primary reasons: to look at the factors surrounding yard injuries in more detail than is currently possible with the FRA injury database, and to examine the role of operator fatigue, or more specifically, work schedules, in yard injuries. Currently the FRA does not collect work schedule data related to nonfatal injuries. Operator fatigue and alertness are major issues in all modes of transportation, including railroad operations along mainlines and in yards. Analysis of work schedule information can provide new insight regarding the contribution of work schedule-related factors to personal injuries that occur in railroad yards.

This section is divided into three major subsections: subsection 5.1 presents the approach that was used to collect and analyze the personal injury and work schedule data; subsection 5.2 presents the results of the analyses; and subsection 5.3 discusses the main findings and limitations to the data and study methods used.

\subsection{Supplemental Data Collection and Analysis Methods}

The supplemental data collection approach involved examination of multiple years of personal injury and work schedule data from a participating railroad. The methods that were used to collect the personal injury and work schedule data are discussed in the following two subsections.

\subsubsection{Personal Injury Data}

Three years (1996 to 1998) of personal injury data were collected from the participating railroad. This data included FRA reportable injuries as well as non-reportable injuries (i.e., injuries for which the participating railroad collects data but does not report to the FRA since the injuries do not meet FRA's reporting requirements. These include minor injuries that do not require first aid and do not result in time away from work). Information was collected on the circumstances of the injury, certain personal factors (e.g., age, railroad experience), and environmental factors (e.g., location of the injury, weather). 
The participating railroad maintained a file for each injury. Each file contained a variety of information sources, though the specific sources depended on the particular case. Some files contained only a completed FRA injury/illness Form FRA F $6180.98^{10}$, while other files contained transcripts, photos, medical records, etc. Potential sources of information about the personal injuries included:

- Handwritten transcripts of testimony from the injured employee and/or witness(es) to incident.

- Risk management officer's personal notes about the injury/case.

- Official correspondence between the risk management officer and other railroad personnel (e.g., counsel, payroll).

- Official correspondence between the risk management officer and injured employee and/or his/her counsel.

- Official correspondence between the risk management officer and the Railroad Retirement Board.

- Official correspondence between the risk management officer and injured party's doctor.

- Copies of doctors' notes, prescriptions, medical bills, invoices, case histories, etc.

- Completed FRA injury/illness forms.

- Injured employee's personnel records, including disciplinary actions, past work histories, resumes, original medical history (at time of hiring).

- Risk management officer's notes to the file.

- Photographs, diagrams, drawings.

- Copies of release forms (for settled cases).

- Transcripts and correspondence related to commissioned surveillance of the injured employee.

- Formal investigation transcripts.

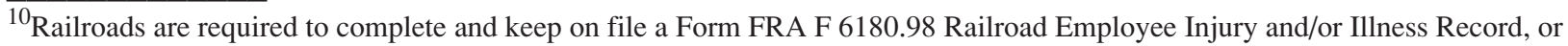
a comparable form that includes the same information, for each reportable injury. This differs from Form FRA F 6180.55a Railroad Injury and Illness Summary, which railroads are required to submit to the FRA on a monthly basis.
} 
- Company monthly "FRA log." This contained a list of injuries per month, including whether the injury was reportable to the FRA. It generally served as a starting point for selecting candidate injury cases.

Only injuries that occurred to employees as a result of performing their usual responsibilities on the railroad property were of interest. Therefore, the following selection criteria were established:

- The injured employee must have sought medical attention (if the injured employee had not sought medical attention, there would be no record of the injury).

- The injury was not fatal.

- The injured party was an employee of the participating railroad.

- The injury occurred on railroad property.

- The injury occurred in the yard (including the RIP track or intermodal facility), on the mainline or on industry track, or in a shop.

- The injury resulted from performing work-related activity.

- The employee was not under the influence of alcohol or drugs at the time of injury.

- Only one injury per person would be included. ${ }^{11}$ When there were multiple injuries, a random numbers table (RNT) was used to select one of the injuries from among the multiple injuries for an employee.

- The injury did not involve a grade-crossing.

Each injury that occurred on the railroad property from 1996 to 1998 was reviewed to determine its eligibility for inclusion in the study. After eligible injuries had been identified, all of the information sources included in each injury file were reviewed and relevant information about each injury was recorded on a form that was developed (see Appendix C) to aid in the data collection process. When personal injury data from a file were inconsistent between two data sources (e.g., the date of birth was listed as 7/1/56 on one data source and 7/1/60 on a second data source), verification was sought from a third source of information. When this was not available, information from the most recent record source was used. When an individual sustained multiple eligible injuries, a RNT was used to select one of the injuries for inclusion in the analyses to ensure independence of the data.

Injury data were collected for a total of 69 individuals. A RNT was used to select a subset of data to spot check. Approximately 15 percent of the cases were selected for spot-checking.

\footnotetext{
${ }^{11}$ The purpose for eliminating multiple injuries is to allow the assumption of independence to be true.
} 
Errors were found in less than 5 percent of all of the data cells, therefore the coding was considered reliable.

Separately, monthly exposure data were collected for the number of cars switched between 1996 and 1998, and the number of hours worked by employees between 1996 and 1998. Since only those injuries that occurred in the yard environment were of interest, crafts that do not work in the yard operating environment were removed from the employee work hour exposure data. These crafts included building maintenance personnel, freight car repair facility personnel, dispatchers, clerks, crew callers, police department personnel, and General and Administrative (G\&A) personnel. Both the number of cars switched per month and the number of employee hours per month were used to calculate injury rates per month between 1996 and 1998. No other exposure data were available.

\subsubsection{Work Schedule Data}

The analysis of work schedule data centered on trainmen (i.e., conductors/foremen and switchmen) and locomotive engineers injured in the yard, since work schedule data were available only for these crafts (railroads are required by law to maintain this information). A total of 27 yard injuries involved T\&E employees between 1996 and 1998. Data were also collected for a craft, experience, age-matched sample of 27 non-injured T\&E employees. The control group was matched using T\&E age and seniority rosters provided by the participating railroad. The purpose of collecting work schedule data for a sample of non-injured T\&E employees was to be able to determine the possible contribution(s) of work schedules to personal injuries in yards by enabling a statistical comparison between the two groups that controlled for as many factors (i.e., age, craft and experience) as possible.

To select the control group, first each craft (trainmen and engineers) was matched. Then, within each craft, all individuals whose experience was within 12 months of that of the injured employee were identified. For each eligible control, the difference between their seniority date and the injured employee's seniority date was computed. Then the difference in months between the injured's date of birth and all eligible controls was calculated. Next the differences in seniority and age were combined. For each injured employee, the individual in the control group who most closely matched the injured employee (i.e., had the fewest combined months' difference) was selected as the match. In case of ties, the individual with the closest seniority date (i.e., fewest months difference in seniority) was chosen, since experience was considered to be more important to match than age.

Once a non-injured match had been identified for each of the 27 injured T\&E employees, work schedule data were collected for 30 days of work prior to the date of the injury (i.e., not including the shift in which the injury occurred) for each insured T\&E employee and each noninsured T\&E employee. For each non-injured employee, the dates of the work schedule data that were collected matched the dates of the work schedule data that were collected for the injured employee. When a non-injured employee worked non-yard jobs more than two-thirds of the 30 days over which data was collected, a replacement was selected based on the next closest match to the injured employee in terms of the fewest number of months' difference (seniority 
and age, combined). Work schedule data was then collected for that individual. The railroad's hand-written crew caller logs were used to provide the work schedule data. The crew caller's logs were manually reviewed and the relevant start and stop times for each injured and noninjured match employee were recorded on a record form that was developed especially for this data collection (see Appendix C).

To verify that the two populations were not significantly different from one another, t-tests were conducted. Overall, the average difference in seniority was seven months $\left(\mathrm{t}_{\mathrm{obt}}=0.04, \mathrm{df}=52\right.$, $\mathrm{p}=0.97)$, and the average difference in age was 14 months $\left(\mathrm{t}_{\mathrm{obt}}=0.25, \mathrm{df}=52, \mathrm{p}=0.81\right)$. Similar results were found within each craft. The average difference in seniority for the trainmen was seven $\left(\mathrm{t}_{\mathrm{obt}}=0.05, \mathrm{df}=42, \mathrm{p}=0.96\right)$ and the average difference in age was 14 months $\left(\mathrm{t}_{\mathrm{obt}} \mathrm{t}=0.22\right.$, $\mathrm{df}=8, \mathrm{p}=0.82)$. The average difference in seniority for the engineers was five $\left(\mathrm{t}_{\mathrm{obt}}=0.005, \mathrm{df}=8\right.$, $\mathrm{p}=0.99)$ and the average difference in age was 15 months $\left(\mathrm{t}_{\mathrm{obt}}=0.12, \mathrm{df}=52, \mathrm{p}=0.91\right)$. Thus, t-tests indicate that the injured and the non-injured groups are not significantly different from each other, suggesting that it is likely that any differences that are found between the injured and non-injured groups are not attributable to differences in craft, seniority or age.

Several caveats regarding the work schedule data merit explanation. Since the study design was retrospective, data on individuals' time away from work was not collected. Therefore, it was not possible to analyze individuals' time and activity away from work since it was not possible to determine what the person was doing during this time (e.g., whether the individual was sleeping/ resting or actively doing something else). Analyses, therefore, were limited to work period activity. Related to this issue, it was not possible to determine when and if employees took any vacation or sick time during the 30 days for which work schedule data was collected. Third, it was not possible to determine whether the employee was working a regular job, relief job, or extra board job. Lastly, employees could work different "jobs" each day, therefore, it was not possible to control for exposure to the yard environment. In fact, it was quite possible that an individual worked in the yard one day and worked an "industry" job the next day. Where individuals from the control (match) group worked a substantial amount of time outside of the yard (i.e., greater than $2 / 3$ of the month), they were excluded from the analysis and another match was selected and their work schedule data used. When either an injured or non-injured employee worked a non-yard job, their data for that work period were recorded as missing, since, even though the employee was working, they were not working in the yard environment.

\subsection{Results}

This section presents the results of the personal injury and work schedule analyses. Descriptive statistics were used to analyze and present the personal injury data, while parametric and nonparametric tests were used to compare the work schedule data for the injured T\&E employees to the work schedule data for the non-injured T\&E matched control group. ${ }^{12}$

\footnotetext{
${ }^{12}$ Analyses were conducted using SPSS v8.0 and Microsoft Excel.
} 


\subsubsection{Personal Injury Data Analyses}

A total of 69 injuries between 1996 and 1998 satisfied the selection criteria. These injuries ranged in degree of severity and railroad location. As shown in Table 33, 52 injuries (75 percent) occurred in the yard environment, which includes Repair, Inspect and Paint (RIP) tracks and an intermodal facility. Eight injuries occurred in a shop or repair facility and nine occurred along the mainline or industry track. All 69 injured employees were male. Since the focus of the analysis was on the yard operational environment, analyses centered on the 52 injuries that occurred in the yard of the participating railroad.

When reporting data, some totals may not add up to 52 since occasionally there were one or more cases in which data were missing, such as the age of the employee or his railroad experience. Separately, some variables lacked sufficient data to report. Variables that were of interest, but lacked sufficient data, are listed in Table 34, along with the number of missing cases.

The type of injury was examined for the injuries that occurred in the yard (see Figure 17). Similar to the national injury data, the greatest number of injuries resulted in a sprain or strain $(n=20)$. Bruises and contusions $(n=9)$; cuts, lacerations and abrasions $(n=9)$ and fractures $(n=5)$ also mirrored national trends.

Next, the bodily location where the injury occurred was examined. Whereas the torso is, by far, the most affected body part based on national data, interestingly, this was not the case at this

Table 33. Participating railroad distribution of injuries by location, 1996 to 1998

\begin{tabular}{lcc}
\hline \multicolumn{1}{c}{ Location } & No. of Injuries & Percentage of Injuries \\
\hline Yard & 52 & 75 \\
Shop & 8 & 12 \\
Mainline/Industry Track & 9 & 13 \\
Total & 69 & 100 \\
\hline
\end{tabular}

Table 34. Variables that lacked sufficient data to report

\begin{tabular}{|c|c|c|}
\hline Variable & $\begin{array}{c}\text { No. of } \\
\text { Missing Cases }\end{array}$ & $\begin{array}{c}\text { Percentage of } \\
\text { Total Cases }\end{array}$ \\
\hline Marital status & 23 & 44 \\
\hline Height & 47 & 90 \\
\hline Weight & 46 & 88 \\
\hline Was injured employee alone at the time of the injury? & 28 & 54 \\
\hline Visibility & 45 & 87 \\
\hline Weather & 36 & 69 \\
\hline Temperature & 36 & 69 \\
\hline
\end{tabular}




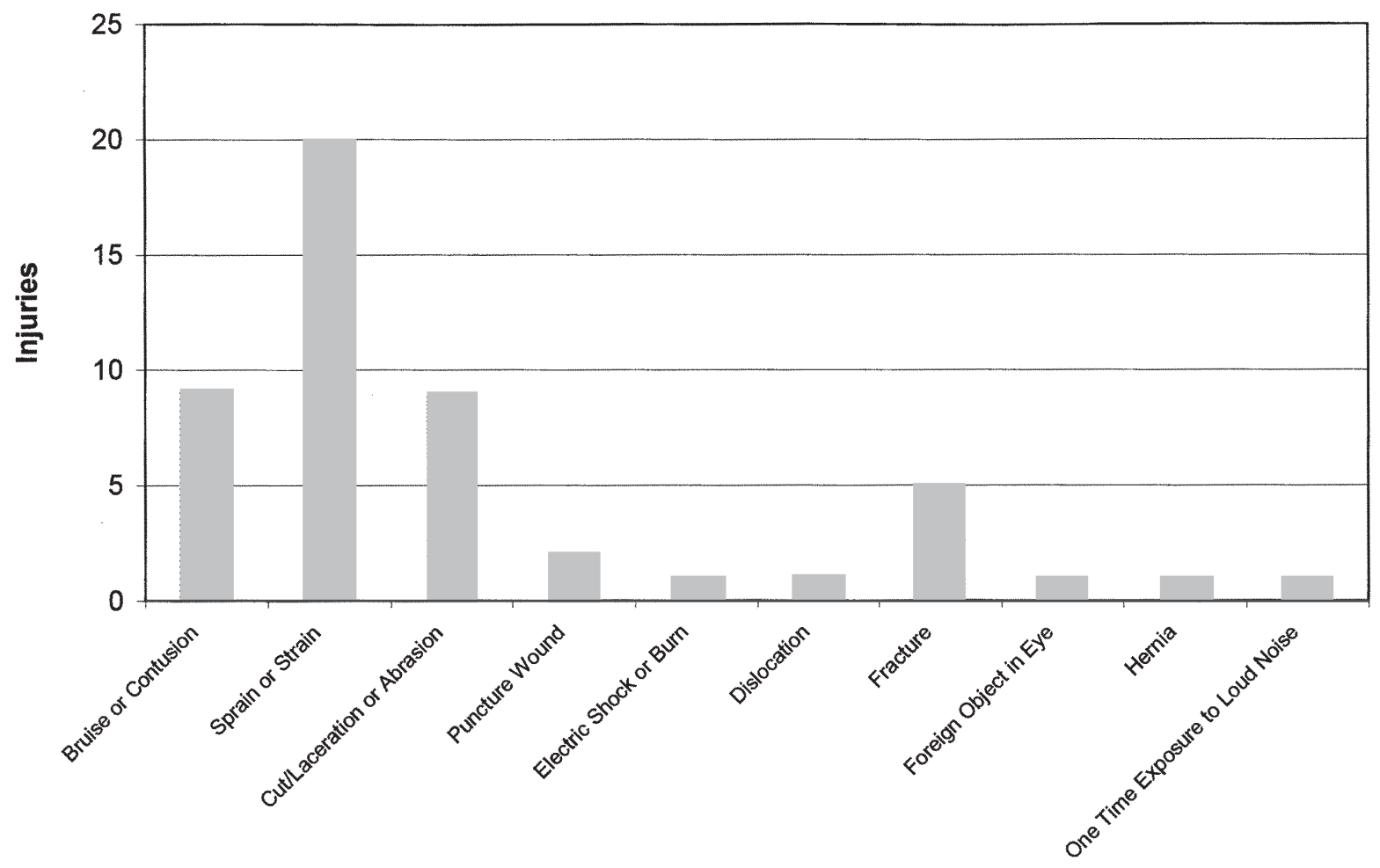

Type of Injury

Figure 17. Participating railroad yard injuries by type, 1996 to 1998

railroad. The upper extremities (arms and hands) were the most affected ( $\mathrm{n}=13$ injuries) body parts, while the lower extremities (legs and feet) and the torso were tied for the second most affected body part ( $\mathrm{n}=11$ each). Figure 18 presents the data for the number of injuries that affected each body part.

The FRA provides railroads with over 70 different physical act codes from which to categorize an injury. Since data were available for only 52 injuries, physical act codes were collapsed into a smaller number of higher level categories. The higher level physical act categories used for the national injury data analysis in subsection 4.3 were used. The results indicate that the act of walking/running/stepping over accounted for the most injuries $(n=12)$. In fact, the single act of walking accounted for 10 of the 12 injuries. The act of getting on, off, up or down accounted for the second-largest number of injuries $(n=6)$. Figure 19 presents the complete data set for the physical act associated with each injury.

Similar to the physical act codes, there are dozens of FRA triggering event codes from which to select when describing the circumstances of the injury. Therefore, the higher level categories employed in the national injury data analysis (see subsection 4.3) were used. Being struck by or against an object resulted in the greatest number of injuries $(n=16)$ while slips, trips and falls resulted in the second-most number of injuries $(n=14)$ (see Figure 20). 


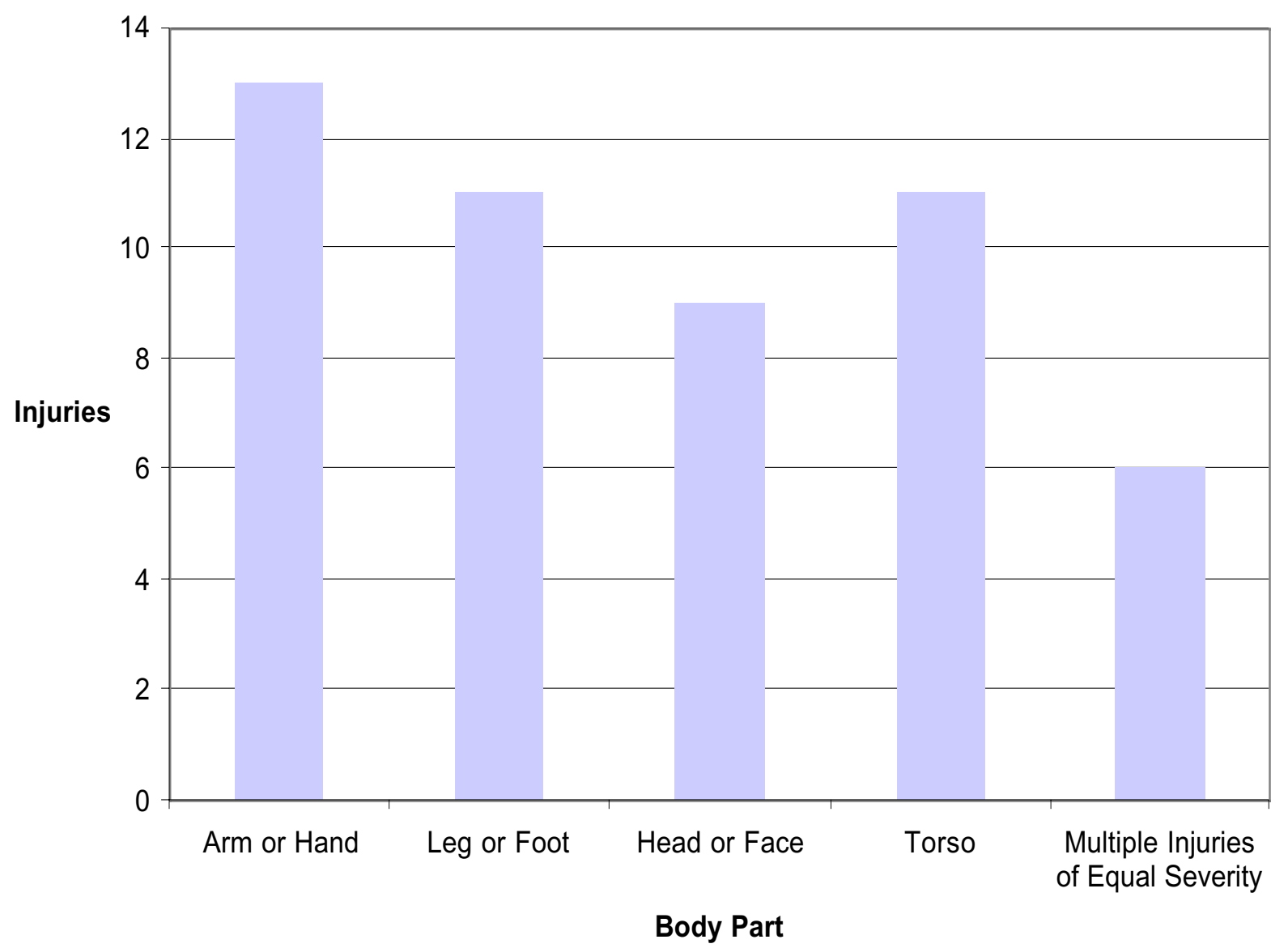

Figure 18. Participating railroad yard injuries by body part, 1996 to 1998

The involvement of track and train equipment in the injuries was also of interest. Specifically, the involvement of three track-related items (ballast, ties, and switches), and three train-related items (couplers, air hoses, and hand brakes), were analyzed. As shown in Table 35, two injuries involved road ballast, five involved cross-ties, and four involved switches. With respect to train equipment, three injuries involved couplers, one involved a handbrake, and two involved air hoses.

The overall involvement of on-track equipment was also examined. Involvement of on-track equipment meant either the injured employee was physically located on or in the on-track equipment at the time of the injury, or the injury resulted from direct contact with the on-track equipment. For example, on-track equipment would be involved if an injury occurred while the individual was coupling two cars; on-track equipment would not be involved if a carman was inspecting a train when he or she tripped on a tie. Results indicate that 20 injuries (38 percent) involved on-track equipment. The data was insufficient, however, to conclusively determine, at the time of the injury, whether the on-track equipment was moving or not.

The crafts that were involved in the yard injuries were also examined. While T\&E crews suffered the most injuries in the yard ( $n=27$, or 52 percent), interestingly, almost half of the yard injuries occurred to maintenance personnel ( $n=23$, or 44 percent). 


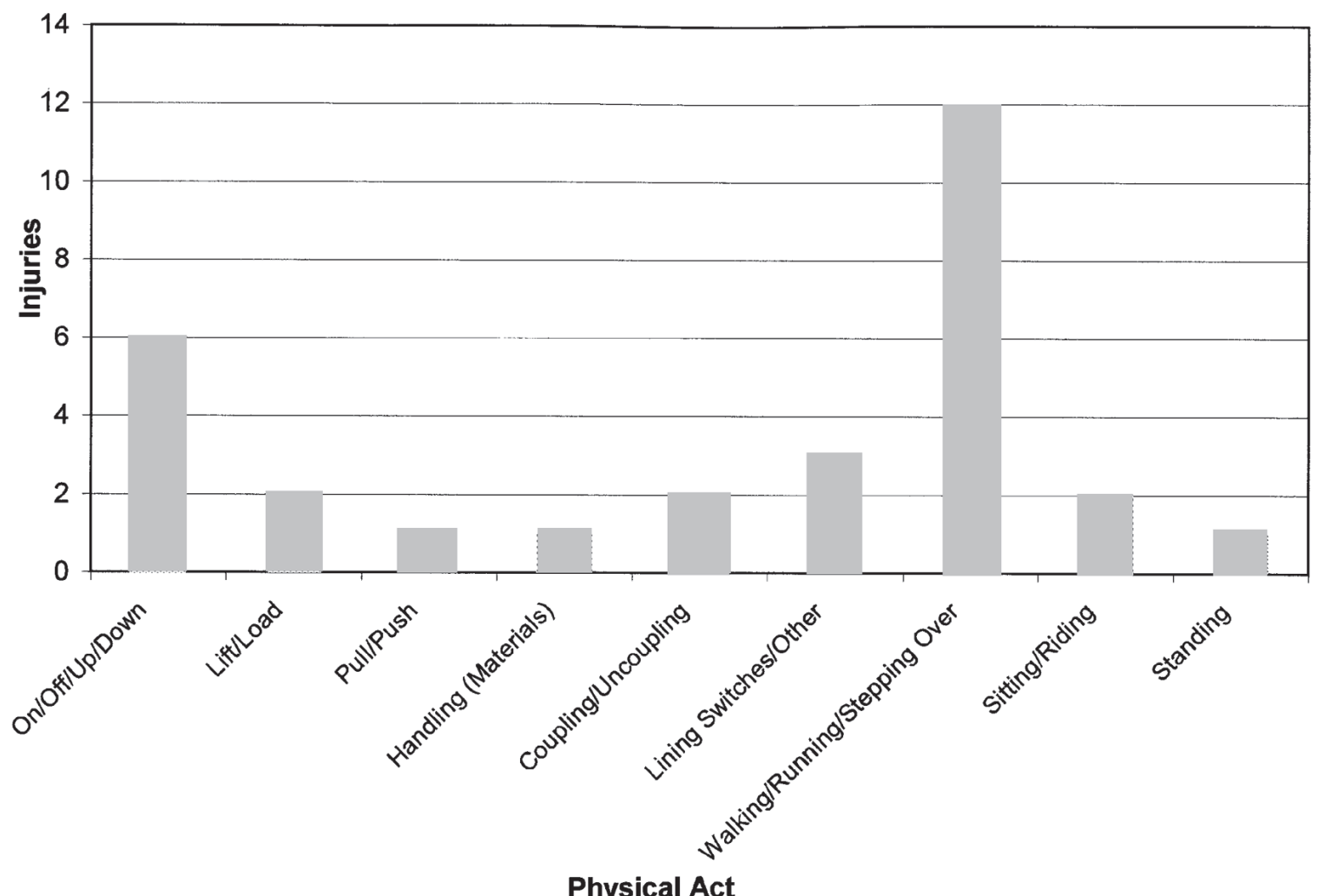

Figure 19. Participating railroad yard injuries by physical act, 1996 to 1998

Next, the severity of the injury was divided into three levels or degrees: 1) the injured employee received medical attention only, i.e., the injured employee sought medical attention, but the "treatment" was not beyond first-aid ${ }^{13} ; 2$ ) the injured employee received first-aid as a result of the injury, but did not miss any work; and 3) the injury resulted in one or more lost workdays (either days absent or restricted/light duty). Interestingly, almost half ( $\mathrm{n}=23$, or 44 percent) of the injuries involved medical attention only. Five injuries required first-aid, and an additional 19 injuries resulted in at least one lost workday (see Figure 21).

Examination of the yard injuries by age indicates that most injuries occurred to those 25 to 34 $(n=14)$ and 35 to $44(n=13)$ while fewer injuries occurred to those younger and older. Figure 22 illustrates the distribution of injuries by age group.

Railroad-specific exposure data were not available. However, industry-wide age distribution data were available from the RRB. These data were used as a surrogate exposure measure to determine if the percentage of injuries associated with each age group at the participating railroad was proportional to the percentage of employees (industry-wide) in each age group. An assumption was made that the age distribution of the yard workforce at the participating railroad was similar to the age distribution of the railroad industry as a whole (i.e., the RRB data). The

\footnotetext{
${ }^{13}$ Injuries in this category would not result in an FRA-reportable injury since treatment was not beyond first-aid.
} 


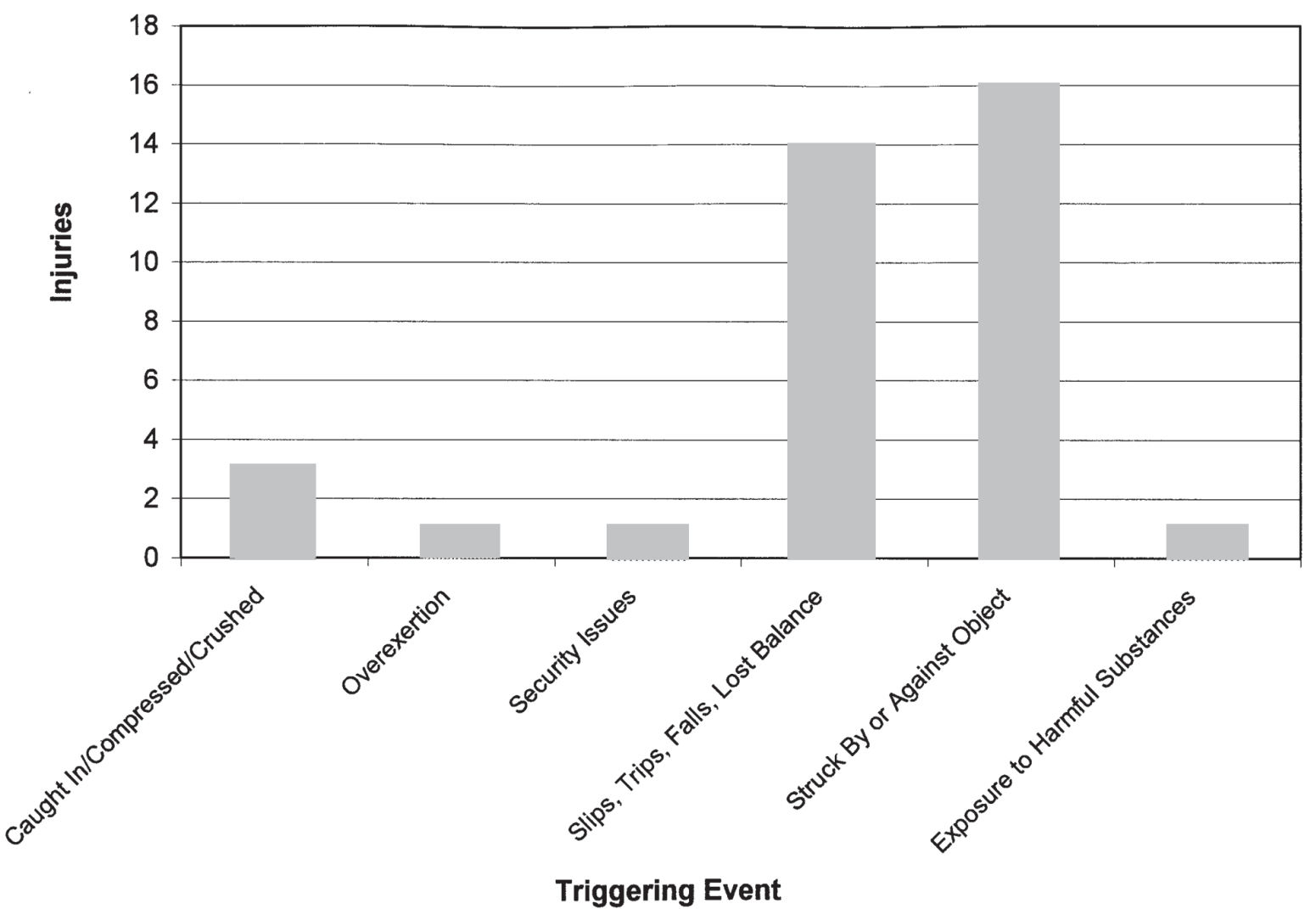

Figure 20. Participating railroad yard injuries by triggering event, 1996 to 1998

RRB age data was used to calculate the relative proportions (i.e., percentages) for each age category. The proportions by age are presented in Table 36. A weighted frequency was then computed for each age bracket. Based on the weighted frequencies, the younger employees at this railroad, particularly those under 35 , suffer disproportionately more injuries compared to employees 35 and older. This age-related finding is similar to that found in the national injury data maintained by the FRA (see Table 14).
Table 35. Participating railroad yard injuries involving track and train equipment, 1996 to 1998

\begin{tabular}{cc}
\hline Type of Equipment & No. of Injuries \\
\hline Ballast & 2 \\
Cross-Ties & 5 \\
Switches & 4 \\
Couplers & 3 \\
Handbrakes & 1 \\
Air Hoses & 2 \\
\hline
\end{tabular}

Next the monthly injury rate was analyzed. Since two railroad-specific exposure data variables were available - the number of cars switched and the number of employee work hours per month - both were used. The number of injuries per 1,000,000 cars switched per month and the number of injuries per 100 employees (200,000 hours) per month were computed. Figure 23 and Figure 24 present the injury rate data per month at the participating railroad. The general pattern 


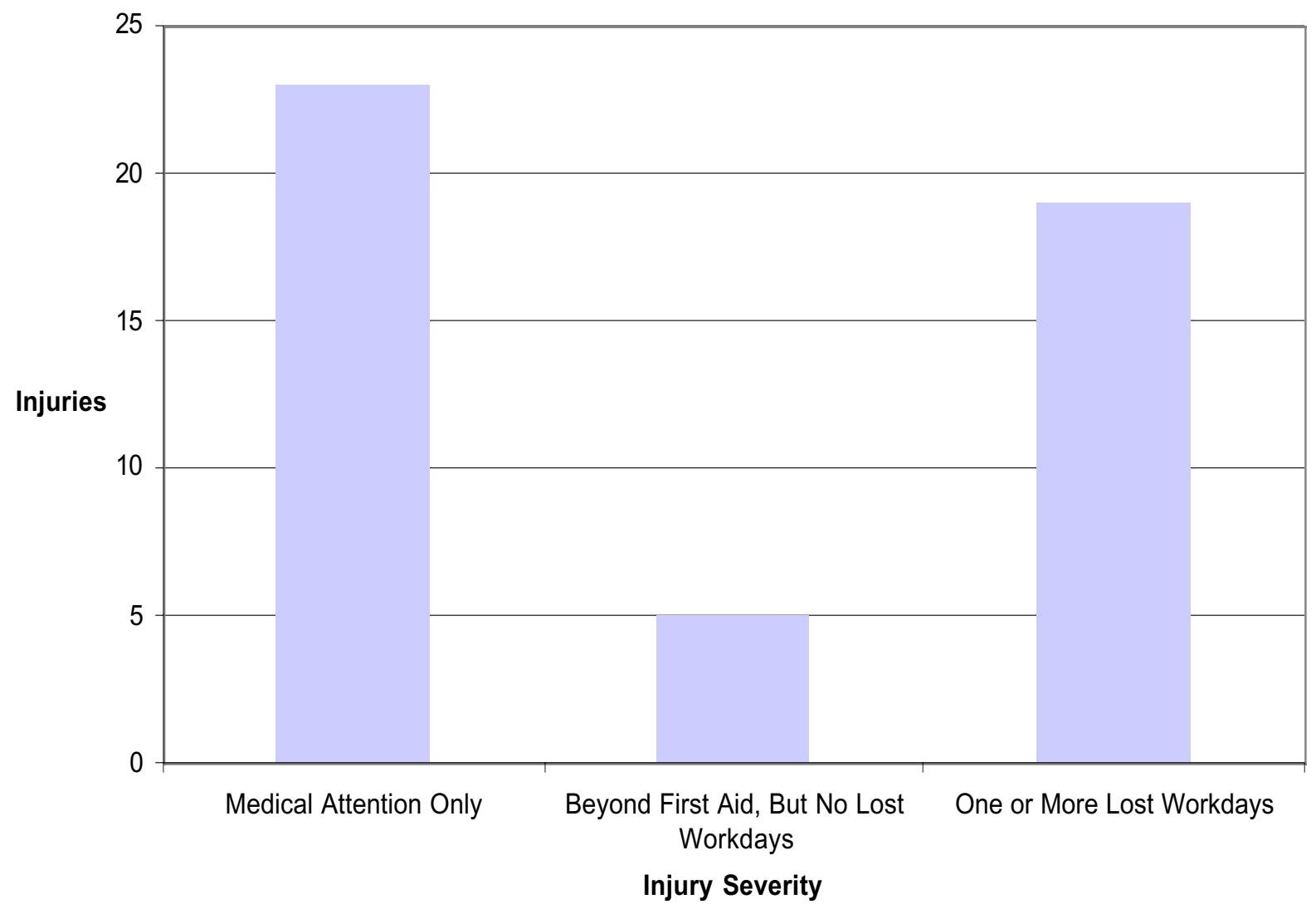

Figure 21. Participating railroad yard injuries by injury severity, 1996 to 1998

is the same between the injury rate per 100 employees and the injury rate per 1,000,000 cars switched. A chi-square test was performed on the number of injuries per million cars switched, ${ }^{14}$ and a significant difference among months was found $\left(\chi^{2}=59.08, \mathrm{df}=11, \mathrm{p}<0.001\right)$. As shown in Figure 23, the injury rates in July (more than 35 injuries/1,000,000 cars switched), May (more than 28 injuries/1,000,000 cars switched) and August (more than 25 injuries/ $1,000,000$ cars switched) are the highest. Interestingly, no injuries occurred in the month of April across three consecutive years.

Data were next grouped into 2 hour periods (e.g., midnight to 2 a.m.). Figure 25 presents the results of the analysis. The greatest number of injuries in any 2 hour period occurred between 10 a.m. and 12 p.m. $(n=9)$, though it is not clear whether this is an effect of the time-of-day or exposure (i.e., it may be that more crews are working during this 2 hour time period than during other 2 hour time periods). Interestingly, the second-highest number of injuries occurred between 8 p.m. and 10 p.m. $(n=7)$. A chi-square test was not performed since the frequency of expected values $\left(\mathrm{F}_{\mathrm{e}}\right)$ was 4.3 for each 2 hour time period, violating one of the rules of thumb for using the chi-square test that stipulates that the $\mathrm{F}_{\mathrm{e}}$ for each cell should be no less than five

\footnotetext{
${ }^{14} \mathrm{~A}$ chi-square test was performed on the injury rate per million cars switched since these data satisfied the assumptions of a chisquare test.
} 


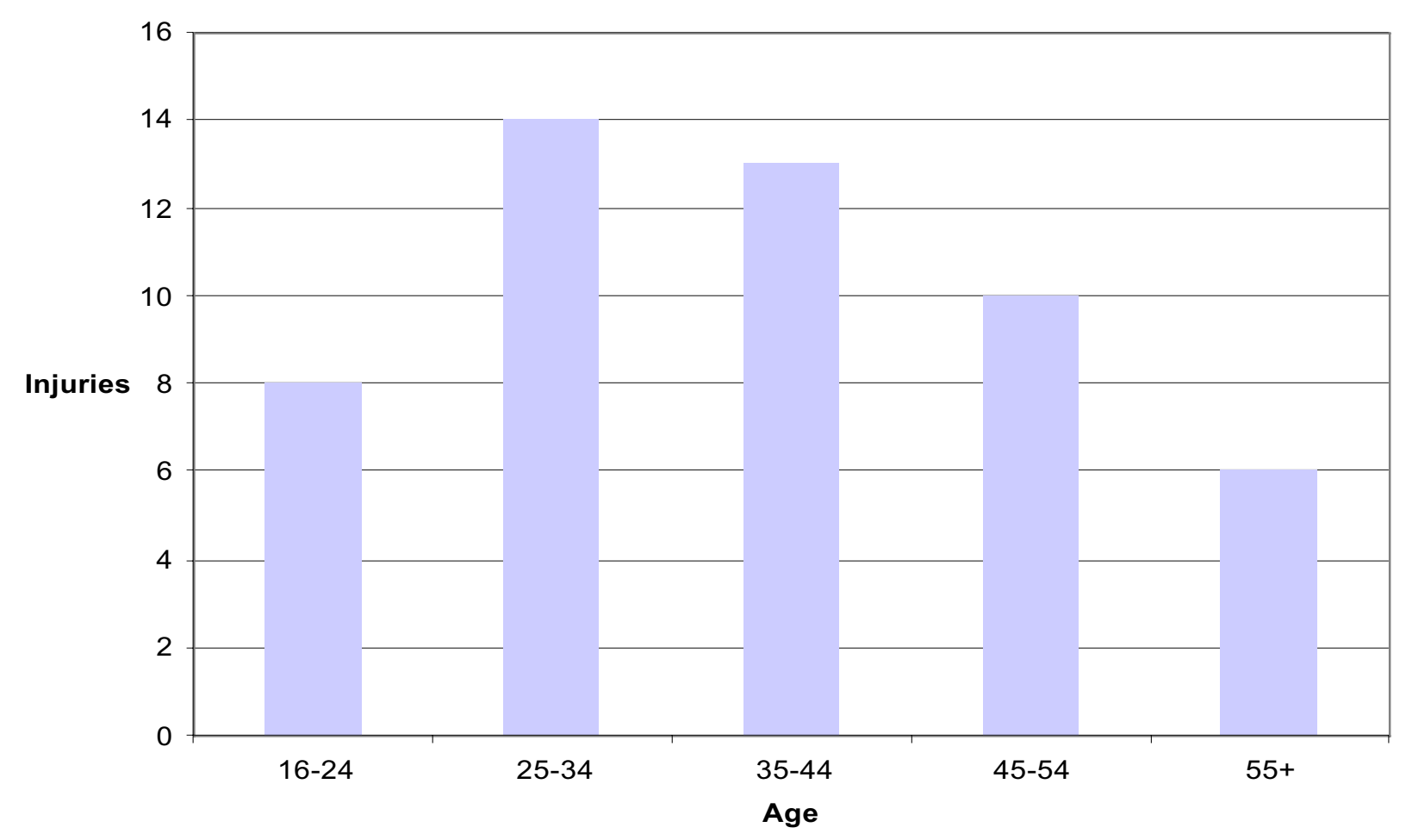

Figure 22. Participating railroad yard injuries by age, 1996 to 1998

Table 36. Age distribution weighted frequencies for participating railroad yard injuries, 1996 to 1998

\begin{tabular}{lrccc}
\hline \multicolumn{1}{c}{ Age Bracket } & Injuries & $\begin{array}{c}\text { \% of Total } \\
\text { Injuries }\end{array}$ & $\begin{array}{c}\text { Age Distribution } \\
(\%) *\end{array}$ & $\begin{array}{c}\text { Weighted } \\
\text { Frequency }\end{array}$ \\
\hline$<25$ & 8 & 15.4 & 3.3 & 4.7 \\
25 to 34 & 14 & 26.9 & 12.9 & 2.1 \\
35 to 44 & 13 & 25.0 & 28.8 & 0.9 \\
45 to 54 & 10 & 19.2 & 38.4 & 0.5 \\
$55+$ & 6 & 11.5 & 16.6 & 0.7 \\
Total & 4573 & 100 & 100 & 1.0
\end{tabular}

*Source: Railroad Retirement Board Statistical Table D-10, 1996 to 1998.

(Harnett, 1982). If one can assume that more crews work a day shift rather than an evening or night shift, the fact that the most injuries in any 2 hour period occur between 10 a.m. and 12 p.m. would be expected. However, the fact that the second-highest number of injuries occurred between 8 p.m. and 10 p.m. would not be expected, given that fewer crews probably work during this time (if this assumption is true). Conversely, if one assumes equal exposure across 2 hour time periods, one would expect 8.3 percent of the injuries to occur between 10 a.m. and 12 p.m. and another 8.3 percent to occur between 8 p.m. and 10 p.m. Yet, 17.3 percent of the injures occurred between 10 a.m. and 12 p.m. and 13.5 percent of the injures occurred between 8 p.m. and 10 p.m. Since exposure data are unavailable, however, it is difficult to determine whether 


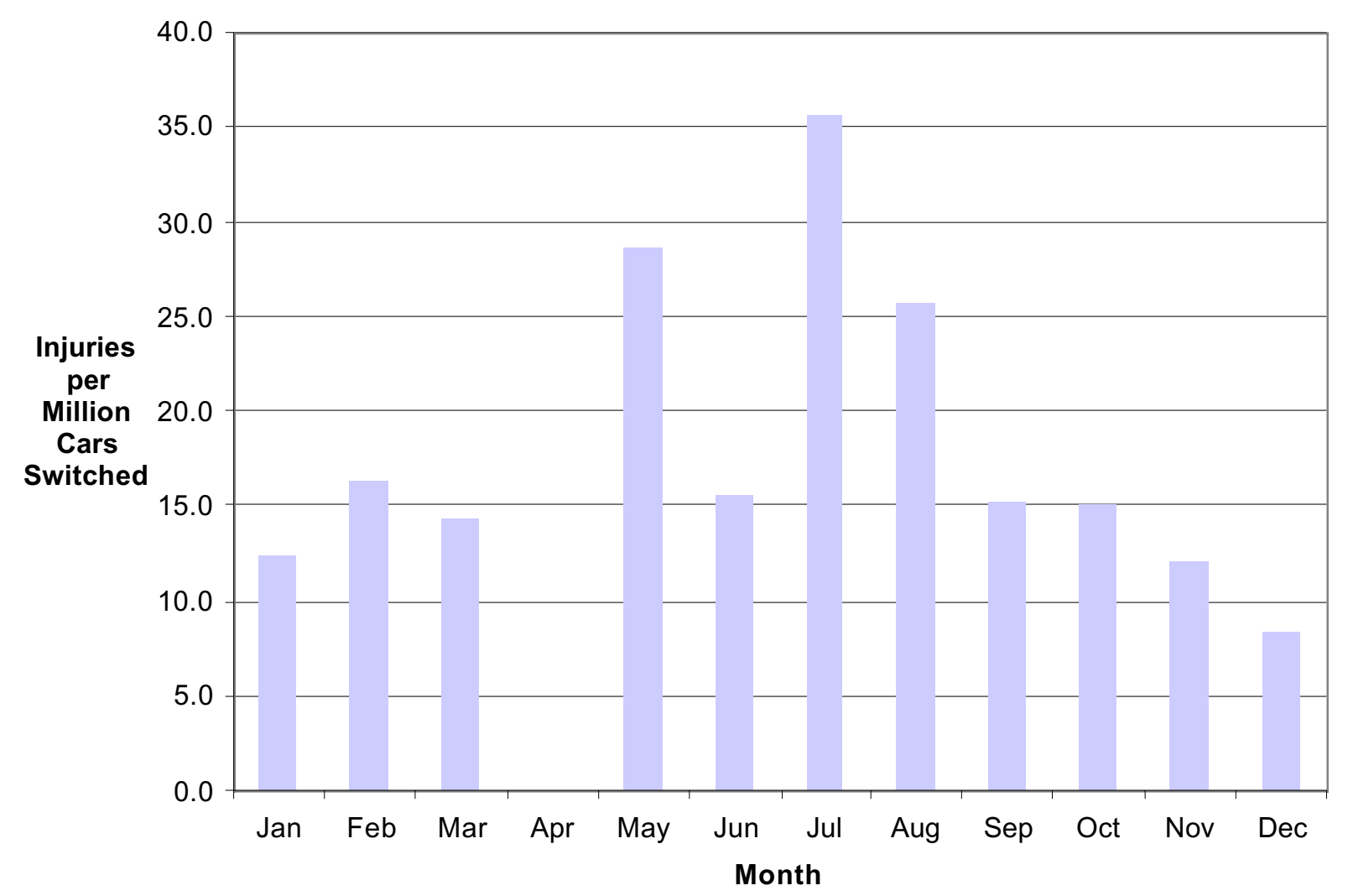

Figure 23. Participating railroad yard injuries per 1,000,000 cars switched per month, 1996 to 1998

these numbers are a result of exposure or time-of-day. Examination of the national injury data also indicates that the most yard LWD injuries occur between 10 a.m. and 12 p.m.

Time-on-task (i.e., hours on duty) was also examined to determine when, during employees' work shifts, injuries occurred. Interestingly, as illustrated in Figure 26, 16 injuries occurred during the fourth to sixth hours of an employee's shift. This figure is twice the next closest 2 hour period (the first 2 hour of the shift). However, data were only available for 37 of the 52 yard injuries. A chi-square test was not performed since it was not possible to determine the expected frequencies for each of the six 2 hour time periods (some employees worked 8 hour shifts, while others worked 10 hour shifts and still others worked 12 hour shifts). Though no statistical test was performed, the difference in the number of injuries occurring during the 4th to 6 th hour on duty compared to all other 2 hour time periods is meaningful.

Next, railroad experience was examined. The national FRA injury database does not include any data on injured employees' railroad experience. However, these data were available for most of the injury cases using either the date-of-hire or seniority date information from the participating railroad. When available, date-of-hire information was used to calculate railroad experience. This information was available for 27 cases. When hire date information was unavailable, seniority date information was used. This information was available for 17 additional cases. 


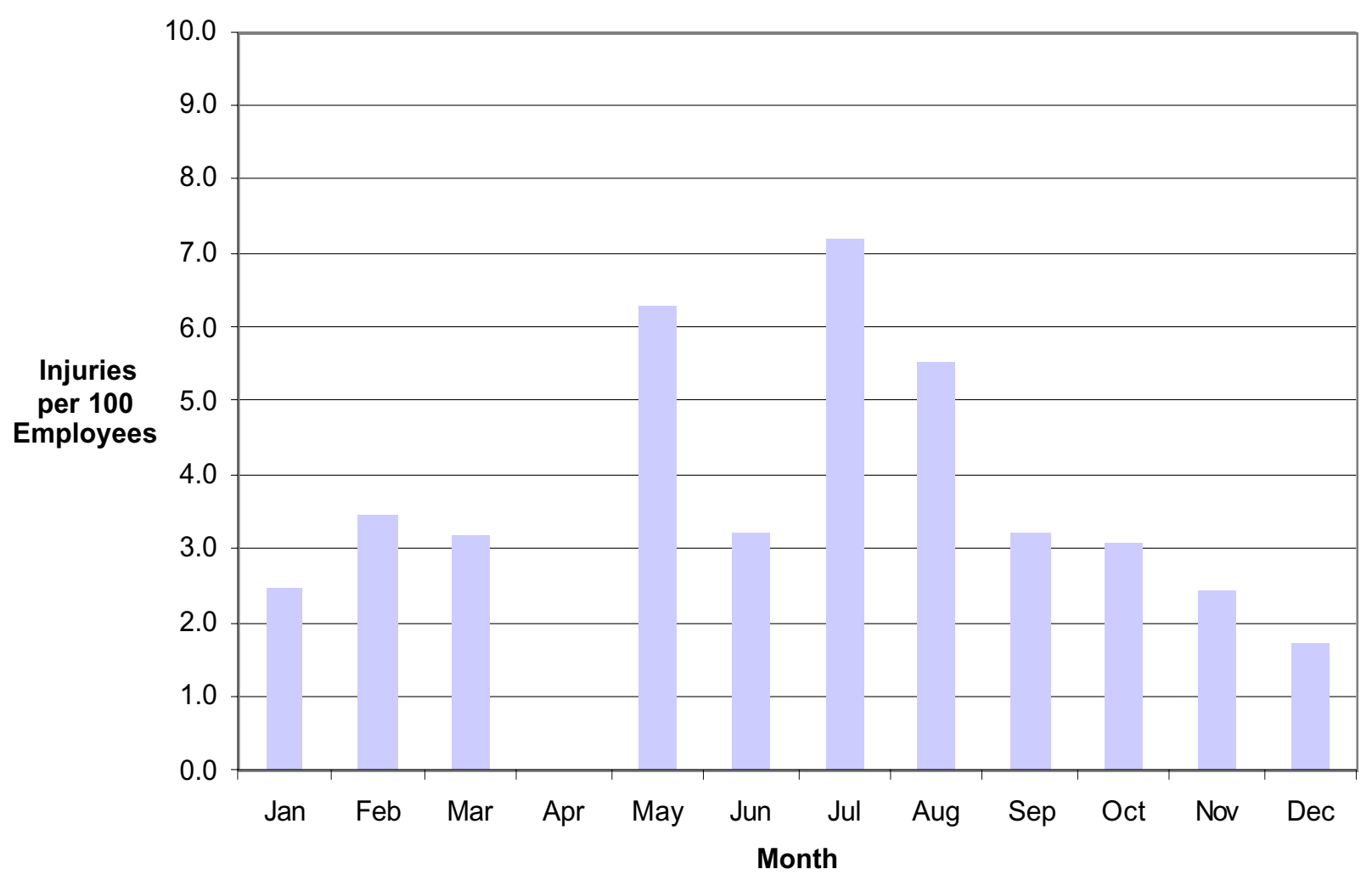

Figure 24. Participating railroad yard injuries per 100 employees per month, 1996 to 1998

The difference between date-of-hire and seniority date for these cases was expected to be minimal (e.g., an individual starts as a switchman and then "marks up" as an engineer two years later).

The range of experience of the injured employees, based on either date-of-hire or seniority date information ( $\mathrm{n}=44$ cases), was 2 to 499 months. Eleven of the 44 injured employees ( 21 percent) for whom data were available had less than two years of experience, 15 (29 percent) had between two and five years of railroad experience, and 18 (35 percent) had more than five years of experience (see Figure 27).

Railroad experience exposure data were not available from the participating railroad; however, data on the number of completed years of service for the entire railroad industry were available from the RRB. These data were used to 1) calculate the percentage of the railroad workforce in each of several experience categories, and 2) compute weighted frequencies for each experience category. The data are presented in Table 37, and indicate that those with less than five years of railroad experience suffer a disproportionate number of the injuries at the participating railroad relative to their representation in the workforce. Specifically, those with less than five years of experience suffer almost three times the number of injuries as their representation in the workforce. Those with more experience incur fewer injuries (percentage-wise) than their representation in the workforce. This analysis assumes that the distribution of railroad 


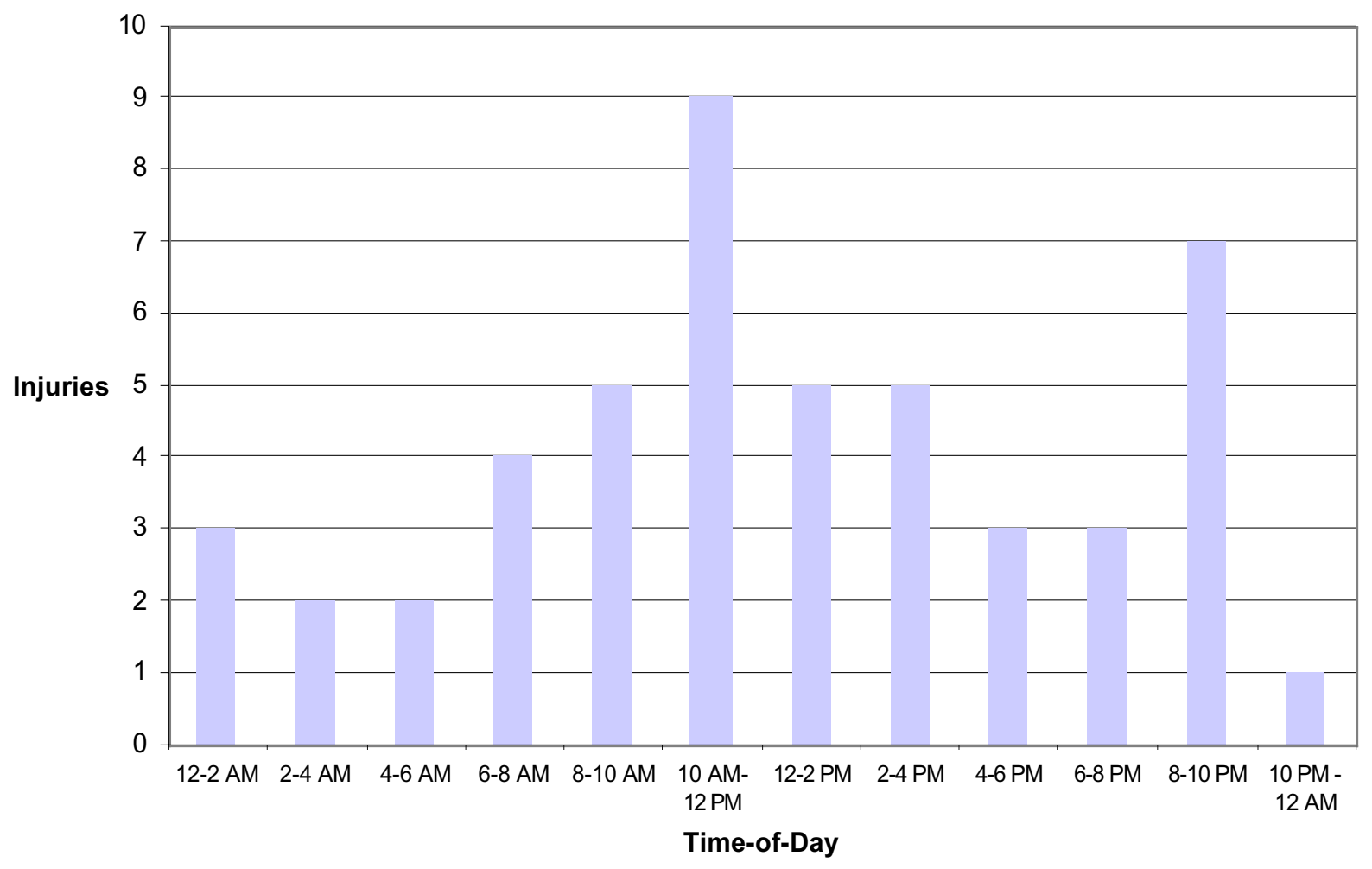

Figure 25. Participating railroad yard injuries by time-of-day, 1996 to 1998

experience at the participating railroad is similar to the distribution of railroad experience industry-wide.

The severity of the injury relative to four different factors - age, time-of-day, hours on duty, and railroad experience - was examined next. The interaction between the severity of the injury and these four factors are presented separately in Figure 28, Figure 29, Figure 30, and Figure 31.

As illustrated in Figure 28, there are a greater number of injuries that resulted in one or more lost workdays in the 25 to 34 and 45 to 54 year old age brackets compared to other age groups, where the greatest number of injuries resulted in medical attention only. However, since the sample size is small, results should be viewed cautiously.

Figure 29 shows that the two 2 hour time periods with the greatest number of injuries also result in the greatest number of severe injuries. Ten of the 19 cases that resulted in one or more lost workdays occurred in these two time periods.

In Figure 30, the three injuries that occurred to individuals on or after their 8th hour on duty were all injuries of the least severe type. There is no clear explanation for this finding. 


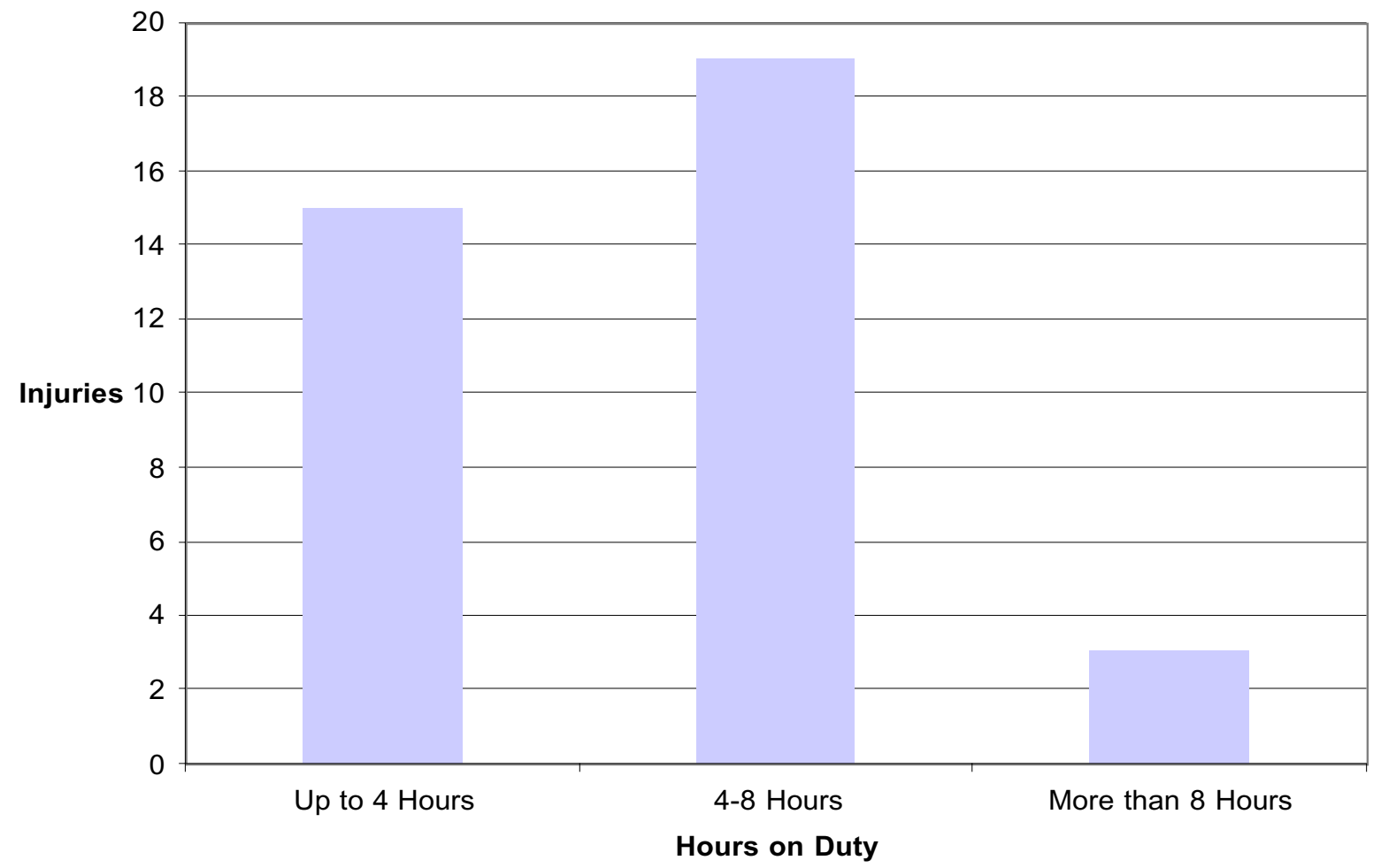

Figure 26. Participating railroad yard injuries by hours on duty, 1996 to 1998

Based on Figure 31, the proportion of least severe, moderately severe, and most severe injuries are distributed proportionately across each level of experience.

Lastly, hazardous materials (hazmat) data were available for 48 of the 52 injury cases. None of the injuries involved hazardous materials.

\subsubsection{Work Schedule Data Analyses}

Data analyses focused on the comparison of the work schedules of the 27 injured T\&E employees to the work schedules of a craft, age and seniority-matched group of non-injured T\&E employees. For each injured T\&E employee and his match, work schedule data were collected for the 30 days preceding the day of the start of the shift during which the injury occurred. Thus, for example, if a locomotive engineer was injured on August 31st, work schedule data were collected for both the injured locomotive engineer and his match between August 1 and August 30 of the year of the injury. Shift start and stop times, along with the date that the shift started, were collected for all 54 employees (27 injured and 27 control). In several instances $(n=7)$, an employee started two shifts in one 24 hour (midnight to midnight) period.

The following questions were addressed:

1. Is there a difference between the two groups with respect to the average shift length worked? 


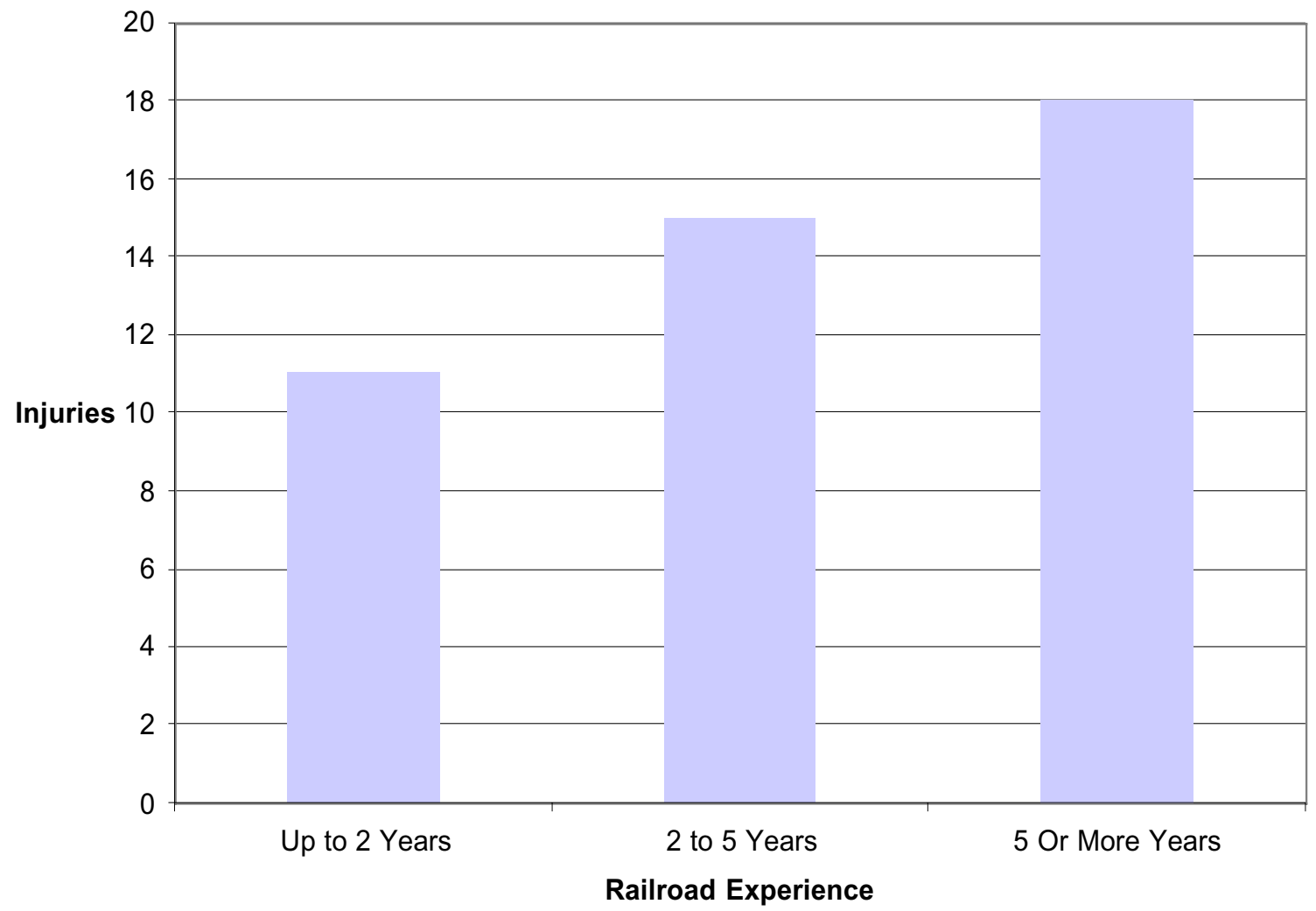

Figure 27. Participating railroad yard injuries by railroad experience, 1996 to 1998

Table 37. Railroad experience-weighted frequencies for participating railroad yard injuries, 1996 to 1998

\begin{tabular}{lcccc}
\hline $\begin{array}{c}\text { Experience } \\
\text { (Years) }\end{array}$ & Cases & $\begin{array}{c}\% \\
\text { of Cases }\end{array}$ & $\begin{array}{c}\text { Railroad Experience } \\
\text { Distribution } \\
(\%)\end{array}$ & $\begin{array}{c}\text { Weighted } \\
\text { Frequency }\end{array}$ \\
\hline$<5$ & 26 & 50.0 & 19.2 & 2.6 \\
5 to 9 & 2 & 3.8 & 9.4 & 0.4 \\
10 to 19 & 3 & 5.8 & 21.7 & 0.3 \\
20 to 29 & 8 & 15.4 & 36.5 & 0.4 \\
$30+$ & 5 & 9.6 & 13.2 & 0.7 \\
\hline
\end{tabular}

2. Is there a difference between the two groups with respect to the total amount of time worked over the 30 day period?

3. Is there a difference between the two groups with respect to the total number of shifts worked?

4. Is there a difference between the two groups with respect to the total number of starts between 8 p.m. and 4 a.m. (i.e., a night or "graveyard" shift)? 


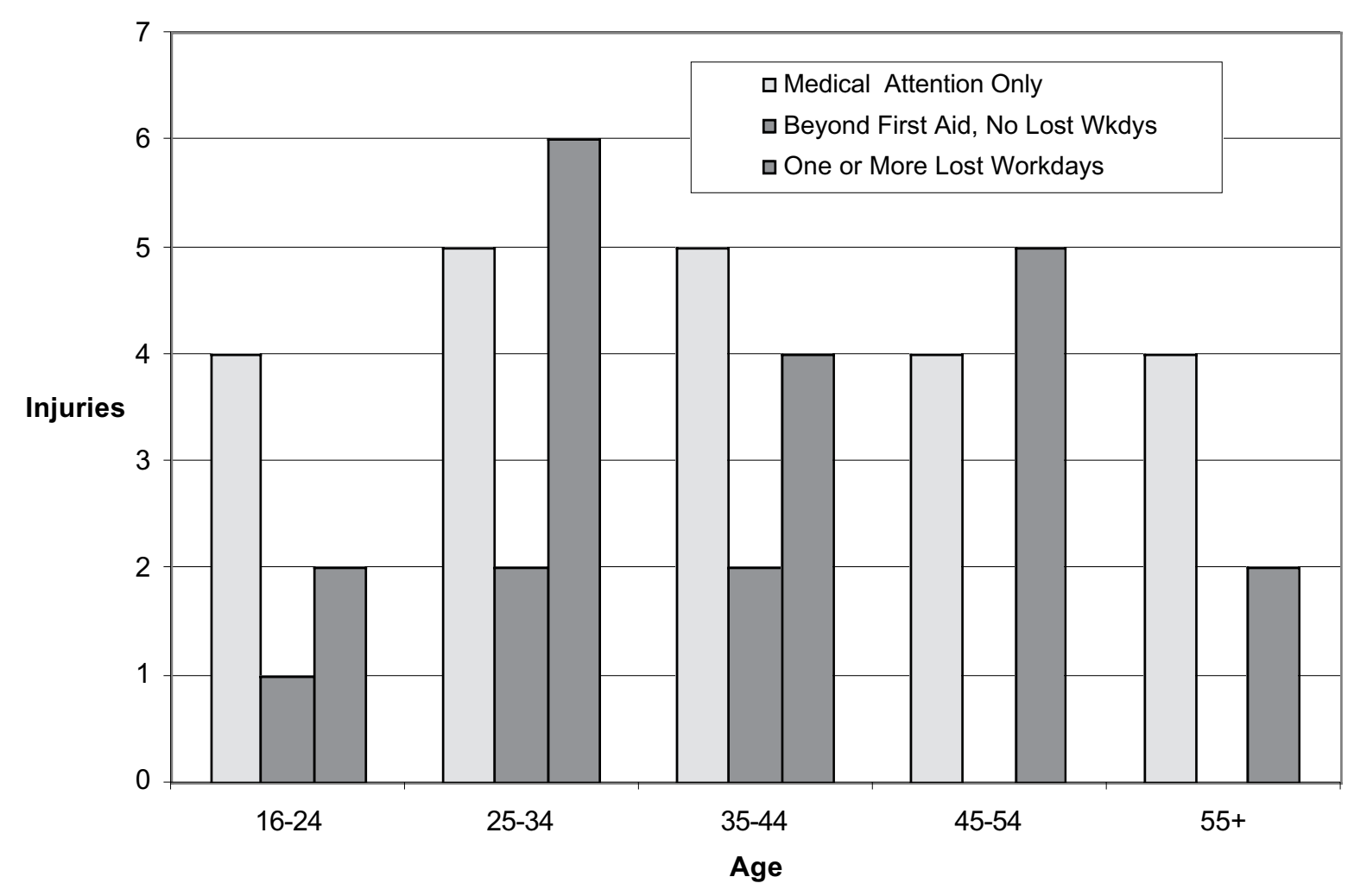

\section{Figure 28. Interaction between participating railroad yard injury severity and age, 1996 to 1998}

5. Is there a difference between the two groups with respect to the number of shifts worked over 8 hours (i.e., an extended work period)?

First the average shift lengths for the two groups were compared to one another. The average shift length for injured employees was 9 hours and 14 minutes ( 9.24 hours) while the average shift length for the matched control group employees was 9 hours and 10 minutes (9.17 hours). Since the distributions of average shift length for each group were asymptotic (i.e., negatively skewed), a Mann-Whitney ${ }^{15}$ nonparametric test was performed. As would be expected, there was not a significant difference between the two groups (Mann-Whitney $\mathrm{U}=330, \mathrm{p}=0.551$ ).

The total amount of time worked by the two groups was examined. Review of the data indicated that the distributions were normally distributed, therefore a t-test was performed. The analysis indicated that there was not a significant difference between the two groups with respect to the total amount of time worked over the 30 day period $\left(\mathrm{t}_{\mathrm{obt}}=-1.335, \mathrm{df}=52, \mathrm{p}=0.188\right)$.

\footnotetext{
${ }^{15}$ According to Minium, King and Bear (1993), the Mann-Whitney test is a frequently used nonparametric substitute for the t-test and is used primarily when the assumptions of a t-test cannot be met. In this instance, the distributions were not symmetrically and normally distributed.
} 


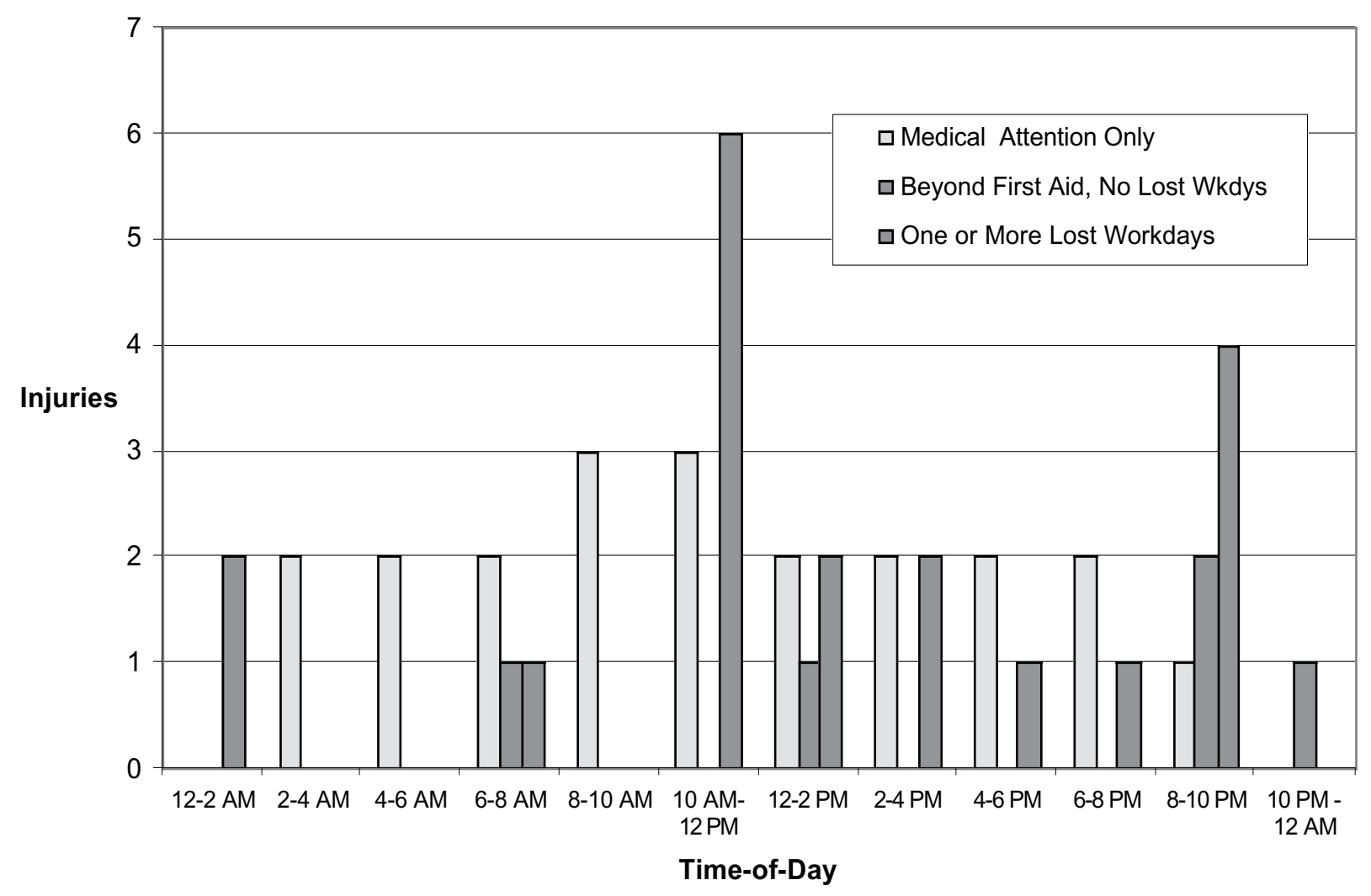

Figure 29. Interaction between participating railroad yard injury severity and time-of-day, 1996 to 1998

Next, the total number of shifts worked were compared. A chi-square test indicated no difference $\left(\chi^{2}=2.74, \mathrm{df}=1, \mathrm{p}=0.10\right)$. In fact, as shown in Table 38 , the non-injured control group worked more shifts than the injured group over the 30 day period.

Finally, the two groups were compared with respect to the total number of shift start times between 8 p.m. and 4 a.m., and the total number of shifts greater than 8 hours. Since both the number of shift start times between 8 p.m. and 4 a.m. and the number of shifts longer than 8 hours depend on the total number of shifts worked by each group, expected frequencies were weighted to reflect the fact that the injured group worked 47 percent of the total shifts and the control group worked the remaining 53 percent. (See Table 39 and Table 40.) Chi-square tests were then performed. There was not a significant difference in either the number of shift starts between 8 p.m. and 4 a.m. $\left(\chi^{2}=2.33, \mathrm{df}=1, \mathrm{p}=0.13\right)$ or the number of shifts greater than 8 hours $\left(\chi^{2}=0.17, \mathrm{df}=1, \mathrm{p}=0.68\right)$. In fact, the injured group started fewer shifts between 8 p.m. and 4 a.m. than expected, though they worked slightly more extended work periods (i.e., greater than 8 hours) than expected. 


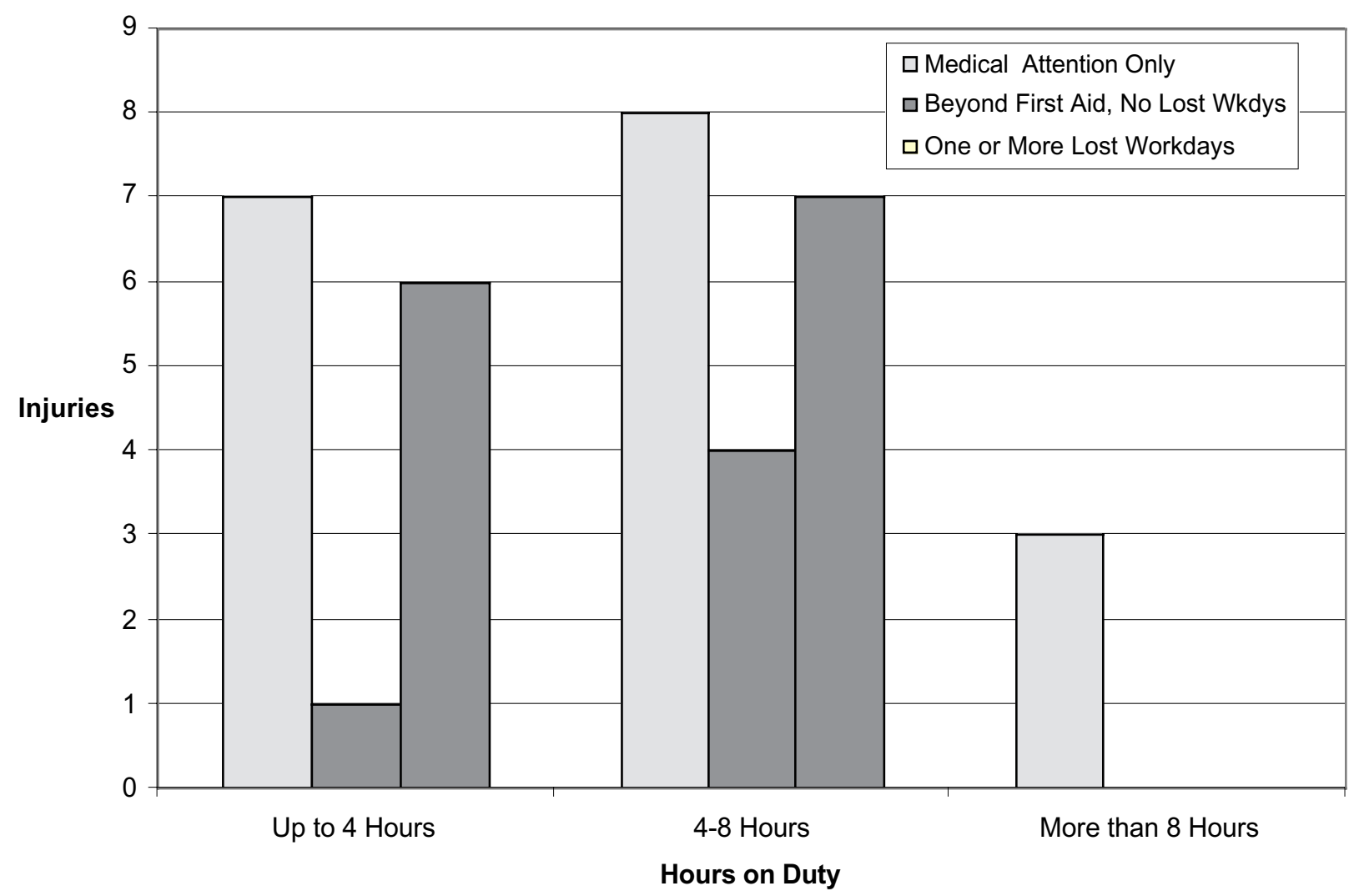

Figure 30. Interaction between participating railroad yard injury severity and hours on duty, 1996 to 1998

\subsection{Discussion}

Subsection 5.3 is divided into two subsections. First, the key findings from the personal injury and work schedule analyses are discussed. Then the limitations to both the data and the study methods are discussed. These limitations form the basis for recommendations for future research and data collection with respect to worker injuries that occur in railroad yards. These recommendations are presented in Section 8.

\subsubsection{Key Findings}

Major findings from the collection and analysis of personal injury and work schedule data from the participating railroad are presented below. Where possible, comparisons are drawn to the national injury data.

Key findings include:

- Twenty-three of the 52 yard injuries resulted in medical attention only. These cases are not "reportable" incidents and therefore represent a new type of injury that is not currently being collected by the FRA. If the data from the participating railroad could be considered 


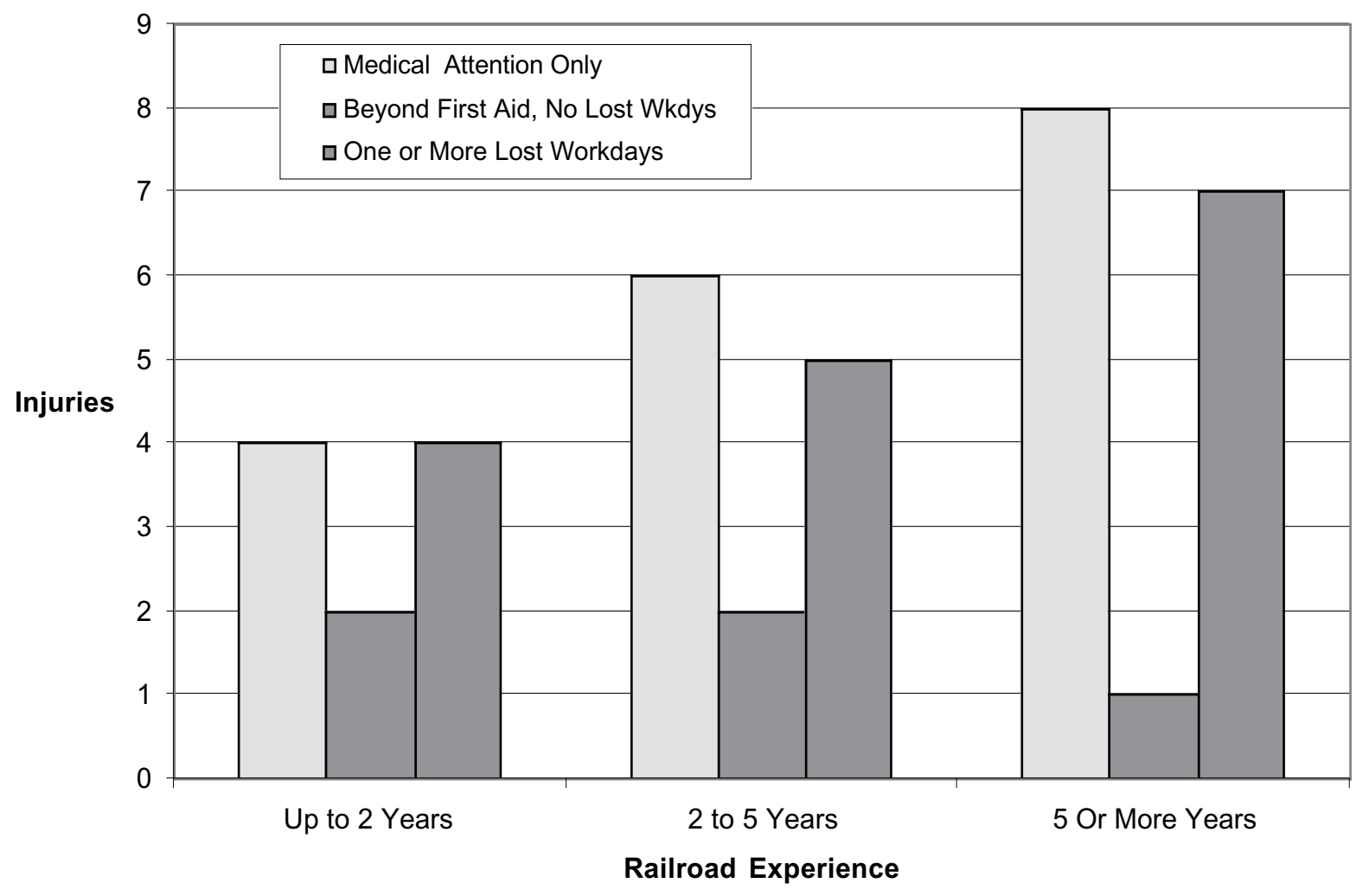

Figure 31. Interaction between participating railroad yard injury severity and experience, 1996 to 1998

Table 38. Total and expected number of shifts worked

\begin{tabular}{lccc}
\hline & $\begin{array}{c}\text { No. of Shifts } \\
\text { Worked }\end{array}$ & $\begin{array}{c}\text { \% of Shifts } \\
\text { Worked }\end{array}$ & $\begin{array}{c}\text { Expected No. of Shifts Worked } \\
\text { (\% of Total) }\end{array}$ \\
\hline Injured & 468 & 47 & $494(50$ percent $)$ \\
Control & 520 & 53 & $494(50$ percent $)$ \\
Total & 988 & 100 & $988(100$ percent $)$ \\
\hline
\end{tabular}

Table 39. Total and expected number of shift start times between 8 p.m. and 4 a.m.

\begin{tabular}{|c|c|c|}
\hline & $\begin{array}{l}\text { Total No. of Shift Start Times } \\
\text { Between } 8 \text { p.m. and } 4 \text { a.m. }\end{array}$ & $\begin{array}{l}\text { Expected No. of Shift Start Times } \\
\text { Between } 8 \text { p.m. and } 4 \text { a.m. }\end{array}$ \\
\hline Injured & 126 & 139 \\
\hline Control & 170 & 157 \\
\hline Total & 296 & 296 \\
\hline
\end{tabular}


Table 40. Total and expected number of shifts greater than $8 \mathrm{hr}$

\begin{tabular}{lcc}
\hline & Total No. of Shifts & Expected No. of Shifts \\
Greater Than $8 \mathrm{hr}$ & Greater Than $8 \mathrm{hr}$ \\
\hline Injured & 175 & 171 \\
Control & 189 & 193 \\
Total & 364 & 364 \\
\hline
\end{tabular}

representative, then only 56 percent of all yard injuries are reportable, while 44 percent of the injuries are non-reportable and therefore not reported to, nor collected by, the FRA. Collection and analysis of these currently unreported injuries may prove useful, since they provide another "layer" of safety analysis. Heinrich (1950) proposed that there is a relationship between major injuries, minor injuries, and unsafe acts. Now known as "Heinrich's Triangle," Figure 32 illustrates this estimated relationship between serious injuries, minor injuries and unsafe acts. For every one major (i.e., lost work time) injury, Heinrich estimated there are 29 minor injuries, and 300 unsafe acts. The unreported injuries identified in the analysis of the personal injury data from the participating railroad may be considered minor injuries, while most of the reportable injuries (those that resulted in one or more lost workdays) may be viewed as major injuries. Based on the theory illustrated by Heinrich's Triangle, therefore, the minor unreported injuries may be important to understanding and preventing more serious injuries. In fact, based on Heinrich's theory, collection and analysis of near misses or unsafe acts is also important in understanding and preventing minor and major injuries in railroad yards.

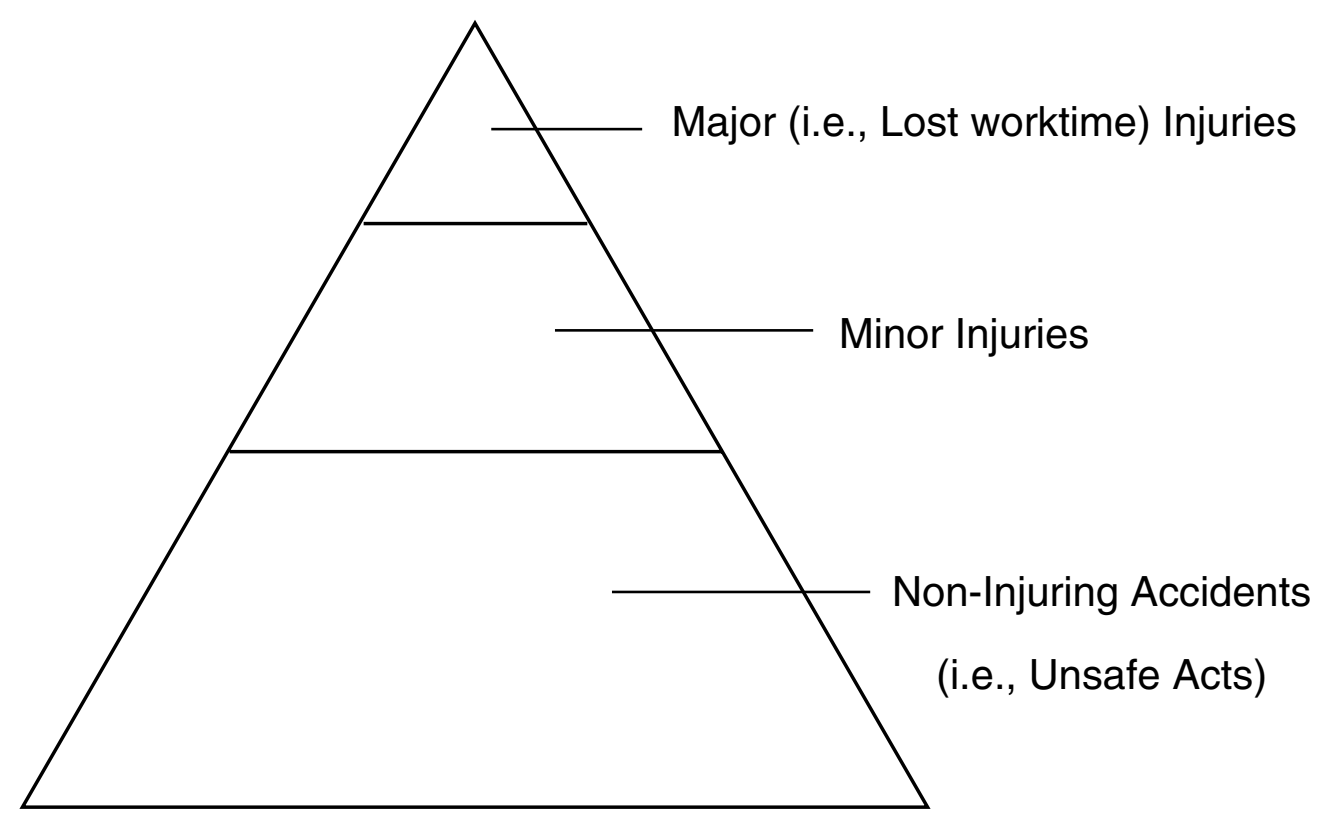

Figure 32. Heinrich's triangle 
- The greatest number of injuries occurred during the injured employees' 4th through 6th hour on duty.

- Although the most injuries in any 2 hour time period occurred between 10 a.m. and 12 p.m., interestingly, the second-most injuries occurred between 8 p.m. and 10 p.m. Exposure data (e.g., the number of employee work hours or cars switched per 2 hour time period) would assist in interpreting these results. Given the difficulty and resources necessary to collect this type of exposure data (i.e., every 2 hours), however, it is unlikely that this data can reasonably be collected.

- There was a statistically significant monthly difference among injuries at the participating railroad. Though the exact differences among months cannot be determined, May, July and August have the highest injury rates. July was also associated with the greatest number of LWD yard injuries in the national FRA injury data.

- The most affected body parts among the participating railroad injuries were the arms and hands (i.e., the upper extremities). This differs from the FRA injury data, in which the torso was the most affected body part.

- Sprains and strains were the most frequent type of injury, and the physical acts of walking, running or stepping over were associated with the largest number of injuries at the participating railroad and in the national FRA injury data. However, while being struck by or against an object accounted for the single-most injuries at the participating railroad yard, slips, trips and falls accounted for the most injuries among the national injury data.

- The work schedule data that was collected represents a type of information that the FRA does not currently collect with respect to reportable nonfatal injuries. There were no statistically significant differences between the injured $\mathrm{T} \& \mathrm{E}$ employees and the non-injured $\mathrm{T} \& \mathrm{E}$ employees with respect to the work schedule variables analyzed. A lack of statistically significant differences does not necessarily mean that operator fatigue is not an issue in yard operations, however. There are a number of checks-and-balances in railroad yard operations, such as constant communication among crew members and watching out for each other. These checks-and-balances may help to prevent operator fatigue from contributing to an injury. However, if there are breakdowns in the checks-and-balances system, then operator fatigue may play a role in injuries. Thus, though no significant differences were found, the issue of operator fatigue in yard operations still merits further study.

\subsubsection{Limitations of the Study Methods and Data}

There are several limitations of both the study methods that were used and the personal injury and work schedule data that were collected. They are presented below. 
- Data limitations

- Limited exposure data available. The only railroad-specific exposure data that were available were the number of cars switched per month and the number of employee work hours per month. These were used to calculate monthly injury rates.

- Partial data. There were a number of injury variables that the FRA does not require railroads to report, but that were of interest to this study. For example, it was desirable to determine if weather or temperature contributed to personal injuries. Some files contained these data, while others did not contain these data. Consequently, these variables were not analyzed.

- Study methodological limitations

- Differences in data that were analyzed. Injury analysis based on the FRA database focused on LWD injuries. Analysis of data from the participating railroad included not only LWD injuries, but also non-LWD injuries and injuries not meeting the FRA's reporting criteria. Comparisons between these analyses must take these differences into account.

- Lack of time-away-from-work data. Given the retrospective nature of the study, data on employees' non-work time were not collected. As a result, what the employee was doing during his time away from work (e.g., whether the employee was sleeping/resting or actively doing something else) was not determined. The absence of this type of information limited the study's ability to explore many of the issues related to work schedules and operator fatigue. 


\section{STRUCTURED INTERVIEWS WITH RAILROAD OFFICIALS}

This section presents the results from a series of structured interviews that were conducted with railroad officials responsible for the development, implementation, and/or oversight of safety programs in railroad yards. The interviews focused on issues that were specific to railroad yards, such as contributors to injuries in yards; however, many of these issues are not limited to railroad yards. In fact, many of the issues discussed are relevant across the entire railroad industry.

A structured interview guide was developed to elicit uniform information from each of the site visits (see Appendix D for a copy of the structured interview questions). Interviews were conducted at four different railroad yards across the country. Subsection 6.1 describes the procedures used in selecting the railroad sites and conducting the structured interviews, while subsections 6.2 through 6.6 summarize the information from the interviews along several main themes.

\subsection{Procedure}

Criteria for selecting sites to visit were first developed. Three different dimensions of a railroad yard were identified: size, switching method and yard type. Each dimension was further separated into two categories. The three dimensions, and their categories, are:

- Railroad size: Class I versus a regional, shortline, or switching operation.

- Switching method: Hump versus flat.

- Yard type: Intermediate versus terminal.

Most railroad yards can be characterized by combining categories from each of the three dimensions. It was desirable to identify railroad yards that represented each of the six categories so that the information gleaned from the structured interviews would be most representative of railroad yards across the country. Four candidate railroad yards were consequently identified as case studies. Table 41 provides some basic demographic information for each railroad yard that was visited. Appendix E contains more detail on each yard, its training program and its injury reporting procedure.

Site visits and structured interviews with officials from the four railroads took place from January 1999 to January 2000, and each typically lasted one full day. Interviews were conducted with some combination of trainmaster, yardmaster, claim agent, safety official, and/or human resources official. At one railroad, local union members who were part of a management-labor safety committee participated in the interview. Anywhere from two to seven individuals were interviewed at each of the four sites; a total of 15 individuals were interviewed. 
Table 41. Structured interview railroad sites

\begin{tabular}{|c|c|c|c|c|c|}
\hline $\begin{array}{c}\text { Railroad } \\
\text { Yard } \\
\end{array}$ & $\begin{array}{c}\text { Yard } \\
\text { Location } \\
\end{array}$ & $\begin{array}{l}\text { Railroad } \\
\text { Size } \\
\end{array}$ & $\begin{array}{l}\text { Type of Car } \\
\text { Switching }\end{array}$ & $\begin{array}{c}\text { Type of } \\
\text { Yard } \\
\end{array}$ & $\begin{array}{l}\text { Average No. of Cars } \\
\text { Switched per Day }\end{array}$ \\
\hline A & Midwest & Switching & Hump & Terminal & 2100 to 2700 \\
\hline B & New England & Regional & Flat & Intermediate & 300 to 350 \\
\hline $\mathrm{C}$ & New England & Class I & Flat & Intermediate & 50 to 70 \\
\hline $\mathrm{D}$ & Midwest & Class I & Flat & Intermediate & 1000 \\
\hline
\end{tabular}

The purposes of the site visits and structured interviews were to:

- Gain an appreciation of the various types of railroad yard environments.

- Identify factors that might contribute to injuries in railroad yards.

- Learn more about railroad yard safety programs.

- Document railroad officials' positive and negative experiences with safety programs.

- Identify industry best practices.

Structured interview questions focused on five major themes. They were:

1. Training.

2. Communications.

3. Safety programs, incentives, and awards.

4. Problem identification and resolution.

5. Regulatory and legal issues.

In addition, information was collected on general yard operations and employee demographics. Results from the structured interviews with railroad officials from the four yards are discussed by topic and are presented below.

\subsection{Training}

Training for yard switchmen at the four sites was similar in many respects. Three of the four sites have an active 6 to 7 week training program for new hires ${ }^{16}$. For these three programs, there is a week of classroom training followed by 5 to 6 weeks of on-the-job training (OJT). The classroom portion of the training covers safety, operating practices and operating rules and may include videotapes as well as lectures and demonstrations. One of the three training programs follows the OJT portion of the training with a day of classroom discussion to share experiences.

The fourth railroad requires new hires to attend a six-week training program offered at a local or community college. Upon completion of this program, the railroad exposes the trainee to a nineweek company training program that combines classroom lectures, discussion and OJT. In this program, the classroom lectures are followed by OJT, and group discussions follow the OJT to allow trainees to share experiences.

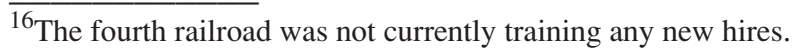


At the three yards that have active training programs, mentors are used in the OJT portion of the training. Railroad management, usually the trainmaster, tries to select experienced mentors who want to train new hires. Depending upon the union agreement for the facility, mentors and the crew working with the trainee may be compensated for this extra responsibility. This in fact was the case at two facilities.

Following successful completion of the training period, trainees complete a 60 to 90 day probationary period in which they work in the yard. During this time the trainee can be dismissed without cause. At the end of the probationary period the trainee becomes a permanent employee, must join the union and receives the benefits of the working contract, including representation in the event of a disciplinary action. At two of the yards visited, yard conductor jobs are filled primarily by experienced workers so new hires must work as a road conductor until a position becomes available in the yard.

In all of the yards that were visited, conductors who go on to become yard engineers must complete standard locomotive engineer training followed by six months of OJT riding with an experienced engineer. In the old days, trainmen and engineers were completely separate and distinct crafts. Firemen served as engineer apprentices, aiding engineers on old steam locomotives. Firemen would eventually be promoted to engineers. However, this craft has all but become defunct due to reduced crew sizes and the use of non-steam locomotives. As a result, nowadays, locomotive engineers generally come from the ranks of conductor.

Two railroads use computer-based training (CBT) for rules training. One railroad uses CBT rules training for all crafts and has found that given the small number of people that must be trained, this method is an efficient and effective way to carry out the training. Another railroad recently implemented a new CBT program for system-wide rules instruction. Officials at this railroad shared several concerns over this CBT system. Specifically, officials felt that CBT eliminates the dialogue and sharing of information and experiences among students, which officials felt was valuable to rules-learning, since not every rule can be applied in every situation. Yard officials also expressed concern that some of the rules that were being taught did not apply to their particular environment, and their students were having trouble with these rules. Their recommendation was to have specialized rules training that would address issues, methods of operation, and hazards that are associated with their specific operating environment.

\subsection{Communication}

Railroads employ a variety of mechanisms to promote safety awareness and report unsafe conditions in the yard. The following two sections discuss the communication methods that the four railroads use for these two purposes.

\subsubsection{Promoting Safety Awareness}

To increase safety awareness, T\&E crews at all four sites conduct daily job safety briefings before they begin their work. As part of the daily briefing, they may read and discuss the "rule of the day." They may also discuss the day's job, how it is going to be performed, and any 
unusual hazards associated with the job as well as strategies to avoid these hazards. Figure 33 presents an example of job briefing guidelines that crews use when conducting job briefings at one of the yards that was visited.

One of the yards has a behavior-based safety improvement program. Management at this site felt that this type of program fosters employee awareness of safe work practices. A second railroad uses observation-based efficiency testing to promote safety awareness. These programs are discussed more fully in subsection 6.4.

One railroad reviews past injuries with each employee every three years. As part of the review, the supervisor and the employee discuss what happened to cause each injury, why the injury occurred, and how a re-occurrence can be prevented. Management at this railroad feels this process makes the employee responsible for his/her own safety behaviors.

Bulletin boards are also used at all four sites to post a variety of safety-related information including procedures for reporting unsafe conditions, illustration of safe work practices and safety program highlights. Minutes of the local Safety Committee meetings may also be posted on bulletin boards or included in a periodic newsletter distributed to employees.

\subsubsection{Reporting Unsafe Conditions}

Every railroad has procedures for reporting unsafe conditions in the yard. The most frequently used method is to report the situation directly to a supervisor, trainmaster or dispatcher. Management at two of the railroads also encourage employees to talk with a member of the local safety committee or the employee's union representative. Two railroads have a corporate or division safety hotline that employees can use 24 hours a day to report an unsafe condition. However, yard managers prefer that employees talk with their supervisor or the trainmaster rather than using the hotline. The four railroads also offer a number of other means for communicating the existence of an unsafe condition, including a company or union-designed unsafe condition report that an employee can fill out and submit to the railroad, and having railroad officials periodically walk around the yard to talk informally with crews.

At one railroad employees who encounter unsafe work conditions are encouraged to report the condition using a number of possible resources, all of which are directed to the safety committee. The safety committee is composed of representatives from all of the major crafts (who are elected by their craft constituents) and management officials, including the trainmaster. Once the safety committee has received an unsafe condition report or notification by someone that an unsafe condition exists, an attempt is made by the committee to address the issue by either fixing it within 24 hours of the condition being reported, or at least putting the process in motion so that the problem can be fixed as soon as possible. In addition to trying to fix the problem within 24 hours, the safety committee also provides immediate feedback to the individual regarding the action to be taken to correct the unsafe condition. Both the railroad officials and a labor safety committee member feel that the system for identifying and responding to problems in this yard is working effectively. 


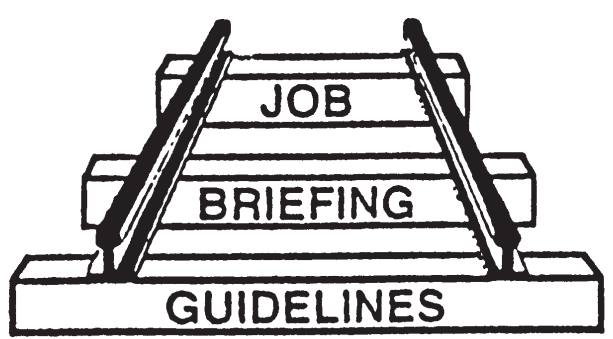

Step 1 Plan the Job Briefing.

A. Develop your own work plan by:

1. Reviewing the work or task to be accomplished.

2. Checking the job location and work area.

3. Breaking the work or task down into a step-by-step procedure.

4. Detemining the tool, equipment and material requirements.

5. Determining what safety rules or procedures are applicable.

B. Consider existing and potential hazards

that might be involved as a result of:

1. Job and weather conditions.

2. The nature of the work to be done.

3. The job location.

4. Determining tool, equipment and material requirements.

5. The equipment to be worked on.

6. Traffic conditions and visibility.

7. The time of day.

8. The safety or personal protective equipment required.

C. Consider how work assignments will be made.

1. Group assignments.

2. Individual assignments.

3. Abilities and experience of individuals.

Step 2 Conduct the Job Briefing.

A. Explain the work or task to employees.

1. What is to be done.

2. Why it is to be done.

3. When it is to be done.

4. Where it is to be done.

5. How it is to be done.

6. Who is to do it.

7. What safety precautions are necessary.

Figure 33. Railroad yard C job briefing guidelines 
In addition, if an employee feels uncomfortable reporting an unsafe condition directly to a company official, they may go through a formalized structure set up by the BLE. Any employee can complete an unsafe condition report and turn it in to a "captain" who then reports it to the safety committee. The report also gets moved up the chain of command within the BLE so that if, at the local level, the unsafe condition report is not addressed, BLE officials notify those higher up within the company. In a worst case scenario, a BLE General Chairman will notify the company's Chief Operating Officer. The UTU has a similar procedure for its members. According to a local union representative who is a safety committee member, it does not matter how the unsafe condition is reported, as long as it is reported, so that they can correct the situation. Reporting unsafe conditions was described as "open door" since everyone talks to everyone else. During the training period, employees at this facility are instructed on the various venues for reporting an unsafe condition.

Another railroad is currently evaluating a process for reporting equipment problems. This system is operational at two yards. Under this system problems are recorded on a log, along with the date and time. Everyday someone from the engineering department reviews the log, corrects the problem, and signs off when the problem has been fixed. Management feels that this system has been successful.

One yard manager reported that even though the railroad makes numerous communication channels available to employees, occasionally an employee might choose to call the FRA rather than work with railroad management to resolve an unsafe condition.

There is also a system in place at some of the railroads that were visited that offers leniency to an employee who reports unfit-for-duty. The system, called Operation Redblock, is a uniondeveloped, company-adopted program in which an employee who reports to work under the influence of drugs or alcohol can take a leave of absence without discipline from the railroad for the first incident. The individual must then participate in a rehabilitation program before returning to work.

\subsection{Safety Programs, Incentives and Awards}

Railroad managers in each of the four yards all expressed the opinion that "safety is an attitude" that must be promoted, but each facility or railroad has implemented different programs to elicit safe work behaviors. Every yard has a daily safety briefing. Beyond this, the programs differ. One railroad established an efficiency testing procedure called, STOP, "Safety, Training, and Observation Program." Under the STOP program, if a railroad official observes someone performing an unsafe act, s/he intervenes immediately to stop the unsafe act, and instructs the employee on the proper procedure. If a person is observed committing multiple errors over time, that individual is called in for additional focused coaching.

Another yard implemented a behaviorally-based safety program to reduce the number of personal injuries in the yard. The idea behind the program, as well as that of behaviorally-based safety programs in general, is that an injury or incident is the result of an individual carrying out unsafe behaviors. Thus, behavioral-based programs emphasize and encourage positive 
behaviors. The goal of the program is to make safe behaviors a habit through the use of 1) positive feedback to reinforce safe behaviors and 2) immediate intervention to correct unsafe behaviors. The program is peer-based. Labor and management convene to identify safe behaviors that they want to increase and then identify a target number of the safe behaviors that will indicate when their goals have been met. Then, through peer-based observation, reinforcement and correction, the program is enacted. The number of safe behaviors is recorded over time and compared to baseline figures. When the number of safe behaviors reaches the target, they are successful. Small incentives such as coffee and donuts, coffee mugs, and free lunches were used to reward safe behaviors. The behaviorally-based safety program at this yard was designed for the railroad by an outside consulting company and has been implemented system-wide. Railroad officials felt that the program had been successful so far, probably due to its novelty, but felt that the challenge would be in maintaining the high number of safe behaviors after the program had been in operation a year or two.

Two of the four railroad yards currently have safety incentive programs. One railroad has an individually-based, quarterly and annual safety recognition program designed to recognize those who did not have a reportable injury. Such items as engraved cups and specially made miniature model railroad cars have been used in the past as quarterly tokens of appreciation to those who were injury-free. At the end of the year, those who remained injury-free would receive a pitcher to go with the cups, or a track set to go with the miniature model railroad cars. Officials felt that these awards were very successful. Recently this railroad supplanted the gifts in the incentive program with a cash system based on safe behavior and discipline experience of the individual. Award is based on long term individual performance, to link individual effort with individual reward.

A second railroad has a similar program with quarterly individual-based and district-based monetary incentives. To receive the individual incentive, an employee has to have no reportable injuries in the last quarter (a "zero hero"). To receive the district incentive, the number of reported injuries within the district had to be below a certain number. The target number of injuries each year is based on a 50 percent reduction in the number of injuries from the year before. Thus, if there were 10 injuries in 1999, the target for 2000 would be five injuries. Railroad management has a similar incentive program.

The remaining two railroads do not have safety incentive programs. Management at one facility felt that some incentive program might be effective in reducing injuries while at the other site management did not feel that such a program would be effective.

One railroad reported conducting a raffle for all employees who had been injury-free. However, railroad officials said that the raffle was not particularly popular with the employees since those who did not win the prize resented not receiving an award, and the program was not repeated. 


\subsection{Problem Identification and Resolution}

Railroad managers at each site were asked to identify the factors that they felt contributed to injuries. The responses fell into three categories_railroad facilities, employee behavior and weather-and are presented in Table 42.

There was not a consistent opinion among managers at the four facilities as to whether or not getting on and off moving equipment is a contributor to yard injuries. Management at one yard that permits the practice felt it can be done safely while the others supported their railroad's policy prohibiting the practice.

When asked to identify factors that might help to reduce yard injuries, yard managers mentioned a number of changes that either reduced injuries to their present levels or show promise for future decreases. These factors centered around railroad facilities and equipment, and employee activities and procedures, and are presented in Table 43.

\section{Table 42. Factors contributing to injuries in railroad yards}

Railroad Facilities and Equipment

- Close clearances between tracks

- Debris in the yard

- Holes in the yard

- Improper ballast

- Inadequate lighting

Employee Behavior

- Complacency/lack of awareness of crews

- Complacency of first-line supervisors

- Poor work habits/improperly executed job steps

- Lack of coordination between crew members

- Fatigue

- Overconfidence of inexperienced workers

- Lack of self-discipline to maintain mental awareness

- Noncompliance with rules

- Distractions in the workplace

- Lack of a "sixth" sense to notice when something is not right, and then to stop, evaluate and proceed

- Physical dexterity

Weather

- Inclement weather 


\section{Table 43. Factors that might help reduce railroad yard injuries}

Railroad Facilities and Equipment

Employee Activities and Procedures
- Cleaning up the yard. Officials at one facility noted that their railroad recently made a substantial investment to clean up the entire property and make capital improvements

- Use of ergonomic (see Figure 34 for an example) and push button switch stands

- Use of radio communications in lieu of hand signals

- Use of radio chest packs to facilitate radio use among crew members

- Use of vehicles to haul and support heavy materials that employees formerly had to haul or support themselves. This was an especially noteworthy improvement in the Engineering department

- Distribution of smaller "walking" stone on switch leads instead of the larger ballast rock

- Re-design of an air hose component to incorporate a valve that employees can use to determine if the hose is still "live" before manipulating or adjusting it

- Improved training, including increased structure and more time dedicated to instruction and learning

- Increased use of personal protective equipment (PPE) such as eyeglasses, ear plugs, and boots

- Increased proficiency testing and added emphasis on behavioral observation

- Daily job briefings to increase employees' attention to job responsibilities and thus reduce complacency

- Three-step protection to prevent the accidental movement of a train anytime a person is fouling equipment

- Executive management's decision to come out to the yard and ride the rails during non-ideal times (e.g., winter), ask safety-related questions, and provide direct answers to employees

- Peer outreach through Operation Redblock

- Introduction of a physical conditioning program prior to the start of daily work

Managers at one yard felt that the condition of their yard, characterized by a lack of conditions that pose safety risks, undoubtedly contributed to their low level of both injuries and claims. They also felt that self-policing by the employees, a feeling of employee ownership of safety and a follow-up program with injured workers to get them back to work all played a role in preventing injuries.

Separately, management at all four facilities expressed the opinion that implementing restricted, or light, duty for yard crafts is difficult for several reasons. First, the job itself is not conducive 


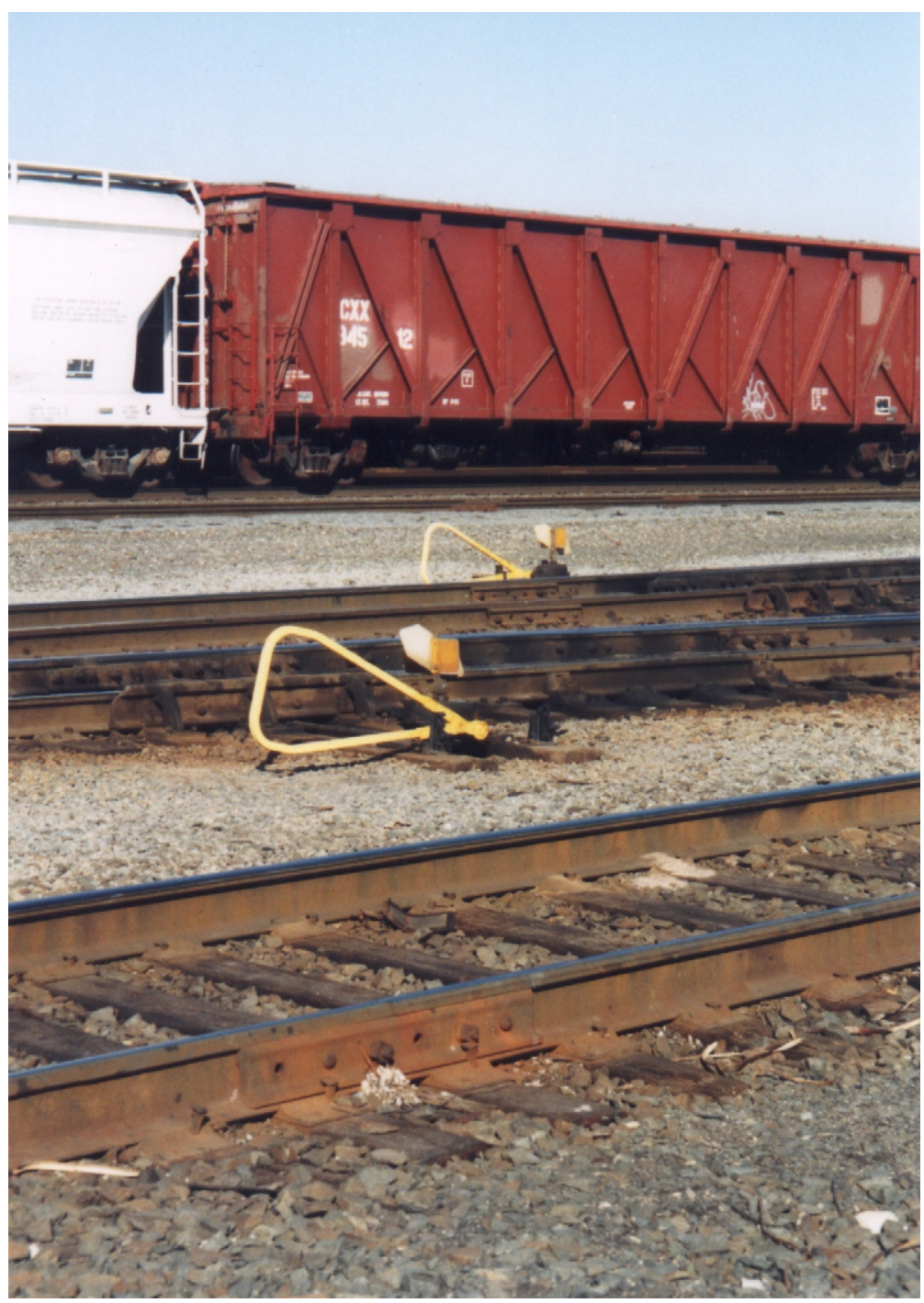

Figure 34. Example of an ergonomic switch stand

to restricted duty due to its labor-intensive nature. It is difficult for an injured conductor or locomotive engineer to work their regular job unless they are completely healthy. An option is to have the injured employee perform other, less labor-intense duties, such as administrative duties. However, often these types of work cut across craft lines and in fact, may violate labor agreements. This option, therefore, may be unacceptable to employees.

When asked about their views on the use of remote control locomotives, railroad officials felt that there were too many unanswered questions with respect to liability, user acceptance, and FRA acceptance to make remote controlled locomotives a realistic candidate improvement to yard safety. 
One safety officer felt that two of the most successful methods of reducing injuries at their railroad have been 1) the prohibition on getting on and off of moving equipment, and 2) the use of three-point protection when working around trains.

There was unanimous agreement among managers at all four facilities that the primary challenge to further reducing injuries in the yard is keeping the employee focused on the job and continuously alert to safety risks. According to these managers, the employee's attitude is key. With young workers this means discouraging overconfidence, and with older experienced workers this means combating complacency.

Railroad yard managers identified a number of additional challenges to further reducing injuries in yards. These include:

- Compliance with the operating and safety rules.

- Getting that small remaining percentage of employees to buy in on safety practices and procedures.

- Increasing communication between employees and front-line managers and supervisors.

- Increased use of personal protective equipment (PPE).

\subsection{Regulatory Issues}

Railroad officials were asked for their opinions with respect to the FRA's role in promoting safety and the relationship of FELA to the work environment. A variety of opinions was offered on each topic, and each is presented below.

\subsubsection{FRA's Role in Promoting Safety in Railroad Yards}

Officials at one yard meet monthly with senior FRA regional officials as part of a casualty reduction effort. This regular meeting has been helpful in keeping both groups abreast of rapid changes in regulation, operating practices and technology. Generally, during the joint FRA/ railroad meeting, outcome ratios or metrics are avoided, focusing instead on process and followup. FRA participation in these meetings has also encouraged the sharing of best practices.

At another facility, management noted that FRA on-property safety audits were helpful. Railroad officials reported that sometimes FRA inspectors find problems that railroad personnel have overlooked. It was also felt that FRA inspectors make valuable suggestions on methods to resolve specific problems. However, management at this railroad pointed out that routine "paper" audits, which require railroad personnel to prepare extensive documentation for FRA inspectors rather than perform their normal job duties, were not seen as beneficial to the railroad.

Officials at another location felt that the FRA sometimes overreacts to situations, typically in response to big events such as a train collision. As a result, officials felt, often a regulation is 
changed or added before the need for the new regulation, or its impact, is fully assessed. Two examples were offered: communication between dispatcher and crew when conveying verbal movement authorities, and the requirement to use End-of-Train (EOT) devices (viewed as unnecessary). The feeling of officials at this yard was that, in general, the railroads are being over-regulated.

Officials noted that many of the FRA inspectors come from the ranks of labor, and thus are perhaps overly sympathetic to labor's concerns. Officials also noted that the FRA enforces rules, but holds the railroad, not the employees, accountable. According to one official, employees should also be held accountable.

\subsubsection{FELA and the Railroad Yard Work Environment}

Railroad officials expressed a variety of opinions regarding FELA's relationship to a safe work environment. Some felt that FELA is an economic, not a safety, issue and if FELA were replaced with a no-fault workers' compensation system, the only change would be in how claims are handled and compensated. In other words, it would not affect the number of reported injuries in yards. Other railroad officials felt that FELA has implications for a safe and harmonious work environment. One individual felt that changing from FELA to a no-fault system would change the employee's motivation and result in less time off following an injury. Others felt that FELA leads to adversarial relationships between labor and management and that without FELA, both workers and management would be more likely to openly discuss safety-related issues and work cooperatively.

\subsection{Discussion}

Based on the four site visits, a number of strategies were identified that appear to foster worker safety in yards. These strategies are summarized and presented below by category.

- Training

- CBT can be an effective method for rules training. However, a forum for employees to share information and experiences should be provided.

- Local community colleges can be a training resource for initial training for yard train and engine crews. However, if this training is primarily classroom-based, the railroad must provide complementary field trips and hands-on training.

- The most effective OJT mentors are those who are selected because of their desire to train others and their skill in teaching others.

- Communications

- Railroads offer a variety of ways for employees to report unsafe conditions. Individual preferences determine which method an employee will exercise. 
- Behavior-based safety programs may have potential to foster employee awareness of safe work practices. However, based on the limited number of sites examined, and railroadspecific issues such as labor contracts, it is premature to endorse this concept without further study.

- $\quad$ Equipment and Facilities

- Ergonomic and push button switch stands, use of radio communication in place of hand signals, use of "walking" stone on switch leads, and a clean work environment can all help to reduce injuries in railroad yards.

- Employee Performance

- Each employee must feel ownership of safety in the yard and must take responsibility for his or her safe work practices. Improved training, emphasis on behavioral observation, and daily job briefings are methods used by the four sites to keep employees focused on safe work practices. Assessing the efficacy of these programs was not a part of this study. 


\section{FOCUS GROUP INTERVIEWS WITH RAILROAD LABOR}

Focus group interviews with railroad yard workers provided a forum to gather information about worker perceptions of the yard environment and to solicit ideas, from the worker's perspective, as to how safety can be improved in railroad yards. These structured group meetings also provided a forum to obtain feedback on two concepts for future data collection-a supplemental anonymous injury survey and a third-party safety reporting system. The following sections describe the procedures used to conduct the focus group interviews, a profile of the participants, and the information gathered.

\subsection{Procedures}

St. Louis, MO, Houston, TX, and Chicago, IL were selected as focus group interview sites due to the large number of railroad yard workers available in each location. St. Louis is a major rail hub connecting trains headed in all points of direction; Chicago is the country's most active rail hub; and Houston is a major intermodal port terminal serving the Gulf of Mexico as well as a major interchange point for east-west rail traffic.

Participants were recruited from the three general crafts that make up the majority of yard workers: trainmen (switchmen and conductors/foremen), engineers, and carmen. An attempt was made to have the make up of each group be representative of the mix of crafts working in a yard at any time. That is, trainmen were most represented, followed by engineers, and then carmen. The unions representing these crafts, the United Transportation Union (UTU), the Brotherhood of Locomotive Engineers (BLE) and the Brotherhood Railway Carmen Division of the Transportation Communication Union (TCU), assisted in identifying candidate participants.

The following criteria were used to identify candidate participants:

1. The candidate must be a trainman, engineer or carman.

2. The candidate must currently work in a yard.

3. The candidate must be interested in sharing his or her perceptions and opinions regarding working in and around the yard environment.

A total of 11 focus groups were conducted. Three to four topics were discussed in each location, and 11 topics were addressed (Table 44 lists the topics addressed at each location.) Each focus group interview lasted 1 1/2 hours and participants were compensated for their participation. Eight focus groups were held with experienced yard workers, and three focus groups were held 
Table 44. Focus group location, worker experience and topics discussed

\begin{tabular}{|c|c|c|c|}
\hline Location & $\begin{array}{l}\text { No. of Focus } \\
\text { Groups }\end{array}$ & $\begin{array}{c}\text { Worker } \\
\text { Experience }\end{array}$ & Topics Discussed \\
\hline St. Louis & 2 & Experienced & $\begin{array}{l}\text { - Factors contributing to yard injuries } \\
\text { - Overall safety climate } \\
\text { - Supplemental anonymous injury survey }\end{array}$ \\
\hline Houston & 3 & Experienced & $\begin{array}{l}\text { - Injury reporting and follow-up process } \\
\text { - Safety incentives and initiatives }\end{array}$ \\
\hline Chicago & 3 & Experienced & $\begin{array}{l}\text { - Reporting unsafe conditions } \\
\text { - Third-party safety reporting system } \\
\text { - Safety rules and procedures } \\
\text { - Training on new rules, procedures and } \\
\text { equipment } \\
\text { - Work schedules and overtime }\end{array}$ \\
\hline Houston & 3 & Novice & $\begin{array}{l}\text { - Initial training } \\
\text { - Overall safety climate } \\
\text { - Injury reporting and follow-up process } \\
\text { Work schedules and overtime }\end{array}$ \\
\hline
\end{tabular}

exclusively with novice workers, that is, individuals who had been working in their present craft less than three years. The reason for conducting three focus groups exclusively with novice workers was twofold. The initial training experience of new hires was expected to differ from that of the veteran workers, and, in addition, less experienced workers were more likely to be affected by irregular work schedules.

\subsection{Participant Profile}

A total of 80 people participated in the 11 focus group interviews. Each group session included representatives from the three crafts. Figure 35 presents the distribution of participants by craft.

Over half of the participants $(n=48)$ were members of the UTU. The remainder were split between the BLE $(n=17)$ and TCU $(n=15)$.

Participants' experience in their present craft ranged from a median of 1.1 years for novice carmen to 27 years for experienced trainmen. (See Figure 36).

\subsection{Focus Group Findings}

The following sections summarize the information gathered from the 11 focus groups, and are organized and presented by topic. Appendix F contains the original set of focus group questions. Where responses from the experienced and novice workers were similar or overlapped, they are reported together; where there are differences in perception and/or opinion between the experienced and novice workers, responses are reported separately. 


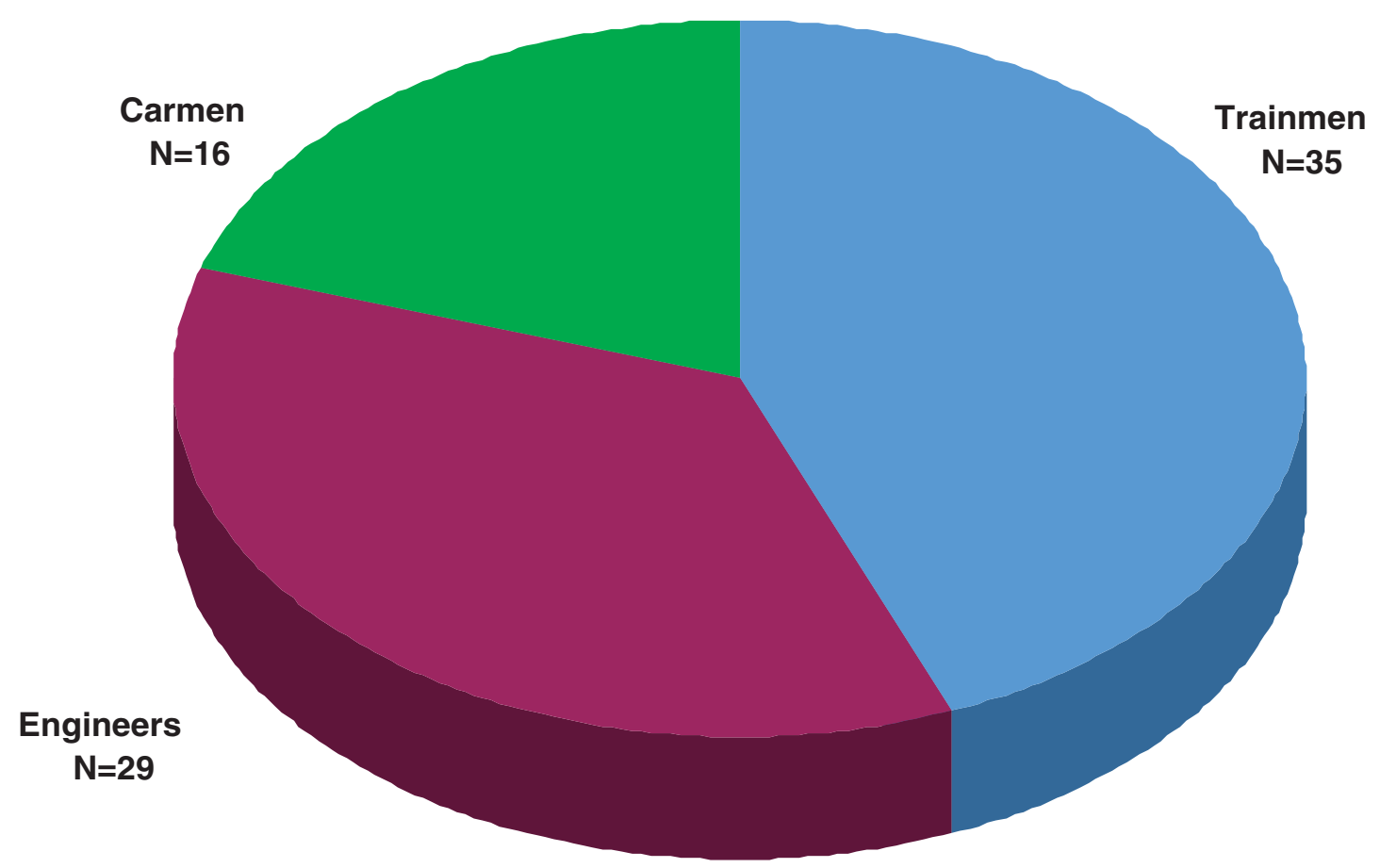

Figure 35. Distribution of focus group participants by craft

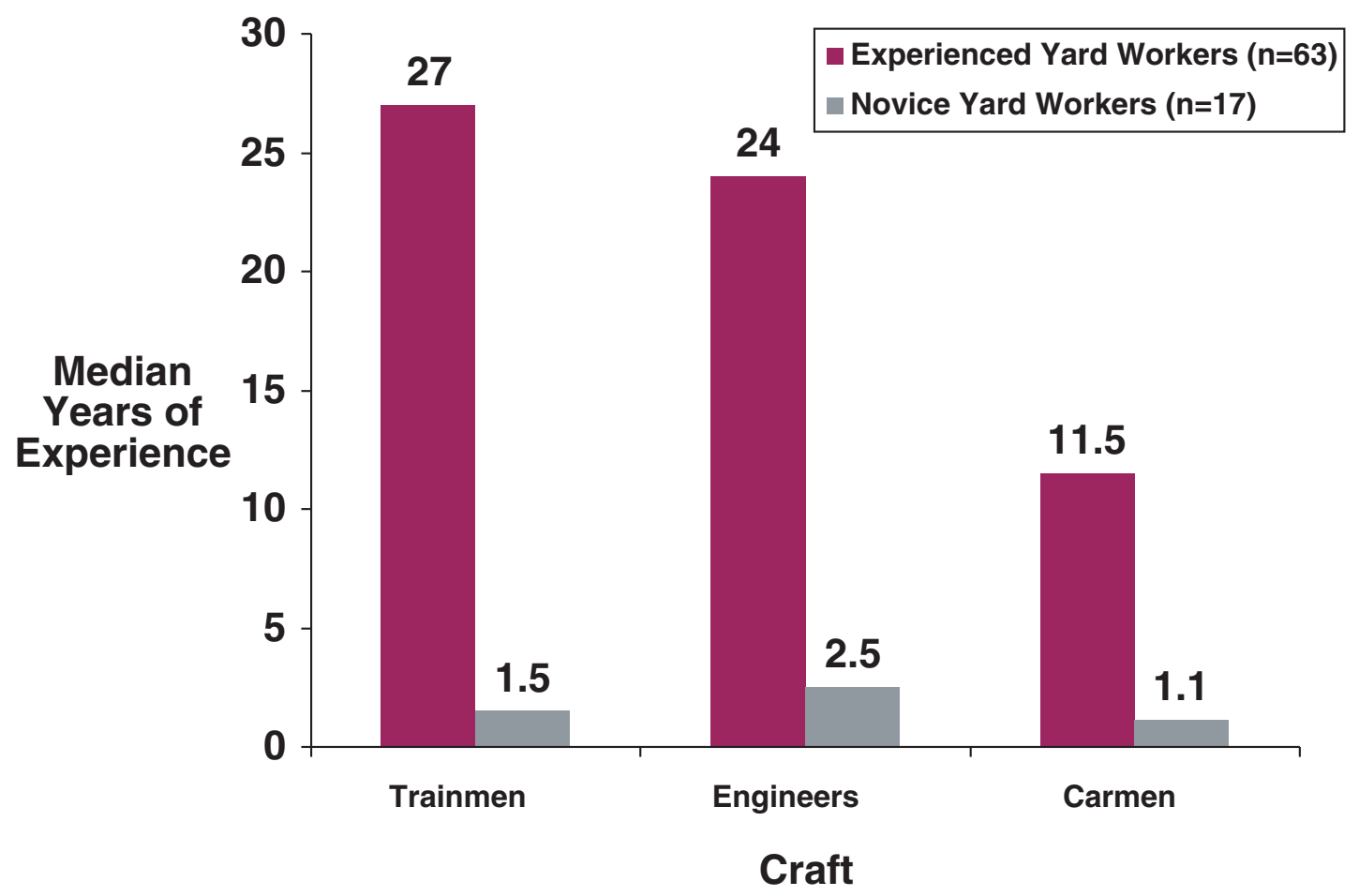

Figure 36. Focus group participant experience in present craft 


\subsubsection{Factors Contributing to Yard Injuries}

Participants identified and discussed a number of factors that they felt contributed to personal injuries in railroad yards. The factors centered around two main themes: 1) railroad facilities, such as poorly maintained equipment, debris in the yard, and inadequate radio channels; and 2) railroad policies and procedures, such as training, operating rules, and work schedules. Each of the factors is briefly discussed below.

- Railroad Facilities

- Poorly maintained equipment, such as locomotive seats, locomotive windows that do not open, sticky switches, problematic pin lifters, defective hand brake handles, and engine oil on the steps, catwalk, and windows of locomotives. Participants felt that an inadequate number of maintenance personnel and budgetary pressure not to repair the equipment may have contributed to this problem.

- Inadequate lighting. Participants noted that some yards did not have overhead lights for nighttime work, while lighting systems in other yards were either inadequate or produced glare. In general, however, any overhead yard lighting was welcome.

- Debris in the yard. Debris around the yard, such as scrap or piping that fell out of a gondola car, was perceived as a problem, particularly at night when it was more difficult to see the debris.

- Inadequate radio channels/poor radio quality. Participants felt that there were too few radio channels in use for the number of people using radios in the yards, and the quality of the radios was also extremely poor. Participants felt that use of the same radio channel by multiple crews resulted in interference, disrupted and repeated broadcasts, confusion, and miscommunication. Participants complained of getting "cut out" because there is so much "flak" on the radio, or having to repeat instructions to a fellow crew member.

- Use of mainline ballast in the yard. Some participants found walking on mainline, 3 in. ballast rock placed along the tow paths in some yards to be difficult and uncomfortable. Use of smaller, $3 / 4$ in. rock around the tow path was suggested because the smaller rock is easier and more comfortable to walk on.

- Inadequate clearance between tracks. In some yards, tracks were perceived to be placed so close together that an individual had to turn sideways to walk between the two tracks. Figure 37 provides an example of a track configuration with close clearance.

- Railroad Policies and Procedures

- Rules related to getting off moving equipment. Some participants felt strongly that their railroads' prohibition on getting off moving equipment has resulted in a more dangerous situation because the energy resulting from the slack action of the cars is transferred to 


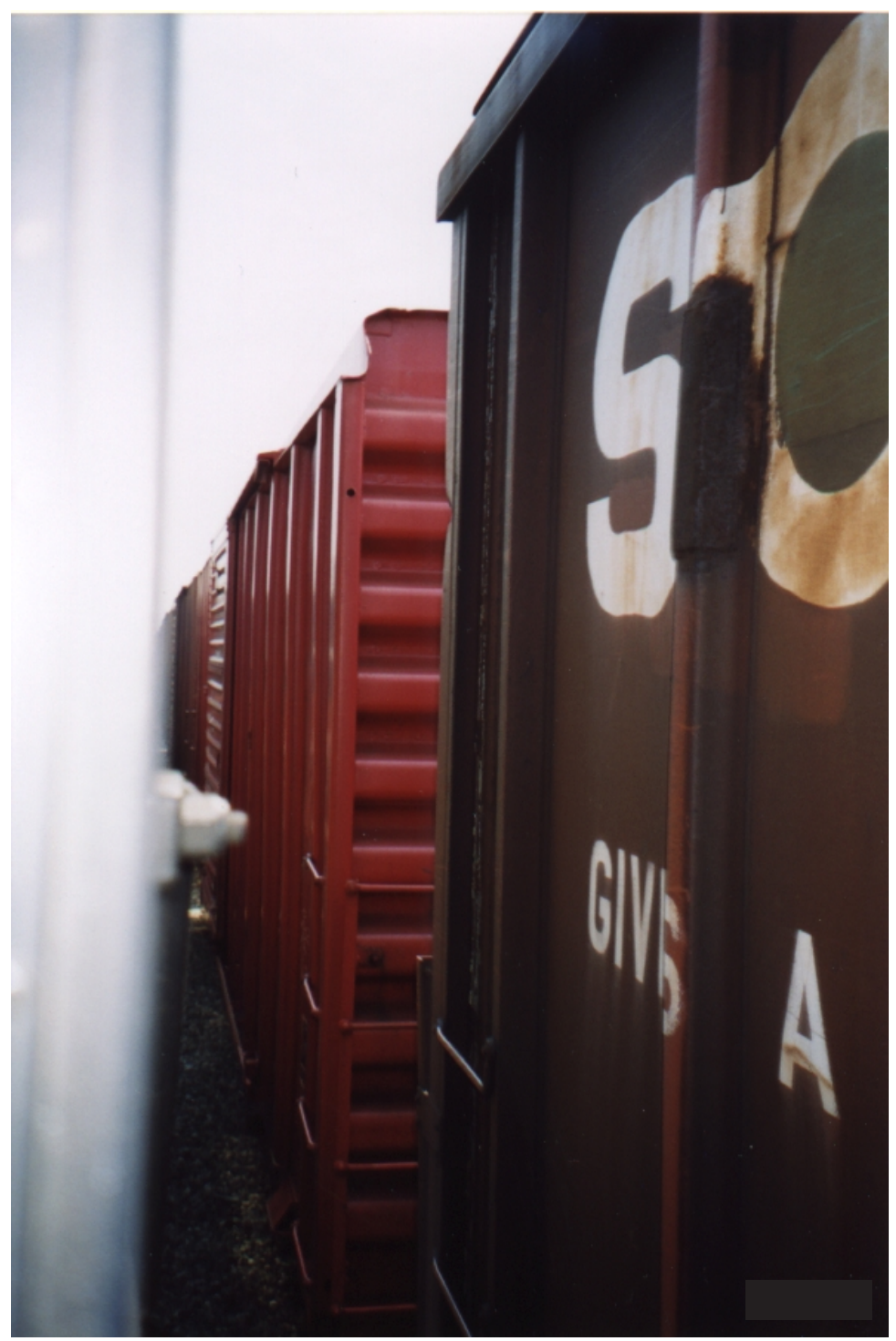

Figure 37. Example of close clearance between railroad tracks in a railroad yard

the trainman. In addition, participants felt that it is important to know how to get off moving equipment in case of an imminent derailment. Participants felt that railroads are doing a disservice to new employees if they do not teach employees how to get off of moving equipment.

Some railroads' rules permit dismounting moving equipment by setting down the trailing leg first. Several participants found this practice more difficult and awkward than using the leading leg. Participants noted that they had been setting down their leading leg first when getting off moving equipment for their entire career. 
- Inadequately prepared new co-workers. The prevalent feeling was that new trainmen and engineers are given work responsibilities before they have mastered the skills to work safely. According to one participant, "You're throwing these new people in here so fast...(that) they don't have their feet on the ground". Several participants also expressed concern that trainmen are promoted too quickly. Participants felt that this resulted in an increase in inexperienced trainmen and engineers, a situation that participants felt jeopardizes the safety of everyone working around them.

- Inadequate training procedures. Some of the training methods used by railroads to train employees on new procedures were perceived by participants as inadequate and aimed at protecting the railroad from litigation rather than on training employees. For example, one participant reported that his railroad mailed an instructional videotape to each employee along with directions to view the videotape and sign and return a form acknowledging that he had viewed the tape. The employee felt that this approach was designed to protect the railroad from future litigation rather than train the employee.

- Harassment. Participants reported that frequent harassment by supervisors was problematic and distracting.

- Irregular work schedules and fatigue. Participants were concerned that irregular work schedules and long hours create the potential for a person to make a mistake because he or she is tired. Participants felt that this was an issue especially for people on the extra board, typically the less experienced and least senior employees, and carmen who are not subject to Hours of Service regulations. In addition, participants felt that inadequate staffing results in pressure to accept overtime. Subsection 7.3.9 provides an in-depth discussion about the issues related to work schedules and fatigue, and their impact on working in railroad yards.

\subsubsection{Overall Safety Climate}

Focus group participants painted a negative picture of the safety climate in railroad yards. They felt that railroads do not care about their employees, do not look out for their employees, and treat them as expendable. The result, according to focus group participants, is that employees trust neither management nor its policies and procedures. Participants felt that harassment and intimidation are commonplace, and are used to pressure employees to do their jobs faster, to cut corners, to not report injuries, and to not repair or report malfunctioning equipment. The prevalent feeling was that the railroads say one thing, but do another. For example, several participants referred to their railroad's policy of empowerment, which empowers an employee to turn down an assignment if they feel it is unsafe; however, participants said that if the employee turns the assignment down, then he or she may be written up for insubordination because he or she did not follow the supervisor's order to perform the assignment. However, one participant felt that his railroad's empowerment policy was particularly effective at protecting him from taking an action that he deemed unsafe. 
Participants felt that railroads use the operating rules against employees, especially if the employee gets injured, in order to protect the financial interest of the railroad. Participants felt that safety incentives, including the Harriman Award, are ineffective and in fact weaken the overall safety climate. One participant described safety incentives as "subtle intimidation" because incentives encourage underreporting of injuries. Participants said that they do not work safely because they will earn a free meal, hat or some other material incentive. Instead, participants reported that their motivation is internal and is based on personal safety and wellbeing.

One group of participants characterized management as having a double standard with respect to safety. Participants perceived pressure to work quickly and to ignore the need for equipment repairs. However, if an employee was injured, it was felt the railroad would place the blame on the employee for not working safely and that he or she could expect to be fired.

Participants felt that there was an adversarial relationship between workers and management, which caused participants to look out for each other in the yard. Participants said that this selfreliance results in informal teamwork, where co-workers will watch out for other co-workers and correct one another if they see someone doing something unsafe. Most participants said that they would correct a co-worker if s/he were doing something in an unsafe manner. However, a few participants said that, although they might correct a new hire, they would be reluctant to correct an "old head" unless there was a significant safety risk. A few of the participants believed that management is trying to undermine this spirit of teamwork by training new employees to not listen to the "old heads," and to tell management when they see an "old head" doing something improperly.

Participants noted several other contributors to a negative safety climate. These included being called into work on day(s) off; poor equipment and track conditions; the lack of response by the railroad in fixing unsafe conditions after they have been reported; lack of counseling after witnessing a traumatic workplace event such as a fatality; complacency of co-workers, poor weather conditions, problems with radio transmissions, excessive speed by carmen on motorized scooters, and working with someone who is not familiar with the particular area of the yard where work must be performed.

While the majority of the participants felt that an overall negative safety climate existed in some railroad yards, many also noted significant improvements in some safety-related areas in the last 15 years. Examples cited included implementation of daily safety meetings and procedures designed to encourage working safely, such as requiring communication among all individuals working in a particular area.

Some typical comments were:

- "The intimidation is incredible. As long as you do everything and get their cars done, then everything's cool, but if you get hurt or break a rule, then it's not." 
- "Empowerment, if it's used properly, is the greatest tool out there in the work force. But the way they write this empowerment is 'Okay, you empower yourself not to throw that switch,' but if you refuse to do a job because you feel it's unsafe, you can be gone for insubordination."

- In reference to being told not to "bad order" a car: It "detracts from your attitude towards safety because not only are you personally being criticized for the work that you think you're doing that may help out an engineer...but on top of that, you're being told by a supervisor that you're not performing your function in a professional way."

- "When it suits, the rule book...is what we go by...[unless] it's more expedient to cut a corner."

- "The only time safety comes up is when it costs them [railroads] something."

- "If you go by the rules all the time every single day, they'll watch you and wait for you to step out of line and get one rule even halfway sideways, that's it. It's over."

\subsubsection{Safety Incentives and Initiatives}

Participants were unanimous in feeling that safety incentives, such as gift certificates to the company store, free meals, clothing, and coffee mugs play little if any role in encouraging safe work practices. Material incentives were seen as a subtle form of intimidation not to report injuries; if an employee reports an injury, then he just cost his co-workers their free meal. Most participants preferred to see the money spent on cleaning the yard and making other safety improvements. Participants felt that the real incentives are given to managers in the form of monetary bonuses, and that this was "upside-down." It was suggested that railroads share these bonuses with their employees. Additional suggestions that were made included repairing the yard, separating tracks that are too close together, and spending the money to hire more people.

According to participants, the Harriman Award also plays little, if any, role in motivating employees to work safely. The award was seen as a political trophy for the railroads, and the award's beneficiaries were the managers whose bonuses are tied to winning the award.

Participants described a number of railroad safety initiatives, including safety days, "switch blitzes," and yard walk-throughs. All efforts by a railroad to fix equipment were welcome, but observation and violation-based programs such as safety days, for example, where a trainmaster goes out to the yard and records safety violations, were unwelcome and seen as unproductive.

Participants were also asked their opinions on behaviorally-based safety programs. Participants felt that there was no need for such an observation-based program since they already look out for each other and correct one another out in the yard. They did not see a need to formalize this approach, and were concerned that any type of formalized, management-sponsored observational program would turn into a "big snitch" program with those who were observed becoming the focus of safety investigations. 
Some typical comments were:

- "They don't have to pay nobody to work safe."

- "The best incentive is to be able to go home with everything we came to work with."

- "The best incentive is to have a safe place to work and know that the people you're working with, they're not worn out, not worked to death."

- "Coming home to my family every night or every day after a day's work. That's my main incentive [to work safely]."

- "I'd trade it all [the incentives] for legitimate safety concerns. Come out here and oil some switches. Put out small rock to walk on."

- "Any incentive program I've seen is upside down. Why should that guy sitting up there in the office be rewarded while we're out there doing the work moving the freight?"

- "If we meet out safety goals as far as safety goes, then everybody gets a bonus every three months. Well, if a guy smashes his thumb, he's thinking, I don't want to turn this in because we're gonna lose our incentive and everybody...is gonna hate my guts. [So he] puts his thumb back in his glove and he goes back to work."

- With respect to a behaviorally-based observation program: "We [already] look out for each other."

- "Work goes better if they leave us alone."

\subsubsection{Injury Reporting and Follow-up Process}

Two themes emerged from discussions on injury reporting and follow-up process. Focus groups participants felt that:

1. Employees are discouraged from reporting minor injuries.

2. The process is designed to place blame on the employee.

Participants reported experiencing harassment and intimidation not to report an injury or when filling out an injury report, and thus were reluctant to report minor injuries. Several participants reported being discouraged by their supervisor from reporting an injury. Some participants expressed concern that, if they reported an injury, they would be labeled by their railroad as "accident-prone" and eventually fired. Engineers feared losing their Engineer certification. Novice employees felt that new employees in the derail period would be even less likely to 
report an injury because they can be fired without cause and without recourse ${ }^{17}$. Participants felt that the result of this reluctance to report minor injuries is that frequently employees simply go home with minor injuries and tend to them on their own time.

Participants also reported that some railroad officials pressured injured employees to make a statement to the railroad immediately after an injury, before receiving medical attention. The immediate pressure to make a statement to railroad officials was seen as another form of harassment, particularly since at the time, the injured employee is not in a clear mental state to recount the facts of the injury. The prevalent feeling among participants was that railroads collect information on the circumstances of the injury to protect their legal position, not to determine the cause of the injury and fix the problem. Participants felt that railroad management was more concerned about determining that the employee was at fault than about the severity of the injury and the employee's well being. Several participants were not comfortable going to a company doctor because they felt that the doctor favored the railroad, and consequently the medical attention that they would receive would reflect the railroad's interest rather than their (i.e., the patient's) interest.

Participants suggested that employees were also reluctant to report an injury for which they were partly to blame, out of fear that the railroad would try to place all of the blame on the employee. They felt that in such cases, the employee is likely to treat the injury on his or her own time. Participants were dissatisfied with the current system that requires an injured employee to report an injury within 24 hours. Participants explained that there are some situations when it is not immediately clear whether the injury will go away (e.g., a strained back). By the time the employee realizes that the injury is more severe than expected, it is too late to report it. If the employee tries to report it, participants felt that the railroad will try to fire the employee because he or she did not adhere to the railroad's 24 hours time limit, and thus violated a rule.

Most union contracts require railroads to conduct a formal investigation or hearing before disciplining an employee. Participants felt that these investigations or hearings were neither formal nor impartial. According to participants, the railroad has already made a decision about the injured employee's discipline before the investigation or hearing begins, regardless of what the employee or witnesses say. According to participants, typically railroads cite a host of rule violations that are used to blame the employee for the injury. Employees use the investigation or hearing to document their side of the story for later arbitration by a third party. The consensus was that investigations or hearings do not in any way attempt to identify root causes of the injury. Separately, a few participants felt that employees who serve on a safety committee receive preferential treatment with respect to these investigations and disciplinary actions following an injury or equipment mishap involving that individual, and that this was unfair.

Some railroads offer an injured employee the option of light duty after an injury. Most participants felt that light duty did not benefit the injured employee, but rather was used by the

\footnotetext{
${ }^{17}$ The "derail" period is a probationary period that lasts for 60 to 90 days following formal training. During this time the trainee works in the yard, but he or she cannot belong to a union, and consequently has no recourse if he or she is disciplined or dismissed.
} 
railroad as a way to show that the employee was not severely injured in the event that the employee files a claim against the railroad. Some participants felt that light duty jeopardizes any potential legal settlement for the injured employee by reducing the perceived severity of the injury.

Some typical comments were:

- "Some of them actually discipline you, fire you, pull you out of service as soon as you're injured."

- "From the beginning of the initial notification of the injury, all attempts are to try to safeguard the carrier's legal position and exactly putting the employee at fault, thereby eliminating any possible claims against the carrier."

- “The attitude is, if you get injured, it's your fault. You're guilty until proven innocent."

- “They don’t harass you. They fire you!"

- "When you get injured, you get more harassment than you can shake a stick at."

- "In investigations, they're their own judge and jury.

- “There's a no-win situation here. They encourage you, if you get injured, to report it. But they're also discouraging you from reporting it. They intimidate you."

- "I've seen people get fired for tripping and getting stitches."

- 'It's all intimidation...I feel like I am being made an example of [because I suffered an injury on-the-job and have not been allowed to return to work] in order to intimidate and scare other switchmen [from reporting an injury]."

\subsubsection{Reporting Unsafe Conditions}

Most participants agreed that today, in contrast to earlier times, railroads make greater efforts to identify and fix unsafe conditions, though the extent of the effort appears to vary by carrier. According to participants, there are a number of ways in which yard workers can report an unsafe working condition. A yard worker may talk to the yardmaster directly; s/he may file an unsafe condition report; or s/he may use the company's safety hotline to report a problem.

Many participants reported that their railroad also had a labor-management safety committee that served in an oversight role to review and follow up on unsafe condition reports to ensure that the repairs are made. Although most participants felt that these safety committees were effective, a few participants expressed concerns. Two specific issues raised were that 1) some individuals used these safety committees as "downtime," and 2) the individual taking the minutes for the 
committee could adjust the results to favor the railroad (e.g., to report fewer unsafe conditions or more unsafe conditions that had been fixed).

Most participants felt it was also important to create a paper trail to hold the railroads accountable for the repair. Separately, some participants notified a union official whenever an unsafe condition was reported to the railroad.

Participants were of the opinion that repair of an unsafe condition typically depended on 1) the cost of the repair; 2) the ease of the repair; 3) the severity of the unsafe condition; and 4) whether the condition delayed trains. Participants expressed frustration with the railroads' decisions not to make certain repairs because the costs of the repairs were not in the budget. Separately, one participant explained that some employees may be reluctant to fill out an unsafe condition report because if the employee suffers an injury while working in the area where the problem exists, they fear that the railroad will say, "It's your fault because you knew the problem was there."

Some typical comments were:

- "[It] Depends on the cost factor whether it gets fixed or not."

- "It always comes down to the carrier's budget."

\subsubsection{Safety Rules and Procedures}

Most participants felt that some safety rules did create a safer work place, while others made things worse (e.g., prohibition on getting off moving equipment), or were there to protect the carrier rather than the employee. Participants reported experiencing pressure to cut corners to complete a job. At the same time they noted a double standard where railroad management typically looks the other way or encourages an employee to cut a corner unless the employee suffers an injury, and then all of the rules are used against the employee in a formal investigation to place blame for the injury on the employee. Participants in the experienced worker groups said that the pressure to cut corners was especially prevalent with the younger employees. However, comments and experiences reported by the novice workers did not indicate that a difference existed in the way they are treated compared to the more experienced workers.

Participants expressed concerns over several specific safety procedures. One concern was that there is no protection for a trainman working in a track while there is switching taking place on both ends of the track, yet a carman working under a similar situation would be protected by blue flag rules. Another concern was the lack of hazmat protection and training. Participants noted, on one railroad, that when servicing local industries that ship hazardous chemicals, railroad employees are not provided with the same personal protective equipment as chemical company employees who load and unload the product. Some participants also wanted more information on the risks that the hazardous materials pose.

Another criticism that participants shared was that, while railroads provide some equipment to assist in doing a job (e.g., use of a "knuckle mate" to assist in coupling cars), they discourage the employee from using the equipment when it is perceived as slowing down the operation. 
Several participants also noted that some safety rules were inconsistently applied. For example, some crafts are required to wear hard hats, while other crafts that work in the same area of the yard are not required to wear hard hats.

Some typical comments were:

- "The book of rules is to protect the carrier in all instances."

- " $[$ Referring to the rules] They're not written to protect me."

- 'If it's costing them money or delays, they don't care whether you live up to the rule or not unless you do something wrong and get in trouble."

- "If you do everything that the rulebook says, you will shut the place down."

- "At some point safety gets to be such a hot topic that you lose focus on what you are supposed to be doing out there."

- "If you break a couple of rules to get it done, as long as you don't get hurt that's cool [to management]."

\subsubsection{Initial Training}

Initial training was discussed with both novice and experienced workers. Novice workers discussed their own training experiences, all of which occurred within the last three years, while the experienced workers discussed their perceptions of the effectiveness of current training programs. As a result of the difference in perspectives and experiences, comments from the novice and experienced workers are presented separately.

\subsubsection{Novice Workers' Training Experiences}

All novice focus group participants reported receiving some formal training prior to working in the yard. Training experiences vary by craft and railroad, and sometimes even within the railroad. Based on participant-reported information, descriptions of carman, switchman, conductor, and locomotive engineer training programs are provided below. These are the crafts that make up a majority of a yard workforce.

Carmen receive one week of classroom-based company safety training and then they go through a three year on-the-job training period under the supervision of an experienced carman, called a journeyman. During this three-year OJT period, trainees learn all of the different tasks that they must perform. Depending on the railroad, trainees may work at different facilities to be exposed to the different operating environments and equipment. Trainees always work with an experienced journeyman during this OJT period. At the end of the three-year period, trainees qualify as carmen. The focus group participants who were carmen reported feeling that this program has adequately prepared them to do their job. 
Switchmen (also known as brakemen) receive 1 to 3 weeks of formal classroom training followed by 2 to 4 weeks of OJT. The OJT includes time in the yard and/or road trips. Upon completion of the OJT, switchmen work with full responsibilities during a 60 to 90 day probationary or "derail" period in which the employee can be terminated without cause at any time. The trainee's salary during this probationary period is typically less than the rate that will take effect at the end of the derail period. After the probationary period, switchmen receive all rights and privileges accorded to the craft, including full pay. In yards, switchmen responsible for a train are called foremen. Foremen do not receive any additional training.

Promotion from a switchman or yard foreman to a road conductor entails an additional 2 to 5 days of formal classroom training followed by two weeks of familiarization trips. Classroom training includes instruction on how to read track bulletins, train movement authorities, and other train authority information. Road conductors are qualified to work road jobs (as a road conductor) and yard jobs (as foremen and switchmen). That is, conductors are not required to work road jobs; in fact, many qualified road conductors continue to work as yard foremen until they gain enough seniority to hold a road conductor's job.

Promotion to locomotive engineer typically follows experience as a road conductor, and can be as soon as six months after being promoted to a conductor. Sometimes the promotion to engineer is mandatory. Engineer trainees, sometimes called firemen, receive 2 to 3 weeks of classroom training followed by 4 to 6 months of OJT riding with qualified engineers. Some railroads also provide their engineers with several weeks of training at a locomotive simulator facility. After an individual qualifies as an engineer, s/he may work as an engineer or s/he may return to work as a conductor or foremen. Job placement following qualification depends upon the workload and staffing levels at the particular railroad.

Carmen were generally satisfied with their initial training experience. In contrast, the majority of the T\&E participants (switchmen, foremen, conductors, and locomotive engineers) felt overwhelmed by the volume of material covered during initial classroom training, especially those who had no prior knowledge of railroading. They felt that they did not really understand the nature of the work, and the inherent risks, until they actually worked in the yard. Several participants, both carmen and T\&E craftsmen, noted that their railroads effectively used a video of railroad accidents to convey the risks of the job. Participants indicated that this made a lasting impression on them, and it also served to effectively weed out several classmates who were not comfortable with the yard operating environment before they started the job.

All of the participants from the T\&E crafts agreed that the OJT portion of their training was critical to learning their job, but the effectiveness of the OJT experience depended upon the OJT mentor. Aspects of the OJT that participants reported as particularly effective included:

- Being able to ask a lot of questions of the mentor.

- The use of a checklist by the OJT mentor to structure the training.

- Having the opportunity to work with a variety of individuals, each sharing different knowledge. 
Problems arise when a mentor does not allow the trainee to carry out tasks or discourages questions. In addition, participants reported that many times what is taught in class and what is done on-the-job differ, for example the use of various hand signals to communicate information between an engineer and a conductor or switchman. Participants also noted regional differences working in different yards, e.g., a method used in one yard may not be used in another yard in the same railroad. In addition, due to staff shortages, in some cases inexperienced (i.e., newly qualified) employees are mentoring new trainees. Participants felt that this was not only ineffective but also dangerous. Another problem that was noted was that engineer OJT particularly focused on how to run a train over the road rather than in the yard, even though there are differences in braking and train handling between running a train over the road and in the yard. For example, a locomotive engineer operating a train in the yard may have to rely on the use of the locomotive engineer's independent brake to slow and stop the train rather than use the train's air brakes. Another problem was that many times trainees are not instructed on the specific characteristics of a yard (e.g., flat spots along the rail, narrow clearance between tracks, etc.) before working there. Some participants are given a "Zone, Track and Spot" book, which describes some of the physical characteristics of a yard; however, the information may be outdated. Lastly, several participants complained that they were assigned to work in a location where they had never taken a student trip or had not been trained, and therefore were not at all familiar with the location when they started their job.

Participants made several suggestions to improve initial training. They are organized by the type of training and are presented in Table 45.

Typical comments included:

- "Your training is basically up to you. The railroad is not taking responsibility for your training."

- "I think they should lengthen the class time, the book work, because that's where a lot of guys make a mistake."

- "Just because that person works for the railroad doesn't mean that person can train."

- “They tell you 'when you get your engineer's license, you are qualified to train."”

- "I've been here a year and I still don't know all the paperwork."

\subsubsection{Experienced Workers' Perspectives}

The experienced workers comments tended to reflect the experiences reported by the novice workers. Participants strongly felt that the current trainman training is inadequate in preparing new hires to become conductors (or foremen) and switchmen. Participants cited both inadequate preparation and inadequate apprenticeship as the primary problems. 
Table 45. Suggestions to improve initial training

\begin{tabular}{|c|c|}
\hline Type of training & Suggestion \\
\hline Switchmen Training & $\begin{array}{l}\text { - Combine classroom training with visits to the yard to gain a } \\
\text { better understanding of what employees are learning in the } \\
\text { classroom. It is easier to understand the nature of a piece } \\
\text { of equipment or a particular train move by actually seeing } \\
\text { and experiencing it. } \\
\text { - Incorporate more time in the field while still doing class } \\
\text { work. } \\
\text { - Demonstrate to trainees what NOT to do in the yard. } \\
\text { - Include training on relevant paperwork, e.g., how to read a } \\
\text { switch list. } \\
\text { - Include training on the railroad's computer systems. } \\
\text { Access to paperwork and timecards are through computer } \\
\text { systems at some railroads, yet participants reported that } \\
\text { they were not trained on how to use these systems. }\end{array}$ \\
\hline Locomotive Engineer Training & $\begin{array}{l}\text { - Increase classroom time. } \\
\text { cars. } \\
\text { - Familiarize engineers with all locomotives that come } \\
\text { through the yard, not just those used by the railroad. } \\
\text { - If possible, use simulator training. }\end{array}$ \\
\hline General Suggestions & $\begin{array}{l}\text { - Select OJT mentors who want to train new employees; train } \\
\text { those mentors, and compensate them accordingly. A } \\
\text { suggestion was made to survey recent trainees to identify } \\
\text { mentors who were particularly effective during their OJT } \\
\text { period. } \\
\text { - Use a checklist or other training aid to structure the OJT so } \\
\text { that both the trainee and the mentor can follow the trainee's } \\
\text { performance and assess his or her abilities. } \\
\text { - Require employees to work in each craft at least two years } \\
\text { before being promoted. This minimum time on job will } \\
\text { provide the employee time to gain sufficient knowledge and } \\
\text { experience that will be used in the job to which they are } \\
\text { being promoted. }\end{array}$ \\
\hline
\end{tabular}

Participants felt that new hires do not receive enough classroom training prior to working in the yard. Participants felt that community college-based conductor training programs were a good idea in principle, but that the programs need to be more intensive. Participants' chief criticism was that the programs do not teach practical skills, and thus, trainees are not adequately prepared to perform work in the yard. Other limitations of the community college programs that were identified are their failure to teach railroad vernacular and their limited exposure to a working yard. 
A concern that all participants shared was that new switchmen must learn on-the-job concurrently with having job responsibilities. Participants noted that in the past, new switchmen worked with larger crews who could watch out for them and help them learn. At the same time, the switchmen had few responsibilities, so they were able to focus on learning the tasks without the burden that comes with job responsibilities. The current practice is for switchmen to qualify after a brief training period, sometimes as little as two weeks. These switchmen often work with a smaller crew who are also inexperienced, and they have more responsibilities than in the past.

Participants made several suggestions on ways to improve training. These were to:

- Give trainees more classroom preparation.

- Increase crew sizes and ensure that new hires train with experienced crew members to minimize the trainee's responsibilities, so that trainees could learn by watching other crew members, and without responsibilities for the train.

- Certify trainmen. According to participants, this would require railroads to train switchmen and conductors more thoroughly.

- Require a minimum apprenticeship period of nine months to one year before qualifying as a switchman.

- Require a conductor to have at least three years of experience before being promoted to an engineer. Participants noted that railroads are promoting conductors to engineers too quickly, resulting in an inexperienced crew that is responsible for training a new switchman or conductor.

Some typical comments from these experienced yard workers were:

- "...[Y] who has three weeks on the railroad. We're just waiting for something to happen."

- "When I hired on you had five people watching what you were doing. Now you have maybe one and he might be an engineer with two years experience and you have a conductor with four months experience and you're going to have a big wreck because they don't know the rules, they don't know anything yet."

- "They're just pushing them out the door too quick."

- "New people are teaching new people."

- "They can pass the test but they can't do the job." 


\subsubsection{Training on New Rules, Procedures and Equipment}

Participants felt that the railroads provide only minimal training on new procedures, rules, and equipment, and that this training was designed more to protect the railroad from potential future litigation than to properly inform and instruct the employees.

In addition, modified or new rules are introduced in bulletin orders and special instructions, and the burden is on the employee to make sure that $\mathrm{s} / \mathrm{he}$ is cognizant of the latest rules. Participants also said that they receive little if any training on new safety procedures such as proper lifting techniques, and that the railroads do not train enough people on how to use, inspect, and repair all of the equipment used in the yard.

Participants noted several particularly problematic training methods. One method was to send employees training material on a new procedure (e.g., using a proper lifting technique), and then to require the employee to sign a form indicating that they have received and reviewed the training material. Participants felt that this was insufficient, and said that safety programs that required employees to sign off that they had received training served as a paper trail to protect the railroad later if an employee suffered an injury. Participants said that the railroad would use the signed piece of paper as "proof" that the employee had been properly trained, thereby absolving the railroad from responsibility for the employee's injury. Participants also felt that simply watching a training video was inadequate if the instruction does not have clear application to working in a yard, or if there is no question-and-answer period following the video to allow for clarification.

Separately, participants noted that information on new or proposed changes to procedures, rules or equipment may be posted on a railroad-run bulletin board in the crew facility, but the information often comes indirectly from the union or informal discussion among employees.

One suggestion to improve training was to implement periodic refresher "training days" to maintain procedural skills for all yard workers.

A typical comment was: "If you watch the movie and you get hurt, then you're at fault" because you supposedly have been trained.

\subsubsection{Work Schedules and Overtime}

Seniority gives the employee control over his or her work schedule. Because of their seniority, most participants who were experienced workers were able to choose a schedule they wanted. Some participants worked steady shifts while others rotated to accommodate their personal needs. Because the more experienced workers had a significant amount of seniority, they were able to choose their own schedules and therefore fatigue was not much of an issue for them. The more experienced participants felt that fatigue was a problem with the younger employees, however, particularly those working the extra board. Participants felt that understaffing contributed to the fatigue of these less senior workers. 
Work schedule choices for novice T\&E workers were more limited. As with the experienced workers, both seniority and personal choice play a role in choosing a work schedule. However, the less seniority an individual had, the fewer options that were available. Some participants had enough seniority to hold a regular schedule but chose to remain on the extra board for a number of reasons. Their reasons included the opportunity to earn more money, to work a variety of jobs, and the flexibility to take off days when they wanted. However, working the extra board was not easy. Specifically, participants noted that it was hard to manage time away from work and it was difficult to know when to sleep when working on the extra board. Those who prefer to work a regular schedule do so because it allows them to plan time with their families.

A technique used by participants on the extra board to aid in determining whether they were going to work within the next 24 hours was to call the crew caller ahead of time to find out how many positions were left to fill and how many employees were ahead of, and behind, them, in terms of seniority. Given this information, participants could make an educated guess as to whether they would be working that day or evening and therefore could plan their free time accordingly.

The experiences of the carmen differ somewhat from the T\&E crafts with regard to work schedules. Carmen reported typically working a regular work schedule, five days per week, 40 hours. A concern shared by the carmen was that they are not covered by Hours of Service. Consequently, at times they have been required to work many hours without rest, especially when working on a "wreck crew" where carmen are called to the scene of a derailment or incident to repair cars at the scene.

The number of hours worked by the novice employees is governed primarily by the amount of work in the yard and the current staffing levels. Many described work as a "feast or famine" situation: either there was too much work and too few people to do the work, or there was not enough work and too many people to fill the positions (i.e., too many people on the extra board, and the extra board was not guaranteed, resulting in less than five days of work in a week). However, when there was a lot of work, participants reported difficulty in being able to take a day off. In fact, a majority of participants reported feeling pressure from their railroads at one time or another to work on their day(s) off, particularly when traffic was heavy in the yard.

Some participants liked working overtime, while other participants, primarily the more experienced workers, were interested only in working their regular hours. Most novice worker participants wanted to work at least some overtime because of the money. Some preferred to extend a regular 8 hour shift to 12 hours. ${ }^{18}$ Others preferred to work an additional shift on a day not normally worked. Doing overtime by "doubling out," that is, working 8 hours, having the next 8 hours off, and then working another 8 hour shift within the same 24 hour period, was not desirable, although some were willing to do it occasionally for the extra money. ${ }^{19}$ Participants noted being particularly fatigued when working this schedule; however, participants noted that if

\footnotetext{
${ }^{18}$ Some labor contracts stipulate that daily overtime will be paid for any work over $8 \mathrm{hr}$.

${ }^{19}$ This schedule is permitted under current Hours of Service laws, 49 CFR 228.
} 
they turned down the second 8 hour shift, it was possible that the crew caller would pass them over for preferred overtime positions later. In general participants resented being coerced to work excessive hours when there is a lot of work in the yard but not enough staff.

Most participants indicated that taking a personal or sick day was extremely difficult. Several participants reported being harassed at one time or another when they tried to take a day off for personal reasons or because they were sick. However, participants noted that union officials could take a day off for union business with no problem.

While most participants understood the nature of working on a railroad, and have learned how to work with the scheduling and crew calling system, they see room for improvements in crew management. One participant expressed concern that it is only after a string of fatalities that railroads improve a work scheduling situation, and usually because a regulatory agency has intervened. Participants offered the following suggestions to alleviate the current work scheduling problems:

- Give employees the choice to not "double out" (i.e., after working 8 hours and having 8 off, have the right to turn down the next 8 hours) without repercussions such as being passed over for assignment at a later date.

- Have the option to work four or five 10 to 12 hour days per work week.

- $\quad$ Limit the weekly maximum number of work hours to 60 .

- Convert some 8 hour jobs to 12 hours, thus enabling those who want the overtime to take it, and alleviating the need for people to work on their assigned days off.

- Have a minimum lead call time of 2 hours for all crafts.

- Offer an optional additional rest period for those on the extra board.

- For work schedules that involve working both days and nights, work the nights first, then the days.

- Have a guaranteed extra board for all crafts. (Some railroads only have a guaranteed board for engineers.)

- Hire more people.

- Enable employees to take a personal or sick day without being questioned, challenged, or harassed by the crew caller.

- $\quad$ Reduce the number of extra board jobs in favor of more regular jobs. 
Some typical comments were:

- "Seniority prevails."

- "They'd rather take the chance that you'll kill somebody than let you off."

- In reference to a crew caller's attitude toward an individual who wants to take a sick day: "If you can make it to the phone, you can make it to work."

- "Nothing gets done until something [bad] happens."

- "You gotta get it [OT] when you can."

\subsubsection{Supplemental Anonymous Injury Survey}

Participants were asked for their opinions regarding an anonymous system in which an injured employee could complete a survey that contained information about their injury and send it to either the FRA or a third party. All of the information would be anonymous. Such a system would provide the FRA with additional insight into the cause of yard injuries. Currently, if an injury meets certain reporting criteria established by the FRA, a railroad is required to report to the FRA, on a monthly basis, certain information about the injury (e.g., location of the injury, type of injury, number of days away, etc.). All injury information that the FRA receives, thus, currently comes from railroad officials ${ }^{20}$.

Participants felt there is a need for employees to report the circumstances involved with an injury, but they had some reservations about the anonymous survey. Participants did not feel it would be possible to make the reporting completely anonymous, and thus, feared retribution from the railroads. This fear permeated participants' responses. One participant suggested that an injured individual might be motivated to skew the information s/he reports if $\mathrm{s} / \mathrm{he}$ thinks it is at all possible that the report will be used against the employee. One participant suggested that if an employee contributed at all to the injury, they would be unlikely to say what they were doing because they would be concerned that this information would be used against them later in an investigation.

Because the survey is not a prescribed form to complete as part of a railroad's injury reporting process, and because only those with a vested interest in the injury are supposed to be privy to information about an injury if it is litigated, participants noted that injured employees would be reluctant to complete the survey out of fear that the railroad would seek retribution on the employee for sharing injury-related information with an uninvolved third-party.

\footnotetext{
${ }^{20}$ This is different than if an employee is cited as having contributed to a train accident, in which case that individual must be notified by the employing railroad that he or she has been cited in the accident and allowed to provide his or her own account of the accident to the FRA via Form FRA F 6180.78.
} 
Participant responses suggested that the only feasible way to distribute the forms is through the unions. Further, confidentiality is absolutely necessary to obtain a high response rate. However, some participants doubted that the system could be truly anonymous and protect the identity of the individual. Participants anticipated that railroads would somehow obtain a copy of the completed injury survey and the employee would be harassed as a consequence. Overall, participants expressed reservations, even if legal protection from use in litigation were provided.

Some comments included:

- "I think it might be received well because it gives the employee a chance to get his side of the story down, which may not necessarily be reflected in the paperwork filled out by whoever fills out the paperwork."

- "It's better than hearing half the story."

- "I'd be scared to death of writing anything down."

- "No way! If the railroads ever got hold of it, they'd use it against you every way they can!"

- "You can say anonymous, but no one believes in anonymous these days."

\subsubsection{Third-Party Safety Reporting System}

Participants were asked their opinions on a system for anonymously reporting unsafe working conditions, near misses and other safety-related problems to a third party for the purpose of collecting, collating and disseminating information to increase safety in the railroad industry. The FRA, individual railroads, and manufacturers and suppliers could use this data to identify safety issues requiring attention. Such a system-the Aviation Safety Reporting System-has existed in the aviation world for over 20 years, and the U.S. Coast Guard and the Maritime Administration are currently jointly developing a similar system to address marine safety issues.

A few participants felt that such a system would be beneficial since it might allow those who fear filling out an unsafe condition report and submitting it to their own railroad, to report a problem to a third party. However, the majority of participants felt that the system was unnecessary for a number of reasons. Participants felt that:

- The FRA and the railroads already know about the problems.

- The railroads will not correct the problems even if problems are identified.

- The system only encourages one "brother" to rat on another.

- The railroads would seek retribution on the person who filed the report.

A few participants noted that some railroads already have a similar type of system in place where near-miss information is collected, while a few other participants felt that the current in-house system of reporting unsafe conditions was sufficient. 


\subsubsection{FRA Role in Railroad Yard Safety}

Although the questions that were the basis for the focus group interviews did not specifically address the FRA, in the course of the discussions participants made a number of noteworthy observations regarding the FRA's activities and responsibilities with respect to railroad yard safety.

Many participants expressed their thanks to the FRA for providing the opportunity to share their experiences and suggestions. While all participants hoped that the results of this effort would lead to improved safety in the yard, many also expressed skepticism about that occurring.

Participants offered a number of observations and suggestions regarding FRA safety inspections. They acknowledged that there are many conscientious FRA inspectors who make the railroads adhere to federal safety standards, but there is concern in some locations that the FRA is more concerned with railroad management's interests than those of labor. Based on the experiences related by participants, the FRA's response to an employee's complaint of a safety violation appears to vary by location. Sometimes an inspector shows up and in other cases the railroad just gets a call. Participants questioned the FRA's practice of giving a railroad advance notice of a routine safety inspection. They felt this gave the railroad time to cleanup the yard and warn everyone to "do everything according to the rules." Participants also felt that the FRA needs more inspectors to effectively conduct inspections and enforce safety standards.

Several participants favored the FRA setting training standards for new trainmen. They felt that federal regulation was the best way to correct the current practice in which inadequately prepared individuals are allowed to work in the yard.

As described earlier, harassment and intimidation are major concerns of all crafts represented in the focus group interviews. Participants felt that the threat of fines from the FRA does not deter railroads from harassing and intimidating employees due to the small monetary fine. Participants were of the opinion that a $\$ 1,000$ fine is not significant to a multi-billion dollar industry. In addition, participants believed that railroads are able to negotiate the amount of the fines with the FRA.

\subsection{Discussion}

The information gathered from the focus group interviews suggests the following major findings with regard to worker safety in yards:

- Punitive work environment. Participants felt that some yard environments are characterized by harassment and intimidation. According to participants, harassment and intimidation result in: 1) less effective training; 2) underreporting of injuries and unsafe conditions; 3) under-maintained equipment and facilities; 4) fatigued employees; and 5) unsafe work practices (e.g., pressure to rush to get a job done). This animosity appears to hinder sharing information and working collaboratively with management to solve problems. 
- Crew Teamwork. Based on participants' responses, railroads appear to have a built-in teamwork structure within T\&E crews. That is, yard workers, principally switchmen, conductors and engineers, on their own initiative, have developed a strong teamwork ethic. Co-worker cooperation and communication characterize this yard worker teamwork.

- Incentive Programs. Focus group participants were unanimous in their feeling that incentive programs with material rewards have little or nothing to do with worker motivation to work safely.

- Initial Trainman Training. The consensus of focus group participants who had been trained within the past three years was that their training did not adequately prepare them to do the job. Similarly, experienced workers expressed concerns that new trainmen with whom they work were not adequately trained.

- Crew Management. Several aspects of current T\&E crew management practices were a source of dissatisfaction to participants. These included difficulty in taking a personal or sick day, schedule uncertainty for the extra board, and pressure to work overtime. With respect to the carmen, because they do not fall under the Hours of Service Act, there was some concern about working a regular shift after being called during the night to work on a wreck crew.

- FRA's Role. Participants offered a range of opinions with regard to the FRA's effectiveness in promoting worker safety.

In addition to these areas, information gleaned from the focus groups have implications for railroad-based and FRA-based data collection efforts designed to better understand the causes of injuries. The major themes in this regard are the following:

- Obstacles to injury data collection. Based on participants' responses, the current organizational climate (e.g., feelings of animosity, intimidation and harassment) appears to inhibit efforts to collect much data regarding the circumstances around an injury. Each side appears to be motivated to protect itself against possible litigation claims rather than to identify the root causes of injuries. There is no incentive to share information and cooperate in identifying the root causes of injuries. Based on participant responses, less severe injuries are going unreported and consequently the statistics maintained by the FRA likely understate the true frequency and types of injuries occurring in railroads.

- Supplemental anonymous injury survey. A supplemental anonymous injury survey (completed by the injured employee) does not appear to be a solution to collecting additional data regarding the circumstances of an injury. This appears to be due in large part to labor's mistrust of management.

- Third-party safety reporting system. A third-party safety reporting system will work only if all of the stakeholders-the FRA, the railroads and the unions-believe that the safety reporting system can provide useful information and each party wants the system to be established. Successful implementation of this type of system requires that all three parties cooperate and 
participate in its development. Participants noted that 1) at some railroads there are already channels to communicate this information within the railroad, 2) they did not feel that their anonymity could be assured, and 3) they felt that the FRA and railroads already know which problems exist. 


\section{CONCLUSIONS AND RECOMMENDATIONS}

This section presents the conclusions from this research and offers recommendations to both the railroad industry and the FRA on options for enhancing and improving railroad yard worker safety.

\subsection{Key Findings}

This study had four objectives as described in subsection 1.2. The conclusions are described below based on each of the objectives.

\section{Injury and Accident Trends in Railroad Yards}

- Railroad yards are the site for half of all railroad accidents. Of these, half are attributed to human factor causes. In terms of injuries, roughly a third of all railroad worker injuries that resulted in one or more lost workdays (days that the employee was not at work or was not able to perform his/her regular job) occur in the yard. Injuries in the yard are also more serious (as measured by the median number of lost workdays) than those in both the railroad industry and private industry as a whole.

- Sprains and strains were the most common type of injury; the trunk/torso was the most frequently affected body part; and slips, trips and falls were the most common triggering event.

- Younger employees (up to 34) suffered a greater percentage of injuries than their representation in the railroad industry, but the median number of lost workdays that resulted increased with age.

- Monthly differences in the human factor-attributed train accident and lost workday injury rates exist, but the reason for these differences remains undetermined. Similarly, diurnal differences exist in the number of injuries that occur over the course of a day, but without exposure data these differences cannot be adequately explained.

- Ambient temperature also appears to contribute to the likelihood of a human factor-attributed train accident, specifically, more accidents occur during extreme temperatures than in milder temperatures. (Temperature data is not available for injuries, therefore it was not possible to examine the role of weather in the occurrence of injuries.) 
- The analysis of personal injury data from a participating railroad revealed some differences between this site and the national industry data. These differences illustrate the variability within the industry and underscore the importance of each railroad examining the unique conditions and injury experiences in each of its yards.

\section{Effect of Work Schedule on Yard Injuries}

- This study examined the effect of work schedules on yard injuries through focus group interviews and statistical analysis of work schedule data from the participating railroad. According to focus group participants, certain work schedules, such as working two 8 hour shifts within a 24 hour period, are very fatiguing. Limited statistical analysis of work schedule data from the participating railroad did not reveal any statistically significant differences between the injured T\&E employees and a matched sample of non-injured T\&E employees. However, this analysis was conducted with a limited sample of data and a limited number of variables. Before fatigue is dismissed as a safety risk factor in railroad yards, the issue of fatigue and work schedules should be studied in more depth and detail than was possible in this study.

\section{Methods for Collecting Additional Causal Factor Data}

- This study examined two methods for collecting additional types of injury and unsafe condition information. One was an anonymous survey to collect information from an injured employee and the second method was a third party safety reporting system to report near misses and unsafe conditions or acts. Based on feedback from the focus group participants, the anonymous survey most likely will not work because of concerns about privacy. The third party safety reporting system may work if the FRA, the railroad industry, and railroad labor are all committed to developing and implementing it.

\section{Labor and Management Opinions and Experiences Regarding Safety}

- Focus groups representing the various yard crafts and structured interviews with railroad yard management provided insight into opinions and experiences regarding yard safety. Both labor and management agreed that improvements in facilities and equipment have paid off in terms of reduced injuries. According to both labor and management, a variety of communication channels exists for reporting unsafe conditions and labor feels that these options are providing adequate means to report their concerns. However, labor felt that some yard environments still contain harassment and intimidation, a situation they felt limits collaborative problem solving and meaningful dialog between labor and management. Management at all four sites that were visited were unanimous in their feeling that the employee must take ownership of safety in the yard and be responsible for his or her own safe work practices. This feeling appears to be shared by labor, as evidenced by the comments of focus group participants with regard to their internal motivation to work safely. 


\subsection{Best Practices for Fostering a Positive Safety Climate and Reducing Injuries}

Discussions with railroad officials during the site visits and focus group interviews with representatives of yard crafts highlighted aspects of individual railroad practices that fostered a positive safety climate and reduced the risk of worker injuries. The experiences of both groups also suggested additional practices that would be enhancements to the safety climate and would likely prevent injuries. The following suggested best practices, based on the information gathered during the present study, are organized around major themes.

\section{Equipment and Property}

- Provide adequate lighting for night work. A train's headlamp and a handheld lantern or flashlight are insufficient.

- Remove trash, debris, and other slip and trip hazards from the yard on a regular and frequent basis.

- Keep equipment such as locomotives well-maintained.

- Install ergonomic switch stands when replacing older manual switches. Railroads that have installed them reported reduced back injuries.

- Use "walking" (i.e., $3 / 4$ in.) stone on switch leads and tow paths.

\section{Training}

- Select OJT mentors who are interested in training new hires and are effective trainers. Compensate mentors appropriately.

- Combine classroom and hands-on practice during initial training. For procedural training it is easier to learn the procedure if demonstration and supervised practice immediately follow the classroom session on the topic.

- Formally structure OJT using a checklist or other training aid.

- If using CBT for rules training, provide a forum for employees to share information and experiences.

- If in-house training resources are limited, explore training programs offered by local community colleges.

\section{Problem Identification and Resolution}

- Offer several methods for reporting an unsafe condition. Some individuals will take the time to fill out a written report, some prefer to have their union representative do the reporting for them while others may find a telephone message suitable. 
- One railroad that was visited had recently eliminated routine alcohol and drug testing following an injury. Unless there is a compelling reason to believe that the employee was under the influence of drugs or alcohol, this procedure may be unnecessary and may intimidate an employee. Elimination of the mandatory nature of alcohol and drug testing may increase or enhance employees' trust.

- An employee-empowered, voluntary, safety committee, with elected representatives from each yard craft, can be effective in identifying and resolving safety-related problems. Among other responsibilities, the committee should be sure to track the status of unsafe condition reports that are filed.

\section{Incentives and Awards}

- Money is better spent on capital safety improvements (e.g., removing debris from the yard, oiling switches frequently) than on material incentives such as hats and coffee mugs.

\section{Safety Programs}

- Job briefings appear to be effective in reinforcing safe work procedures.

- A behavior-based safety program may be effective in re-enforcing safety behaviors, but any such program must be accepted by employees.

\section{Interaction with Employees}

- Create a supportive work environment. Based on the focus groups, it appears that harassment and intimidation are present in some railroad yard environments, and may lead to unsafe conditions and situations. According to focus group participants, harassment and intimidation result in: 1) less effective training; 2) underreporting of injuries and unsafe conditions; 3) under-maintained equipment and facilities; 4) fatigued employees; and 5) unsafe work practices (e.g., pressure to rush to get a job done). Railroads may want to examine the extent to which these feelings exist among their workers and take steps to create a more supportive work environment.

- Foster crew teamwork. Based on participants' responses, railroads appear to have a built-in teamwork structure within T\&E crews. That is, yard workers, principally switchmen, conductors and engineers, on their own initiative, have developed a strong teamwork ethic. Co-worker cooperation and communication characterize this yard worker teamwork. Railroads have the opportunity to foster safety and productivity goals through this existing teamwork. Examples of areas where teamwork might foster safety and productivity include team training, enhanced communications, and coordination of switching activity.

- Improve crew management. Several aspects of current T\&E crew calling practices were a source of dissatisfaction to focus group participants, and could result in potentially unsafe 
conditions where employees are overworked and fatigued. The practices of other industries characterized by shift work and irregular schedules, both within the U.S. and abroad, might offer some examples for railroad management to consider. For some specific participant suggestions for improving crew management, see subsection 7.3.9.

\subsection{Recommendations for Improved Analysis of Worker Safety}

Enhancements to the FRA's accident and injury data collection and reporting process and additional research offer the potential to provide additional insight into strategies and methods for improving worker safety in yards. They are discussed in the following two subsections.

\subsubsection{Improved Data Collection and Reporting Procedures}

The conduct of this research project identified the following potential improvements to the FRA injury and accident data collection and reporting process:

\section{Develop Better Exposure Measures}

- More in-depth analysis of yard injury and accident data requires additional injury and accident exposure measures. Number of cars switched per month is a candidate exposure measure for both injuries and accidents. This metric, in contrast to the currently reported "yard switching miles," would be a measure of actual operations rather than an estimated measure, which may be the case for number of switching miles.

\section{Develop Better or More Complete Instructions, Definitions and Guidelines}

- Provide an option for "rail" as a type of material associated with an injury (see field 5m, "Result," on FRA Form F 6180.55a). Currently there is no option for reporting the involvement of rail. Other roadbed-related codes are available for describing the circumstances or involvement of other materials in the injury, including "tie," "switch," and "ballast."

- Definition, criteria and guidelines for when and how to properly use the "human factor" injury cause code are lacking. To this end, the FRA might consider including a list of human factor codes from which to select if an injury is attributed to a "human factor." The availability of this data will provide a clearer picture of the nature of human factor attributed injuries, information that is of interest to both the FRA and the industry. Representatives from the FRA as well as railroad labor and management could work with experts in human factors, human performance and/or ergonomics to develop an appropriate set of codes.

\section{Collect Additional Injury-Related Data}

The negative organizational climate that appears to exist in the yard environment likely will limit the effectiveness of new data collection initiatives that focus on obtaining supplemental 
information on injuries. Specifically, based on focus group participants' comments, a supplemental anonymous injury survey is not recommended as a means to collect additional data regarding the circumstances of an injury. Instead, the FRA could request that railroads provide additional data in their monthly injury reports (Form FRA F 6180.55a). Railroads already record some of this data, but there is no requirement to report it. Other data could be collected and reported by the railroads relatively easily. The FRA can incorporate these additional variables through its four "dummy" blank data expansion fields that exist in the current injury database structure. The additional injury-related data include:

- Data on the time the injured employee began his or her shift is a candidate for inclusion in the injury database. The availability of this information will enable the FRA and others to determine the role of time-on-task with respect to injuries. Railroads already record the shift start time, as required by FRA Form FRA F 6180.98, and therefore reporting this information should require minimal effort by the railroads.

- Work experience of the injured employee would prove useful to future safety studies. The U.S. Department of Labor Mine Safety and Health Administration (MSHA), using its MSHA Form 7000-1 (see Appendix B for a copy), collects data on an injured employee's 1) experience in his or her current job, 2) experience at his or her current location (mine), and 3) total mining experience (see www.msha.gov/FORMS/70001INB.HTM for more information). The FRA may want to consider collecting similar data for injured railroad employees. Specifically, the FRA could collect data on the injured employee's 1) experience at his or her current job, 2) experience at his or her current location (e.g., yard) and 3) total railroading experience. The availability of this information will enable the FRA and others to determine the relationship of work experience to incidence of injuries.

- The FRA data collection procedure might incorporate a feature for reporting steps taken by the railroad to prevent the recurrence of the injury or accident. The MSHA requires mines to provide this data as part of its routine accident and injury reporting process (see MSHA Form 7000-1 in Appendix B). The availability of this information may assist the railroad industry in focusing countermeasure efforts and may provide valuable insight into the industry's use of various approaches to prevent railroad accidents and injuries.

- Expand injury data collection to include all railroad injuries that require any type of medical attention. This might provide enhanced insight into the causes of injuries. This research project pointed out that it is likely that there are a number of minor injuries that do not meet the FRA reporting criteria but that could provide additional and meaningful information regarding injuries in the railroad industry. Further, it is possible that injuries that only require first aid (which are currently not being reported to the FRA) are very similar to those that require medical treatment beyond first aid (which are reported to the FRA). This may increase the reliability of the data that is collected on minor injuries, i.e., reportable injuries that do not result in any lost or restricted time. 
- Another option is to revise the reporting criteria to include only injuries that result in lost work time or restricted duty, thereby focusing analytical efforts on the severe injuries. Currently, the FRA requires that some minor injuries (for example, injuries that require medical treatment beyond first aid) be reported. In fact, a majority of the reportable injuries are LWD injuries. However, it is possible that these non-LWD reported injuries may be more similar to unreported non-LWD injuries than to the (reported) LWD injuries. If this is true, the portion of reportable injuries that are non-LWD injuries may be considered part of a larger number of less serious unreported non-LWD injuries. According to Macaskill and Driscoll (1998), in fact, in Australia some states have injury reporting thresholds of five or even 10 days of lost worktime for some industries. They suggest that such thresholds emphasize the "more reliable and interpretable data" (p. 10). The trade-off is that data on the less severe injuries, i.e., the non-LWD injuries, are not collected.

\section{Report Data on Injury Severity}

- The FRA should consider reporting data on the severity of railroad injuries in its annual Railroad Safety Statistics report. This data is currently already being collected by the FRA. Several possible severity measures that might be reported include the median number of days absent from work (DAFW), which the BLS currently reports; the median number of lost workdays (LWD; includes both days absent and/or restricted duty); and/or the total number of DAFWs or LWDs. Injury severity data would complement the injury frequency data that the FRA currently reports in its annual Railroad Safety Statistics report, thus providing a more complete picture of railroad safety.

\section{Encourage and Facilitate Industry Adoption of Computer-Based Data Collection and Reporting}

- The FRA should consider facilitating railroads' use of computer-based injury data collection, storage, and reporting systems. Computer-based systems may increase the consistency of the data across injuries, and may make the reporting process easier for railroads. For example, a railroad claims agent could record information into a ready-made data collection form in a hand-held Personal Digital Assistant (PDA) at the site of the injury or in the field. The SOFA committee made a similar recommendation that data collection be supported by computer systems and suggested that this may reduce the effort required to report an incident and may increase the accuracy of the data reporting (SOFA, 1999).

\section{Continue to Work Collaboratively with Railroad Management and Labor}

- FRA inspectors should continue to work with both railroad labor and management as partners to foster safe work practices in railroad yards. This can occur through the FRA's 1) continued participation on railroad safety committees, 2) sharing of suggestions for "best practices" and "lessons learned," and 3) sharing of positive experiences from other railroads that inspectors have visited. 


\subsubsection{Future Research}

The results of this study suggest areas for future research on issues related to worker safety in yards. They are discussed below.

\section{Examine the Relationship of Work Schedules to Injuries}

- Although the analyses of work schedule data indicated that there were no significant differences between the injured group and a non-injured matched group, fatigue may nevertheless play a role in railroad yard injuries. Existing data sources are not adequate to explore this issue. Ideally, 30 days of work schedule data for the period prior to the date of the injury should be examined. It is therefore recommended that the FRA work with a limited number of railroads ${ }^{21}$ and, on a trial basis, have them record the work schedules for each employee injured in a yard and an age, craft and experience-matched control group. At the end of an appropriate period, the injury and schedule data can be analyzed to determine if there is a relationship between work schedules and injuries in yards. The decision to collect this type of data on a permanent basis would depend on the results of this evaluation. In fact, the Switching Operations Fatality Analysis (SOFA) committee recently recommended that one month of work schedule data be routinely collected as part of the investigation process for each railroad fatality (SOFA, 1999).

\section{Examine the Impact of FELA on Injury Reporting and Data Collection}

- FELA's effect on injury reporting is unclear. Based on the tenets of the at-fault system, it is logical for railroad management and labor to not want to openly exchange injury-related information, particularly if either party believes that they are partly culpable. To examine the role of FELA on injury reporting in the railroad industry, it is proposed that the FRA compare the railroad yard environment to a similar heavy equipment/manufacturing environment that is unionized (e.g., an auto assembly plant) and that is covered by no-fault workers compensation. A study can be designed and implemented to compare injuries and the injury reporting process between the at-fault and no-fault environments.

\section{Examine the Feasibility of Developing a Third-Party Anonymous Safety Reporting System}

- The FAA and the Coast Guard/Maritime Administration have established third-party safety reporting systems to collect and collate data on near misses and other unsafe acts in their respective industries. The purpose of these systems is to better understand the precursors and circumstances surrounding these dangerous incidents and disseminate this information to the industry and others. The feasibility of developing and implementing a similar third-party near-miss data collection system for the railroad industry merits serious consideration.

Based on information collected from the focus groups and structured interviews, such a system will work only if all of the parties involved-the FRA, the railroads and the unions-

\footnotetext{
${ }^{21}$ Railroads that use electronic record-keeping of T\&E employees' work schedules are recommended.
} 
believe that it can provide useful information and each party wants the system to be established. The feasibility study should explore under what circumstances the safety reporting system can be successful, stakeholder expectations from such a system, and protections/assurances that each party needs. The study should also concentrate on identifying barriers to the development of such a system and effective strategies to overcome barriers to implementation of the safety system. The feasibility study should be as inclusive as possible, and should involve Class I and shortline and regional railroads, all representative unions, as well as FRA staff members.

\section{Conduct Root Cause and Error Analysis of Railroad Yard Injuries}

- Analyses of existing FRA accident and injury data are limited due to the type of data that are collected and the retrospective nature of the data collection. Several industries are beginning to conduct human factor root cause analyses to identify the chain-of-events that led to the accident or injury. In fact, in the railroad industry both Railtex and Canadian Pacific Railway have adopted this process. The rationale behind this approach is that the immediate act that preceded the accident or injury is simply the last step in a series of events that truly led to the incident. Root cause analyses focus on "unwinding the tape" to explore what led to the incident. To do this, individual, environmental, and managerial factors are examined. Each of these factors can be, and often is, at least partly responsible for providing a situation conducive to the incident's occurrence. Thus, root cause analysis can be viewed as a holistic or systemic evaluation of the circumstances associated with an accident or injury. Root cause analyses yield complex and rich information regarding the likely causes of an accident and injury, and therefore may be very useful in formulating countermeasures to prevent the recurrence of similar injuries or accidents in the future.

The first step would be to design a data collection methodology and instruments to collect root cause information. The methodology would be based on Reason's (1990) Generic Error-Modeling System (GEMS) or a similar error taxonomy. Railroad officers from participating railroads would then be trained on how to conduct a root cause analysis, and given the tools to collect root cause information. The process would likely involve interviewing injured employees, or those involved in a train accident, as the injuries or accidents occur, using formal structured interviews to probe for root causes and chain-ofevent factors. After the participating railroads collect the root cause data, they would submit it to the FRA or a third party to have the data analyzed to identify root causes of the injury or accident. Root causes will include factors such as what the injured person was doing at the time of the injury as well as circumstances and environmental issues that set up the situation that led to the injury or accident. A byproduct of this study will be the development of tools and methods that railroad industry officials could incorporate with their corporate injury and accident investigation procedures in the future to help them determine the likely causes of injuries and accidents on their respective properties. 


\section{Conduct an Information Exchange Workshop}

- Currently the FRA accident and injury data that are collected provide an answer to the question, What types of accidents and injuries occur in the railroad industry? To further reduce accidents and injuries in the railroad industry, it is necessary to move beyond asking What? to Why do train accidents and injuries occur in the railroad industry? A workshop on the state-of-the-art in injury data collection, analysis and reporting in the railroad industry, as well as other industries and modes of transportation, would provide an ideal forum for the exchange of ideas on collecting data that would lead to a better understanding of accident and injury causation. Both private industries and governing agencies responsible for injury and accident data collection should be invited. An emphasis should be placed on lessons learned, both positive and negative. The workshop could include presentations from railroad industry officials as well as representatives from other modes of transportation who could explain their reporting process, their accident and injury investigation procedures, the types of data

that are collected, and how the data are used. A workshop such as this would have an added benefit of promoting partnerships among the FRA and railroads, as well as among the various DOT administrations.

Explore the Feasibility and Effectiveness of Behavior-Based Safety Programs in the Railroad Environment

- Behavior-based safety programs have gained popularity and success in many industries trying to reduce the number of injuries in the workplace. These types of programs may have potential to foster employee awareness of safe work practices in railroad yards and thereby reduce injuries; however, feedback from labor representatives and some of the railroadspecific issues, including labor contracts, suggest that the feasibility and potential effectiveness of behavior-based safety programs in the railroad industry requires further study. The FRA should explore the feasibility of a behavior-based safety program, including 1) the development of a behavioral model to guide any such safety program, 2) the willingness of employees to participate, 3 ) under what circumstances employees would participate, and 4) the expected benefits and risks. 


\section{REFERENCES}

Bureau of Transportation Statistics. (1998). Transportation Statistics Annual Report 1998. (Report No. BTS98-S-01). Washington, DC: U.S. Department of Transportation.

Federal Railroad Administration. (1995). Accident/Incident Bulletin No. 163. Calendar Year 1994. Washington, DC: U.S. Department of Transportation.

Federal Railroad Administration. (1997). FRA Guide for Preparing Accident/Incident Reports. (Report No. DOT/FRA/RRS-22). Washington, DC: U.S. Department of Transportation.

Federal Railroad Administration. (1999). Railroad Safety Statistics Annual Report 1998. Washington, DC: U.S. Department of Transportation.

Harnett, D. L. (1982). Statistical Methods, 3rd Edition. Philippines: Addison-Wesley Publishing Company, Inc.

Heinrich, H. W. (1950). Industrial Accident Prevention (3rd Edition ed.). New York: McGrawHill.

Macaskill, P., and Driscoll, T. (1998). National occupational injury statistics: what can the data tell us? Occupational Injury: Risk, Prevention and Intervention. London, UK: Taylor and Francis.

Minium, E., King, B., and Bear, G. (1993). Statistical Reasoning in Psychology and Education, 3rd Edition. New York: John Wiley and Sons, Inc.

Reason, J. (1990). Human Error. Cambridge, UK: Cambridge University Press.

Saphire, D. (1991). FELA and Rail Safety: A Response to Babcock and Oldfather, The Role of the Federal Employers' Liability Act in Railroad Safety. Transportation Law Journal, 19(2), 401-413.

Schwartz, V. E., and Mahshigian, L. (1986). The Federal Employers' Liability Act, a Bane for Workers, a Bust for Railroads, a Boon for Lawyers. San Diego Law Review, 23:1, 1-15.

Transportation Research Board. (1994). Compensating Injured Railroad Workers Under the Federal Employers' Liability Act. Washington DC: National Academy Press. 
U.S. General Accounting Office. (1996). Federal Employers' Liability Act: Issues Associated with Changing How Railroad Work-Related Injuries are Compensated. (Report No. GAO/ RCED-96-199). Washington, DC: Author. 


\section{APPENDIX A}

\section{FRA AND OSHA JURISDICTION OVER RAILROAD EMPLOYEE OCCUPATIONAL} SAFETY AND HEALTH

The FRA has had a longstanding role in assuring that railroads provide safe transportation by rail. This involvement dates back to the late 19th century when the U.S. Congress directed the Interstate Commerce Commission (ICC) to enforce statutory provisions requiring the use of various safety appliances on railroad cars and engines for the protection of employees and travelers. Since enactment of that legislation, specific statutory authority has been created with respect to several other aspects of railroad employee safety including locomotive inspection standards, reporting and investigation of railroad accidents, the maximum permissible hours of service of railroad employees and the transportation of hazardous cargoes. In 1970, Congress passed the Federal Railroad Safety Act. This legislation extended the ICC authority to the DOT by giving the Secretary of Transportation the ability to exercise broad and general regulatory powers as deemed necessary in all areas of railroad safety. The Secretary of Transportation delegated this responsibility to the FRA.

Another piece of landmark legislation, the Occupational Safety and Health (OSH) Act of 1970, created the situation where railroad workers were subject to potential dual regulation by both the Secretary of Labor and the Secretary of Transportation. The OSH Act requires most employers engaged in a business affecting commerce ${ }^{22}$ to furnish each of their employees with a place of employment free from recognized hazards causing or likely to cause death or serious injury. Since passage of this legislation, the Department of Labor, through the Occupational Safety and Health Administration (OSHA), has developed and promulgated an extensive set of occupational safety and health standards. Some standards apply to all employees while others apply only to employees engaged in certain types of work.

Recognizing that oversight authority for worker safety already existed in other agencies, Congress included a provision (Section 4 (b)(1)) in the OSH Act stating that the provisions of the OSH Act shall not apply to working conditions where another Federal agency exercises statutory authority to prescribe or enforce standards or regulations affecting occupational safety or health. In keeping with the policy stated in Section 4(b)(1), and to avoid duplication of efforts in the area of railroad occupational safety and health, in March 1975 the FRA issued an advance notice of proposed rulemaking proposing standards in three areas of railroad employee occupational safety: 1) means of egress from buildings and structures, 2) general environmental controls and 3) fire protection. Subsequently, the FRA issued a notice of proposed rulemaking in July 1975.

\footnotetext{
${ }^{22}$ There are some exceptions, including public employees, miners and the self-employed, as well as very small businesses.
} 
After conducting hearings on the proposed rules and reviewing written comments, the FRA announced that it was terminating the rulemaking process and did not intend to issue any other occupational safety and health standards concerning problems outside of the general area of railroad operations.

In March 1975 the FRA Administrator issued a policy statement published in the Federal Register which stated that "....we believe that the proper role for FRA in the area of occupational safety in the immediate future is one that will concentrate our limited resources in addressing hazardous working conditions in those traditional areas of railroad operations in which we have special competence." (CFR Part 221, published in Federal Register, Vol. 43, No. 50, March 14, 1978.)

The policy statement continued:

"...FRA has decided to focus its resources and energies for the immediate future on the safety of railroad operations. As used herein, 'railroad operations' refers to the movement of equipment over the rails. The term 'safety' includes health-related aspects of railroad safety to the extent such considerations are integrally related to operational safety hazards or measures taken to abate such hazards. The term 'safety of railroad operations' then relates to the conditions and procedures necessary to achieve the safe movement of equipment over the rails."

The FRA identified three areas where it intends to exercise its expertise: 1) track, roadbed, and associated devices and structures; 2) equipment, and 3) human factors. These are areas where the FRA has specific statutory authority. In addition to the areas mentioned above, the FRA enforces the Department of Transportation's comprehensive Hazardous Materials Regulations with respect to the carriage or shipment of hazardous materials by rail.

Since passage of the OSH Act the FRA and OSHA have worked cooperatively to define the areas of railroad occupational safety that are best handled by each agency. Areas where there is joint but not overlapping responsibility are presented in Table A-1.

In terms of railroad yards, OSHA regulations apply in the following areas:

- Walking-working surfaces in repair facilities, except for inspection pits.

- Means of egress from fixed repair facilities.

- Design of work platforms such as cranes which are mounted on moving equipment.

- $\quad$ Noise exposure in shops. 
Table A-1. FRA and OSHA jurisdictions for worker safety in railroad operations

\begin{tabular}{|c|c|c|}
\hline Occupational Area & FRA Jurisdiction & OSHA Jurisdiction \\
\hline $\begin{array}{l}\text { Walking-Working } \\
\text { Surfaces }\end{array}$ & $\begin{array}{l}\text { Design of locomotives and other } \\
\text { rolling stock. } \\
\text { Movement of rolling stock } \\
\text { through repair shops; inspection } \\
\text { pits. } \\
\text { - Ladders, platforms and other } \\
\text { surfaces on signal masts, catenary } \\
\text { systems, railroad bridges, } \\
\text { turntables, and walkways beside } \\
\text { tracks in yards or along rights-of- } \\
\text { way. }\end{array}$ & $\begin{array}{l}\text { Railroad offices, shops and } \\
\text { other fixed work places. }\end{array}$ \\
\hline Means of Egress & - Rolling stock. & $\begin{array}{l}\text { Fixed facilities other than } \\
\text { employee sleeping quarters } \\
\text { covered by the Hours of Service } \\
\text { Act. }\end{array}$ \\
\hline $\begin{array}{l}\text { Powered Platforms, } \\
\text { Manlifts, and Vehicle- } \\
\text { Mounted Work } \\
\text { Platforms }\end{array}$ & $\begin{array}{l}\text { - Vehicle on which work platform is } \\
\text { mounted. }\end{array}$ & - All work platforms. \\
\hline $\begin{array}{l}\text { Occupational Health } \\
\text { And Environmental } \\
\text { Control }\end{array}$ & $\begin{array}{l}\text { - Ventilation standards as they apply } \\
\text { to locomotive cab or caboose } \\
\text { environments, passenger } \\
\text { equipment or to operational } \\
\text { situations in yards or along the } \\
\text { right-of-way. } \\
\text { - Noise exposure levels relative to } \\
\text { locomotive cabs and cabooses, } \\
\text { retarder noise and other noise } \\
\text { emanating primarily from railroad } \\
\text { operations. } \\
\text { - Noise levels in sleeping quarters } \\
\text { for employees covered by Hours } \\
\text { of Service Act. }\end{array}$ & $\begin{array}{l}\text { - Noise exposure levels in shop } \\
\text { areas, office areas and other } \\
\text { settings in which "industrial" } \\
\text { noise emissions predominate or } \\
\text { where exposure may be limited } \\
\text { without the potential disruption } \\
\text { of safe transportation activities. }\end{array}$ \\
\hline Hazardous Materials & $\begin{array}{l}\text { - Transportation of hazardous } \\
\text { materials by rail. }\end{array}$ & $\begin{array}{l}\text { - Instances where both shipment } \\
\text { and storage or use of hazardous } \\
\text { materials prior to transport. }\end{array}$ \\
\hline $\begin{array}{l}\text { Personal Protective } \\
\text { Equipment }\end{array}$ & $\begin{array}{l}\text { - Activities unique to rail operations, } \\
\text { e.g., coupling/ uncoupling cars. }\end{array}$ & $\begin{array}{l}\text { - In general, OSHA regulations } \\
\text { apply. }\end{array}$ \\
\hline $\begin{array}{l}\text { Materials Handling } \\
\text { and Storage }\end{array}$ & $\begin{array}{l}\text { - Any equipment used in operating } \\
\text { a railroad. } \\
\text { Locomotive cranes and other on- } \\
\text { track vehicles used for } \\
\text { maintenance. }\end{array}$ & $\begin{array}{l}\text { None. OSHA provides } \\
\text { consultation to FRA as needed. }\end{array}$ \\
\hline Machinery and Tools & - None & $\begin{array}{l}\text { - OSHA regulations apply in } \\
\text { railroad shops and other work } \\
\text { places. }\end{array}$ \\
\hline
\end{tabular}


- Personal protective equipment that is not unique to the railroad environment (e.g., steel-toed shoes, work gloves, hard hats).

- Hand and power tools, welding, cutting and brazing equipment, electrical equipment.

FRA's policy closes with the following:

"We believe the policy set forth in this document will assure that each of the principal Federal agencies charged with the responsibility for carrying out this program, that is, FRA and OSHA, will concentrate its efforts in those areas in which it possesses the greatest experience and expertise. In those cases in which there may be some question as to which is the primary regulatory agency, cooperative efforts between the two agencies should avoid the creation of regulatory gaps on the one hand, or unnecessary duplication on the other. At any time that a hazardous working condition impacts upon the overall safety of railroad operations, FRA will take the initiative in developing a proper regulatory response."

Over the years since passage of the OSH Act, the FRA and OSHA have worked cooperatively to assure the occupational safety and health of railroad workers in accordance with the stated FRA policy. In addition, since railroads are required to report occupational injuries and illnesses to the FRA and not OSHA, the FRA provides this data to OSHA. 


\section{APPENDIX B}

\section{FRA AND MSHA ACCIDENT/INJURY REPORT FORMS}

Appendix B contains several relevant FRA accident and injury forms that railroads are required to complete on a periodic basis. Form FRA F 6180.55 (see Figure B-1) is used by railroads to report monthly summaries of injuries and illnesses. Form FRA F 6180.55a (see Figure B-2) is used to provide specific information about each injury and illness that occurred in the month that is being reported, and accompanies Form FRA F 6180.55. In addition to reporting certain information about each injury or illness, a railroad must maintain certain information about the injury or illness on file. Form FRA F 6180.98 (see Figure B-3) can be used for this purpose, though the FRA does not require that railroads maintain this specific form, just the information contained therein.

If there is a train accident, a railroad must complete a Form FRA 6180.54 (see Figure B-4). If an employee is implicated as the cause of a train accident, then the railroad must complete a Form FRA F 6180.78 (see Figure B-5) to notify the employee that he or she has been implicated. The implicated employee then has the option of completing a Form FRA F 6180.81 (see Figure B-6) and submitting it to both the employee's railroad and the FRA. For more information about how to fill out each form, see the FRA Guide for Preparing Accident/Incident Reports (FRA, 1997).

Lastly, a copy of MSHA's Form 7000-1 Mine Accident, Injury and Illness Report (see Figure B-7) is included for purposes of comparing a railroad injury report form to one used in a similar industry. 
DEPARTMENT OF TRANSPORTATION FEDERAL RAILROAD ADMINISTRATION (FRA)

\begin{tabular}{|l|l|l|}
\hline 1. Name of Reporting Railroad & 2. Alphabetic Code & 3. Report Month \& Year \\
\hline 6. Name of Reporting Officer & \\
\hline 8. Address
\end{tabular}

OMB Approval No.: 2i 30-05[0] \begin{tabular}{|l|l|l|}
\hline 4. State Alphabetic Code & 5. County \\
\hline
\end{tabular}

7. Official Title

9. Telephone (Area Code) (Number)

10

$$
1,
$$

, being first duly swom, do say upon my oath that I

am

Name of Affiant)

, of the railroad aforesaid and as such officer of the said railroad it is my duty to have supervision

(Title of Office held by affiant)

over the record of reportable incidents arising from the operation of the said railroad, and that I have caused to be compiled from the said record and to be carefully examined the annexed report in attached hardcopy forms or magnetic media or electronic submission of such incidents occurring during the month named at the head of this sheet; and that the said report is true and complete to the best of my knowledge and belief.

Subscribed and sworn to before me, a notary public in and for the State and County aforesaid, this day of

Use an im-

[L.S $]$

pression seal) Notary Public)

(Signature of affiant)

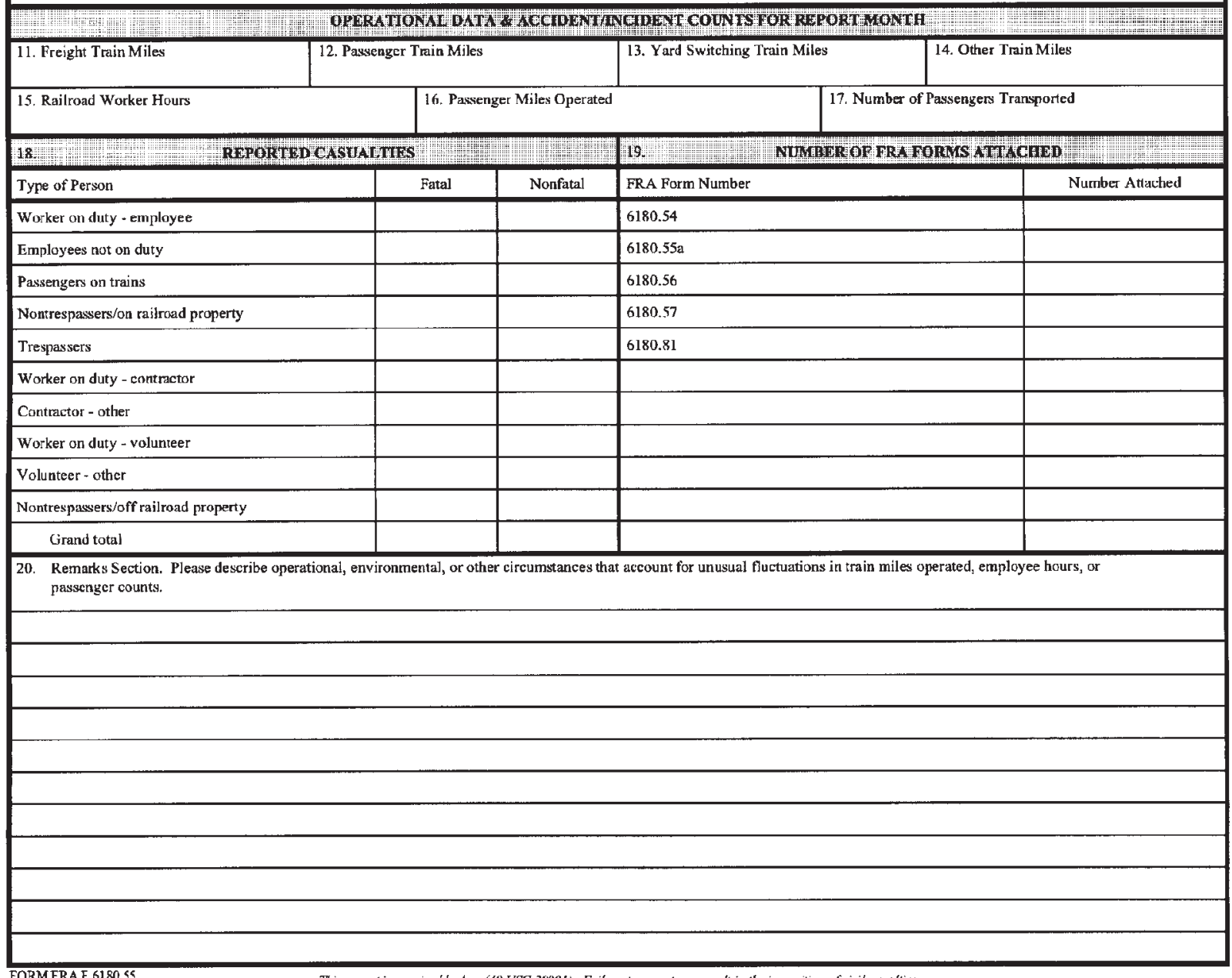


DEPARTMENT OF TRANSPORTATION

RAILROAD INJURY AND ILLNESS SUMMARY FEDERAL RALROAD ADMINISTRATION (FRA)

(Continuation Sheet)

SHEET

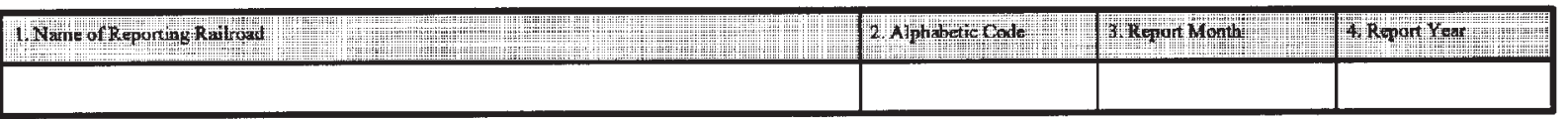
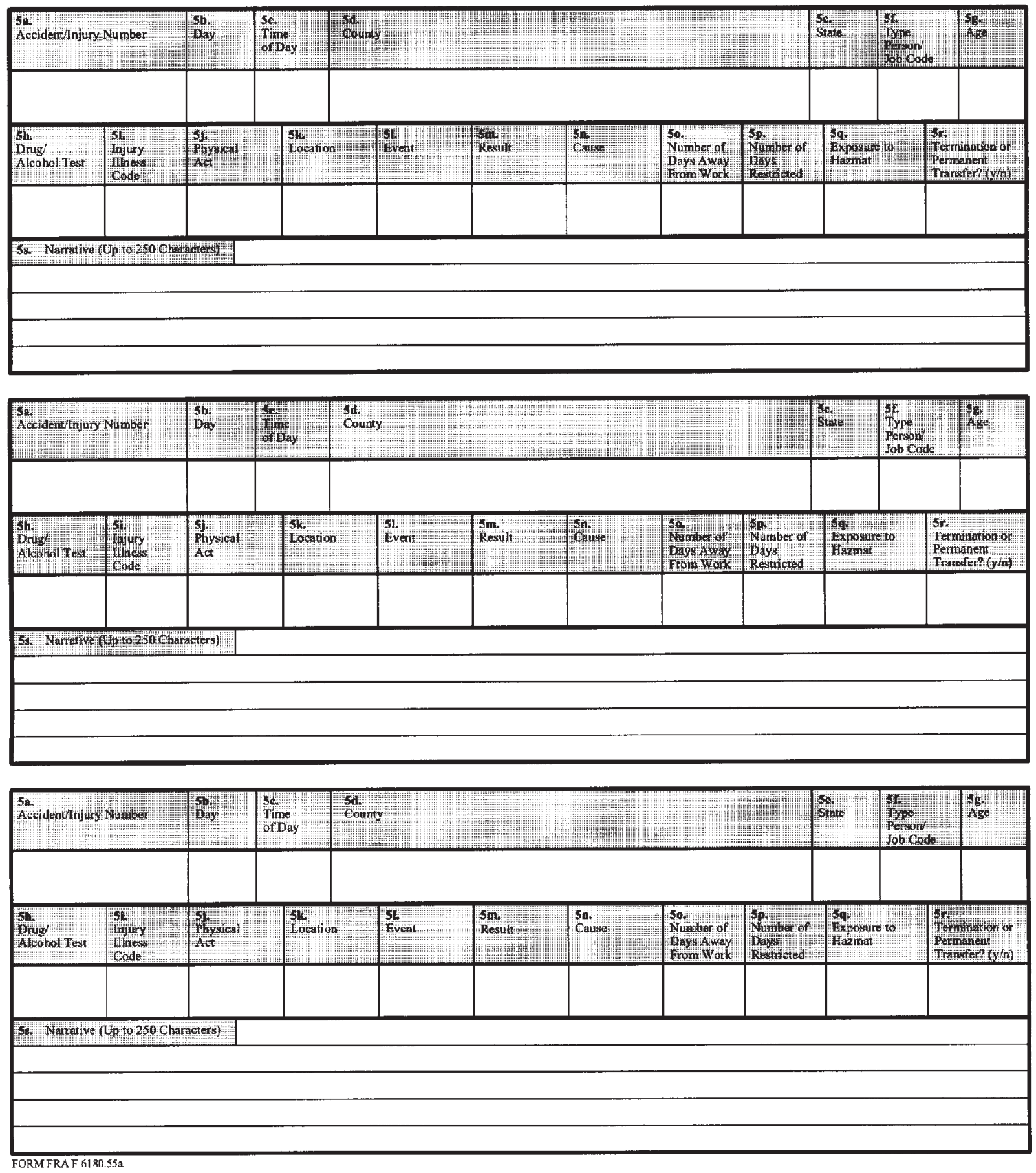

Figure B-2. Form FRA F 6180.55a railroad injury and illness summary (continuation sheet) 
DEPARTMENT OF TRANSPORTATION

RAILROAD EMPLOYEE INJURY AND/OR ILLNESS RECORD FEDERAL RAILROAD ADMINISTRATION (FRA)

OMB Approval Na.: 2130-050

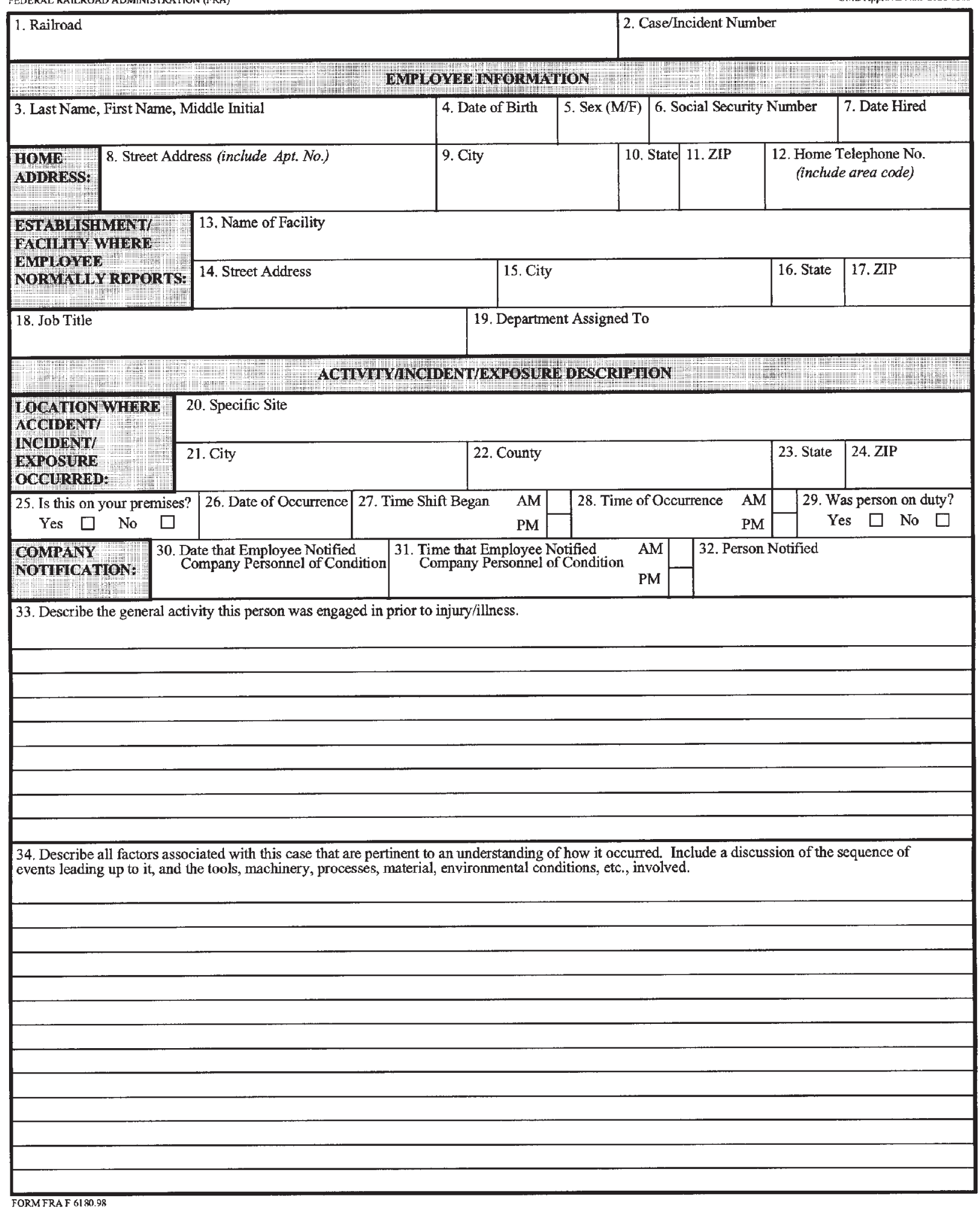

Figure B-3. Form FRA F 6180.98 railroad employee injury and/or illness record 
38. Check any of the following consequences resulting from this injury/condition:

$\square$ Death. Date of:

$\square$ Restriction of work. Total days of restricted activity:

as of:

$\square$ Occupational illness. Date of initial diagnosis:

$\square$ Instructions to obtain prescription medication, or receipt of prescription medication. as of:

$\square$ Missed a day of work or next shift. Actual days absent from work:

$\square$ Medical treatment. This includes any medical care or treatment beyond "first aid" that is given, or should have been given, regardless of who provided the treatment. "First Aid" treatment is limited to very simple procedures, e.g., application of a bandaid on minor scratches, cuts, abrasions, etc.

$\square$ Transfer to another job or termination of employment.

39. If any of the above consequences occurred, the injury/condition is almost always reportable to FRA on Form FRA F 6180.55a. If you believe this case does not meet the reporting criteria, you must give a brief explanation below of the basis for this decision. Was the case reported? Yes $\square \quad$ No 
DEPARTMENT OF TRANSPORTATION

RAIL EQUIPMENT ACCIDENT/NCIDENT REPORT

OMB Approval No:: 2130-05:0

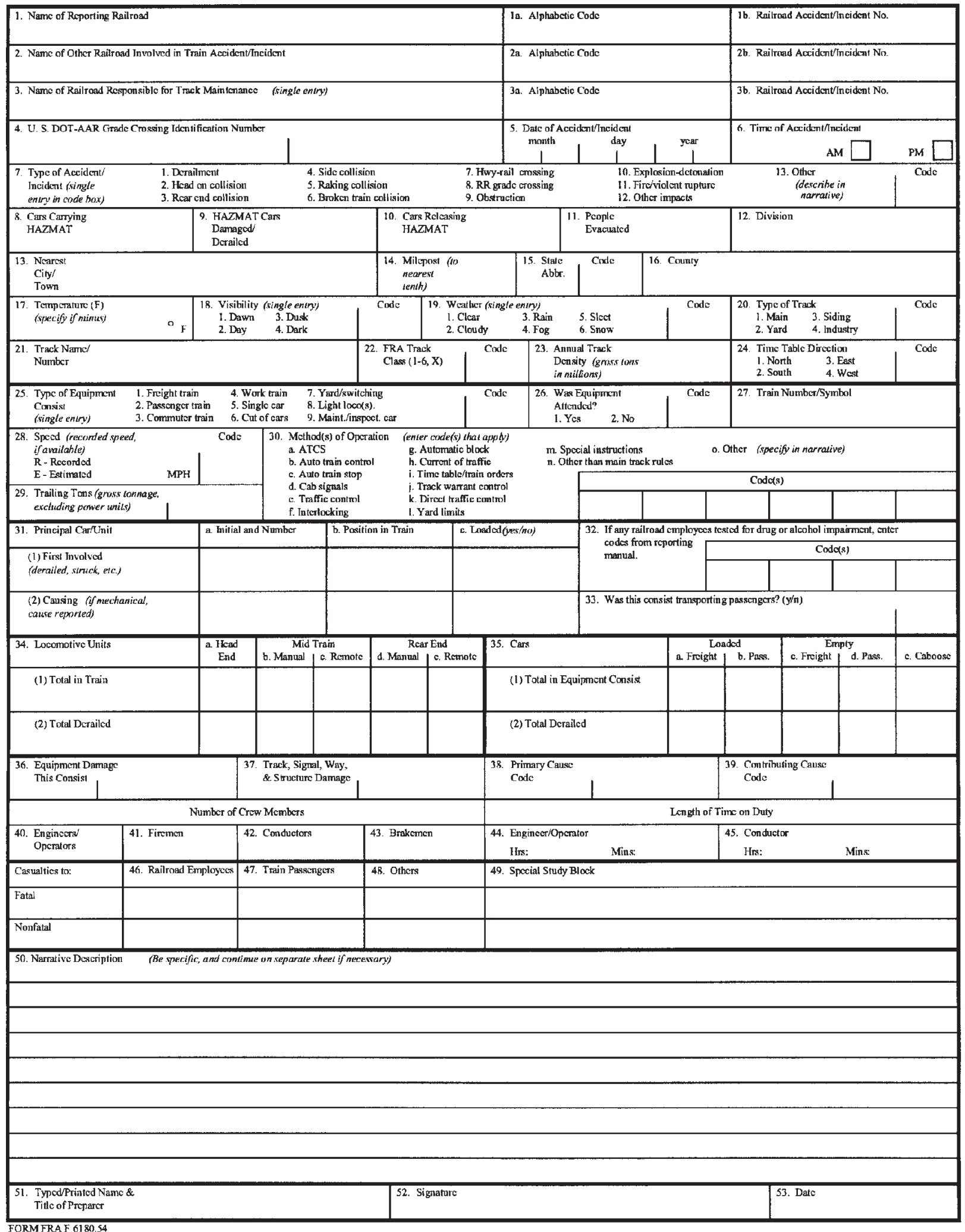

Figure B-4. Form FRA F 6180.54 rail equipment accident/incident report 


\section{NOTICE TO RAILROAD EMPLOYEE INVOLVED IN RAIL EQUIPMENT ACCIDENT/INCIDENT ATTRIBUTED TO EMPLOYEE HUMAN FACTOR \\ EMPLOYEE STATEMENT SUPPLEMENTING RAILROAD ACCIDENT REPORT}

DEPARTMENT OF TRANSPORTATION

FEDERAL RAILROAD ADMINISTRATION (FRA)

OMB Apjroval No.: 2130-050

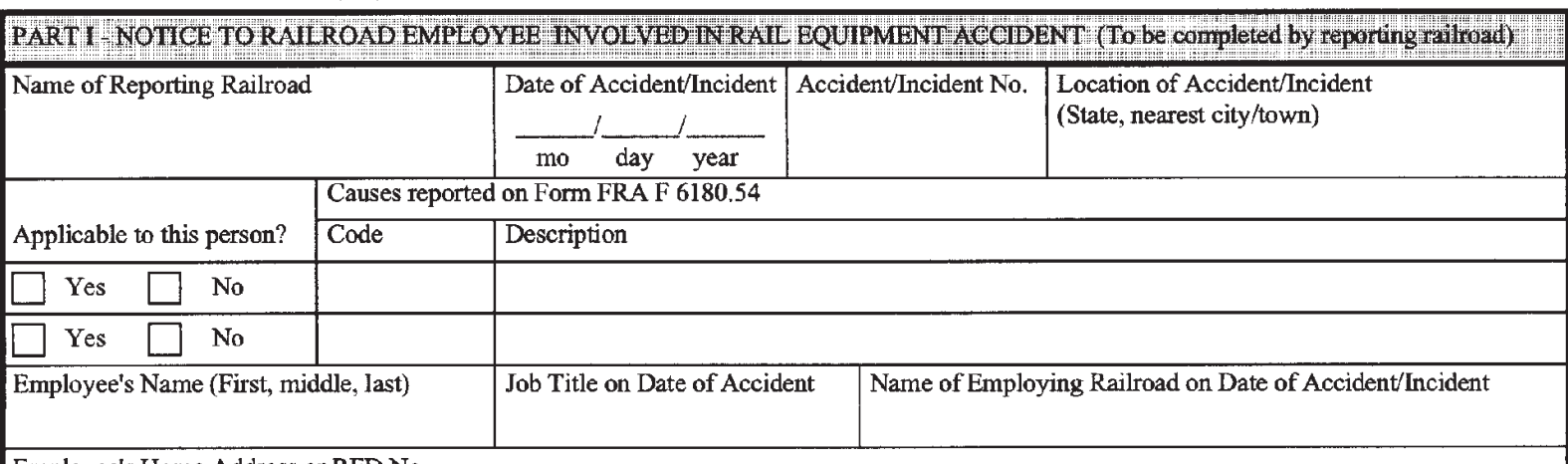

Employee's Home Address or RFD No.

Notice to Recipient. An accident occurred on the above date which the railroad alleges was at least partially caused by an action, lack of action, or the physical condition of a railroad employee. The railroad is sending you this notice because it believes that you had a role, but may not necessarily be the primary or only person responsible for the accident's occurrence. The railroad has reported to FRA that the primary and/or major contributing cause( $(\mathrm{s})$ of this accident are those listed above. Other causal factors related to this event may be described in the narrative portion of the railroad's report; a copy of which is attached.

You may submit a statement to FRA with a copy to this railroad and comment on any aspect of the railroad's report. The decision whether to submit such a statement is entirely optional on your part. If you choose to do so, please see the additional notices and instructions on the reverse of this form.

\begin{tabular}{|l|l|l|l|l|l|l|l|l}
\hline Name of Railroad Representative & Signature of Railroad Representative & Date Signed & Dailed/Hand Delivered \\
\hline
\end{tabular}

Name and address of railroad representative to whom form is to be retumed:

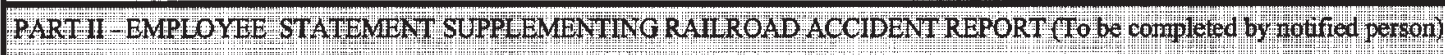

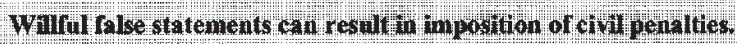

(Continue statement on separate sheet, if required, and mail with statement)

I have carefully read this statement and confirm that it is true to the best of my knowledge and belief.
Date Mailed/Hand Delivered to FRA:

Date Mailed/Hand Delivered to Railroad:

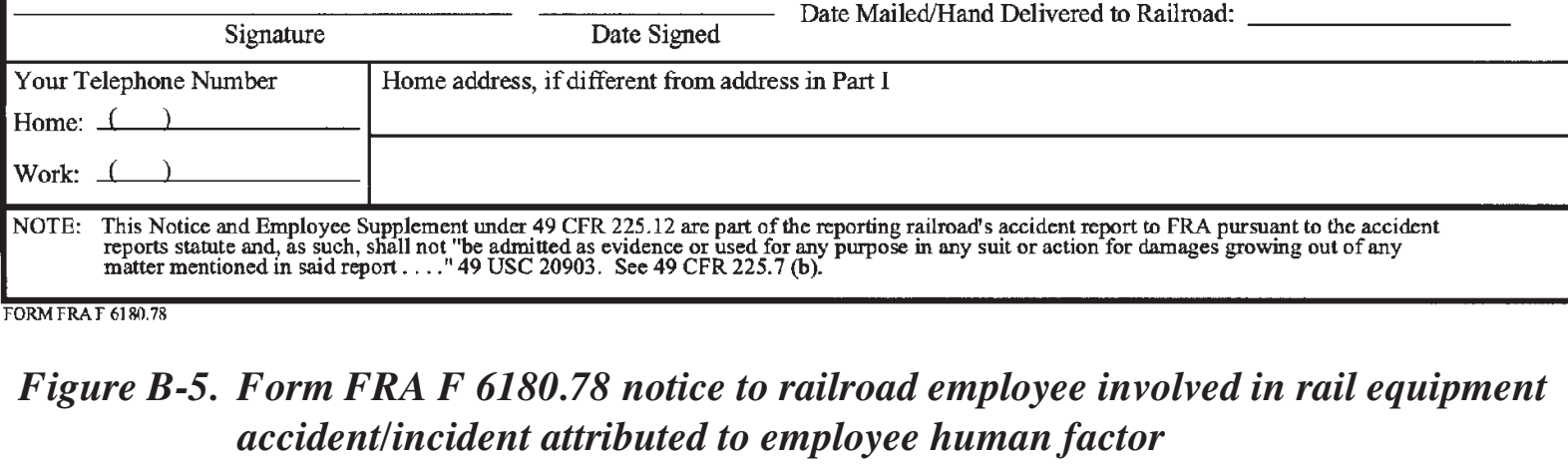




\begin{tabular}{|c|c|c|}
\hline Wem of Reporting Rullrand & $\begin{array}{l}\text { Rell roud Accident/Incident Wo. } \\
\text { (Eloek 16, Fild F 6180.54) }\end{array}$ & Dute of Accident/Incident (mo/day/year) \\
\hline
\end{tabular}

The rail road has dateralined that (check only one)

1 - One or nore reilroud wployent comitted un act or anission or were in a physicel condition that was - prinary or a contributino cume of the eccident/incident.

D b. Either no raflroed enplope comitted en ect or caission or we in a physical condition that was a primary or a contributing case of the eccident/incident or it is uncertain whethar amy person wo was a railroed eaploye camittad an ect or anission or was in a physical condition that was a prinary or a contribut in ceume of the eccident/incident.

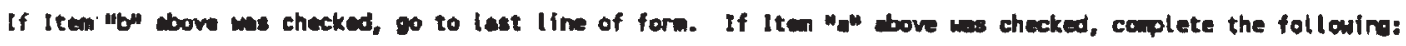

The railroed has Identified: (check only one)

1 1. All of the rail road emplovees who camitted an ect or anission or were in a physical condltion that wes primary or contributing cause of the sceident/incident.

1 2. Some, but not all, of the railrond aploves wo comitted en act or onission or were in a phyical condition that was a primery or contributing ceuse of the eceident/incident.

1 3. Wone of the railrond mployese whe comitted en ect or onission or was in a physical condition that was a primery or contributing ceuse of the eccident/incident.

If Iten "3" above was checked, so to last line of form.

If Item "q" or "2" cbove we checked, complete the following for exch employe whom the railroad has identilied as having conaitted an act or oniseion or having boen in a phyicel condition that was a prinary or contributing ceuse of the accident/ incident: (Attuch additional peges if wore room is neaded.)

\begin{tabular}{|c|c|c|c|}
\hline $\begin{array}{l}\text { Nent of Reilroad Employe } \\
\text { (lest, first, middle) }\end{array}$ & Job Title & $\begin{array}{l}\text { Rellroud Code of } \\
\text { Enploying Reilroed }\end{array}$ & $\begin{array}{l}\text { Cause Coders' Applicable } \\
\text { to this Emplovee }\end{array}$ \\
\hline
\end{tabular}

Briefly describe the eployee's act, omission or phrical condition that was a primary or a contributire cause of this accident/incident. The manings of most cuse codes are al ready stated in the wra cuide for Prepering Accident/Incident Reports." Briefly expend further, if information is not al ready stated in the narrative section of the Rail Equipment Aceident/Incident Report.

Did this enployes die an a result of the eccident? 0 Yes 1 Wo

\begin{tabular}{|l|l|l|}
\hline Typed Meme and Title & Signature & Date \\
\hline
\end{tabular}

FRA F 6180.81 (10/90)

Figure B-6. Form FRA F 6180.81 employee human factor attachment 
Instructions on Completing Form FRA F 6180.81,

"Emplojee Human Factor Attachment"

This form should be completed only when a railroad, in reporting a rail equipment accidentlincident to FRA, assigns any of the cause codes listed under "Train Operntion - Human Factors" in the "FRA Guide for Preparing Accident/Incident Reports." except Cause Code 506, as the primary cause or a contributing cause of the rail equipment accident/incident.

\section{Note on Notices to Railond Employes Inrolved in Rall Eauipment Accidents/Incideats:}

Part I of FRA's Form FRA F 6180.78, "Notice to Railroad Employee Involred in Rail Equipment Accident/Incident Attributed to Employee Human Factor" ("Notice"), must be completed and the entire form (Parts I and II) forwarded to each emplojee listed in the Emplogee Human Factor Attachment as causing or contributing to the accident, with certain exceptions. The railroad's Ruil Equipment Accident/lncident Report and Emplojee Human Factor Attachment must not be delajed in order to complete the Notice.

A Notice for an employee must not be sent if that employee has died as a result of the accident. A Notice for an employee is not required (and is not recommended) if the employee has died of whatever causes by the time that the Notice is ready to be sent.

A Notice for an employee must be sent within $\mathbf{4 5}$ days from the end of the month in which the accident/incident occurred, unless (i) the employee has died by the time that the Notice is ready to be sent or (ii) the reporting railroad, in its reasonable discretion, believes that notification of the employee should be deferred for a time on medical grounds.

\section{PAPER WORK REDUCTION ACT STATPMENT}

Public reporting burden for this colloction of information is estimated to average 15 minutes per response, including the time for reviewing instructions, searching existing data sources, gathering and maintaining the data needed, and completing and reviewing the collection of information. Send comments regarding this burden eatimate or any other aspect of this collection of information, including suggestions for reducing this burden, to Office of Safety Analysis, RRS-20, Federal Railroad Administration, 400 7th Street, S.W., Washington, D.C. 20590; and to the Regulatory Policy Branch (OMB No. 2130-0500), Office of Management and Budget, New Executive Office Bldg., 726 Jackson Plece, N.W., Washington, D.C. 20530.

-US. craten-51222o/202a 


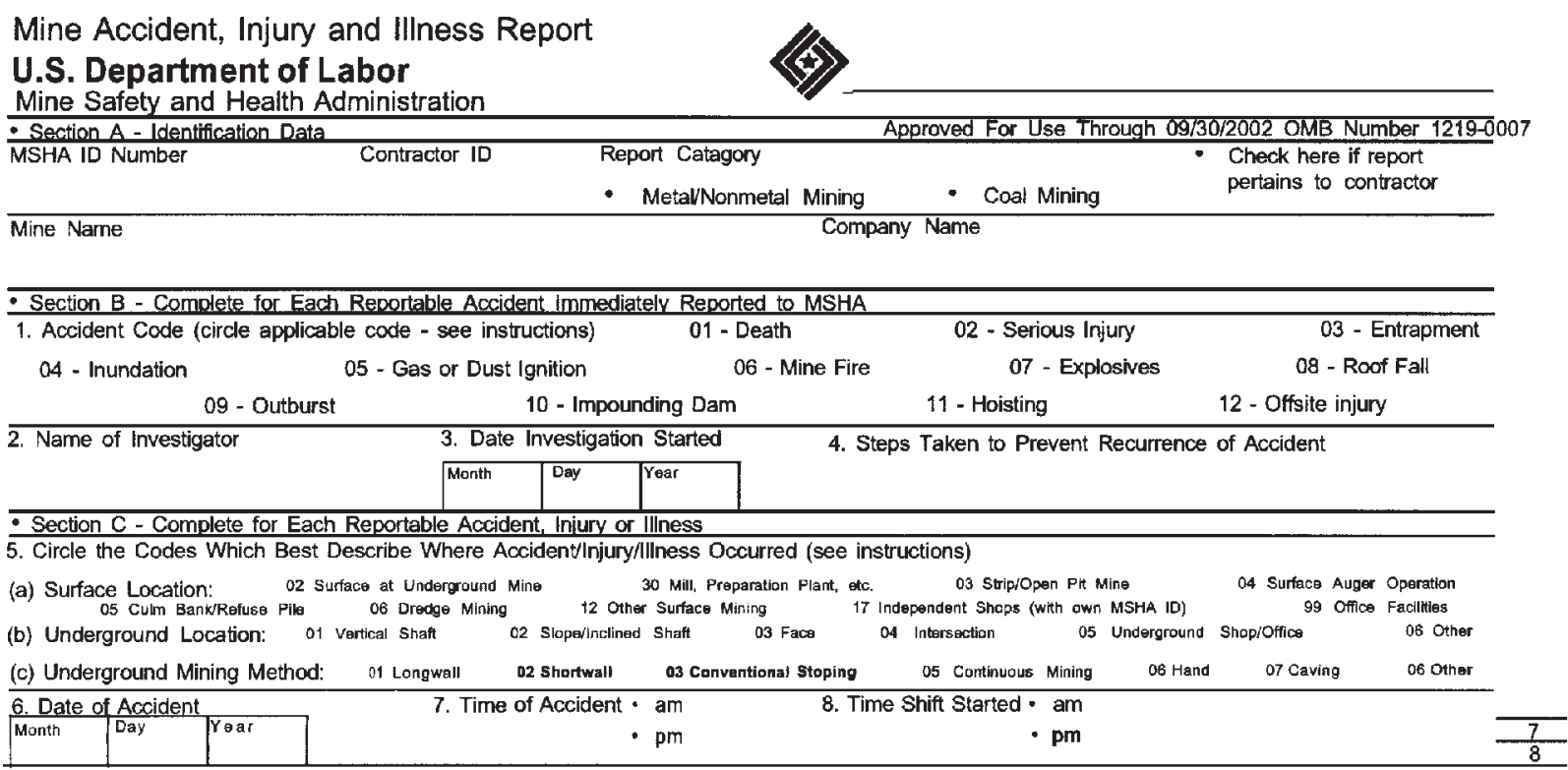

9. Describe Fully the Conditions Contributing to the Accident/Injury/liness, and Quantity the Damage or Impairment

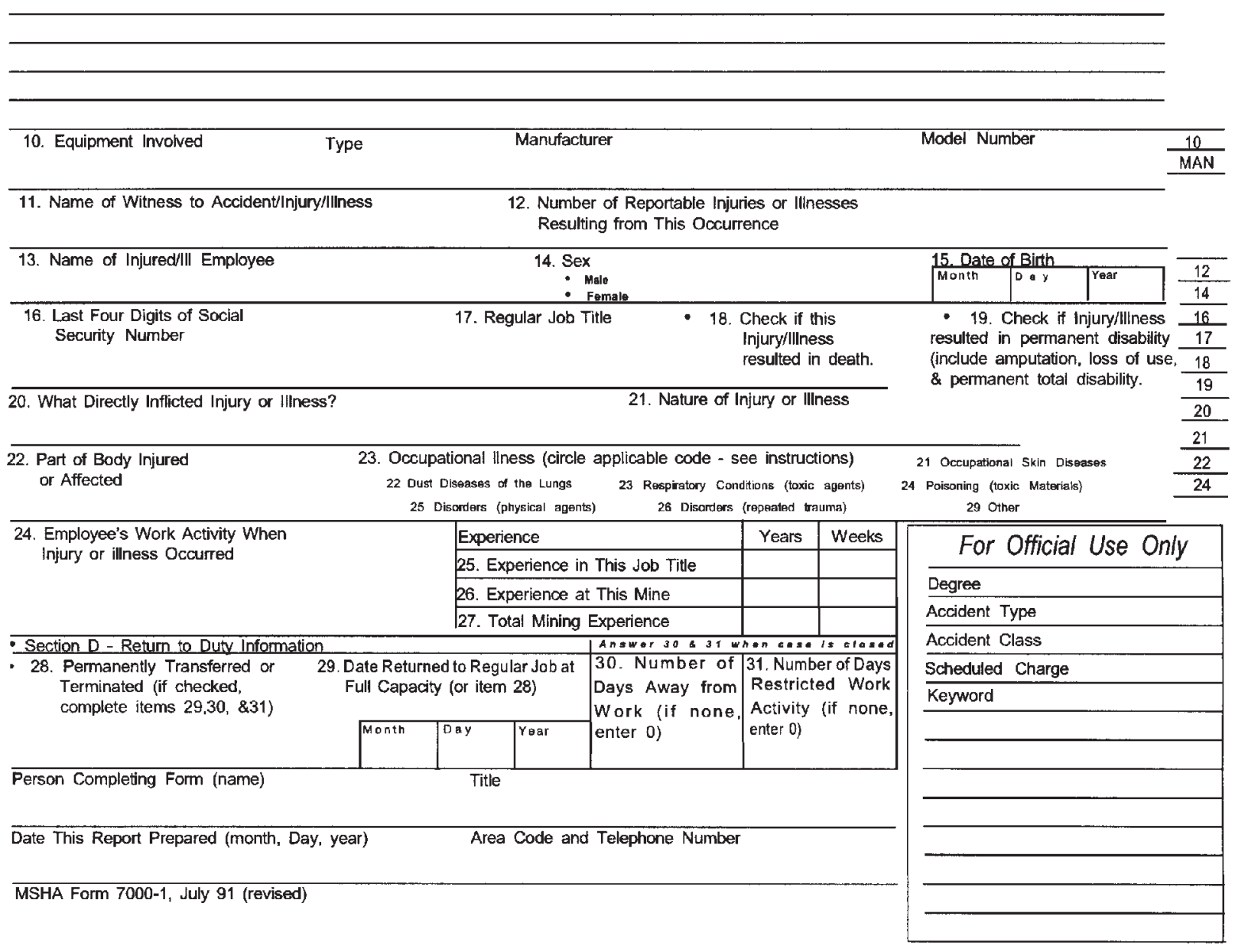

Figure B-7. MSHA Form 7000-1 mine accident, injury and illness report 


\section{APPENDIX C}

\section{DATA COLLECTION FORMS}

Two forms were developed to aid in the collection of personal injury and work schedule data at the participating railroad. They are presented in Figure C-1 and Figure C-2. 


\section{Injury/illness Record Form}

Location: A

Date:

Section 1: Background information

1. Age:

2. Sex:

M F

3. Marital status: Single/never married

Married

Divorced/separated/widowed

4. Height:

5. Weight:

6. Date hired:

7. Union seniority:

8. Job title:

9. Department:

10. Was person on duty? Yes No

11. Home city and state:

\section{Section 2: Injury-related information}

12. Year injury occurred:

13. Month injury occurred:

14. Day injury occurred:

15. Day of week injury occurred:

16. Time injury occurred:

17. Location where injury occurred (on railroad property):

Departure yard Receiving yard Classification yard Hump track Other

18. Job being performed at time of injury: Transfer Hump Industry Pull-down

19. Nature of injury:

20. General location of injury (on body):
Arm/hand
Leg/foot
Head/face
Torso
Multiple body parts

21. Specific (e.g., eye):

22. Was the injured employee alone at the time of the injury?

Yes No

23. Exposure to hazmat?

Yes

No

24. Visibility:

Dawn

Day

Dusk

Dark

25. Weather condition: Clear

Cloudy

Rain

Fog

Sleet Snow

26. Temperature:

27. What was the employee doing at time of injury (phyact):

28. Event being done at time of injury:

Figure C-1. Personal injury data collection form 
29. Was on-track equipment involved?

Yes

No

Other

30. Was moving on-track equipment involved?

Yes

No

31. Ballast involved?

Yes

No

32. Tie involved?

33. Switch involved?

Yes

No

34. Coupler involved?

Yes

No

35. Hand brake(s) involved?

Yes

No

36. Air hose(s) involved?

Yes

No

37. Injury narrative:

Yes

No

38. Number of resultant lost workdays:

39. Number of days absent:

40. Number of days of restricted duty:

41. Was injury beyond medical attention?

Yes No

42. Was injury beyond first-aid?

Yes No

43. Was injury reported to FRA?

Yes

No

44. Was injury associated with an accident?

Yes

No

Section 3: Work schedule information

45. Time shift began: 


\section{Work Schedule Data Sheet}

Researcher Name:

AX\#:

Date:

Employee: Injured / Control Group

FMIH:

Craft: Engineer / Switchman

If part of control group, who is the injured employee match (FMI H):

\begin{tabular}{|c|c|c|c|c|c|}
\hline & \multirow[b]{2}{*}{ Date } & \multirow[b]{2}{*}{ Shift start/stop time } & \multicolumn{3}{|c|}{ Shift } \\
\hline & & & 1 & 2 & 3 \\
\hline \multicolumn{6}{|c|}{$\begin{array}{l}\text { (Use this space to record actual } \\
\text { injury date and time if } 3^{\text {ru }} \text { shift) }\end{array}$} \\
\hline \multicolumn{6}{|c|}{ Shift on which injury occurred ${ }^{1}$} \\
\hline \multicolumn{6}{|c|}{1 day prior } \\
\hline \multicolumn{6}{|l|}{2 days prior } \\
\hline \multicolumn{6}{|l|}{3 days prior } \\
\hline \multicolumn{6}{|l|}{4 days prior } \\
\hline \multicolumn{6}{|l|}{5 days prior } \\
\hline \multicolumn{6}{|l|}{6 days prior } \\
\hline \multicolumn{6}{|l|}{7 days prior } \\
\hline \multicolumn{6}{|l|}{8 days prior } \\
\hline \multicolumn{6}{|l|}{9 days prior } \\
\hline \multicolumn{6}{|l|}{10 days prior } \\
\hline \multicolumn{6}{|l|}{11 days prior } \\
\hline \multicolumn{6}{|l|}{12 days prior } \\
\hline \multicolumn{6}{|l|}{13 days prior } \\
\hline \multicolumn{6}{|l|}{14 days prior } \\
\hline \multicolumn{6}{|l|}{15 days prior } \\
\hline \multicolumn{6}{|l|}{16 days prior } \\
\hline \multicolumn{6}{|l|}{17 days prior } \\
\hline \multicolumn{6}{|l|}{18 days prior } \\
\hline \multicolumn{6}{|l|}{19 days prior } \\
\hline \multicolumn{6}{|l|}{20 days prior } \\
\hline \multicolumn{6}{|l|}{21 days prior } \\
\hline \multicolumn{6}{|l|}{22 days prior } \\
\hline \multicolumn{6}{|l|}{23 days prior } \\
\hline \multicolumn{6}{|l|}{24 days prior } \\
\hline 25 days prior & & & & & \\
\hline 26 days prior & & & & & \\
\hline 27 days prior & & & & & \\
\hline 28 days prior & & & & & \\
\hline 29 days prior & & & & & \\
\hline 30 days prior & & & & & \\
\hline
\end{tabular}

Employee Name:

${ }^{1}$ If injury occurred during third shift, it is likely that the date the injury occurred and the date the shift began will be different (e.g., started shift 1/26 at 11:00PM and was injured 1/27 4:30AM). In these instances, record BOTH the actual date and time the injury occurred AND the actual date that the shift began. Count backward from the date that the shift began.

Figure C-2. Work schedule data collection form 


\section{APPENDIX D}

\section{STRUCTURED INTERVIEW QUESTIONS}

A series of questions was developed to assist in guiding the structured interviews of railroad managers at participating railroad yards. The questions are organized around seven main themes and are presented below.

1. Yard operation

1.1 How many employees work in the yard per shift?

1.2 How many miles of track are there in the yard? Roughly how many tracks are there in the arrival, classification and departure yards? Is there a container facility?

1.3 How many trains/cars are classified or handled in the yard each day?

1.4 Is there a repair shop on-site?

1.5 Who does the car inspections at this facility?

2. Scheduling and hours of service

2.1 What are the hours of operation at this particular yard?

2.2 How long are the shifts?

2.3 How many scheduled days off do employees have per week? Are the days off typically back-to-back, or are they separated in the week? How frequently do employees work one of the two days off? Both days off? How many hours do employees work per week, on average?

2.4 How is the scheduling done here? What types of schedules do yard employees have available? Are schedules/jobs based on seniority within the yard environment, or does seniority cover an entire division or district? 
3. Employee characteristics

3.1 What is the typical job tenure for employees working in yards? Are new hires inexperienced on the railroad, or do they come from other railroad trades/crafts? What jobs do most new hires come from? How long do yard employees remain at their jobs? What jobs do they typically take when they do decide to leave the yard?

3.2 What is the range of education for yard employees?

3.3 What percent of yard employees are male/female?

3.4 What is the typical starting age of employees working in the yard? What is the average age of employees working in the yard?

4. Reporting procedures

4.1 Who fills out the injury/illness reports at your railroad? Does your railroad train personnel how to complete the injury/illness reports? What does the training involve? Is the training standardized across the entire railroad?

4.2 What defines a "Human Factor" as the probable reason for an injury/illness (question 5n- "cause")?

4.3 Are there any problems with the current method of reporting injuries and illnesses to the FRA? What are they? Why are they a problem? How can they be fixed?

4.4 What safety-related information do you collect for injuries and illnesses in addition to that required by the FRA?

4.5 What additional information would you like to have about an injury or illness in order to help prevent this type of injury or illness from occurring in the future? Put another way, if you could learn anything about the circumstances that contributed to an injury or illness in order to help prevent them from happening again, what would you like to know?

5. Working environment and safety culture

5.1 What job conditions (e.g., fatigue, weather, misuse of equipment, shipper negligence) and other factors do you believe contribute to employee injuries at this facility?

5.2 What impact do FRA regulatory activities (e.g., rules, reporting requirements, audits) have in promoting safety at your railroad? Which have the greatest impact on promoting safety at your railroad? Which have no impact or a negative impact on safety? 
5.3 What technological changes do you foresee that may reduce or increase the number of injuries to yard employees? Is your railroad likely to implement these new technologies?

5.4 What is your railroad's policy regarding restricted/light duty during recuperation from a work-related injury?

6. Railroad safety programs

6.1 How are yard employees trained with respect to safety? Are they required to attend safety training classes, view safety related videos, or read any written safety materials? Do you offer any voluntary training of this nature? If so, what has employee response been?

6.2 How does your railroad encourage and reward safe work practices? Do you believe that such recognition or rewards have contributed to a reduction in the injury rate for yard employees?

6.3 How do you solicit suggestions from your employees regarding yard safety issues? How do you encourage employees to make suggestions?

6.4 Do you have safety committees that review accidents and injuries (both reportable and non-reportable), and recommend solutions to workplace hazards? Who are the members of these committees? Have the committees been successful in identifying hazards and suggesting improvements?

6.5 Have there been any particularly successful safety programs or procedures used at your railroad? How/why were they successful?

6.6 Have there been any particularly unsuccessful safety programs or procedures used at your railroad? How/why were they unsuccessful?

6.7 Is there any system in place at your railroad for reporting unsafe working conditions?

6.8 Is there any system in place at your railroad to enable or allow an employee to report unfit-for-duty?

7. Additional questions

7.1 What do you see as the top challenges to reducing the number of injuries and illnesses to zero at your railroad?

7.2 Are there any unique circumstances in the yard that make reducing the number of injuries and illnesses particularly difficult or challenging? 
7.3 What railroad, government, or employee actions, activities, or programs do you think have most contributed to the decrease in injuries and illnesses?

7.4 What suggestions do you have for reducing the number of injuries and illnesses in yards?

7.5 What changes in the working environment might occur if FELA were repealed and a no-fault type of compensation were instituted?

7.6 What do you see as impediments to an anonymous reporting system (either by phone or mail-in form) whereby all employees, including supervisors and managers, can report safety violations and safety near-violations to an independent (non-government, nonindustry) facility without fear of any form of retribution or litigation? The purpose of the system would be to identify hazards in the workplace so that they can be corrected. 


\section{APPENDIX E}

\section{SITE DESCRIPTIONS}

Appendix E contains descriptions of the four yards that were visited. Each site is described in terms of its functions and size. Then its approach to training is explained. Finally the railroad's injury reporting procedures are described.

\section{E.1 Railroad Yard A}

\section{E.1.1 Description}

Railroad Yard A is a large terminal railroad located in the Midwest. Due to its nature as a terminal railroad (a switching railroad with very little mainline), Yard A serves many different railroads. In addition to a hump classification yard, it also contains a diesel shop and engine house, as well as a car repair facility.

Yard A is an around-the-clock operation, and generally 50 to 60 jobs work per day. Most jobs involve three people — an engineer, conductor and switchman - though some jobs consist of two or four people. More jobs work first shift than second or third. Railroad Yard A requires that its employees have a minimum of a high school degree or equivalent; few yard employees have college degrees.

There are several types of jobs due to the large size of this yard operation:

- Industry jobs, where crews pick-up and set-off cars at local industries

- Transfer jobs, in which assembled trains are dropped off at other railroads

- Hump jobs, in which cars are sorted to their next destination

- "Pull down" jobs, in which crews connect strings of cars from multiple classification tracks, ultimately forming an assembled train.

Yard A does not have regularly assigned jobs like other railroads. Rather, it utilizes a " 24 hour" assignment board where jobs can be reserved no earlier than 24 hours before the job is scheduled to begin. Further, an individual can take or change an assignment as little as 2 hours before the job is scheduled to begin. This enables the more senior trainmen and engineers to effectively 
hold down regular jobs (similar to a regularly scheduled job), but the job is not guaranteed. On any given day, a more senior employee may "bump" a person off of that job. Yard A also has an extra board, which is used to fill in the gaps in the assignment board each day. Scheduled employees are guaranteed two consecutive days off per week, and extra board employees are guaranteed two days off, though they are not guaranteed to be consecutive. New employees are usually on the extra board for three to six months before moving to regular status.

\section{E.1.2 Training}

New hire switchman training lasts seven weeks and includes both classroom training and OJT. It starts with one week of classroom training, which includes a strong emphasis on safety rules. Besides safety rules the trainee is exposed to basic operating rules and operating practices. Videos illustrating the proper operating practices required of the switchman enhance the classroom instruction. After the first week of classroom instruction the trainee is given six weeks of OJT.

During this six weeks the training is overseen by a "peer mentor" who not only assigns the day to day schedule, which includes varied shifts, but also observes and evaluates the trainee on a weekly basis. The mentor chooses the crews that the trainee is assigned to based on the crews' experience and willingness to work with students. The mentors are experienced switchmen who are compensated for this extra responsibility of work with the new switchman. The crew members who work with the trainee also receive extra "training" compensation.

At the conclusion of the six-week OJT period the trainees return for an additional day in the classroom. This last day is a review of the shared experiences of the OJT, some additional rules instruction and finally a rules test. If successful in completing the seven week training period, the employee is placed on the extra board for a 60 day probationary period, during which he or she may be dismissed without cause. After the probationary period, the employee becomes a Union member and receives the benefits of the working contract.

\section{E.1.3 Injury Reporting Procedures}

On Railroad A, employees are required to report all injuries, regardless of severity, to their supervisor. Injuries requiring medical attention are treated at a local medical clinic. In all cases, the safety manager and claim agent are called as part of the response effort.

Injury inquiries are led by the department head for the employee(s) involved. Safety, claims and other departments are involved as needed and depending on the complexity of the given case. A report, verbal or written, is given to senior management within hours of the occurrence, with follow up as appropriate. Countermeasures found in this process are implemented by the appropriate department and followed up during the monthly FRA/management safety meeting. 


\section{E.2 Railroad Yard B}

\section{E.2.1 Description}

Railroad Yard B is a medium-sized, regional flat switching yard located in New England. Yard $\mathrm{B}$ is approximately one mile long, has 33 tracks for switching, and one mainline runs through the yard. Currently the engine house at this yard is not in use and equipment is sent elsewhere for major repairs. A shop truck visits the yard daily to make minor repairs.

This yard operates around-the-clock, seven days a week. On an average day, 300 to 350 cars are switched at Yard B. Two crews work in the yard performing switching operations, and during the day shift on weekdays a third crew picks up and sets off cars at local industries. Most crews consist of a conductor or brakeman and an engineer, but some crews have three people. A total of 32 employees staff this yard on 13 jobs over the course of the week. The jobs are either "switching" or "local" jobs. A switching job involves making up trains while a local job involves delivering cars to, or picking up cars from, local customers. Typically, the shift length for yard jobs is 8 hours and for local jobs it is 10 hours.

Railroad B tries to hire people with a GED or high school degree although it is not a requirement for the yard positions. The trainmaster at this yard reported that nearly half of the new hire trainmen leave within six months of their hire date because of the work schedule.

\section{E.2.2 Training}

Conductor training lasts six weeks, and is composed of both classroom training and OJT. Rules are taught using computer-based training. To begin, a new hire must have at least a high school degree. As part of new conductor training, instructors review hazards associated with yard work with the trainee, both in the classroom and in the field. During OJT, railroad officials try to match trainees with a conductor who wants to be a mentor. During the first 15 days of the OJT, the trainee only works day shifts as a safety precaution. After the first 15 days, trainees are rotated into evening and night shifts. As another safety precaution, trainees only work 8 hours, even though some jobs may last longer. During OJT, trainees wear bright orange vests to indicate that they are students and to suggest extra attention be paid to the students for everyone's safety. After the six weeks of conductor training, trainees take a series of tests, including a rules test. Railroad B has adopted a policy that offers trainees two opportunities to pass the final rules exam.

Upon successful completion of training, new hires work a probationary period of 90 days, any time during which they may be released without cause. During this probationary period, railroad officials try to expose trainees to the worst conditions they will face in order to prepare and familiarize them with the working environment of the railroad yard. 


\section{E.2.3 Injury Reporting Procedures}

After an injury occurs, it is reported to the yardmaster, who reports the injury to the trainmaster. Depending on the circumstances and severity of the injury, the injured employee may be drug tested. The injured individual also files the initial injury report. Then there is an investigation into the facts and circumstances underlying the injury. The investigation is led by the trainmaster or yardmaster, and directed by the Director of Safety. Among other areas, officials in the investigation look for procedural failures and human error/failures. After the investigation is completed, there is a hearing, in which a decision is made regarding culpability. A hearing is conducted for any injury, regardless of the severity and regardless of whether the injury is reportable to the FRA. If discipline against the injured employee is warranted, it is also imposed at this time. According to officials at Yard B, the hearings have reduced the number of injuries reported at Railroad B due to the hearing process's fact-finding nature, its focus on accountability on both the railroad's side and the individual's side, and its financial impact. Their experience has been that since the hearing process was instituted, fewer minor injuries with questionable relation to workplace activity are reported.

\section{E.3 Railroad Yard C}

\section{E.3.1 Description}

Railroad Yard C is a medium-size Class I, intermediate, flat switching, classification yard located in the Northeast. Yard $\mathrm{C}$ also serves as an interchange point for some road crews and several regional railroads. Yard $\mathrm{C}$ is about one mile long, and contains two main lines that run through the middle of the yard. An intermodal facility is operated on one side of the yard, while local freight is switched on the other side. In addition to the intermodal and freight traffic from local industries, several road and passenger trains pass through daily. Yard C contains a small engine house, and runs a ballast operation where empty cars are inspected on-site and sent to a nearby quarry for ballast.

This yard is primarily a Monday to Friday operation with a fairly constant workload. No jobs work on Saturdays and only one switcher works on Sundays. As a consequence, there is little overtime, and few of the T\&E crews work extra days. On weekdays, approximately 60 percent of the crews work during the day shift; 25 percent work the evening shift; and the remainder work the night shift. Most T\&E crews that work in Yard $\mathrm{C}$ have regularly scheduled jobs. Because of the number of local industries serviced by this yard, there are three yard switcher jobs and four industry jobs daily. Crews may alternate between working local jobs and switching in the yard. The switcher jobs are scheduled for 8 hours but occasionally work 2 hours of overtime. Industry jobs typically work slightly longer shifts of 9 to 11 hours. A limited spare board provides relief as needed. Turnover at this yard is low, reflecting the desirability of working here. There is a large number of qualified individuals to fill few vacancies so it takes 20 to 25 years of seniority to hold a regular job here. 
A total of 75 people work in Yard C per day. This figure covers all shifts and all jobs (i.e., Transportation, MOW and MOE), and includes both yard jobs and local industry jobs. Approximately 35 employees are from the T\&E crafts.

\section{E.3.2 Training}

Employees working in this yard tend to be experienced railroaders so training is not an issue. However, if new trainmen/conductors are hired, they are sent to a six week off-site school for training.

\section{E.3.3 Injury Reporting Procedures}

If an employee is injured while working in the yard, first the trainmaster is notified. The trainmaster, in turn, contacts an outside company that records the injury. This company then notifies the risk manager from the railroad. The risk manager is responsible for investigating the injury (along with a yard manager, such as the trainmaster), obtaining a statement from the injured employee and filing the paperwork with a central office. The risk manager focuses on lost time and reportable injuries. As part of the investigation, railroad officials conduct a root cause analysis, where they look for "pinpoints" that indicate the underlying cause(s) of the injury.

\section{E.4 Railroad Yard D}

\section{E.4.1 Description}

Railroad Yard D is a large Class I, intermediate, flat switching and classification yard located in the Midwest. Like other intermediate yards, Yard D also serves as an interchange for road crews. Yard D is about one mile long, and includes two yard tracks that serve as main line through the yard, several arrival and departure tracks on each side of the yard (east and west), and about 40 classification tracks in the middle. In addition, Yard D contains a diesel shop and engine house, where locomotives are serviced and repaired; several RIP tracks, where light repairs are performed on rolling stock; and an equipment repair facility, where rolling stock undergo major repairs, including replacement of ends.

An average of 10 crews switch 16 trains per day (about 1000 cars). Typically, five crews work an 8 hour day shift; three crews work an 8 hour evening shift; and two crews work an 8 hour night shift. In addition to these 10 crews, there is one utility man who works a 24 hour shift, and can be used to assist in all aspects of yard operation, including hostling. An average of two crews per day work some overtime. Yard crews usually consist of a locomotive engineer, a conductor (or foreman) and a helper. Yard crews are assigned two consecutive days off.

T\&E crews qualify to work both road and yard jobs at one time at this particular railroad. However, due to the desirability of working in the yard (no travel involved, work hours are more regular than road jobs, two consecutive assigned days off), T\&E crews that work in Yard D have a minimum of 20 to 25 years of experience as conductors and engineers. There are both a 
regular yard board and a spare yard board for each craft. Currently, about 30 conductors/ switchmen and 12 locomotive engineers work in Yard D.

\section{E.4.2 Training}

Candidates first go through a 5 to 6 week course designed by the railroad but taught through several local and community colleges. After successfully completing the course, candidates undergo 9 weeks of railroad company training. Classroom and OJT are combined and interspersed. During this time, the railroad employs a special training facility where trainees can learn to use equipment and practice procedures without the distraction or danger of other trains or operational activity. Only the trainees' equipment is present.

During the OJT portion of the training, the trainee is periodically matched with a conductor. The railroad makes an effort to match trainees with conductors who want to train others and the railroad compensates those who serve as trainee mentors. Whereas on some railroads an individual is trained to become a switchman first, and then receives two additional weeks to qualify as a conductor, at this railroad, individuals are trained immediately to become conductors. Typically, after becoming qualified, conductors will hold road jobs until they have enough seniority to hold a yard job. When moving to the yard environment, the conductor is given up to 14 days of on-the-job yard familiarization training to prepare him/her for the specifics of operating in the yard.

Locomotive engineer trainees receive 26 weeks of formal, engineer-specific training.

\section{E.4.3 Injury Reporting Procedures}

If an employee is injured, s/he first notifies the yardmaster. If an ambulance is required, one is called. Next, the trainmaster is notified. After the injury is attended to, the facts and circumstances surrounding the injury are documented. Both the supervisor and the injured employee complete forms that describe the injury and the circumstances that surrounded the injury. The incident report that the employee completes after an injury includes several valuable subjective questions, such as whether the employee had "a safe place in which to work" and whether the workplace was "adequately lighted." Information is collected on any injury that is reported, regardless of its severity. This information includes the number of hours off prior to the injury and the number of consecutive days worked. The paperwork is sent to a division or district office and a claim agent responds. Eventually the paperwork is sent to the centralized corporate office where, if the injury meets reporting criteria, administrators prepare the information for transmission to the FRA.

The injury reporting and investigative process that this railroad uses deviates from most other railroads in a number of ways. First, they do not routinely administer drug and alcohol tests immediately following an injury. They also no longer hold formal investigations. Rather, local officials conduct a root cause analysis to determine the root cause(s) of the injury with the goal of rectifying the situation. There are three steps that are involved in the root cause analysis. They are: 
1. Gather the facts of the incident. This step involves examination of the immediate area, and answering the following questions with respect to the injury: What happened? When did it happen? Where did it happen? How did it happen?

2. Identify the immediate cause. This step involves tracing the sequence of events leading up to the injury, and focusing on unsafe acts and conditions. The act or condition that immediately caused the injury is the "immediate cause."

3. Identify the root cause. In this step, the individual investigating the injury is encouraged to repeatedly ask "Why" the injury occurred, until whatever occurred to lead to the immediate cause is identified.

Once the root cause(s) has been identified, the analysis requires that the inquiring individual document the action taken to prevent its reoccurrence.

The elimination of routine formal investigations and drug and alcohol testing following an injury is an attempt by the railroad to improve the relationship between labor and management, and to foster employees' trust. As a result of these new policies, there has been an increase in the number of injuries reported. However, it is felt that the injuries that are being reported now are simply those that were not being reported before. In fact, the increase in the number of reported injuries is viewed as a step toward greater trust between labor and management rather than an indication of a more hazardous work environment. 


\section{APPENDIX F}

\section{FOCUS GROUP QUESTIONS}

Appendix F contains the list of questions used to guide the focus group discussions held with railroad labor. They are presented below, and are organized by the city in which they were used.

\section{St. Louis Focus Group Questions}

1. Factors contributing to yard injuries

1.1 Tell us about an injury that you or a co-worker had and what you think contributed to it.

1.2 Off all the factors that you mentioned, which do you think is the biggest contributor to injuries in your yard?

1.3 How can these factors be corrected?

1.4 Are there any other factors that you feel we have left out that contribute to injuries in yards?

2. Overall safety climate

2.1 What motivates you to work safely?

2.2 What detracts from your motivation to work safely?

2.3 What pressures have you experienced to cut corners or compromise safety?

2.4 What discrepancies have you seen between your railroad's safety policies and actual day-to-day practices?

2.5 How much responsibility do you yourself feel you have for maintaining a safe work place?

2.6 What barriers to safety have you experienced, or are aware you of, in your yard?

2.7 Anything we left out? 
2.8 Of all the barriers you have mentioned, which one is the most common?

2.9 Which one is the most difficult to overcome?

3. Supplemental injury survey

3.1 Under what circumstances would you be willing to take the time to fill out a supplemental injury report after being injured on-the-job?

4. Concluding

4.1 Is there anything else that you would like to add to what we have discussed tonight/ today?

Houston Focus Group Questions

1. Injury reporting procedures

1.1 Tell us about an injury that you or a co-worker had and how you went about reporting it.

1.2 What factors would cause an employee to be reluctant to report an injury?

1.3 What role does fear of harassment or intimidation play in your decision to report an injury?

1.4 How effective are formal hearings or investigations in identifying the root causes of injuries?

2. Supplemental injury survey

2.1 Under what conditions would you be willing to fill out a supplemental injury report after being injured on-the-job?

3. Railroad safety initiatives, incentives and awards

3.1 Tell us about any safety initiatives or programs that you have been a part of and whether or not you believe they have contributed to reducing injuries in yards.

3.2 What other safety initiatives can you suggest that might reduce the risk of injury?

3.3 How effective are safety incentives, such as individual or group awards or compensation, in maintaining a safe working environment?

3.4 What effect do safety incentives have on underreporting of injuries? 
3.5 Of all of the safety initiatives we have discussed, which one do you feel has the greatest positive impact on maintaining a safe work environment?

3.6 What relationship does the Harriman Award have to a safe environment and safe operating practices?

3.7 [What do you think about participating in a behaviorally-based approach to safety (explain here)? Would you feel comfortable participating as an observer? As the observed?]

4. Concluding

4.1 Is there anything else that you would like to add to what we have discussed tonight/ today?

\section{Chicago Focus Group Questions}

1. Channels of communication

1.1 In your experience, if you encountered an unsafe working condition in the yard, what did you do?

1.2 What procedures are in place at your railroad to report an unsafe working condition or a safety violation? How effective are these procedures?

1.3 What is the best (or most effective) way to get an unsafe working condition corrected in your yard?

1.4 How effective was your training in preparing you to work safely in the yard? What would you have done differently?

1.5 When new procedures or rules are introduced, how are you informed or trained? How timely is the training or information? How effective is it?

1.6 The Federal Aviation, Coast Guard, and Federal Highway Administrations all have a formal procedure for anonymously reporting unsafe working conditions and safety violations. The goals of these reporting systems are to (1) identify and (2) remedy unsafe working conditions and actions, NOT to punish an individual for violating a safety rule or a railroad for not properly maintaining their yard. Is there a need for this type of system for the railroad industry? Would you use it?

2. Safety rules and procedures

2.1 How effective are your railroad's safety rules in creating a safe workplace and preventing injuries? 
2.2 Can you think of any rules that are particularly effective at preventing injuries/ maintaining a safe workplace?

2.3 Can you think of any rules that are particularly ineffective at preventing injuries/ maintaining a safe workplace?

2.4 Can you think of any rules, practices or procedures that are not currently in place but that would prevent injuries if followed?

2.5 What pressures have you experienced to shortcut procedures or bend rules?

3. Work schedules and overtime

3.1 How much control do you have in determining your work schedule?

3.2 How much does your work schedule affect your ability to manage your time away from work?

3.3 What is your favorite work schedule? What aspects of the schedule make it your favorite? (poll the group)

3.4 How could work scheduling practices or work schedules be improved?

3.5 What reasons are there to work overtime?

Houston (Novice Worker) Focus Group Questions

1. Training

1.1 How were you trained for your present craft? (Have everyone respond. Order by craft.)

1.2 How effective was your training in preparing you to work safely in the yard?

1.3 In what areas could your training have better prepared you for performing your job?

1.4 What changes do you recommend in the training program?

2. Overall Safety Climate

2.1 What motivates you to work safely? (Have everyone respond.)

2.2 What detracts from your motivation to work safely? (Try to get a response from everyone) 
2.3 What pressures have you experienced to cut corners or shortcut procedures?

2.4 What discrepancies have you seen between your railroad's safety policies and actual day-to-day practices?

3. Injury Reporting Procedures

3.1 What factors would cause an employee to be reluctant to report an injury?

3.2 What role does fear of harassment or intimidation play in your decision to report an injury?

4. Work Schedules and Overtime

4.1 Tell us what your current work schedule is. (Ask everyone.)

4.2 How much control do you have in determining your work schedule?

4.3 How much does your work schedule affect your ability to manage your time away from work?

4.4 What reasons are there to work overtime?

4.5 What is your favorite work schedule? What aspects of the schedule make it your favorite? (poll the group)

4.6 How could work scheduling practices or work schedules be improved?

5. Supplemental Injury Survey (if time permits)

5.1 Under what conditions would you be willing to fill out a supplemental injury report after being injured on-the-job? 